Departamento de Ingeniería Topográfica y Cartografía

Escuela Técnica Superior de Ingenieros en Topografía, Geodesia y Cartografía

\title{
MODELO COLABORATIVO BASADO EN GEODISEÑO PARA LA RED DE TRANSPORTE DE ENERGÍA ELÉCTRICA: SISTEMATIZACIÓN DE LA GEO-INFORMACIÓN EN EL CICLO DE VIDA DE LOS PROYECTOS
}

\author{
Autor: \\ Francisco Javier Moreno Marimbaldo \\ (Ingeniero en Geodesia y Cartografía)
}

Director:

Dr. Miguel Ángel Manso Callejo 


\section{DEDICATORIA}

Este trabajo lo dedico, con gran cariño y admiración, a mis padres...,

... porque todo cuanto he conseguido ha sido gracias a ellos.

\section{AGRADECIMIENTOS}

Deseo agradecer a Red Eléctrica de España por, simplemente, darme la oportunidad de trabajar en lo que me gusta y disfrutar cada día, y por la confianza al permitirme imaginar y construir una de las actividades clave en sus proyectos. Añado a muchos compañeros, que con el día a día he podido entender su trabajo, y han dado voz y voto a una disciplina ajena al sector eléctrico.

También quiero mostrar mi agradecimiento y admiración a mi director, el Dr. Miguel Ángel Manso Callejo, por su paciencia, su contacto frecuente que ha ayudado a que no abandone, su humanidad, su talento, su consejo siempre acertado y por entender qué necesitaba en cada momento. Sin duda, su ayuda ha sido fundamental...

Por último, agradezco a mis padres la educación recibida, el carácter que he heredado de mirar siempre hacia delante y la ilusión y apoyo incondicional que siempre han mostrado en cada cosa de he emprendido. También a Fátima y mi hija Daniela, "las chicas de mi vida", por su amor infinito y la felicidad en la que vivimos, que al fin y al cabo... es de lo que se trata. 


\section{RESUMEN}

Los proyectos de infraestructuras eléctricas de alta tensión se desarrollan de forma secuencial en diferentes fases: planificación, análisis ambiental de alternativas, definición del proyecto de ingeniería, obtención de permisos y construcción. Cada una de ellas se compone de diferentes procesos en los que los aspectos técnicos no son los únicos a tener en cuenta. En el diseño del proyecto pueden establecerse diferentes alternativas técnicamente válidas que afectan de distinto modo el territorio que atraviesan y, por tanto, el número y tipo de grupos de interés con los que debe establecerse algún tipo de comunicación. Además, los proyectos no siempre los diseña la misma unidad organizativa ni los mismos técnicos, sino que pueden intervenir diferentes técnicos, unidades o empresas subcontratadas. En este sentido la tesis aborda un enfoque metodológico y un marco de trabajo basado en geodiseño que permitirá establecer la metodología para gestionar la información geográfica de los proyectos integrando los modelos de: comprensión del ámbito de estudio, de propuesta de cambio, de evaluación del impacto de los cambios propuestos, de ocupación del territorio y modelos de decisión que se implementan mediante modelos de geoprocesamiento a lo largo de su diseño.

De otra parte, se conoce que la sociedad y algunos colectivos sienten necesidades y preocupaciones relacionadas con las infraestructuras eléctricas. Las preocupaciones pueden provocar oposición y dificultar el desarrollo de la Red de Transporte de electricidad - RdT. En el área de desarrollo de la RdT hay dos ámbitos principales que pueden diferenciarse: 'el ámbito técnico del sector eléctrico' y el 'ámbito del territorio'. El primero abarca la necesidad de desarrollo de la RdT, y el segundo cubre las percepciones y evaluaciones de los resultados específicos de ese desarrollo. En ambos ámbitos, las partes interesadas plantean diferentes preocupaciones y necesidades en relación a la intrusión visual del paisaje, los valores de las propiedades, el medio ambiente, la salud, la imparcialidad y la transparencia percibidos.

La tesis también aborda la gestión integrada de los grupos de interés, en los modelos de geodiseño y en la gestión de la trazabilidad de la Información Geográfica utilizada en el diseño de la infraestructura, para que la respuesta y su gestión a lo largo del proyecto se haga conforme a criterios homogéneos y corporativos, evitando la subjetividad y la improvisación.

La principal contribución de la tesis es un marco de trabajo basado en geodiseño para los proyectos de infraestructuras de transporte de energía eléctrica, fundamentada en la gestión de la Información Geográfica sobre la que se adoptan las decisiones. Esta información también proporciona el soporte para gestionar los grupos de interés por su ámbito geográfico de influencia, y facilita la ejecución de numerosos algoritmos de geoprocesamiento que sistematizan las tareas de las distintas fases del proyecto homogeneizando su diseño, a la par que dan soporte a los modelos de la metodología de geodiseño y posibilitan la trazabilidad de la toma de decisiones. 


\section{ABSTRACT}

High-voltage electrical infrastructure projects are developed sequentially in different phases: planning, environmental analysis of alternatives, definition of the engineering project, obtaining permits and construction. Each of them is made up of different processes in which the technical aspects are not the only ones to take into account. In the design of the project, different technically valid alternatives can be established that affect in a different way the territory they cross and, therefore, the number and type of stakeholders with which some type of communication must be established. Furthermore, projects are not always designed by the same organizational unit or the same technicians, but may involve different technicians, units or subcontracted companies. In this sense, the thesis addresses a methodological approach and a framework based on geodesign that will allow establishing the methodology to manage the geographic information of the projects, integrating the models of: understanding the scope of study, proposal for change, and evaluation of the impact of the proposed changes, land occupation and decision models that are implemented through geoprocessing models throughout its design.

On the other hand, it is known that society and some groups feel needs and concerns related to electrical infrastructure. Concerns can provoke opposition and hinder the development of the Electricity Transmission Network - ETN. In the ETN development area there are two main areas that can be differentiated: "the technical area of the electricity sector" and the "area of the territory". The first one covers the need for the ETN development, and the second one covers perceptions and evaluations of the specific results of that development. In both areas, stakeholders raise different concerns and needs regarding visual intrusion into the landscape, property values, the environment, health, fairness and perceived transparency.

The thesis also addresses the integrated management of the stakeholders, in the geodesign models and in the traceability of the Geographical Information used in the design of the infrastructure, so that the response and its management throughout the project is done in accordance to homogeneous and corporate criteria, avoiding subjectivity and improvisation.

The main contribution of the thesis is a geodesign-based framework for electrical energy transport infrastructure projects, based on the management of the Geographic Information on which decisions are made. This information also provides the support to manage the stakeholders by their geographical area of influence, and facilitates the execution of numerous geoprocessing algorithms that systematize the tasks of the different phases of the project, homogenizing its design, while supporting the models of the geodesign methodology and enable the traceability of decision making. 


\section{ÍNDICE}

ÍNDICE

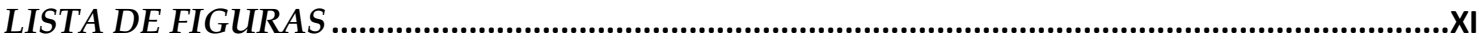

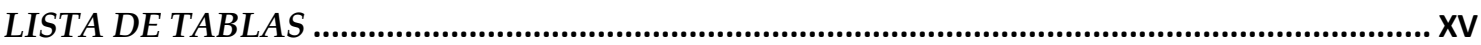

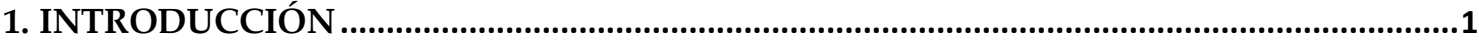

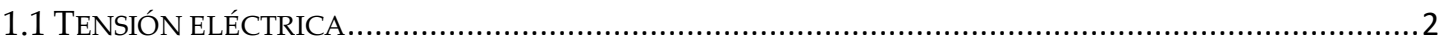

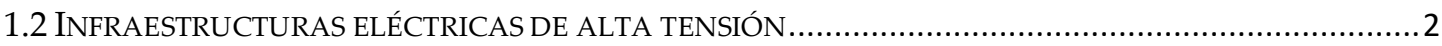

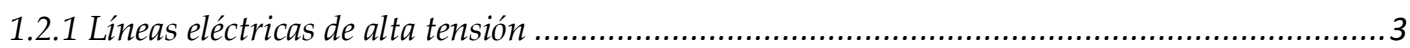

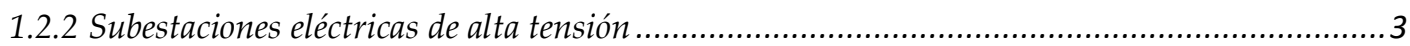

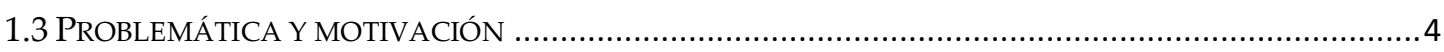

1.4 DESCRIPCIÓN DEL PROYECTO DE INVESTIGACIÓN ……...................................................................

1.5 HIPÓTESIS Y CUESTIONES QUE SE PRETENDE RESPONDER POR LA INVESTIGACIÓN ……...................

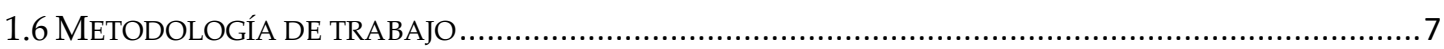

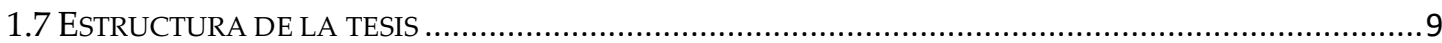

2. ANTECEDENTES Y MARCO DE LA INVESTIGACIÓN.........................................................11

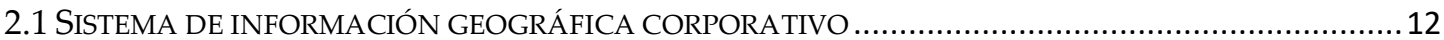

2.2 Proyecto de Infraestructura ElÉCtrica de Alta Tensión (IEAT) …………...................14

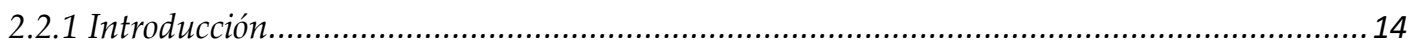

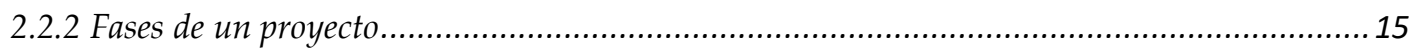

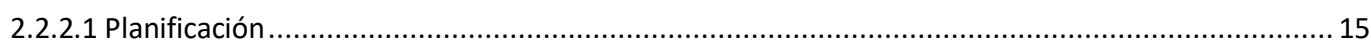

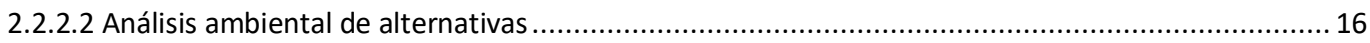

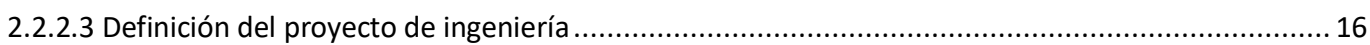

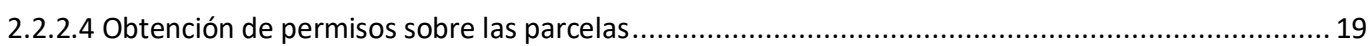

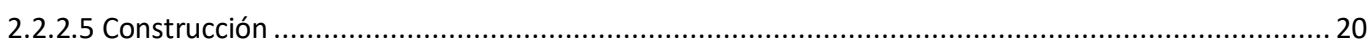

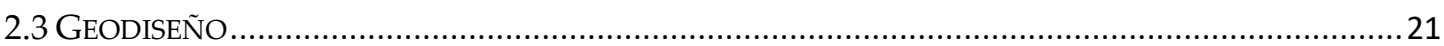

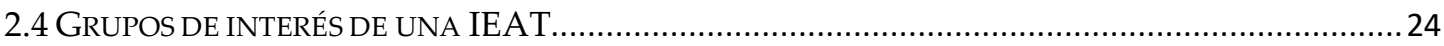

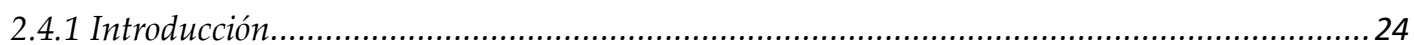

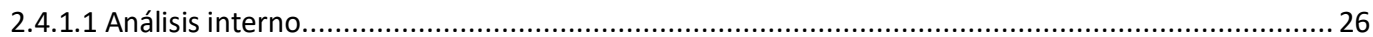

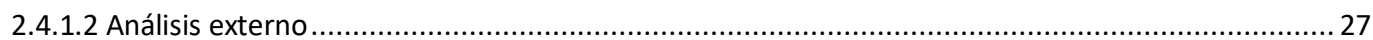

2.4.2 Gestión geográfica de los grupos de interés...................................................................... 30

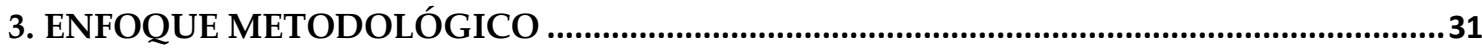

3.1 MARCO DE TRABAJO BASADO EN GEODISEÑO PARA IEAT ........................................................

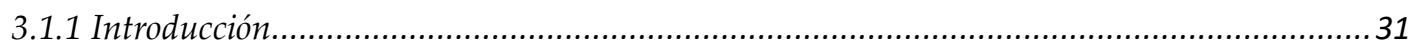

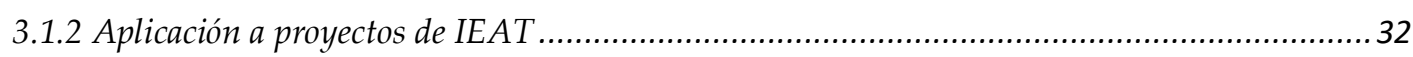

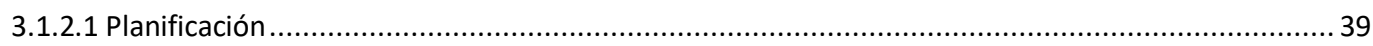

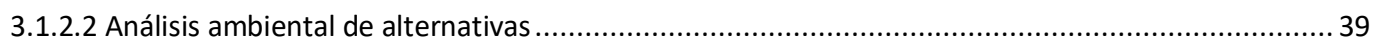

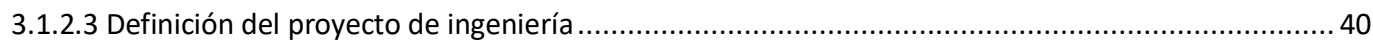

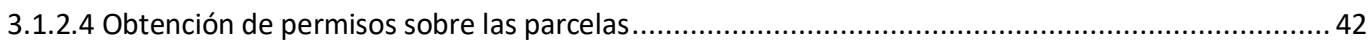

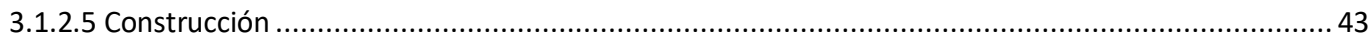

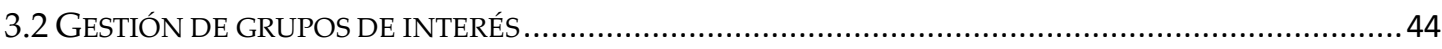

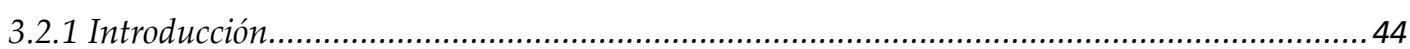

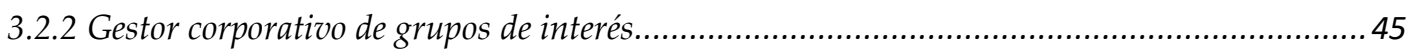




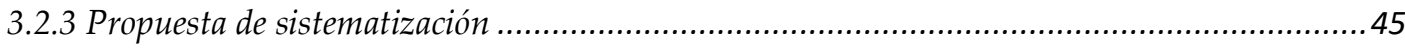

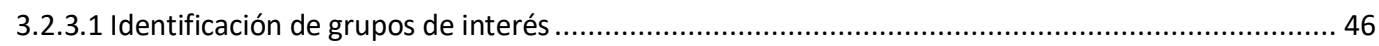

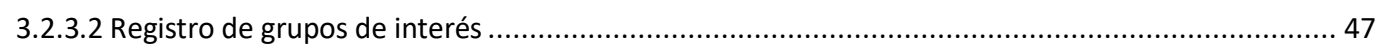

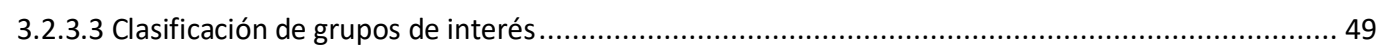

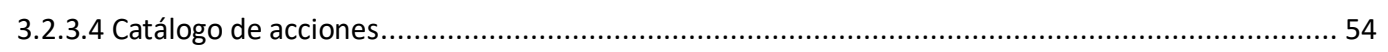

3.2.3.5 Gestión de grupos de interés en el flujo de trabajo basado en geodiseño para IEAT ...................... 58

3.2.4 Integración de la gestión de grupos de interés en el marco de trabajo basado en geodiseño .....62

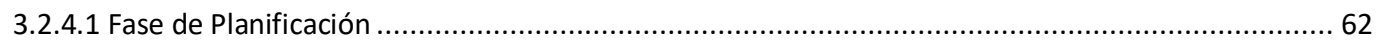

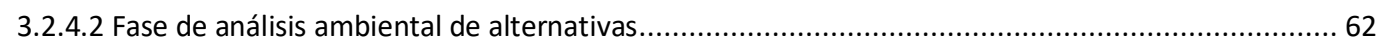

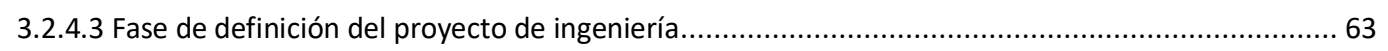

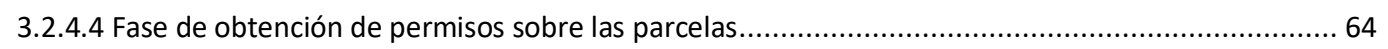

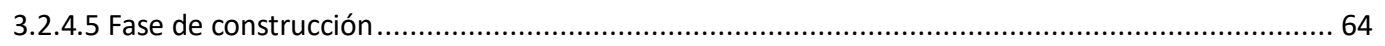

3.2.4.6 Síntesis de la integración de la gestión de grupos de interés en el marco de trabajo..................... 65

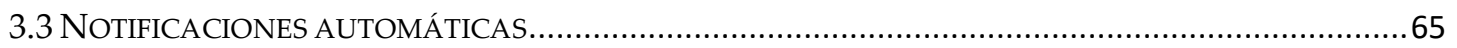

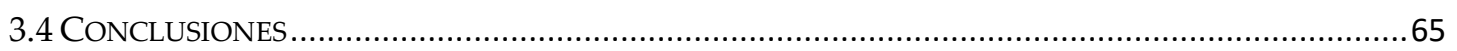

4. IMPLEMENTACIÓN Y RESULTADOS .........................................................................69

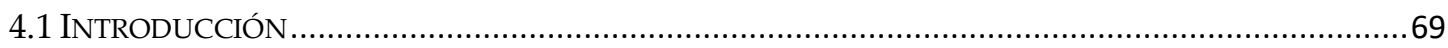

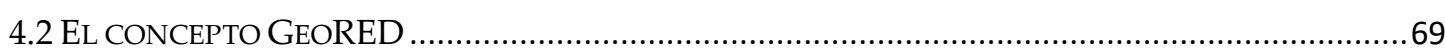

4.2.1 Metodología de diseño de la implementación ............................................................... 75

4.3 IMPLEMENTACIÓN DEL MARCO DE TRABAJO BASADO EN GEODISEÑO PARA IEAT ......................76

4.3.1 Consola o gestor de información geográfica de los proyectos............................................ 76

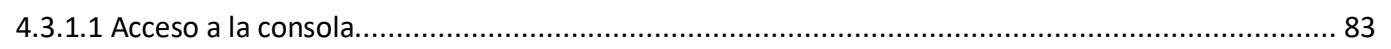

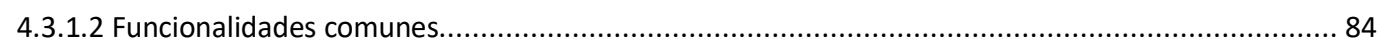

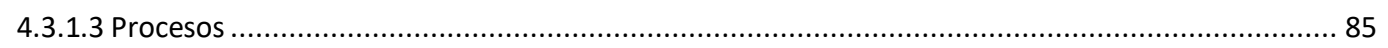

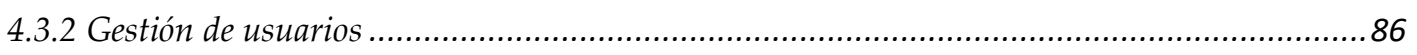

4.3.3 Sistema de notificaciones automáticas ..................................................................87

4.3.3.1 Configuración de notificaciones según perfil de usuario ......................................................... 88

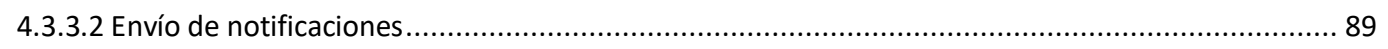

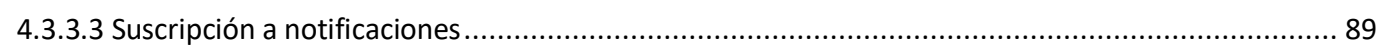

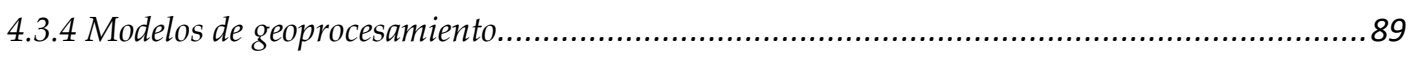

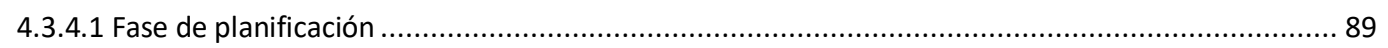

4.3.4.1.1 Modelos para comprensión del ámbito de estudio ......................................................... 89

4.3.4.2 Fase de análisis ambiental de alternativas.......................................................................... 97

4.3.4.2.1 Modelos para comprensión del ámbito de estudio (Fase análisis ambiental) ....................97

4.3.4.2.2 Modelos de propuesta de cambios (Fase análisis ambiental)........................................ 105

4.3.4.2.3 Modelos de evaluación de impactos en el entorno (Fase análisis ambiental) ................... 106

4.3.4.2.4 Modelos de ocupación del territorio (Fase análisis ambiental) ..................................... 108

4.3.4.2.5 Modelos de decisión (Fase análisis ambiental)......................................................... 110

4.3.4.3 Fase de diseño del proyecto de ingeniería.......................................................................... 111

4.3.4.3.1 Modelos para comprensión del ámbito de estudio (Fase ingeniería) ............................. 112

4.3.4.3.2 Modelos de propuesta de cambios (Fase ingeniería).................................................. 119

4.3.4.3.3 Modelos de evaluación de impactos en el entorno (Fase ingeniería) ............................... 124

4.3.4.3.4 Modelos de ocupación del territorio (Fase ingeniería) ................................................ 126

4.3.4.3.5 Modelos de decisión (Fase ingeniería) .................................................................... 135

4.3.4.4 Fase de obtención de permisos.......................................................................................... 136

4.3.4.4.1 Modelos para comprensión del ámbito de estudio (fase permisos) ................................ 136

4.3.4.4.2 Modelos de ocupación del territorio (fase permisos) .................................................. 136

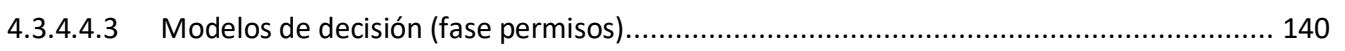

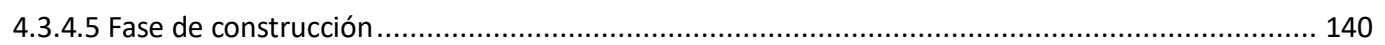


4.3.4.5.1 Modelos para comprensión del ámbito de estudio (Fase construcción) .....

4.3.4.5.2 Modelos de evaluación de impactos (Fase construcción).

4.3.4.5.3 Modelos de ocupación del territorio (Fase construcción)

4.3.4.5.4 Modelos de decisión (Fase construcción)

4.3.5 Trazabilidad de la información geográfica del proyecto ................................................. 144

4.3.6 Gestión de grupos de interés ..................................................................................... 147

4.3.6.1 Base de datos geográfica de grupos de interés ...................................................................... 147

4.3.6.2 Identificación, registro y categorización de los grupos de interés ............................................. 148

4.3.6.3 Asociación de acciones a los grupos de interés ..................................................................... 150

4.3.6.4 Alertas automáticas al gestor corporativo de grupos de interés .............................................. 151

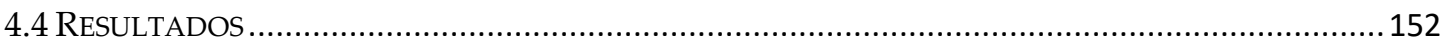

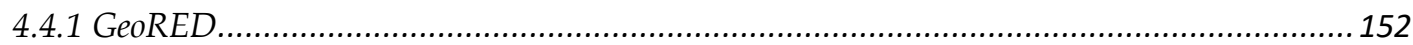

4.4.2 Marco de trabajo basado en geodiseño .............................................................. 153

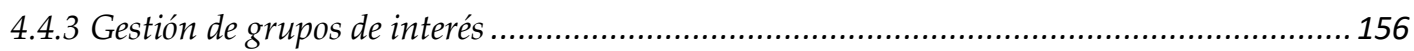

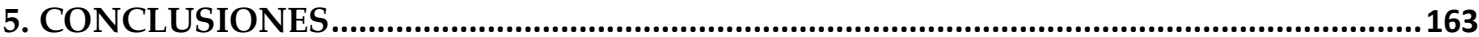

5.1 REVISIÓN DE LAS CUESTIONES DE INVESTIGACIÓN............................................................ 164

5.1.1 Armonización del tratamiento de la IG de proyectos de líneas eléctricas de alta tensión....... 164

5.1.2 Integración del marco de trabajo basado en geodiseño en el SIG corporativo - GeoRED....... 165

5.1.3 Gestión conjunta de condicionantes técnicos y de los grupos de interés de un proyecto en el marco de trabajo basado en geodiseño .............................................................................. 166

5.2 CONFIRMACIÓN DE LAS HIPÓTESIS PLANTEADAS CON ANTERIORIDAD A LA INVESTIGACIÓN ... 166

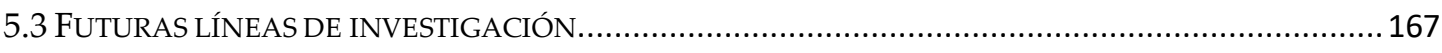

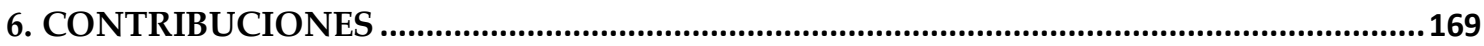

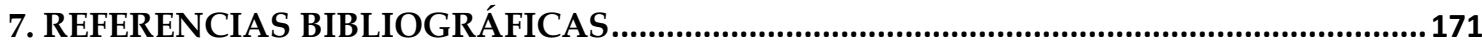




\section{LISTA DE FIGURAS}

Figura 3-1. Flujo de información geográfica simplificado y escalas de trabajo en un proyecto de IEAT .........32

Figura 3-2. Figura adaptada de "A Framework for Geodeign" ( Steinitz, 2012) .......................................................33

Figura 3-3. Tipos de modelos a aplicar en el marco de geodiseño para IEAT...........................................................34

Figura 3-4. Relación de modelos para gestión de trazabilidad en un proyecto de IEAT.........................................37

Figura 3-5. Marco de trabajo basado en geodiseño para IEAT ........................................................................................... 38

Figura 3-6. Modelos en la fase de planificación .................................................................................................................

Figura 3-7. Modelos en la fase de análisis ambiental de alternativas ...........................................................................40

Figura 3-8. Modelos en la fase de definición del proyecto de ingeniería..................................................................... 41

Figura 3-9. Modelos en la fase de obtención de permisos sobre las parcelas.............................................................4

Figura 3-10. Modelos en la fase de construcción .....................................................................................................4

Figura 3-11. Flujo de trabajo en la gestión sistemática de grupos de interés ...........................................................46

Figura 3-12. Matriz Poder - Interés (adaptada de Mendelow, 1981)..........................................................................50

Figura 3-13. Matriz Poder - Dinamismo (adaptada de Mendelow, 1981) .....................................................................51

Figura 3-14. Simbología para clasificar a los grupos de interés ………......................................................................51

Figura 3-15. Ejemplo de uso de la nueva matriz para clasificar a los grupos de interés.......................................53

Figura 3-16. Ejemplo de matriz de influencias entre 5 grupos de interés................................................................53

Figura 3-17. Ejemplo de resultados de prueba piloto con 13 proyectos .......................................................................57

Figura 3-18. Fusión de los modelos del marco de trabajo basado en geodiseño para IEAT con la estrategia

de gestión geográfica de grupos de interés.................................................................................................................59

Figura 4-1. Interfaz gráfica de GeoRED ..................................................................................................................

Figura 4-2. Convivencia de diferentes servicios de mapa para colaboración ...........................................................72

Figura 4-3. Relación de los contenidos con los usuarios .............................................................................................73

Figura 4-4. Diferentes configuraciones de servicios de mapa........................................................................................... 74

Figura 4-5. Vistas 2D, 3D y Google Street View sincronizadas.................................................................................. 75

Figura 4-6. Consola para gestionar la información geográfica de los proyectos ......................................................77

Figura 4-7. Ejemplo de cuadros de mando de la consola...........................................................................................8

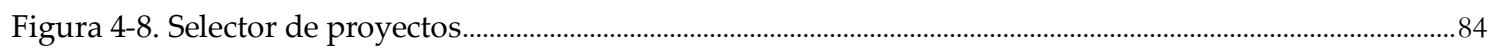

Figura 4-9. Ejemplo de cuadros de mando de la consola antes y después de su ejecución ...................................85

Figura 4-10. Ejemplo de suscripción y envío de notificaciones.....................................................................................8

Figura 4-11. Procesos para comprensión de ámbitos de estudio en fase de planificación ...................................89

Figura 4-12. Modelo de cálculo del ámbito del análisis................................................................................................99

Figura 4-13. Ejemplo de la delimitación del ámbito (a) puntos Origen y Destino. (b) Ámbito de análisis.....99

Figura 4-14. Modelo de geoprocesamiento para la generación de alternativas de pasillo....................................95

Figura 4-15. Ejemplo gráfico de la aplicación de los polígonos de Thiessen para la generar alineaciones.....96

Figura 4-16. Modelo que genera la alineación dentro de cada pasillo .......................................................................96

Figura 4-17. Significado geográfico de la planificación ................................................................................................96

Figura 4-18. Procesos de los modelos para comprensión del ámbito de estudio de análisis ambiental ..........97

Figura 4-19. Widget para definir el ámbito de estudio de línea o subestación..........................................................98

Figura 4-20. Mapa de Regiones Biogeográficas (fuente Rivas-Martínez et al. 2017).............................................98

Figura 4-21. Ejemplo de interfaz gráfica para generar mapa de capacidad de acogida del ámbito.................100

Figura 4-22. Interfaz para gestión de pesos de categorías de condicionantes territoriales ...................................100

Figura 4-23. Ejemplo de mapa de capacidad de acogida de línea..............................................................................101

Figura 4-24. Proceso de generación de mapa de capacidad de acogida.....................................................................101

Figura 4-25. Proceso de generación de diagnóstico territorial de línea .....................................................................102

Figura 4-26. Ejemplo de diagnóstico territorial de proyecto de línea...........................................................................102

Figura 4-27. Ejemplo de diagnóstico territorial de proyecto subestación.................................................................103 
Figura 4-28. Superposición de proyectos de línea y subestación para colaboración de los equipos............... 103

Figura 4-29. Ejemplo gráfico del cálculo de visibilidad general en el ámbito de análisis................................... 104

Figura 4-30. Ejemplo de análisis de visibilidad de los ámbitos de estudio de línea y subestación ..................104

Figura 4-31. Procesos que dan soporte a los modelos de propuesta de cambio en la fase medioambiental105

Figura 4-32. Widget de edición para alternativas de pasillo y áreas favorables..................................................105

Figura 4-33. Ejemplo de alternativas de pasillo y de áreas favorables..................................................................... 106

Figura 4-34. Ejemplo de coincidencia geográfica de los proyectos de línea y subestación................................... 106

Figura 4-35. Procesos para evaluar el posible impacto de las alternativas y áreas favorables propuestas .. 106

Figura 4-36. Ejemplo de resultado de evaluación de afectación a las unidades del paisaje................................ 107

Figura 4-37. Ejemplo del resultado del proceso de impacto ambiental de alternativas o áreas favorables. 107

Figura 4-38. Mapa de sensibilidad de riesgo de colisión de aves ................................................................................ 108

Figura 4-39. Ejemplo del resultado del proceso que calcula el riesgo de colisión de aves.................................. 108

Figura 4-40. Procesos de los modelos de ocupación del territorio.............................................................................. 108

Figura 4-41. Mapa de densidad de caída de rayos por km² y año. Datos 2001-2016 de AEMET .................... 109

Figura 4-42. Ejemplo del resultado del proceso que calcula la zona de riesgo de caída de rayos ................... 109

Figura 4-43. Mapa de zonas de corrosión de REE..................................................................................................... 110

Figura 4-44. Ejemplo del resultado de ejecución del proceso de zonas de corrosión............................................ 110

Figura 4-45. Procesos del modelo de decisión .................................................................................................................... 110

Figura 4-46. Ejemplo gráfico de selección de alternativas de pasillo y áreas favorables.................................... 111

Figura 4-47. Ejemplo gráfico de la evolución de la información geográfica en fase de ingeniería................... 112

Figura 4-48. Procesos del modelo para comprensión del ámbito de estudio de ingeniería.................................. 112

Figura 4-49. Ejemplo de encuentro de proyecto de línea y subestación.................................................................... 113

Figura 4-50. Ejemplo 3D de las entidades que tienen geometría en el entorno...................................................... 114

Figura 4-51. Geoproceso que automatiza el análisis de la visibilidad de cada apoyo......................................... 115

Figura 4-52. Herramientas de análisis de visibilidad de GeoRED ............................................................................... 117

Figura 4-53. Geoproceso que combina los resultados de visibilidad de cada apoyo analizado ....................... 118

Figura 4-54. Ejemplo gráfico del resultado del análisis de la visibilidad................................................................ 118

Figura 4-55. Ejemplo de escenario 3D de análisis de visibilidad ............................................................................... 119

Figura 4-56. Procesos de los modelos de propuesta de cambio en fase de ingeniería........................................... 119

Figura 4-57. Ejemplo de superficies de afectación de un camino de acceso ........................................................... 120

Figura 4-58. Cuadro de mando de carga de caminos de acceso de línea ................................................................. 121

Figura 4-59. Ejemplo de camino de acceso a una subestación..................................................................................... 121

Figura 4-60. Cuadro de mando de carga de afectaciones de línea ............................................................................ 122

Figura 4-61. Ejemplo de afectaciones de línea aérea ................................................................................................. 122

Figura 4-62. Ejemplo de afectaciones de línea subterránea.......................................................................................... 123

Figura 4-63. Ejemplo de afectaciones de un proyecto de subestación...................................................................... 123

Figura 4-64. Procesos de los modelos de evaluación de impactos en fase de ingeniería ..................................... 124

Figura 4-65. Ejemplo de interfaz para el cálculo de indicadores de afectación de proyecto de línea............. 125

Figura 4-66. Procesos de los modelos de ocupación del territorio en fase de ingeniería ...................................... 126

Figura 4-67. Formulario de selección del origen de numeración de parcelas.......................................................... 127

Figura 4-68. Ejemplo de numeración de parcelas de proyecto .................................................................................... 129

Figura 4-69. Ejemplo de la herramienta de depuración de GeoRBD .......................................................................... 133

Figura 4-70. Procesos de decisión en la fase de ingeniería ......................................................................................... 135

Figura 4-71. Procesos para comprensión del ámbito de estudio en fase de obtención de permisos................ 136

Figura 4-72. Procesos de los modelos de ocupación del territorio en fase de obtención de permisos ............ 136

Figura 4-73. Ejemplo de registro en campo del primer contacto con propietarios ................................................. 139

Figura 4-74. Procesos de los modelos de decisión en fase obtención de permisos ................................................ 140

Figura 4-75. Procesos de los modelos para comprensión del ámbito de estudio de la fase constructiva ..... 141 
Figura 4-76. Ejemplo de avance de obtención de permisos a las parcelas afectadas

Figura 4-77. Procesos de los modelos de ocupación del territorio en fase de construcción..................................142

Figura 4-78. Ejemplo de diferencia entre ocupación temporal de proyecto y de construcción............................143

Figura 4-79. Ejemplo gráfico del estado de avance de la construcción de un proyecto de línea.......................143

Figura 4-80. Procesos de decisión de la fase de construcción ......................................................................................144

Figura 4-81. Procesos de los modelos de trazabilidad..............................................................................................145

Figura 4-82. Ejemplo de trazabilidad de la información geográfica ...........................................................................146

Figura 4-83. Ejemplo de log de trazabilidad de un proyecto ......................................................................................146

Figura 4-84. Esquema-resumen del modelo de datos de grupos de interés ............................................................147

Figura 4-85. Arquitectura de herramienta geográfica ...............................................................................................148

Figura 4-86. Interfaz gráfica de la herramienta ...................................................................................................................149

Figura 4-87. Información para el registro de grupo de interés .............................................................................150

Figura 4-88. Atributos para asociar una acción a un grupo de interés ......................................................................151

Figura 4-89. Apariencia de la consola antes y después de la ejecución de procesos de fase ambiental .........155

Figura 4-90. Misma figura que 3-16 (a). Ámbitos geográficos de influencia de los 13 proyectos .....................158

Figura 4-91. Representación de la matriz poder-interés-impacto del conjunto de grupos de interés analizados en los 13 proyectos

Figura 4-92. Representación de matrices del proyecto $\mathrm{n}^{\mathrm{o}}$ 8.......................................................................................160

Figura 4-93. Trazado propuesto del proyecto $\mathrm{n}$ 으 a su paso por el municipio 2037..............................................161 


\section{LISTA DE TABLAS}

Tabla 2-1 Afectaciones consideradas tradicional y actualmente …........................................................ 17

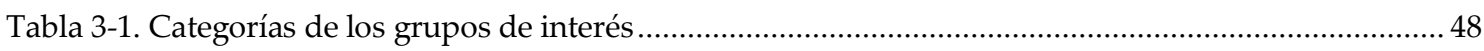

Tabla 3-2. Datos de registro de ámbito geográfico de influencia ................................................................. 48

Tabla 3-3. Asociación de grupos de interés con fase de proyecto ............................................................ 48

Tabla 3-4. Factores que ayudan a evaluar la importancia de cada proyecto ............................................. 52

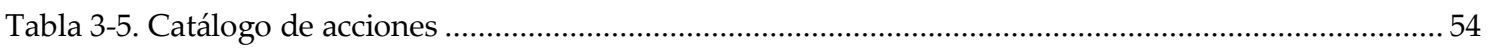

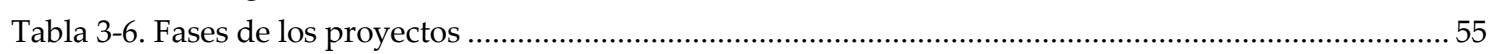

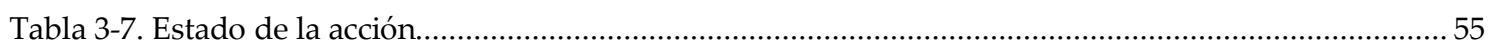

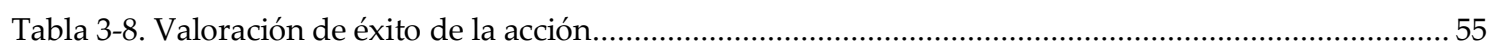

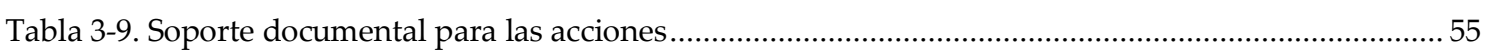

Tabla 3-10. Evidencias de cumplimiento de las acciones ejecutadas...........................................................56

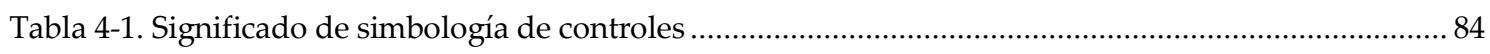

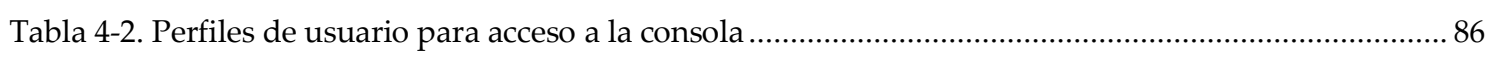

Tabla 4-3. Configuración de notificaciones por defecto según perfil de usuario...........................................8 88

Tabla 4-4. Valores de dificultad para la acogida de áreas de influencia de infraestructuras lineales............90

Tabla 4-5.Valores de dificultad para la acogida de accesibilidad ................................................................ 91

Tabla 4-6. Valores de dificultad para la acogida por pendiente del terreno .............................................. 91

Tabla 4-7. Valores de dificultad para la acogida por existencia de Valor Natural ...................................... 91

Tabla 4-8. Valores de dificultad para la acogida por existencia de Figuras de Protección Ambiental .......... 92

Tabla 4-9. Valores de dificultad para la acogida por proximidad de núcleos de población ......................... 92

Tabla 4-10. Valores de dificultad para la acogida por existencia de zonas de interés social........................ 92

Tabla 4-11.Valores de dificultad para la acogida por existencia de elementos físicos del terreno ............... 93

Tabla 4-12. Valores de ponderación para la generación de los mapas de capacidad de acogida ..................93

Tabla 4-13. Categorías de los condicionantes territoriales para mapa de capacidad de acogida ..................99

Tabla 4-14. Ejemplo de indicadores a calcular para evaluación de impactos de proyecto de línea.............. 125

Tabla 4-15. Ejemplo de ordenación de parcelas de proyecto en formato tabla.......................................... 128

Tabla 4-16. Lista de afectaciones e indicadores que se calculan en proyectos de línea ............................... 130

Tabla 4-17. Ejemplo de tabla de afectaciones de línea................................................................................. 131

Tabla 4-18. Ejemplo de baremo para obtención de permisos ................................................................... 137

Tabla 4-19. Estructura de campos para tabla de permisos..................................................................... 138

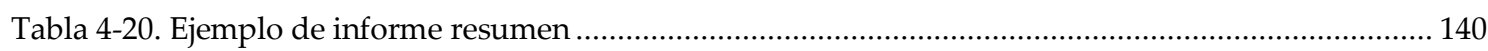

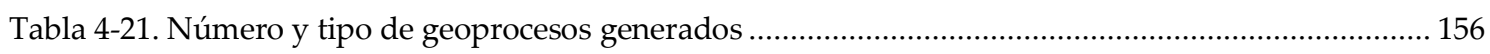

Tabla 4-22. Proyectos analizados, fase de desarrollo, sus grupos de interés y las acciones realizadas........ 158 


\section{INTRODUCCIÓN}

El suministro de energía eléctrica es esencial para nuestra sociedad ya que "juega un papel importante en el mantenimiento del nivel de vida" (Ramachandra, et al., 2006). La energía eléctrica es el motor del crecimiento de cualquier país en desarrollo; de hecho, ninguna de las principales actividades económicas puede sostenerse sin fuentes de alimentación adecuadas y fiables (Kumar, et al., 2002). Además de los desafíos específicos de suministro, prestación de servicios y de producción, que representan por sí mismos un sector importante, la industria de la energía eléctrica puede jugar un papel clave en la competitividad entre muchos otros sectores económicos (Kumar, et al., 2002). Se supone que la energía eléctrica debe ser un factor dinamizador de toda la economía y las infraestructuras (Kumar, et al., 2002) y nunca debería haber ningún obstáculo para su crecimiento. Por esta razón las políticas energéticas de los gobiernos deben fijarse, como un objetivo irrenunciable, el garantizar el suministro de energía en condiciones óptimas de seguridad, calidad y precio.

En la construcción de grandes infraestructuras lineales, como una nueva línea de alta tensión que puede llegar a medir cientos de kilómetros- hay una gran cantidad de factores diferentes y condicionantes de grupos de interés involucrados, que ejercen una influencia sobre el diseño. Todos esos factores no coincidirán necesariamente con los diferentes puntos de vista de los grupos de interés, a pesar de que deben ser estudiados en su conjunto durante todo el proyecto para tomar las decisiones pertinentes. Por ejemplo, un bosque de alcornoques o un yacimiento arqueológico no son significativos desde el punto de vista de la infraestructura eléctrica, pero tienen un gran valor ambiental e interés cultural, respectivamente. Actualmente, no es posible conseguir al mismo tiempo una puesta en común de todos los puntos de vista en este tipo de proyectos. Ni las administraciones ni las empresas encargadas de la planificación y la ejecución de las infraestructuras de transporte de energía eléctrica cuentan con las herramientas que les permitan hacer frente a las necesidades, restricciones, limitaciones o deseos de cada grupo de interés involucrado. El uso de Sistemas de Soporte a la Planificación (PSS) (Geertman \& Stillwell, 2003) (Vonk, et al., 2005) y de Sistemas de Soporte para la toma de decisiones (DSS) (Aditya, 2010), permiten reorientar el desarrollo de estos proyectos hacia una metodología. Esto permitirá tomar decisiones en base a la realidad del territorio, por lo tanto, los nuevos proyectos serán más sólidos, organizados, eficientes y avanzarán más ágilmente. La representación, en el mismo entorno de las diferentes necesidades de los actores involucrados, crea, de forma espontánea, un marco de colaboración que permite el consenso en la toma de decisiones.

Se ha seleccionado el contexto de la Red de Transporte de energía eléctrica (RdT) con el objetivo de equilibrar la transformación del territorio y la preservación de las características ambientales, sociales y culturales de cada zona. Los proyectos con los que se desarrolla la RdT se componen de diferentes fases, alineadas en un flujo de información geoespacial, en el que el resultado de una fase define el contexto geográfico de la siguiente. Los modelos de datos y formatos de los resultados de cada fase son bien conocidos y definidos. Sin embargo, el procedimiento seguido para llegar a cada resultado depende de los criterios personales del técnico responsable. Esto provoca una falta de homogeneidad en los criterios para el análisis y la toma de decisiones necesaria para lograr resultados corporativos homogéneos. 


\subsection{Tensión eléctrica}

Comúnmente denominado voltaje, la tensión eléctrica o diferencia de potencial es la magnitud física capaz de cuantificar la diferencia de potencial eléctrico entre dos puntos. Es decir, es el voltaje con que la electricidad pasa de un cuerpo a otro, siendo su unidad de medida el Voltio.

Considerando dos puntos (A y B) con diferencia de potencial entre sí, al unirlos mediante un conductor, se produce un flujo de electrones. El punto de mayor potencial (A) cede parte de su carga al punto de menor potencial (B) a través del conductor hasta que ambos alcancen el mismo potencial eléctrico. Esta transferencia de cargas es lo que se conoce como corriente eléctrica que, en función del voltaje, se diferencia entre alta, media y baja tensión.

En España, bajo el Real Decreto 223/2008, se diferencian cuatro categorías para diferenciar las líneas de alta tensión:

1. Se considera Categoría Especial cuando: la tensión nominal es igual o superior a $220 \mathrm{kV}$; o las tensiones normalizadas son entre 220 y $240 \mathrm{kV}$. La Red de Transporte de electricidad (a grandes distancias) se realiza en ocasiones a alta tensión de Categoría Especial.

2. Se considera $1^{\text {a }}$ Categoría cuando: la tensión nominal es superior a $66 \mathrm{kV}$ e inferior a 220 $\mathrm{kV}$; o las tensiones normalizadas son $110 \mathrm{kV}, 132 \mathrm{kV}$ y $150 \mathrm{kV}$. La Red de transporte y el Sistema de Distribución de Energía Eléctrica, se realiza en ocasiones a alta tensión de $1^{\text {a }}$ Categoría.

3. Se considera $2^{2}$ Categoría cuando: la tensión nominal es superior a $30 \mathrm{kV}$ e igual o inferior a $66 \mathrm{kV}$; o las tensiones normalizadas son $45 \mathrm{kV}$ y $66 \mathrm{kV}$. El Sistema de Distribución de Energía Eléctrica se realiza en ocasiones a alta tensión de $2^{\mathrm{a}}$ Categoría.

4. Se considera 3 $3^{\text {a }}$ Categoría también denominada media tensión, cuando la tensión nominal es superior a $1 \mathrm{kV}$ e igual o inferior a $30 \mathrm{kV}$.

\subsection{Infraestructuras eléctricas de alta tensión}

La RdT de energía eléctrica es la parte del sistema de suministro eléctrico constituida por los elementos necesarios para llevar hasta los puntos de consumo y a través de grandes distancias, la energía eléctrica generada en las centrales eléctricas.

En el transporte de electricidad se producen pérdidas y para reducirlas se eleva la tensión, lo que tiene ventajas desde el punto de vista eléctrico y desventajas desde el punto de vista de la ocupación del territorio.

Desde el punto de vista eléctrico, lo que se consigue al elevar las tensiones es disminuir la intensidad que circula por las líneas obteniendo con ello una de reducción de pérdidas al transportar la misma potencia.

Cuando una corriente eléctrica circula por un conductor, éste aumenta su temperatura. Es decir, la energía eléctrica se ha transformado en energía térmica (efecto Joule). A mayor intensidad, mayor temperatura del conductor $\mathrm{y}$, por tanto, mayor es la pérdida. 
La potencia perdida en el transporte es directamente proporcional al cuadrado de la intensidad de la corriente que circula y a la resistencia:

$$
P=I^{2} \cdot R
$$

Sin embargo, desde el punto de vista de ocupación del territorio, el elevar la tensión conlleva la necesidad de mayores aislamientos entre las fases del circuito que se traduce en mayor distancia entre los conductores y la necesidad de cambiar los voltajes o transformar las diferencias de potencial en los extremos (Subestaciones).

Según el reglamento de líneas eléctricas vigente en España (BOE, 2008), las distancias mínimas de aislamiento entre conductores se han establecido en función de la tensión, y van aumentando desde los 0,1 metros para las líneas de 3,6 kV hasta los 3,2 metros para las de 420kV.

Estas distancias mínimas provocan que las dimensiones de cada torre o apoyo eléctrico crezcan y, por tanto, su ocupación permanente de suelo, las servidumbres derivadas de la instalación y la visibilidad de la misma.

La RdT de electricidad, en cuanto a la ocupación del territorio, puede clasificarse en dos grandes grupos:

\subsubsection{Líneas eléctricas de alta tensión}

Una línea de transporte de energía eléctrica o línea de alta tensión es básicamente el medio físico mediante el cual se realiza la transmisión de la energía eléctrica a grandes distancias.

Las líneas eléctricas pueden ser aéreas o subterráneas. Las aéreas suelen construirse en entornos rústicos y las subterráneas en entornos urbanos. Independientemente de las diferencias técnicas, existe una gran diferencia en cuanto a dimensiones y, por tanto, en cuanto a ocupación del territorio y su impacto en el entorno.

Una línea aérea está constituida tanto por el elemento conductor, usualmente cables de acero, cobre o aluminio, como por sus elementos de soporte, las torres o apoyos de alta tensión. Una línea subterránea es una infraestructura para la transmisión de energía con cables subterráneos.

Puesto que la mayoría del aislamiento es proporcionado por el aire, las líneas aéreas de alta tensión son generalmente el método más barato de transmisión de energía en grandes proporciones. La capacidad de la línea de transporte de electricidad afecta al tamaño de estas estructuras principales que, al ser instalaciones lineales, e indirectamente afectan a los recursos naturales, socioeconómicos, culturales y paisajísticos del entorno que atraviesan.

En el caso de líneas subterráneas, gracias a los aislantes de los cables conductores, la tensión en el exterior de los mismos es nula, por lo que los cables pueden ir totalmente pegados. La elección de separarlos es para incrementar la capacidad de transporte de la línea.

\subsubsection{Subestaciones eléctricas de alta tensión}

Las subestaciones eléctricas son las instalaciones encargadas de realizar transformaciones de la tensión, de la frecuencia, del número de fases o la conexión de dos o más circuitos. Se trata de un 
conjunto de equipos eléctricos y sistemas cuya finalidad es adecuar distintos niveles de tensión y corriente implicando, además del transformador, todos los elementos necesarios para las maniobras, protección y control del conjunto de potencia, permitiendo el flujo de energía a los sistemas y líneas de transporte.

Constituyen los nodos eléctricos que conectan las líneas que transportan y distribuyen la electricidad.

Considerando que los elementos eléctricos deben contar con el debido aislamiento para que no se produzcan arcos eléctricos entre ellos, podemos clasificar las subestaciones en función del elemento aislante:

a) Subestación de intemperie

El elemento aislante es el aire o, dicho de otro modo, el espacio o distancia existente entre los elementos de la red.

b) Subestación blindada

En la subestación eléctrica blindada más usual el elemento que trabaja como aislante es el gas SF6 (hexafluoruro de azufre). Este tipo de subestaciones se conocen como GIS (Gas Insulated Switchgear).

Independientemente de las características técnicas de cada una, existe una gran diferencia en cuanto a dimensiones y, por tanto, en cuanto a ocupación del territorio y su impacto visual, ya que el aislamiento por SF6 hace que las distancias entre elementos de la red se reduzcan enormemente. Por este motivo las blindadas suelen estar dentro las ciudades en el interior de edificios y las de intemperie suelen estar ubicadas en zonas rústicas.

Considerando el significado geográfico de las instalaciones de alta tensión, en cuanto a ocupación del territorio y su impacto visual, este trabajo de investigación se centrará en las líneas aéreas y subestaciones de intemperie.

\subsection{Problemática y motivación}

La RdT de electricidad se amplía y desarrolla por medio de proyectos que tradicionalmente usaban información geográfica como elemento de segundo nivel. Estos proyectos tienen una marcada componente territorial ya que las instalaciones modificarán el entorno en el que serán construidas. También con sus grupos de interés con los que tendrán que interactuar. El carácter secundario que se había dado a la información geoespacial en este tipo de proyectos no potenciaba su gestión geográfica, creándose una distancia entre las disciplinas técnicas del proyecto de la futura instalación y la disciplina de las geociencias en las que se apoyaban.

A su vez, la gestión geográfica presentaba diferentes problemas que debían abordarse en conjunto para obtener una solución global. Estos problemas derivaban del crecimiento no controlado en el uso de información geográfica que provocaba:

- dispersión en cuanto al almacenamiento, con diferentes estructuras de datos y en diferentes sistemas de coordenadas, a veces, no informados 
- duplicidad de información que, por la falta de centralización del almacenamiento, se adquiría o generaba varias veces

- múltiples versiones de la misma información sin el control necesario para su uso consciente

- disparidad de criterios en cuanto al tratamiento y uso de la información

- información que, teniéndose, no era utilizada

- información que debía utilizarse y no se tenía y tampoco se adquiría o generaba

- no existía trazabilidad en el uso y tratamiento de la información geográfica

- una vez que la instalación era construida y se ponía en servicio, la información geográfica utilizada durante las fases anteriores de diseño del proyecto se perdía o era muy complicado recuperarla

El no gestionar de un modo organizado la información geográfica de los proyectos aumentaba la distancia entre la definición del proyecto y toda la información geográfica relacionada con él. La reducción de esta distancia presentaba una oportunidad de mejora importante en la gestión de proyectos gracias a la consideración de la gestión geográfica como elemento de primer nivel que aporta herramientas de ayuda para la toma de decisiones.

El conjunto de problemas identificados ha ofrecido una oportunidad y la motivación necesaria para desarrollar la presente tesis doctoral.

\subsection{Descripción del proyecto de investigación}

El objetivo principal de esta investigación es la definición, y posterior materialización mediante herramientas SIG (Sistema de Información Geográfica), de un marco de referencia metodológico colaborativo basado en geodiseño, para los proyectos de nuevas instalaciones de transporte de energía eléctrica, que sean capaces de involucrar a los diferentes grupos de interés y responsables implicados.

Los objetivos específicos son:

1. Identificar a todos los grupos de interés involucrados en el ciclo de vida de los proyectos de nuevas instalaciones eléctricas de alta tensión, sus condicionantes y restricciones, y las relaciones entre ellos.

2. Diseñar una metodología capaz de gestionar la información geoespacial existente en el ciclo de vida de un proyecto de instalación eléctrica de alta tensión teniendo en cuenta los condicionantes, las restricciones y las relaciones entre los distintos grupos de interés.

3. Materializar la metodología en un Sistema de Información Geográfica, en plataforma web, capaz de gestionar la información geoespacial existente en el ciclo de vida de un proyecto de instalación eléctrica de alta tensión, en el que cada grupo de interés pueda reflejar sus condicionantes y visualizar en un mismo entorno, los condicionantes de los grupos de interés con los que tiene relación en el proceso. 


\subsection{Hipótesis y Cuestiones que se pretende responder por la investigación}

La presente tesis está compuesta por tres hipótesis:

- H1: Los condicionantes y restricciones de los diferentes grupos de interés involucrados en los proyectos de nuevas instalaciones eléctricas de alta tensión pueden representarse, por medio de su abstracción con un modelo de datos geoespacial, en un Sistema de Información Geográfica.

- H2: Es posible gestionar, mediante una metodología de trabajo basada en geodiseño, la información geoespacial asociada al ciclo de vida de los proyectos de instalaciones eléctricas de alta tensión, homogeneizando los procedimientos corporativos para todas las fases de los proyectos. La hipótesis que se plantea es que la representación y gestión, en el mismo entorno, de los diferentes requerimientos de los actores involucrados, crea espontáneamente un marco colaborativo que facilitará el consenso en la toma de las decisiones

- H3: Las interacciones entre condicionantes, restricciones y preferencias (técnicas, socioeconómicas, medioambientales o políticas) de los grupos de interés involucrados, en los proyectos de instalaciones eléctricas de alta tensión, pueden ser gestionadas por un Sistema de Información Geográfica colaborativo, basado en geodiseño, como herramienta de ayuda a la toma de decisiones consensuadas.

La innovación de la investigación reside en la definición de un nuevo modelo metodológico basado en geodiseño que permita, por un lado, involucrar a todos los grupos de interés existentes en los proyectos de instalaciones eléctricas de alta tensión y, por otro lado, que se homogenicen los procedimientos/criterios en todas las fases de dichos proyectos.

La segunda aportación se basa en la implementación, en plataforma web, de un Sistema de Información Geográfica capaz de hacer convivir, en el mismo entorno, las diferentes vistas de un Sistema de Información Geográfica que representa a cada uno de los grupos de interés.

Las preguntas de investigación que se responderán en esta tesis doctoral, relacionada con las tres hipótesis planteadas son:

¿Es posible armonizar el tratamiento de la información geográfica de los proyectos de líneas eléctricas de alta tensión e integrar su ciclo de vida en el flujo de trabajo basado en geodiseño?

¿Es posible implementar una metodología como flujo de trabajo basada en geodiseño para proyectos de líneas eléctricas de alta tensión e integrarla en GeoRED (SIG corporativo de REE) como una herramienta de sistema de soporte a la planificación?

¿El uso del flujo de trabajo basado en el geodiseño para el desarrollo de proyectos de líneas eléctricas de alta tensión, como el implementado por REE, ayudará a administrar de forma geográfica y conjuntamente, tanto los activos proyectados como los que están en servicio, con los grupos de interés identificados en cada caso? 
Los objetivos específicos del proyecto de investigación y las hipótesis planteadas en el mismo han sido abordados y se ha respondido a las preguntas de investigación en los trabajos publicados.

Si bien ambos trabajos se han centrado en las líneas eléctricas de alta tensión, como parte de la RdT de electricidad, el conjunto de la tesis recoge las partes de la red con relevancia geográfica al completo: las líneas de transporte y las subestaciones.

\subsection{Metodología de trabajo}

El objetivo general se centra en establecer un modelo colaborativo de geodiseño en el contexto del desarrollo de proyectos de nuevas instalaciones de transporte de energía eléctrica. La metodología de trabajo se apoya en los siguientes objetivos específicos como líneas de estudio a desarrollar:

1. Revisión bibliográfica:

Estado del arte de los modelos de geodiseño aplicables a proyectos de instalaciones de transporte de energía eléctrica, así como de la gestión de grupos de interés.

2. Definición de un marco conceptual y un catálogo de acciones suficientes para la gestión de los grupos de interés vinculados con el desarrollo y el mantenimiento de proyectos de líneas eléctricas de alta tensión.

Identificación y caracterización de los grupos de interés (actores involucrados), recopilando las necesidades de los distintos grupos en cada contexto geográfico con el objetivo de favorecer su colaboración y el flujo de información en un mismo entorno.

3. Diseño del marco metodológico basado en geodiseño:

Definición de las metodologías que permitan la homogeneización de los procedimientos a aplicar en cada fase de los proyectos.

4. Diseño centrado en el Usuario de la plataforma de trabajo:

Realizar identificación, análisis e interpretación de las necesidades de los grupos de interés, para orientar el marco de referencia de forma que se favorezca el entorno de geodiseño y la colaboración.

5. Implementación del prototipo:

En base a las necesidades detectadas, realizar un diseño funcional e implementación de prototipo para materializar el entorno de trabajo.

6. Pruebas de concepto:

Orientar las pruebas de concepto a la eficacia del modelo y la evaluación de la satisfacción de los usuarios pertenecientes a los grupos de interés involucrados. 
Para emprender las investigaciones enumeradas en los objetivos o metodología a seguir, se planteó este plan de trabajo:

1. En relación a la identificación de los grupos de interés del contexto y sus relaciones:

a. Análisis de la metodología de trabajo actual, con el objetivo de evidenciar sus carencias en cuanto a la participación, o no, de los grupos de interés.

b. Análisis de las relaciones, existentes por las obligaciones legales y las no existentes pero necesarias, que permitirían una mejor aceptación social de los proyectos.

2. En relación con el diseño del marco metodológico basado en geodiseño:

a. Identificar los hitos intermedios y condiciones técnicas de los resultados a obtener en cada fase de los proyectos de instalaciones eléctricas de alta tensión.

b. Relacionar las fases de los proyectos por medio de un flujo de trabajo que dé consistencia a la metodología.

3. En relación al diseño centrado en el usuario de la plataforma de trabajo y su implementación:

a. Definición de roles de usuario

b. Definición de la gestión de usuarios

c. Definición de la gestión de contenidos

d. Definición de la gestión de las relaciones entre usuarios y contenidos

e. Definición de interfaz de usuario de la plataforma para interactuar con los contenidos

f. Supervisión de la implementación del prototipo

g. Pruebas de concepto y consulta a usuarios

Finalmente, y de acuerdo a la planificación prevista estos eran los resultados esperados:

1. Metodología de trabajo basada en modelos colaborativos de geodiseño para proyectos de instalaciones de transporte de energía eléctrica.

2. Sistema de Información Geográfica corporativo y colaborativo (GeoRED) capaz de reproducir las relaciones existentes entre los grupos de interés, en entorno web, con vistas adaptadas a cada grupo de interés y sus necesidades. 


\subsection{Estructura de la tesis}

La tesis se ha estructurado de acuerdo a los siguientes capítulos:

- Capítulo 1: Introducción

- Capítulo 2: Antecedentes y Marco de la Investigación

- Capítulo 3: Enfoque metodológico

- Capítulo 4: Implementación y resultados

- Capítulo 5: Conclusiones

- Capítulo 6: Contribuciones

- Capítulo 7: Referencias bibliográficas 


\section{ANTECEDENTES Y MARCO DE LA INVESTIGACIÓN}

En pleno proceso de expansión de la alta velocidad y la construcción de plantas de generación de energía renovable, mayoritariamente eólica y fotovoltaica, el diseño de los proyectos de nuevas instalaciones de alta tensión estaba dirigido desde el punto de vista político y no se le daba la debida consideración a los contextos locales, sociales y medioambientales. Existe el riesgo de un crecimiento no sostenible de las redes de transporte de energía eléctrica, que puede minar seriamente los niveles aceptables de calidad del medio ambiente y el paisaje. Por esta razón, es necesario investigar nuevos procedimientos metodológicos y tecnológicos para canalizar el potencial transformador de la nueva infraestructura a través de procesos de desarrollo sostenible. Aquí es donde el geodiseño se presenta como un enfoque metodológico alternativo para investigar cómo involucrar a diferentes grupos de interés, desde los técnicos a los grupos de interés locales, en un proceso abierto y participativo que facilite la transparencia y visibilidad en las diferentes decisiones y responsabilidades.

Estas decisiones, que tienen consecuencias territoriales o, dicho de otra manera, modificarán el entorno por el que finalmente se construya la instalación, necesitan estar soportadas documentalmente de mapas o herramientas visuales de los mismos, así como los indicadores resultado del análisis de la información geográfica del proyecto sobre la descriptiva del territorio.

Este soporte documental con componente geográfica aporta un entorno único para la comunicación, la colaboración, las iteraciones, las negociaciones, los acuerdos y, finalmente, las decisiones.

Un ejemplo reciente de la importancia de la geo-información es la definición de las zonas más eficientes desde el punto de vista de la generación fotovoltaica, dentro de éstas la localización de laderas con pendiente orientada al sur, con distancias superiores a 10 y 20 kilómetros de subestaciones de $220 \mathrm{kV}$ y de $400 \mathrm{kV}$ respectivamente para la viabilidad de la instalación y además, con el objetivo de acercar la industria del sector energético a las zonas despobladas, localizar aquellos municipios con escasa densidad de población que cumplan las condiciones anteriores.

Este tipo de análisis, que son de gran valor añadido para la planificación eléctrica, no serían posibles sin información geográfica y los análisis cruzados que pueden derivarse de cada problemática.

La carencia de un modelo, o marco metodológico, colaborativo para la gestión de la información geográfica en las distintas fases de proyecto, diseño e implementación de una instalación eléctrica de alta tensión, motiva su investigación y la exploración de la aplicabilidad de los principios del geodiseño en este ámbito, limitando el alcance al ciclo de vida de la geo-información asociada a dichos proyectos.

El Marco de la Investigación se compone de tres grandes bloques que son conceptos independientes y, por sí mismos, de envergadura considerable.

La implantación de una Infraestructura Eléctrica de Alta Tensión - IEAT es una herramienta necesaria en la transición energética que debe cumplir con los planes de generación de 
renovables. Estos planes necesitan del desarrollo y ampliación de la red de transporte de energía eléctrica que garantice una combinación de generación renovable diversificada: solar, hidroeléctrica, eólica, biomasa, etc., permitiendo la conexión de muchos productores: pequeños, medianos y grandes, y que se adapte a las diferentes características territoriales.

Esta transición energética implica también algunos cambios sociales (Delgado, 2019). La percepción social de las instalaciones de generación renovable está condicionada positivamente por los beneficios ambientales que produce. Sin embargo, las líneas eléctricas que hacen posible el escenario renovable están condicionadas por sus impactos negativos, especialmente el que produce sobre el paisaje. A diferencia de lo que ocurre con las carreteras o los trenes de alta velocidad, existe una gran contradicción cuando se relaciona su fin social con su impacto sobre el medio ambiente. Así, por ejemplo, (Delgado, 2019) afirma que los trenes de alta velocidad son mejor aceptados por la población local que las líneas eléctricas a pesar de que su impacto ambiental es infinitamente mayor, siendo por contra inferior la utilidad que proporciona su fin social. Las líneas eléctricas ocupan poca superficie, se limita al terreno ocupado por los apoyos, siendo no significativa la destrucción de recursos ambientales en la mayor parte de los casos. No tienen efecto barrera ni de fragmentación de ecosistemas, ya que la fauna y flora pueden convivir con las líneas eléctricas, y no se producen emisiones ni residuos asociados a su operación y mantenimiento. Incluso, su impacto puede llegar a resultar nulo sobre los factores físicos y biológicos.

La población afectada por la construcción de una IEAT quiere este servicio público, pero rechaza su implantación. Los anglosajones bautizaron esta contradicción como efecto NIMBY (Not In My Back Yard) y que alguien tradujo felizmente al español como efecto "span": sí, pero aquí no (Delgado, 2019). El efecto NIMBY es el resultado de un dilema social caracterizado por la separación espacial de ventajas e inconvenientes (Vlek \& Keren, 1992).

Cambiar esta percepción es una tarea necesaria ante los nuevos retos de la transición energética; que requiere, a su vez, la aplicación de nuevos enfoques analíticos por el grado de complicación que se produce al solaparse las cuestiones económicas, sociales y ambientales (Delgado, 2019).

El problema no es solo la implantación de una línea eléctrica que, a priori, vaya a tener impacto visual en el medio, sino el que se pueda producir un cambio de las condiciones en que la humanidad y los ecosistemas se han ido desenvolviendo a lo largo del tiempo.

\subsection{Sistema de información geográfica corporativo}

Gracias al nivel de madurez de la Sociedad de la Información (Campagna, et al., 2014), se dispone de muchas fuentes de datos digitales de muchas regiones del planeta, entre ellos los geoespaciales. Poco a poco se va haciendo realidad el concepto de Digital Earth introducido por Craglia en 2012, (Craglia, et al., 2012) y se dispone de información geográfica oficial y voluntaria (por ejemplo, Open Street Map - OSM) que permiten respaldar el análisis y la toma de decisiones, específicamente en los procesos de diseño y geodiseño.

La información geoespacial, en cualquiera de sus formas, es una parte muy importante del conocimiento que genera y gestionan las empresas cuyos activos están implantados en el 
territorio. Los Sistemas de Información Geográfica (SIG) se han convertido en uno de los principales actores en los procesos de virtualización y mejora en una organización, ya que constituyen una herramienta de gran utilidad para promover el cambio educacional, cultural $u$ organizativo, propiciar la participación de todos los grupos de interés dentro y fuera de la misma, el desarrollo de competencias y habilidades en gestión de información, el desarrollo de metodologías internas, protocolos, estándares y finalmente, traducirlo todo en un único repositorio de conocimiento, siendo el propio SIG parte del mismo.

Cerca del $80 \%$ de la información tratada por empresas, cuyos activos están instalados en el territorio, tiene una componente espacial y por tanto puede ser georreferenciada, lo que demuestra que la toma de decisiones depende en gran parte de la calidad, exactitud y actualidad de esta información geoespacial.

Los SIG corporativos constituyen, además de una herramienta de análisis y gestión territorial, un elemento clave que facilita el proceso de adecuación de las organizaciones al nuevo paradigma sociotécnico. Un SIG corporativo es un sistema encargado de suministrar información geoespacial a todos los individuos de una organización y a todos los niveles: operativo, táctico y estratégico. También debe ser la base de los intercambios de información geoespacial con entidades externas a la propia organización. Siendo las siguientes las principales características que debe cumplir un SIG corporativo:

- Único: Único sistema para toda la organización.

- Integral: Satisface todas las necesidades de la organización.

- Integrado: Todos los grupos de interés de la organización forman parte de él

La información geoespacial que se gestiona según este modelo deberá estar almacenada en un repositorio único que garantice la seguridad, la centralización, la actualidad y el acceso a los datos.

La mayor parte de las dificultades y barreras que impiden la implementación y funcionamiento óptimo de los SIG corporativos no son problemas de tipo técnico, sino dificultades de carácter metodológico, organizativo o derivadas de la inadecuación y rechazo de la organización y/o de los usuarios potenciales a los procesos de cambio impuestos por el nuevo escenario.

La implementación exitosa de un SIG corporativo en una organización trasciende más allá de su propósito inicial, que es el de servir de herramienta para el análisis espacial, pasando éste a convertirse en un motor de cambio y adecuación de la organización.

Con todo ello se facilita la preparación y adaptación paulatina a los principales retos que actualmente se presentan en las organizaciones para adecuarse al necesario cambio mediante la virtualización progresiva y la mejora de la gestión del conocimiento individual y de grupo, y cuyos resultados se traducirán en dar mejores y nuevos servicios, ser más eficientes en sus funciones y facilitar las condiciones necesarias para potenciar un adecuado desarrollo económico y social en su ámbito de actuación. 


\subsection{Proyecto de Infraestructura Eléctrica de Alta Tensión (IEAT)}

La evaluación de las diferentes alternativas en el desarrollo de la Red de Transporte (RdT) de energía eléctrica está presente en todos los proyectos que el gestor de la red en España debe acometer. Este gestor de la RdT es el responsable del desarrollo y ampliación de la red, de realizar su mantenimiento, con criterios homogéneos y coherentes para proporcionar la fiabilidad y disponibilidad requerida, de gestionar el tránsito de electricidad entre sistemas exteriores y la península, y de garantizar el acceso de terceros a la red en régimen de igualdad.

El desarrollo de la RdT, que se lleva a cabo por medio de proyectos, y considerando los avances en el negocio internacional, debe obedecer a enfoques metodológicos corporativos en la gestión de la trazabilidad de los datos geoespaciales de cada proyecto. El diseño, propuesta e implementación de un marco de geodiseño para el desarrollo de proyectos de IEAT ayudará a gestionar geográficamente los activos proyectados y en servicio de REE, tanto dentro como fuera de España.

\subsubsection{Introducción}

En el contexto de la red de transporte de electricidad se desarrollan proyectos de longitud considerable (desde algunos kilómetros y hasta decenas e incluso centenas de kilómetros) de infraestructura lineal en los que hay que equilibrar la transformación del territorio afectado y la preservación de las características ambientales, sociales y culturales de la zona.

Los proyectos consisten en una sucesión de fases alineadas a lo largo del flujo de la Información Geoespacial (IG), en el que el contexto geográfico de una fase es definido por el resultado de la fase anterior, produciéndose un incremento de detalle de la IG al ir aumentando la escala de trabajo (Nyerges, et al., 2016). Los modelos de datos y los formatos de los resultados para cada fase se conocen y están bien definidos. Sin embargo, el procedimiento utilizado para llegar a cada resultado depende del saber hacer y de los criterios personales del técnico responsable. Este problema provoca una falta de homogeneidad en los criterios de análisis y en la toma de decisiones necesarios para lograr resultados corporativamente homogéneos.

En el ciclo de vida del proyecto se identifican dos tipos de interacciones fundamentales: la primera se produce dentro de cada fase, con interacciones entre los diferentes equipos de trabajo, que representan a todas las partes interesadas por medio de los condicionantes alertados, y que están relacionados con el tipo de información de la fase y con su escala correspondiente; la segunda entre los equipos responsables de cada fase. De estas dos interacciones se preocupa, principalmente, el marco de trabajo basado en geodiseño para el desarrollo de proyectos de IEAT cuya parte de proyectos de línea se analizó como parte del trabajo de investigación de la tesis en 2018 (Moreno-Marimbaldo, et al., 2018).

Así, la primera de las interacciones se apoyará en los modelos de geoprocesamiento cuyos resultados darán soporte a la toma de decisiones de cada fase. Y la segunda interacción se apoyará en la terna retroalimentación -iteración-consenso, ineludible en cualquier marco de trabajo de geodiseño. Considerando que el resultado de cada fase acota y define el ámbito de estudio de la fase siguiente, esta terna (retroalimentación-iteración-consenso) aparece de forma espontánea por los ajustes necesarios por la adecuación del resultado de cada fase. 


\subsubsection{Fases de un proyecto}

Cada proyecto de IEAT, planificada por REE y aprobada por el Consejo de Ministros, se ejecuta siguiendo un ciclo de vida que se compone de 5 fases principales y que son además secuenciales:

1. Planificación

2. Análisis ambiental de alternativas

3. Definición del proyecto de ingeniería

4. Obtención de permisos sobre las parcelas

5. Construcción

Este ciclo de vida del proyecto sincroniza diferentes tipos de información como son, por ejemplo: los análisis de necesidades y sus documentos técnicos, los estudios de viabilidad, los documentos de tramitación administrativa, los cálculos de obra civil para la cimentación de líneas y subestaciones, los caminos de acceso, los movimientos de tierras, los cálculos eléctricos y mecánicos de la línea y sus apoyos, los análisis de impactos en el territorio y sus habitantes y los datos geoespaciales que ayudan a explicar el proyecto en cada una de sus fases. Siendo los datos geográficos el elemento vertebrador de los procesos de geodiseño que se proponen en esta tesis.

Las transiciones entre fases consecutivas se caracterizan por tres hechos ya destacados: el resultado de una fase acota el ámbito geográfico de la siguiente, la escala de trabajo de los datos geográficos crece conforme se avanza de fase en el proyecto y que en cada una de las fases existe un equipo técnico especializado en la temática concreta de la fase.

\subsubsection{Planificación}

Esta fase tiene como objetivo definir las necesidades del sistema eléctrico, que se traducen en nuevas líneas y nuevas subestaciones, o la modificación y/o ampliación de las existentes. Entre las nuevas líneas se identifican las rutas eléctricas a reforzar, el abastecimiento de electricidad a nuevas localizaciones, la conexión de las nuevas centrales de generación y renovables, o el propio mallado de la red de transporte para mantener la calidad de suministro. Las nuevas subestaciones serán los nodos de conexión necesarios para conectar líneas a la red. El resultado del ejercicio de planificación es evolución necesaria de la red a ejecutar en los años siguientes (Planificación, 2020).

Debido al carácter más energético que territorial, la información geográfica de esta fase sirve únicamente para mostrar, sin precisión, un primer borrador del futuro trazado de líneas o localización de subestaciones. La escala de trabajo es por tanto pequeña, y considerando los mapas de la red que genera REE, es próxima a 1:1.000.000.

Aunque en los últimos años la información geográfica de la planificación ha ido mejorando en cuanto a las geometrías que la representan, tradicionalmente las líneas eléctricas planificadas han sido poligonales con pocos vértices, es decir, eran líneas prácticamente rectas y las subestaciones han tenido una aproximación de 50-60 kilómetros de su localización final.

Estas geometrías se utilizaban, entre otras cosas, para orientar y delimitar el ámbito de estudio a los técnicos de la fase de análisis de alternativas ambientales. Es decir, la información geográfica de la planificación de cada instalación sirve para definir el ámbito de estudio de la siguiente fase. 


\subsubsection{Análisis ambiental de alternativas}

Esta fase tiene como objetivo la identificación, definición y clasificación de las alternativas viables, desde el punto de vista ambiental, que representan las estrategias para dar solución a la problemática abordada.

Estas alternativas (al menos 3) se traducen en pasillos o corredores de ancho variable para las líneas, y áreas favorables para subestaciones, cuyo territorio delimitado cumple con las características ambientales, sociales, patrimoniales, históricas y orográficas para albergar una nueva instalación eléctrica de alta tensión. La obligatoriedad de evaluar ambientalmente tres alternativas de proyecto en España está establecida por la Ley 21/2013, de 9 de diciembre de 2013.

Tradicionalmente se ha realizado únicamente mediante el análisis visual de cartografía y trabajo de campo de verificación de los resultados de dicho análisis. Se basaba fundamentalmente en la experiencia del técnico responsable y del sesgo que introduce su criterio personal. Este criterio personal implicaba que cada proyecto se realizaba con un criterio no homogéneo.

La escala de la información geográfica en esta fase aporta un gran incremento de detalle respecto de la anterior, realizándose con escalas entre 1:25.000 y 1:10.000.

En la actualidad, el análisis ambiental de alternativas se apoya en el análisis digital y automático de información geográfica relevante del medio biótico, físico, socioeconómico y paisajístico que da como resultado un diagnóstico territorial que facilitará la toma de decisiones a la hora de identificar y seleccionar los pasillos de las futuras líneas o áreas favorables de las subestaciones con menor impacto. Este trabajo automatizado será complementado con trabajo de campo para validar o modificar el diagnóstico territorial y confirmar las decisiones con las que concluye la fase.

\subsubsection{Definición del proyecto de ingeniería}

Considerando únicamente lo concerniente a la información geográfica del proyecto, en esta fase cada proyecto de ingeniería se representa por diferentes conceptos que tienen significado geográfico o implican ocupación del territorio. La escala de trabajo en esta fase es de gran detalle en el rango de 1:1.000 a 1:2.000.

Los pasillos de línea o áreas favorables de subestaciones resultantes de la fase anterior, es decir, las alternativas ambientales viables, representan los ámbitos de estudio de cada proyecto de ingeniería. Es decir, se ha pasado de un único ámbito de estudio en el que se realizaba el análisis de alternativas, a diferentes y más reducidos nuevos ámbitos de estudio para albergar, en cada uno de ellos, un proyecto de ingeniería.

El proyecto de ingeniería de líneas dará como resultado un trazado cuya implantación en el territorio deriva en una serie de ocupaciones permanentes, materializándose los vértices de este trazado por medio de los apoyos. A su vez, estos apoyos soportan los cables conductores cuya proyección vertical significa una superficie de servidumbre de paso para el mantenimiento de la instalación. Los cables conductores pueden sufrir desplazamiento por el efecto del viento, lo que genera una servidumbre de vuelo bajo la cual se establecen una serie de prohibiciones de 
construcción de edificios, y distancias mínimas a cumplir con cualquier elemento de índole natural o cruzamiento con otras infraestructuras.

Otra parte importante de ocupación permanente del proyecto de ingeniería de líneas lo representan los caminos de acceso a los apoyos, que en condiciones de orografía pronunciada llevan consigo una afectación territorial de envergadura considerable.

Los proyectos de ingeniería de líneas también analizan las dimensiones de las ocupaciones temporales necesarias para la ejecución de la construcción. Estas ocupaciones temporales pueden ser las necesarias para el acopio de material o para el asentamiento o maniobras de las máquinas y grúas utilizadas en este tipo de obras. Otro tipo de ocupaciones temporales las representan los elementos de protección que se instalan para mantener la seguridad en el tendido de cables que cruzarán por encima de otras líneas eléctricas, telefónicas, de ferrocarril o de carreteras.

En el caso de líneas subterráneas, todo su trazado materializa una ocupación permanente donde la colocación de cámaras de empalme y arquetas de telecomunicaciones asociadas a la línea eléctrica provocan que el ancho de la canalización no sea uniforme. Esta canalización también genera una serie de servidumbre y distancias mínimas de seguridad que deben tenerse en cuenta en cualquier actuación próxima a la instalación.

Las ocupaciones temporales de las líneas subterráneas coinciden conceptualmente con las de línea aérea en cuanto a elementos de seguridad, acopio de material y maniobra de maquinaria.

La redacción de los proyectos de ingeniería de líneas ha ido cambiando en los últimos años. La Tabla 2-1 muestra las afectaciones analizadas en un proyecto de línea tradicional y actual.

\begin{tabular}{|c|c|c|c|}
\hline \multicolumn{2}{|r|}{ Tradicional } & \multicolumn{2}{|r|}{ Actual } \\
\hline 1 & Traza de la línea & 1 & Traza de línea \\
\hline 2 & Localización de apoyos & 2 & Localización de apoyos \\
\hline 3 & $\begin{array}{l}\text { Superficies por vuelo de cables sin viento } \\
\text { lateral }\end{array}$ & 3 & Ocupación permanente de línea aérea \\
\hline 4 & Superficies de tala de arbolado & 4 & Ocupación temporal de línea aérea \\
\hline & & 5 & Superficie de tala de arbolado \\
\hline & & 6 & Caminos de acceso a los apoyos \\
\hline & & 7 & Servidumbre por vuelo de cables sin viento lateral \\
\hline & & 8 & $\begin{array}{l}\text { Servidumbre por vuelo de cables con viento lateral de } \\
120 \mathrm{~km} / \mathrm{h}\end{array}$ \\
\hline & & 9 & Ocupación permanente de línea subterránea \\
\hline & & 10 & Ocupación temporal de línea subterránea \\
\hline & & 11 & Localización de hitos de trazado subterráneo \\
\hline & & 12 & Localización de cámaras de empalme \\
\hline & & 13 & Localización de arquetas de telecomunicaciones \\
\hline & & 14 & Distancias mínimas de seguridad \\
\hline
\end{tabular}

Tabla 2-1 Afectaciones consideradas tradicional y actualmente

Cada vez toma más relevancia la vertiente geográfica de proyectos considerados, a priori, exclusivamente del sector energético. Muestra de esta afirmación lo explica el número de 
ocupaciones permanentes o temporales que se calculaban hace 15 años y los que se calculan en la actualidad

En el caso de proyectos de subestaciones los cambios han sido menores ya que las afectaciones de éstos siempre han considerado la plataforma de la subestación, el camino de acceso y los movimientos de tierras necesarios para la nivelación del terreno.

Desde el punto de vista de la información geográfica, la definición del proyecto de ingeniería finaliza con la generación de la Relación de Bienes y Derechos (RBD) afectados por el mismo. Este proceso se realizará únicamente de uno de los proyectos analizados en las alternativas que sirvieron de inicio para esta fase.

Esta RBD es una lista de parcelas catastrales afectadas por el proyecto con sus atributos descriptivos, la información de sus propietarios y la magnitud de las afectaciones del proyecto en cada parcela.

La forma de cuantificar la afectación sobre cada parcela se realiza por medio de la coincidencia espacial o geográfica de las afectaciones del proyecto y las parcelas catastrales que representan y delimitan la propiedad del territorio sobre el que se realizará la obra.

En el año 2006, gracias a la evolución de los Sistemas de Información Geográfica, a la interoperabilidad de datos geográficos promovida por la iniciativa del Instituto Geográfico Nacional (IGN, 2020) en cuanto a las Infraestructuras de Datos Espaciales (IDE, 2020) y, en este sentido, las facilidades ofrecidas por la Dirección General del Catastro a través de los servicios web de la Oficina Virtual del Catastro (hoy Sede Electrónica del Catastro) (SEC, 2020) en cuanto a acceso a la información catastral, supuso un punto de inflexión en la gestión geográfica de las afectaciones provocadas por los proyectos de IEAT.

Con anterioridad a este punto de inflexión, la generación de una RBD de línea era un proceso lento y de una precisión muy alejada de lo que se realiza hoy en día. El proceso tradicional era el siguiente:

1. Se realizaba un levantamiento topográfico para generar el parcelario sobre el que apoyar las afectaciones resultantes del análisis de la fase anterior.

2. Se asociaba a cada parcela levantada una referencia catastral por medio de consultas a las administraciones locales.

3. Se realizaba una lista o tabla paralela al parcelario para registrar los nombres de los propietarios.

a. Inicialmente la información para esta lista se obtenía por medio de consultas orales y los lugareños que tenían este conocimiento.

b. Aproximadamente, a partir del año 2000 esta tarea se realizaba por medio de una solicitud de certificación catastral cuya información se transcribía manualmente a la tabla.

4. Se cuantificaba, de forma manual, la magnitud de cada afectación sobre cada parcela y se escribía, también de forma manual, en la tabla de parcelas.

5. Se generaban, también de forma manual, los planos del proyecto 
Este proceso era un proceso de alto coste de personal dedicado, alto coste administrativo, de trabajo de campo, de plazos muy dilatados llegando a tardarse aproximadamente 12 meses para una línea de 50 kilómetros de longitud, con escasa información de la afectación de la línea y, con anterioridad al uso de las certificaciones catastrales, de escasa precisión.

Con posterioridad a 2006, los procesos de generación de RBD de línea se han ido automatizando progresivamente, siendo en la actualidad una tarea menor en el desarrollo del proyecto. Los procesos actuales son los siguientes:

1. Una vez obtenidas las superficies de afectación del proyecto, se obtiene la cartografía catastral de forma automática gracias al servicio WFS de la Sede Electrónica del Catastro (SEC, 2020).

2. Se obtiene, de forma masiva y automática gracias a los permisos que otorga el ser usuario registrado en la SEC, los datos protegidos del catastro que aportan la información de la propiedad de cada parcela.

3. Se realiza una cuantificación automática de la magnitud de cada tipo de afectación sobre cada parcela.

4. Se genera, de forma automática, la RBD.

5. Se generan, de forma automática, los planos del proyecto.

El proceso actual puede realizarlo un único técnico, calculando 10 tipos de afectación más, con información oficial y más precisa, y en cuestión de minutos.

En cuanto a la generación de RBD de subestaciones, considerando el menor número de parcelas afectadas en comparación con el de línea, la evolución no ha significado grandes avances en cuanto a reducción de plazos y costes asociados.

\subsubsection{Obtención de permisos sobre las parcelas}

El objetivo de esta fase es la obtención de los permisos de paso o actuación, en cada caso, sobre las parcelas afectadas por el proyecto de ingeniería. En esta fase no se genera información geográfica, sino que se utiliza la información generada en la fase anterior, por lo que la escala de trabajo es la misma y oscila entre 1:1.000 y 1:2.000.

Para la obtención de los permisos de paso o actuación sobre cada parcela catastral, previamente se ha tenido que publicar en los medios públicos de información como son el Boletín Oficial del Estado, periódicos de tirada comarcal o local, un documento informativo que recoge la RBD afectados por cada proyecto. Previamente a la publicación se realiza una revisión y depuración de la relación de bienes para eliminar aquellas afectaciones no significativas desde el punto de vista geográfico, como por ejemplo las afectaciones resultantes con gran perímetro y escasa superficie, que indica que se trata de afectaciones que, aunque los sistemas son capaces de calcularlas, no tienen significado territorial. Esta depuración se realizaba manualmente, con dos juegos de datos en papel, donde había que buscar y localizar cada parcela en el plano y su correspondiente registro en la tabla RBD.

Una vez depurada y publicada y, tras resolverse cualquier alegación al respecto, se procede al contacto directo con cada propietario para proceder a la firma del permiso de paso o actuación, 
que intenta siempre resolverse por el mutuo acuerdo, y a la compensación económica por la modificación de las condiciones de cada parcela o los daños a elementos constructivos o cultivos que se provocarán durante la obra.

Este contacto directo se traduce en una tabla de permisos acompañada de cada permiso firmado. Paralelamente, a medida que se iban obteniendo estos permisos, se generaba manualmente un informe indicando si la instalación podía ser construida o no. Esa tabla indicaba al departamento de construcción aquellas partes de la instalación en las que se podía iniciar la obra.

El procedimiento tradicional trataba de facilitar a los propietarios de las parcelas afectadas la comprensión de la RBD por medio de los planos de proyecto que plasmaban cómo sería la parcela tras la construcción de la instalación. Estos planos de proyecto, impresos con tinta negra sobre papel blanco, generaban en muchos casos problemas de entendimiento a las personas poco habituadas a la lectura de los mismos.

En la actualidad la depuración se realiza de forma digitalizada, con la tabla RBD y planos de proyectos sincronizados a nivel de parcela, y mediante interfaz interactiva bidireccional. Es decir, localizar una parcela en uno de los dos entornos, tabla o plano, significa su localización automática en el otro.

Las herramientas de comunicación para facilitar el reconocimiento de las parcelas y cómo será el territorio tras la construcción de la instalación son digitales, con cartografías detalladas y ortofotografías aéreas, además de entornos 3D con capacidad para realizar análisis de visibilidad que aportan realismo a los resultados de los análisis.

Gracias a las herramientas digitales, la tabla de permisos que se obtienen "a pie de parcela" o en su defecto en oficina de campo para tal fin, se va completando de forma automática on-line a través de los servicios web de registro de permisos.

En el caso de proyectos de subestaciones, nuevamente, las dimensiones hacen más manejable la información catastral de los mismos.

\subsubsection{Construcción}

Una vez obtenidos los permisos de paso o actuación sobre las parcelas afectadas, se puede comenzar la obra. Tradicionalmente, hasta no disponer de todos los permisos de un proyecto no se comenzaba la obra, motivado por el trabajo administrativo de trasladar los permisos obtenidos a la documentación para solicitar las licencias de obra pertinentes.

En la actualidad, la determinación de si un proyecto de línea puede construirse o no, ya no se determina de forma global para el proyecto, sino que se realiza apoyo a apoyo y también de forma automática al considerar que, si todas las parcelas relacionadas con las afectaciones de un mismo apoyo tienen permiso, incluido su camino de acceso, dicho apoyo puede ser construido.

En esta fase, además de la compensación económica por los daños a elementos constructivos o cultivos previstos en la redacción del proyecto y recogidos en la RBD, se realiza la compensación por daños propios de la obra y los no previstos. 
En muchas ocasiones, estos daños no previstos son consecuencia de modificaciones leves del proyecto que, aunque son necesarias y tienen que ser autorizados por los ingenieros responsables del proyecto, generan afectaciones no contempladas a priori.

El proceso de construcción finaliza con una nueva tabla de permisos actualizada y la generación de planos as-built que reflejan la realidad del territorio.

En esta fase, la información geográfica que se genera para el replanteo del proyecto de ingeniería y la generación de los planos as-built oscila entre 1:1.000 y 1:500.

\subsection{Geodiseño}

En la construcción de instalación eléctrica de alta tensión, como una nueva línea eléctrica de alta tensión - que puede llegar a medir cientos de kilómetros-, muchos condicionantes pueden ejercer una influencia sobre el diseño. No coinciden necesariamente los condicionantes con los diferentes puntos de vista de todas las partes interesadas, aunque deben estudiarse en su totalidad a lo largo del proyecto para tomar las decisiones pertinentes. Por ejemplo, un bosque de alcornoque y un sitio arqueológico no son significativos desde el punto de vista de la infraestructura eléctrica, pero tienen un gran valor ambiental e interés cultural, respectivamente. Hasta ahora no ha sido posible lograr que las distintas partes interesadas en este tipo de proyectos presenten simultáneamente sus puntos de vista. Ni las administraciones ni las empresas responsables de la planificación y de la ejecución de las infraestructuras de líneas eléctricas cuentan con las herramientas que les permitan atender las necesidades, restricciones, limitaciones y deseos de cada perfil o parte interesada. El uso de Planning Support Systems (PSS) y Decision Support Systems (DSS) permite reorientar el desarrollo de estos proyectos hacia una nueva metodología. Esto permitirá tomar decisiones basadas en la realidad del territorio, por lo tanto, los nuevos proyectos serán más sólidos y organizados, eficientes y será más ágil su gestión y trazabilidad.

"La esencia del concepto de Geodiseño no es nueva: está presente implícitamente en la arquitectura orgánica de Frank Lloyd Wright (1867-1959)" (Cocco, et al., 2015). "Mientras que los procesos tradicionales de planificación y diseño separan el análisis de contexto, el diseño y la evaluación en pasos explícitos, el Geodiseño integra la exploración de ideas con la evaluación directa en el mismo momento, generando una solución de diseño avanzada." (Lee et al., 2014). Geodiseño "es el diseño con el territorio y para el territorio y que tiene como objetivo la transformación contextualizada del paisaje, respetando las condiciones naturales y culturales " (Miller \& William, 2012). Este concepto está ganando creciente interés internacional debido al potencial proporcionado por el uso de tecnologías geoespaciales (methods and tools "Geospatial Information Science and Technology") (Goodchild, 2010). En este contexto, el geodiseño puede proporcionar un marco metodológico sistemático para la planificación regional y urbana con el fin de integrar, de manera sostenible, las actividades humanas con el entorno natural, respetando las peculiaridades culturales y permitiendo un proceso de toma de decisiones consensuadas. También se abordó de manera explícita en el libro "Design with Nature", por Ian McHarg (McHarg, 1961). En la planificación del paisaje, Steinitz (Steinitz, 1990) desarrolló un modo experimental mediante el uso de métodos de modelado de simulación.

Las definiciones anteriores son un acercamiento al concepto de geodiseño basado en las contribuciones y matizaciones realizadas a lo largo del tiempo de varios autores (Steinitz, 1990), 
(Goodchild, 2010) , (Miller \& William, 2012) , (Lee, et al., 2014)y (Cocco, et al., 2015). Ya en 1969, (Steinitz \& Rogers, 1969) pudieron sintetizar en un modelo de planificación coherente los enfoques de cuatro especialidades: arquitectura del paisaje, ingeniería, planificación urbana y regional y diseño urbano. Si bien la planificación y el conjunto de herramientas de ayuda para realizarla (PSS), adoptar las mejores decisiones espaciales (DSS), e involucrar a más colectivos en la toma de decisiones (PPSS- Public Participatory Support Systems) se vienen utilizando y aparecen en la literatura.

Según Steinitz (Steinitz, 2012), el marco de trabajo de geodiseño para cada estudio, será determinado por sus participantes, y especialmente por los requerimientos planteados por la gente local, junto con algunas instituciones. Sin embargo, estos grupos de interés están a menudo en desacuerdo, siendo estas tensiones un catalizador común para el estudio de geodiseño. Probablemente los grupos de interés deseen formar parte del equipo de geodiseño en todas las fases del proyecto. Los diseños propuestos deben reflejar sus prioridades $\mathrm{y}$, debido a posibles desacuerdos entre las partes, tendrán que desarrollarse alternativas. El equipo de geodiseño también tiene la responsabilidad de considerar alternativas más allá de las ya conocidas e imaginadas. Todos los productos y los resultados, incluyendo diseños alternativos y la evaluación del impacto, tendrán que someterse a examen por los interesados y sus múltiples procesos de decisión. Este marco no sugiere un proceso lineal singular, sino que propone un proceso iterativo con bucles de retroalimentación entre las diferentes etapas.

Hay un número creciente de ejemplos relacionados con la planificación regional, urbana y paisajística. El marco de geodiseño propuesto por Steinitz (Steinitz, 2012) se ha aplicado en varios casos, por ejemplo (Cocco, et al., 2015), (Rivero, et al., 2015) o (Campagna, et al., 2016). Uno de ellos, analiza los resultados de uno de los primeros casos de aplicación del concepto de geodiseño en Brasil (Cocco, et al., 2015), para evaluar la capacidad de equilibrar la transformación urbana y preservación de las características ambientales de la zona de estudio.

Aunque la mayoría de los ejemplos de aplicación del geodiseño están relacionados con la planificación regional y urbana, hay algunos estudios de infraestructuras lineales que tienen cierta semejanza con el caso de estudio. En este caso de infraestructuras lineales, hay algunas similitudes en las consecuencias de la construcción de una nueva carretera y una nueva línea de alta tensión, debido a las condiciones cambiantes a lo largo de la nueva infraestructura. Santini y Pecori desarrollaron en 2014 (Santini \& Pecori, 2014) un trabajo que tiene por objetivo implementar una herramienta para la evaluación de los efectos positivos y negativos que surgen por la modificación, o nueva construcción, de las infraestructuras de transporte por carretera en el territorio. Su metodología permite adquirir un conocimiento profundo de la zona de estudio (del medio ambiente y de los recursos económicos), para verificar la sensibilidad de cada zona en relación al conjunto de actuaciones del proyecto de construcción de nuevas carreteras, y evaluar los diferentes escenarios de localización para el mismo tipo de proyecto o analizar diferentes escenarios de impacto para una misma localización.

Desde la perspectiva de "PSS", autores como (Harris, 1989) , (Vonk, et al., 2005) , (Kumar, et al., 2002) , (Geertman \& Stillwell, 2003) analizan las diferentes metodologías usando computadoras para la planificación espacial y del paisaje, y presentaban las barreras para su uso generalizado. 
(Steinitz, 2012), (Abukhater \& Walker, 2010) enfatizan en la colaboración necesaria entre los profesionales de las Geociencias y los profesionales del diseño para que trabajen conjuntamente: diseñen. También profundizaron en el concepto de "planificar con personas y no solo para las personas", todas con sus diferentes matices. (Aditya, 2010) define el concepto de colaboración como un Sistema de Información Geográfica (SIG) participativo (PGIS) que puede utilizarse para la toma de decisiones. Para autores como (Hanzl, 2007) y (Kubicek, 2010) PSS es un concepto general que describe el software que da soporte a la planificación urbanística, y matizan que las herramientas PPGIS (Public PGIS) posibilitan que colectivos que antes no podrían participar en la planificación ahora lo puedan hacer gracias al software y sus complementos que no requieren de uso de licencias costosas. En esta línea, la evolución de los SIG de escritorio, con licencias costosas e incluso elitistas por esta razón (Pickles, 1995), hacia entornos web con visores de mapas tanto en dos dimensiones (2D) como en 3D, o herramientas de análisis Web-GIS, etc. facilitan la interpretación de la planificación por personas ajenas a esta disciplina como juristas, políticos o ciudadanos en general (Hanzl, 2007).

Esto ha coincidido en el tiempo con el cambio de paradigma que la propia sociedad ha motivado en los procesos de planificación, pasando de ser desarrollados por profesionales con una estructura poco flexible a un proceso de negociación colectiva (Brail \& Batty, 2008). Este cambio ha motivado la necesidad de integrar en la planificación nuevas herramientas que faciliten la comunicación y la diseminación de información, pautas e ideas que intervienen en dichos procesos. Todo ello, sin ser exhaustivo, se conforman como los cimientos del geodiseño. De forma paralela en el ámbito de las Geociencias existe una bifurcación de la disciplina de la GeoVisualización y el Visual Analytics que se une con los DSS y definen la sub-disciplina Geovisual Analytics for Spatial Decision Support (Andrienko, et al., 2007). Aunque el dominio de la GeoVisualización no solo está relacionado con la planificación, ayuda a los colectivos menos técnicos en la planificación a participar en la gestión de toma de decisiones.

De esta forma se confluye en el concepto de geodiseño que se materializan en herramientas informáticas avanzadas que dan soporte a planificaciones más avanzadas y que requieren la colaboración exhaustiva de los grupos de interés. Desde este punto de vista algunos autores como (Flaxman, 2009) lo definen como un conjunto de técnicas y tecnologías habilitadoras para la planificación de entornos naturales y construidos en un proceso integrado que incluye conceptualización, análisis, especificación de diseño, participación y colaboración de los interesados, creación de diseño, simulación y evaluación (entre otras etapas); (Dangermond, 2009) lo sintetiza, afirmando que aporta análisis geográficos en el proceso de diseño, apoyando la visión de (McHarg, 1961), que define los campos de la arquitectura del paisaje, la planificación urbana y espacial y el Ecodiseño, dando a los profesionales involucrados en el diseño, herramientas para explotar la información geográfica dentro de sus flujos de trabajo de diseño, gracias al aumento de las tecnologías SIG; Complementando la perspectiva de los DSS, geodiseño tiene sentidos amplios y estrictos. En el primero, geodiseño es un proceso de creación de soluciones para problemas geoespaciales, que incluye actividades de diseño y toma de decisiones en diversas etapas del proceso. En un sentido más estricto, geodiseño se centra específicamente en la fase de diseño, en las actividades de diseño creativo (como el dibujo) y los métodos y tecnologías de retroalimentación asociados que permiten una iteración y modificación de diseño 
rápida; Y es similar al enfoque de (Flaxman, 2009) "GeoDesign is a design and planning method which tightly couples the creation of design proposals with impact simulations informed by geographic contexts", o al de (Ervin, 27 May 2011), para quien el geodiseño mejora las actividades tradicionales de planificación y diseño ambiental con el poder de las tecnologías modernas de información, comunicación y colaboración, proporcionando simulaciones bajo demanda y análisis de impacto para proporcionar una integración más efectiva y responsable del conocimiento científico y valores sociales en el diseño de futuros escenarios alternativos. Sin embargo, cuando se trata de formalizar el papel del geodiseño, (Artz, 2010) , (Ball, 2010) y (Dangermond, 2012), no lo consideran solo como un concepto teórico sino como un método práctico para medir, modelar, interpretar, creando e influenciando las decisiones de actividades como agricultura, planificación urbana y otras disciplinas.

En relación a los modelos de geodiseño, (Steinitz, 2012) planteó un marco genérico (posiblemente visionario), como una evolución del concepto de modelos del marco de diseño del paisaje desarrollado en el libro Alternative Futures for Changing Landscapes (Steinitz, et al., 2003) , para proyectos de diseño que requieren iteración, retroalimentación y colaboración, siendo útil para estudios de planificación que pueden aplicarse a diferentes escalas, de regional a local, e introduce la colaboración integrada y el aspecto participativo. Como un resumen de esta revisión de trabajos relacionados, e identificando paradigmas, propuestas y modelos, se hace notar la convergencia y / o las iniciativas en evolución sobre DSS, PSS, PGIS y PPGIS sobre el concepto de geodiseño y la propuesta metodológica, o el marco para geodiseño, planteada por Steinitz (Steinitz, 2012) como referencia en este área.

Foster (Foster, 2016) ha comparado el proceso de geodiseño con las teorías de diseño reconocidas y sugiere "Creative problem solving processes; design processes". En él, presenta muchas similitudes con cinco procesos de diseño estudiados ( (Simon, 1977) y (Simon, 1977) ; (Asimov, 1962) ; (Fogler \& LeBlanc, 1995) ; (Brown, 2009); (Kumar, 2012) ). Sin embargo, para (Foster, 2016) hay una distinción clave que hace que el proceso de geodiseño sea único.

Dado los escasos o nulos antecedentes documentados de entornos de geodiseño aplicados al diseño de IEAT, en esta investigación se plantea el objetivo del diseño e implementación de un nuevo marco de trabajo basado en geodiseño, basado en la aplicación secuenciada de modelos, tal como hace el marco de trabajo propuesto por (Steinitz, 2012), en el que el flujo y la trazabilidad de la información geográfica adopta un papel relevante.

\subsection{Grupos de interés de una IEAT}

\subsubsection{Introducción}

Hasta ahora no ha sido posible lograr que las distintas partes interesadas en este tipo de proyectos presenten simultáneamente sus puntos de vista. Ni las administraciones ni las agencias / empresas encargadas de la ejecución y planificación de las infraestructuras de líneas eléctricas cuentan con las herramientas que les permitan atender las necesidades de cada perfil o parte interesada. El uso de Planning Support Systems y Decision Support Systems permite reorientar el desarrollo de estos proyectos hacia una nueva metodología, lo que permite la toma de decisiones basadas en la realidad del territorio. La gestión de -grupos de interés- ha sido, hasta 
ahora, un anexo a la ejecución de los proyectos de IEAT y de una forma no sistematizada, sino que se ha realizado a criterio del responsable del proyecto. En esta tesis se explora la posibilidad de fusionar la gestión de la información geoespacial de este tipo de proyectos, con la gestión de grupos de interés expandiendo la funcionalidad del flujo de trabajo basado en geodiseño de IEAT incorporando, de forma natural, la gestión de grupos de interés en el flujo de trabajo y que está soportada por el modelo de sostenibilidad de Red Eléctrica de España - REE (Sostenibilidad-GRE, 2020).

A continuación, se abordarán los antecedentes y trabajos relacionados en la gestión de grupos de interés, con un enfoque interno, apoyándonos en las necesidades y la estrategia de sostenibilidad de la compañía (Sostenibilidad-GRE, 2020), y otro externo analizando la gestión de compañías similares.

Las relaciones entre las empresas y sus grupos de interés son cada vez más elaboradas y cada vez existen más interacciones y mayor influencia en los negocios por parte de sus grupos de interés. Esta realidad se ve potenciada por la creciente demanda de información y transparencia por parte de la sociedad y la existencia de distintos canales de comunicación.

La identificación de los interesados de un proyecto y su clasificación es vital para su posterior gestión en todas las fases del proyecto. Como se ha presentado en la sección anterior, un proyecto de desarrollo de la red de transporte de electricidad consta de 5 fases: Planificación, análisis de alternativas -desde el punto de vista ambiental-, definición del proyecto de ingeniería, obtención de permisos y construcción.

Tal como se indica en la Guía de los fundamentos para la dirección de proyectos (PMBOK®, s.f.) un interesado es un individuo, grupo u organización que puede afectar, verse afectado, o percibirse a sí mismo como afectado por una decisión, actividad o resultado del proyecto.

Esta guía (PMBOK®, s.f.) menciona como uno de los modelos adecuados de clasificación de grupos de interés, la matriz de poder/interés, que asocia a los interesados en base al nivel de autoridad y participación que poseen, y también la matriz de influencia/impacto, que los asocia en base a su participación activa y capacidad para efectuar cambios en la planificación o ejecución del proyecto.

Con el objetivo de sistematizar la gestión de los grupos de interés en los proyectos de HVTL en REE se han realizado un análisis interno para recoger los diferentes puntos de vista de los actores involucrados en proyectos. También el análisis de cómo se está abordando el tratamiento de los grupos de interés en el ámbito nacional e internacional. Con tal fin, se ha recopilado información de las experiencias de los TSO (Transmission System Operator) europeos y de otras grandes entidades y empresas pertenecientes a sectores muy diversos. Además, se han utilizado las "lecciones aprendidas" de INSPIRE-Grid (INSPIRE-GRID-Project, 2013) y BESTGRID (BESTGRID-Project, 2015) que se enmarcan en el ámbito de la aceptación pública, y que son dos proyectos europeos promovidos por RGI (RGI, 2019). 


\subsubsection{Análisis interno}

Durante los últimos años REE ha observado una mayor capacidad de influencia de ciertos grupos de interés en el desarrollo de proyectos de HVTL. En diversos grupos de trabajo europeos de compañías del sector también se ha observado la misma tendencia, lo que ha llevado a la conclusión unánime de la necesidad de desarrollar el tratamiento de los grupos de interés de manera sistemática y homogénea en la gestión de proyectos ya que contribuye a reducir las externalidades negativas, a identificar de forma más temprana los riesgos, a la detección de nuevas oportunidades de aceptación de las instalaciones de la HVTL y, en definitiva, a hacer más sostenible su actividad.

También en los últimos años se ha consolidado en REE, como herramienta que facilita la toma de decisiones sobre las instalaciones en fases de proyecto o en explotación, el Sistema de Información Geográfica (GIS) corporativo GeoRED, que aporta un nuevo punto de vista a la gestión de grupos de interés.

La compañía REE, como ejemplo de compañías del sector eléctrico, entiende a los grupos de interés como aquellos colectivos afectados por sus servicios o actividades y colectivos cuyas opiniones y decisiones influyen en los resultados económicos o impactan en su reputación. Es una definición similar a la propuesta por el grupo de trabajo de Freeman (Freeman \& Mcvea, 2001).

La Responsabilidad Social Corporativa (RSC) o la comunicación corporativa son conceptos que surgen de la necesidad de gestión de los grupos de interés, siendo los propios grupos de interés y la reputación de la compañía parte importante del modelo de negocio subyacente (Freeman, 2012). Así surge la necesidad de que las compañías pongan el foco en los intereses de los empleados, accionistas, proveedores, clientes y comunidades relacionadas para crear tanto valor como sea posible en beneficio de los grupos de interés. La comunicación corporativa está condicionada por la estrategia de gestión de grupos de interés para alinearla con la estrategia de la propia compañía en cuanto a sostenibilidad y RSC (Cáceres, et al., 2015).

La compañía dispone desde el año 2004 de un modelo corporativo de gestión de sus grupos de interés con la misión de "generar valor compartido e influir en la mejora de la reputación de la compañía", y a finales de 2013 completó su inventario de grupos de interés, en el que se recogía únicamente una categorización a través del tipo de relación con cada grupo de interés. Su utilidad se restringía a la clasificación, pero dista de la sistematización que ésta necesita.

Dado que el REE entiende la sostenibilidad como el compromiso con su perdurabilidad a través de la creación de valor compartido para todos sus grupos de interés, la compañía realizó una revisión del inventario de grupos de interés con el objetivo de definir el mismo a nivel de Grupo (Sostenibilidad-GRE, 2020). Fruto de esta revisión, en 2018 la compañía alcanzó la máxima puntuación en el criterio del Índice Dow Jones de Sostenibilidad que evalúa el compromiso y desempeño con sus grupos de interés, contando con un modelo de gestión con la misión de generar valor compartido e influir en la mejorar su reputación. Este modelo incorpora los requerimientos de normas y estándares de referencia en la materia como son la AA1000, IQNet SR10, ISO26000 o Global Reporting Initiative (Globalreporting, 2019). Es en esta revisión donde 
ha definido sus compromisos con los grupos de interés y el canal de comunicación más adecuado a la categoría de cada grupo (Sostenibilidad-GRE, 2020).

Así, este modelo de gestión corporativo se asienta bajo los principios de transparencia, diálogo y colaboración mutuos y tiene como elementos principales la identificación de los diferentes grupos de interés, el conocimiento de sus necesidades y expectativas, el establecimiento de los compromisos y marcos de relación y el desarrollo de herramientas de evaluación y mejora.

\subsubsection{Análisis externo}

Desde el punto de vista del análisis externo y tras analizar 31 experiencias cabe destacar, por su posible aplicabilidad a los proyectos de HVTL, otras compañías europeas del sector eléctrico como National Grid (National-Grid, 2019), Eirgrid Group (Eirgrid-Group, 2019), Elia (ELIA, 2019), RTE (RTE, 2019), Stattnet (Statnett, 2019), TenneT (Tennet, 2019), 50Hertz (50Hertz, 2019), Energinet (Energinet.dk, 2019) o los proyectos BESTGRID (BESTGRID-Project, 2015) e INSPIRE GRID (INSPIRE-GRID-Project, 2013).

La gestión de los grupos de interés en los TSO europeos, está orientada hacia la generación de redes de confianza en el medio-largo plazo lo que facilita la creación de entornos de consenso.

En este análisis externo se han consultado las fuentes accesibles de las entidades consultadas, aunque probablemente se desarrollen otras estrategias no publicadas con los grupos de interés. Las principales lecciones aprendidas de este análisis son las siguientes:

Se destaca en la práctica totalidad de los casos la importancia de comenzar la apertura a los diferentes grupos de interés desde las fases iniciales, incluyendo la fase de planificación, ya que es en ésta en la que se puede trasladar a la sociedad en general, y las comunidades locales específicamente, la justificación objetiva, la comprensión y aceptación de la necesidad y de los beneficios de la red de transporte de electricidad. Si se logra este objetivo de aceptación, el acuerdo sobre las condiciones y características particulares del proyecto es mucho más asequible. Además, se pueden proponer soluciones que en etapas más avanzadas ya no son posibles de realizar.

En los proyectos de los TSO europeos, la actuación se basa en ofrecer abundante información adaptada a los distintos grupos de interés en sus distintas fases, haciendo hincapié en los temas más sensibles para la población: afectación visual-paisaje, campos electromagnéticos, medio ambiente, etc. Entre las lecciones aprendidas de BESTGRID destaca de manera explícita que "antes de comenzar el diálogo y la participación es crucial ofrecer toda la información del proyecto a los grupos de interés". Siendo una de las herramientas utilizada por varios TSO el diseño de una página web por proyecto en la que se publica toda la información relevante y que se permita hacer consultas y/o aportar sugerencias de manera específica. También existen casos en los que se usan cuentas de redes sociales creadas para proyectos concretos.

Destaca la diversidad de formatos y soportes comunicativos empleados, desde los más convencionales: reuniones, jornadas informativas o edición de material divulgativo, hasta los más innovadores apoyados en las TIC: webs con GIS, redes sociales y creativos: autobús informativo itinerante. 
Los proyectos piloto de BESTGRID coinciden en concluir que la interacción personal y las relaciones son el elemento que consideran potencialmente más importante en el éxito de la implicación de los grupos de interés. Sus lecciones aprendidas insisten en que incluso si es demasiado tarde para discutir sobre la necesidad de un proyecto, siempre hay que estar dispuesto a explicarlo.

También desde BESTGRID y la iniciativa danesa Energinet (Energinet.dk, 2019) se insiste en que la discusión con los grupos de interés sobre las alternativas de pasillos, o trazados, explicitando los criterios utilizados y sobre el propio diseño de los proyectos genera confianza y seguridad entre éstos, permitiéndoles aportar soluciones desde la perspectiva del conocimiento local.

En las experiencias analizadas de otras infraestructuras lineales fuera del ámbito europeo se trabaja de manera estratégica en el empoderamiento de los grupos de interés (por ejemplo, ofreciendo formación en distintas materias relacionadas con la expansión de la red, reforzando las capacidades de las ONG para que puedan ejercer un papel de "validador externo", etc.), lo que genera múltiples beneficios en el corto (tramitación y construcción) y en el medio plazo (vida útil de la instalación).

Las entidades que trasmiten experiencias sobre la participación de representantes de distintos grupos de interés en la toma de decisiones, incluso en situaciones complejas o de gran sensibilidad social, valoran en su difusión que estas iniciativas contribuyen a aumentar la credibilidad y legitimidad del proceso (IFC, 2019).

No se han encontrado referencias en las que la apertura y la gestión temprana de grupos de interés haya generado respuestas de rechazo, pero no se puede descartar que no hayan existido. Es muy probable que se hayan producido, pero que no se han difundido.

La falta de tradición de participación en los procesos de planificación y en la construcción de grandes proyectos está cambiando progresivamente, pero requiere de un aprendizaje conjunto de las administraciones, las empresas, el tejido social y el conjunto de la población hacia actitudes y habilidades de consenso y colaboración en la sociedad española, como se refleja mayoritariamente en la experiencia internacional.

Las conclusiones del análisis externo, para desarrollar el nuevo modelo de gestión de grupos de interés que se propone, son:

- Es importante comenzar la relación con los grupos de interés desde las fases más tempranas del proyecto ofreciendo información homogénea, adaptada a los distintos grupos de interés y específica de cada proyecto a lo largo de sus etapas (webs, redes sociales, newsletters, formularios de consultas...).

- En el entorno internacional se considera que una buena gestión de grupos de interés repercute muy positivamente, no solo en el buen fin del proyecto, sino en los resultados de su gestión económica y en el cumplimiento de los plazos. Además, contribuye a aumentar la credibilidad y la legitimidad del proceso, y la buena reputación de la empresa promotora. Esta gestión de los grupos de interés se orienta hacia la generación 
de redes de confianza a medio-largo plazo y de entornos de consenso. Es decir, no solo se actúa como respuesta al rechazo social.

- Se considera que no es suficiente utilizar medidas de información o comunicación y se avanza hacia un modelo de participación constructiva de los grupos de interés en la toma de decisiones de un proyecto, que faciliten el consenso y la aceptación de la instalación. En este sentido, se valora la interacción personal y las relaciones como el elemento más importante para el éxito de la implicación de la gestión de los grupos de interés.

- La gestión de grupos de interés se puede considerar muy incipiente en España, en relación con otros países europeos (ligada a la RSC) y no son muchas las organizaciones que tienen experiencia real y contrastada en esta materia. Sin embargo, la integración de las perspectivas de diferentes partes interesadas durante este tipo de proyectos se está volviendo cada vez más importante en el debate público (Zipf, et al., 2019).

- En cuanto a la aplicabilidad de las conclusiones, en los países europeos más desarrollados (como Alemania, Francia, Reino Unido, Italia o Bélgica), la sociedad está más habituada a la participación en las transformaciones del territorio que les afectan y cuentan con experiencia colectiva en afrontar este tipo de situaciones. En estos países existen además entidades orientadas a la intermediación que ejercen un papel eficaz de consenso entre los intereses sociales de los distintos grupos de interés afectado y las necesidades de un proyecto de interés público. Esto no ocurre en la sociedad española que ha sido más pasiva en la expresión de los intereses colectivos. La realidad es que la fase de planificación eléctrica en España carece de una adecuada comunicación de la justificación de la necesidad de desarrollo de los proyectos de infraestructura allí contemplados. Por tanto, para reducir los riesgos en la ejecución de las previsiones de la planificación conviene hacer mayor esfuerzo en explicar y justificar los proyectos, dando a conocer sus beneficios económicos, sociales y ambientales. Los grupos de interés deben contar con una temprana y buena información de justificación, desde los primeros momentos en los que la planificación comienza a tener significado geográfico para mejorar su aceptación social. En este objetivo están interesados tanto la administración promotora de la planificación, como REE que es el ejecutor de los proyectos. Con tal fin se han de generar contenidos de información valida y movilizar acciones de comunicación eficaz y atractiva.

- Es útil y conveniente sistematizar la acción sobre grupos de interés en los proyectos que tengan una mínima incidencia territorial (ambiental o social) reduciendo riesgos en la falta de aceptación y mejorando la reputación de la entidad que conoce y respeta a sus grupos como interés.

- Además, en las fases de consultas previas y en el diseño de proyectos se obtienen claros beneficios. Principalmente una mejor gestión del riesgo en el proyecto y mejora de la reputación de la compañía, cuando se promueve y se logra una participación activa de los grupos de interés. Esto se debe a la integración de factores económicos, sociales y ambientales en la gestión, así como el conocimiento de lo que esperan los grupos de interés del proyecto y de su ejecución, en aras de un desarrollo sostenible. Siendo esta una de las conclusiones claras de este análisis externo trasladable a la operativa de la compañía y a los sistemas de ayuda de planificación y gestión. Es conveniente difundir 
información útil, precisa y pormenorizada a los interesados que les facilite la comprensión sobre cómo será el territorio con el proyecto ejecutado. Se deben evitar las dudas sobre los efectos de la construcción o el funcionamiento y minimizar los temores irracionales. De esta forma se pueden eliminar la mayor parte de las respuestas negativas de carácter emocional.

Como conclusión final de este análisis externo se desprende que, para disponer de una gestión sistemática de los grupos de interés, se propone crear un marco conceptual que dé soporte a los grupos de interés, así como la creación de un catálogo de acciones suficiente.

\subsubsection{Gestión geográfica de los grupos de interés}

Tradicionalmente se ha considerado a los grupos de interés como entidades organizadas o individuales a las que informar o con las que alcanzar un acuerdo, muchas veces negociado, cuando surgían problemas que dificultasen la planificación o ejecución de los proyectos.

El gestor de la RdT de electricidad en España cuenta, desde 2004, con el modelo corporativo de gestión de sus grupos de interés creado en 2004 por REE ha sido revisado en varias ocasiones y se completó a finales de 2013, con una última revisión en 2018. Es en ésta donde se ha definido sus compromisos con los grupos de interés y el canal de comunicación más adecuado a la categoría de cada uno de ellos (Sostenibilidad-GRE, 2020). En ella el modelo corporativo estaba pensado como una clasificación de grupos de interés, en función de las categorías de los mismos, y de un catálogo de acciones que, combinados, permitiesen a priori estimar las preocupaciones y necesidades de cada uno y, por otro lado, saber interpretar corporativamente cómo debe ser la relación con cada uno de ellos.

Algo que no recoge este modelo corporativo es la sistematización de la gestión y, por tanto, tampoco cómo relacionarlo con los sistemas corporativos de información.

El objetivo final de la gestión de los grupos de interés en REE es que su gestión geográfica se convierta en una gestión sistemática que se realice de forma paralela a la gestión de la información geográfica necesaria para cada fase de los proyectos. 


\section{ENFOQUE METODOLÓGICO}

Numerosas restricciones afectan el diseño de infraestructuras eléctricas: pendiente del terreno, distancias a centros urbanos o áreas protegidas, partes interesadas, administración, etc. Todas se deben estudiar en su conjunto para tomar las decisiones más apropiadas. En el desarrollo de proyectos de Infraestructuras Eléctricas de Alta Tensión (IEAT), se genera y analiza un gran volumen de información geográfica en el ciclo de vida del proyecto. Cada escala de información geográfica está asociada con una fase del proyecto y las transiciones de escala corresponden a los cambios en los equipos técnicos involucrados.

El geodiseño es un marco conceptual y tecnológico que trata de ofrecer herramientas gráficas de diseño soportadas sobre la geografía (el territorio), para que los profesionales puedan compartir datos y encontrar diseños adecuados a las características de sostenibilidad de cada territorio, en un entorno colaborativo y participativo, para el diseño de proyectos a implantar en el territorio, y en obras de ingeniería y construcción. Lo que se encuentra alineado con los objetivos y metas de la Agenda 2030 para el Desarrollo Sostenible (ONU, 2020), concretamente con el conjunto de Objetivos de Desarrollo Sostenible número 9 - ODS-9 (Construir infraestructuras resilientes, promover la industrialización inclusiva y sostenible y fomentar la innovación) y el conjunto de ODS-11 (Lograr ciudades y asentamientos humanos inclusivos, seguros, resilientes y sostenibles).

Considerando que una nueva IEAT formará parte de los elementos que estructuran "lo que hay" en el territorio (junto a los accidentes naturales, vías de comunicación, construcciones, etc...) y "lo que está sucediendo" en el territorio (cómo el territorio se comporta en cuanto a sus actividades sociales, culturales o económicas), en cada fase del diseño se incorpora la información geográfica que representa los condicionantes de los diferentes colectivos involucrados e interesados, y es necesario utilizar información geográfica con escalas, cada vez más precisas, en los estudios correspondientes.

Con el objetivo de minimizar los impactos ambientales, sociales y locales, al tiempo que proporcionar a las partes interesadas herramientas para la planificación y la toma de decisiones, se ha generado el marco de trabajo basado en geodiseño para su aplicación al desarrollo de proyectos de IEAT, con el apoyo de metodologías y la ejecución de procesos automatizados que garantizan la trazabilidad de su desarrollo a través de las etapas del ciclo de vida del proyecto.

El marco de trabajo ayuda a integrar los principios del geodiseño, armonizando los procedimientos corporativos en todas las fases del proyecto, teniendo en cuenta las necesidades y preocupaciones notificadas por las partes interesadas, a través de un proceso de diseño guiado por mecanismos de retroalimentación, iteración y consenso. Como resultado, aporta también un flujo de trabajo participativo transparente, visible y mejorado para desarrollar nuevas IEAT.

\subsection{Marco de trabajo basado en geodiseño para IEAT}

\subsubsection{Introducción}

La metodología de Steinitz (Steinitz, 2012) se basa en un conjunto de modelos interrelacionados, por lo que el equipo de diseño aborda, de forma estructurada e impulsada por la toma de 
decisiones, la ejecución de un proyecto de una manera diferente a los procesos de diseño típicos. Junto con esta estructuración única del proceso antes de su implementación, el análisis del proceso de geodiseño revela otros dos componentes esenciales: colaboradores y tecnologías.

GeoRED aporta esta base tecnológica necesaria para soportar, por un lado, la implementación de los diferentes modelos que permitirán dar homogeneidad y criterio corporativo a todos los proyectos y, por otro lado, gestionar los diferentes puntos de vista de los grupos de interés de cada fase de cada proyecto.

Cada proyecto podría ser gestionado de múltiples formas, pero si consideramos la fuerte vinculación con el territorio y las consecuencias que suponen la implantación de las IEAT, se ve justificada la conveniencia de aplicar un marco de trabajo basado en geodiseño que de soporte a las metodologías corporativas en un escenario de homogeneidad y sistematización de las tareas. Los primeros acercamientos a la necesidad de un marco de trabajo basado en el geodiseño se realizaron, en primer lugar, en 2012, con un trabajo que abordaba la colaboración necesaria en un flujo de trabajo que ya secuenciaba y conectaba las diferentes fases como un proyecto, evidenciando en cada una de ellas las necesidades para el ejercicio de geodiseño (Moreno, et al., 2012) y en segundo lugar, en 2014, en un trabajo que describía cada fase del proyecto desde el punto de vista de la aplicación de los principios del geodiseño (Moreno \& Manso-Callejo, 2014).

Partiendo de los trabajos de 2012 y 2014, en 2018 se abordó un trabajo de investigación basado en la aplicación de diferentes modelos, con procedimientos homogéneos, en cada una de las fases descritas que además proporcionarán un sistema de trazabilidad de la evolución del proyecto (Moreno-Marimbaldo, et al., 2018). En este trabajo se particularizó a los proyectos de líneas por su mayor significado geográfico que los de subestaciones. Tras este trabajo de 2018, se ha implementado el marco de trabajo basado en geodiseño para su aplicación a este tipo de proyectos en su conjunto, es decir, proyectos de línea y de subestaciones.

\subsubsection{Aplicación a proyectos de IEAT}

El marco de geodiseño de Steinitz (Steinitz, 2012) es interpretado por Foster, (Foster, 2016) como una estructura impulsada por los responsables de la toma de decisiones y cuidadosamente diseñada para facilitar su ejecución de un modo efectivo. Con este mismo objetivo, el flujo simplificado de información geográfica en la metodología que aquí se propone, para el marco de trabajo basado en geodiseño de IEAT es el que se presenta en la Figura 3-1 en el que además se identifican los rangos de escalas de trabajo usuales en cada fase de proyecto.

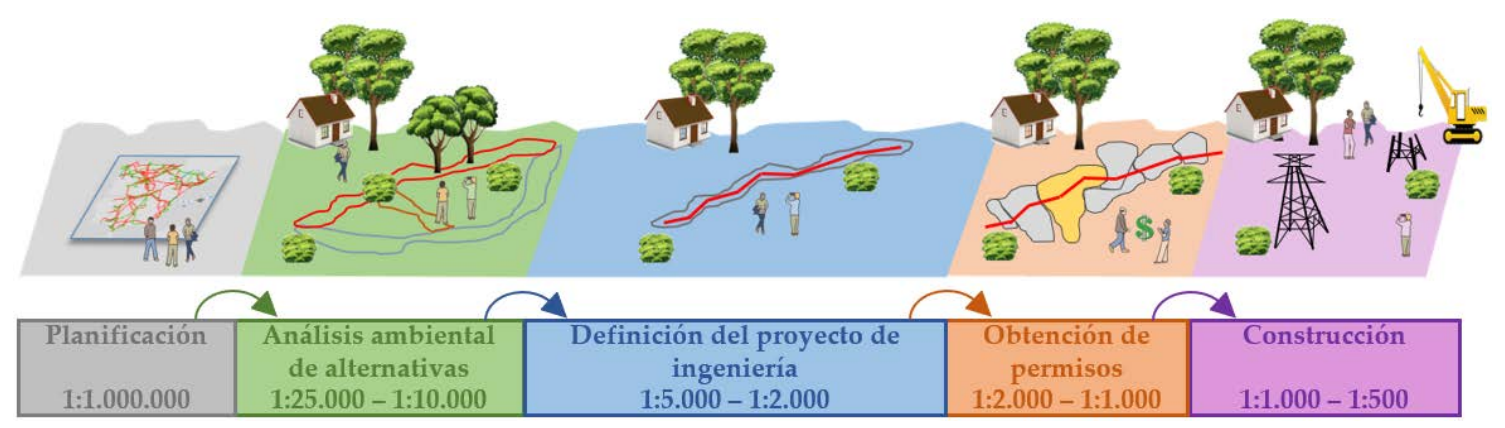

Figura 3-1. Flujo de información geográfica simplificado y escalas de trabajo en un proyecto de IEAT 
El modelo propuesto, podría considerarse como un modelo de modelos que se aplican a cada una de las fases y existe una dependencia entre modelos de fases consecutivas. Este modelo se ha inspirado, adaptándolo al tipo de diseño que se aborda, en el marco para geodiseño de (Steinitz, 2012). Al igual que en él ocurría si no hay información suficiente en una fase (datos), o es insuficiente para aplicar cualquier modelo, su adquisición se convierte en una actividad prioritaria. De forma similar ocurre con los procesos a desarrollar en cada fase, si los procesos no se pueden modelar, se realizará un trabajo específico sobre algún aspecto de la dinámica del proyecto de IEAT, es decir, si alguno de los procesos no se puede automatizar, o requiere de información no relevante para el sistema, se realizará una tarea cuyo resultado sí será utilizado para dar continuidad al flujo de información.

El marco de geodiseño de Steinitz (Steinitz, 2012) establece seis tipos de modelos (ver Figura 3-2). Estos modelos son la interpretación de una serie de preguntas que permiten comprender cómo es el ámbito de estudio, y su comportamiento en conjunto, y que recorre tres veces de forma secuencial. La primera de ellas, en sentido descendente para descubrir por qué hay que intervenir en el territorio, la segunda, en sentido ascendente para decidir qué hay que hacer en esa intervención. La tercera vez, de nuevo de forma descendente, para decidir cómo y cuándo hay que hacerlo.

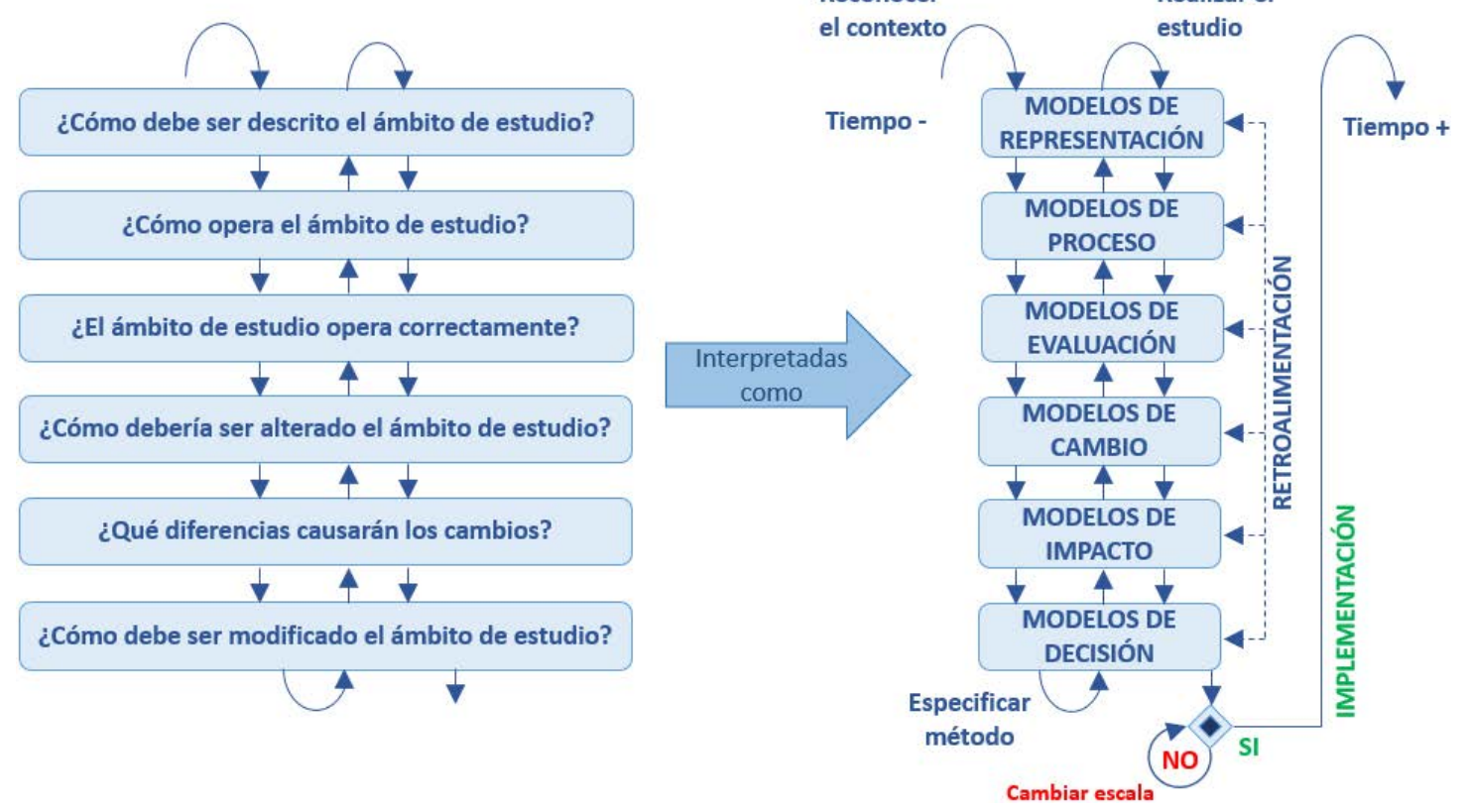

Figura 3-2. Figura adaptada de "A Framework for Geodeign" ( Steinitz, 2012)

Analizando la propuesta de Steinitz (Steinitz, 2012) y la forma de desarrollar las infraestructuras eléctricas de alta tensión en España, se concluye que no es necesario realizar la primera iteración, ya que es la planificación eléctrica (Planificación, 2020) la que indica por qué hay que intervenir, tampoco es necesario realizar la segunda iteración ya que lo que hay que hacer son las propias infraestructuras eléctricas de alta tensión y, sin embargo, sí hay que descubrir cómo y cuándo hay que hacerlo. 
De este análisis se obtiene la propuesta de los modelos que marca el enfoque metodológico abordado en esta tesis.

Los modelos propuestos para todas las fases son de cinco tipos, transversales al proyecto y secuenciales en cada de las fases como se muestra en la Figura 3-3 aplicándose de forma descendente en cada fase.

\begin{tabular}{|l|c|c|c|c|}
\hline Planificación & $\begin{array}{c}\text { Análisis ambiental de } \\
\text { alternativas }\end{array}$ & $\begin{array}{c}\text { Definición del proyecto de } \\
\text { ingeniería }\end{array}$ & $\begin{array}{c}\text { Obtención de } \\
\text { permisos }\end{array}$ & Construcción \\
\hline \multirow{2}{*}{ Modelos para comprensión del ámbito de estudio } \\
\hline Modelos de propuesta de cambios & \\
\hline Modelos de evaluación del impacto & \\
\hline Modelos de ocupación del territorio & \\
\hline \multirow{2}{*}{ Modelos de decisión } & \\
\hline
\end{tabular}

Figura 3-3. Tipos de modelos a aplicar en el marco de geodiseño para IEAT

En el primero se trata de comprender el ámbito de estudio para posteriormente proponer los cambios viables que definen los del segundo tipo. El tercer tipo evalúa los impactos que tendrían los cambios propuestos en el entorno estudiado. El cuarto tipo cuantifica la afectación directa en el territorio y, por último, el quinto tipo se encarga de facilitar la toma de decisiones. Estos últimos se sustentan en personas y la componente humana es difícilmente automatizable ya que, al igual que en los modelos de decisión de (Steinitz, 2012), una decisión normalmente está acompañada de una negociación que lleva a un acuerdo final.

Al igual que en el modelo "A framework for Geodesign" de Steinitz (Steinitz, 2012), la escala de trabajo condiciona el tipo de información que interviene en el análisis de cada fase. En el caso de un proyecto de IEAT, se pasa irremediablemente de las escalas menores a las mayores, lo que lleva a que en cada fase la precisión de la información geográfica vaya creciendo. El salto de escala entre las fases vendrá establecido por el marco de trabajo que se propone. Así, las escalas utilizadas en las primeras fases son mucho menores que en las fases de detalle.

Considerando las cinco fases principales en las que se divide cada proyecto de IEAT, donde los resultados de cada fase alimentan la siguiente $y$, considerando el flujo de tareas lineal, puede entenderse cada una de las fases como proyectos diferentes y cada uno de ellos asociados a su disciplina. Así, habrá que realizar un proyecto de planificación para detectar las necesidades energéticas futuras; un proyecto de análisis ambiental de alternativas, para cada instalación planificada, obteniendo como resultado al menos tres alternativas, cuando el proyecto requiera de Estudio de Impacto Ambiental, que deben ser viables desde el punto de vista medioambiental; un proyecto de ingeniería para cada de las alternativas medioambientales, seleccionándose finalmente uno; un proyecto de obtención de permisos para las parcelas afectadas para el proyecto finalista y, por último, un proyecto de construcción. 
La fase de planificación se representa cartográficamente como una aproximación o un boceto. En la fase de análisis ambiental de alternativas se analiza el territorio utilizando fuentes cartográficas oficiales que ya consideran, a nivel de organización territorial, sus condicionantes que implican la búsqueda de los pasillos o áreas de menor impacto. En la fase de ingeniería se genera información geográfica propia mediante topografía clásica, fotogrametría, vuelos LiDAR o uso de información geográfica oficial; Así, dentro del pasillo de menor impacto la información geográfica que lo describe adquiere una riqueza realmente elevada. En la fase de obtención de permisos se combinan dos fuentes de información geográfica, la oficial de la Sede Electrónica del Catastro -SEC- (SEC, 2020) y la resultante de la fase de ingeniería. Finalmente, en la fase de construcción, la información geográfica para el trabajo de campo de replanteo del proyecto diseñado y del proyecto construido que puede presentar modificaciones respecto del diseñado.

Los análisis de cada fase son secuenciales y los resultados de una forman parte de la siguiente. Inicialmente el ámbito de estudio se corresponde con todo el territorio nacional y sobre el que se planifican las instalaciones futuras. Cada una de ellas es un ámbito de estudio particular y concreto para cada futura instalación. En la secuencia de fases del proyecto estos ámbitos de estudio se irán reduciendo en extensión y aumentando en cuanto a precisión de la información geográfica que los describe. En cada fase se secuencian un conjunto de modelos que desembocan en una decisión final. Esta secuencia de modelos de cada fase guarda relación con los de otras fases, por lo que para cada proyecto también es un objetivo gestionar la trazabilidad de la información geográfica que los describen y poder analizar los estados en los que cada proyecto se encuentra y los que cada proyecto ha ido recorriendo para así entender las decisiones particulares en cada fase.

La trazabilidad en los modelos para comprensión de los ámbitos de estudio muestra cómo las escalas de trabajo y el detalle de la información geográfica irán creciendo a la vez que se avanza en el desarrollo del proyecto, es decir, cómo los ámbitos de estudio se van concretando y focalizando en regiones más concretas. La trazabilidad de los modelos de propuesta de cambios y en los de ocupación del territorio mostrará cómo, en cada fase, la nueva IEAT modificará el entorno y ocupará el territorio respectivamente. La trazabilidad de los modelos de impacto en el entorno mostrará lo que significa la nueva IEAT desde los distintos puntos de vista contemplados: medioambiental en el estudio de alternativas, socioeconómico en la fase de ingeniería y parcelas catastrales en la obtención de permisos y construcción. La trazabilidad de los modelos de impacto en el paisaje mostrará cómo la cuenca visual en el estudio de alternativas iniciales se concreta en la visibilidad de los apoyos en la fase de ingeniería y, finalmente se tendrá la trazabilidad de todas las decisiones alcanzadas en el proceso.

La Figura 3-4 muestra cómo los modelos de cada fase se relacionan para gestionar la trazabilidad de la información geográfica, y de qué tipo son cada uno de los modelos aplicados en cada fase. 


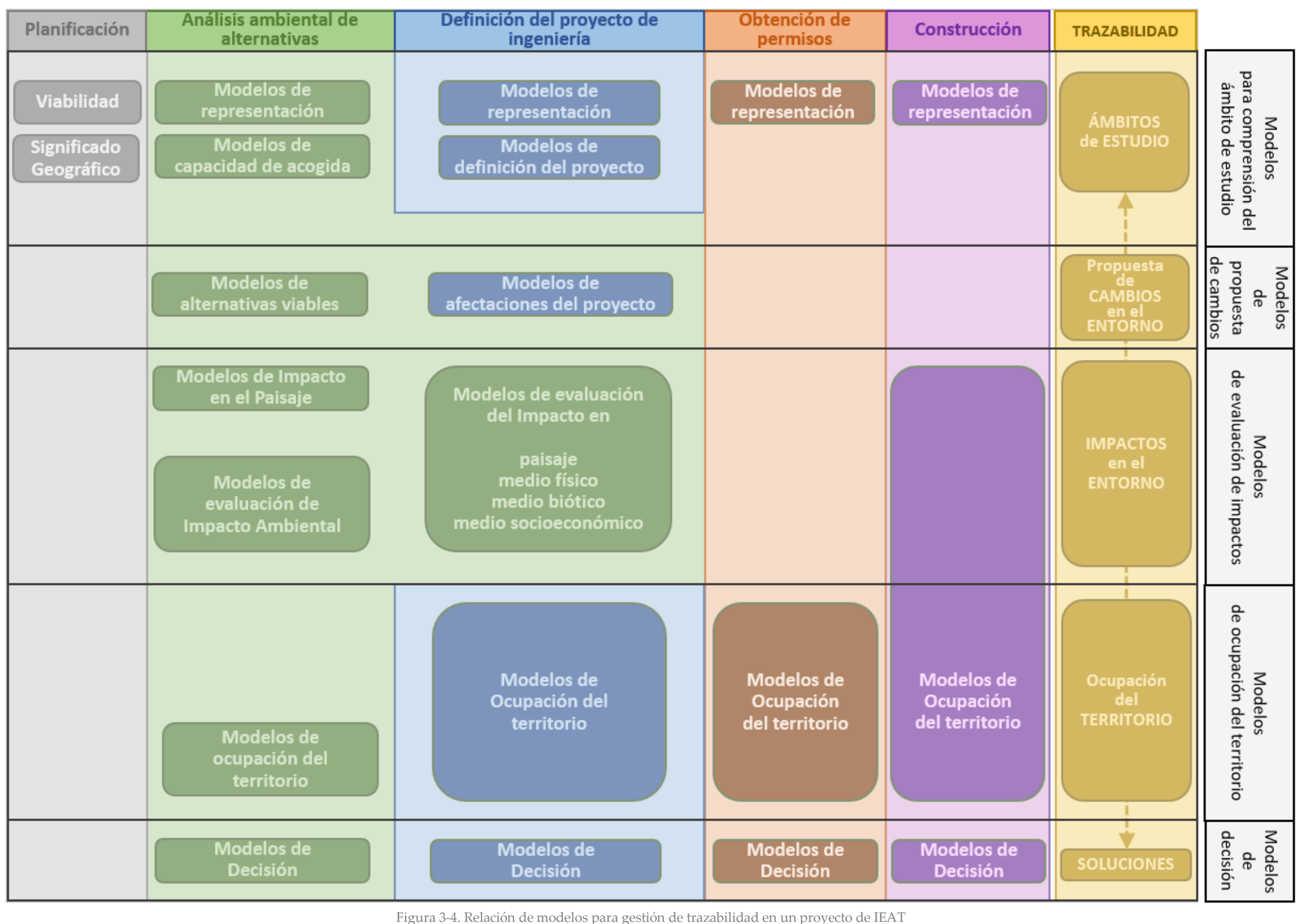

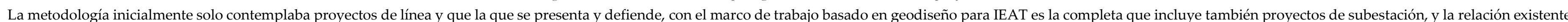
entre ambos tipos de infraestructuras. La Figura 3-5 detalla gráficamente la secuencia de procesos del enfoque metodológico del marco de trabajo basado en geodiseño para la IEAT de cada fase y cómo se secuencian entre ellas. 


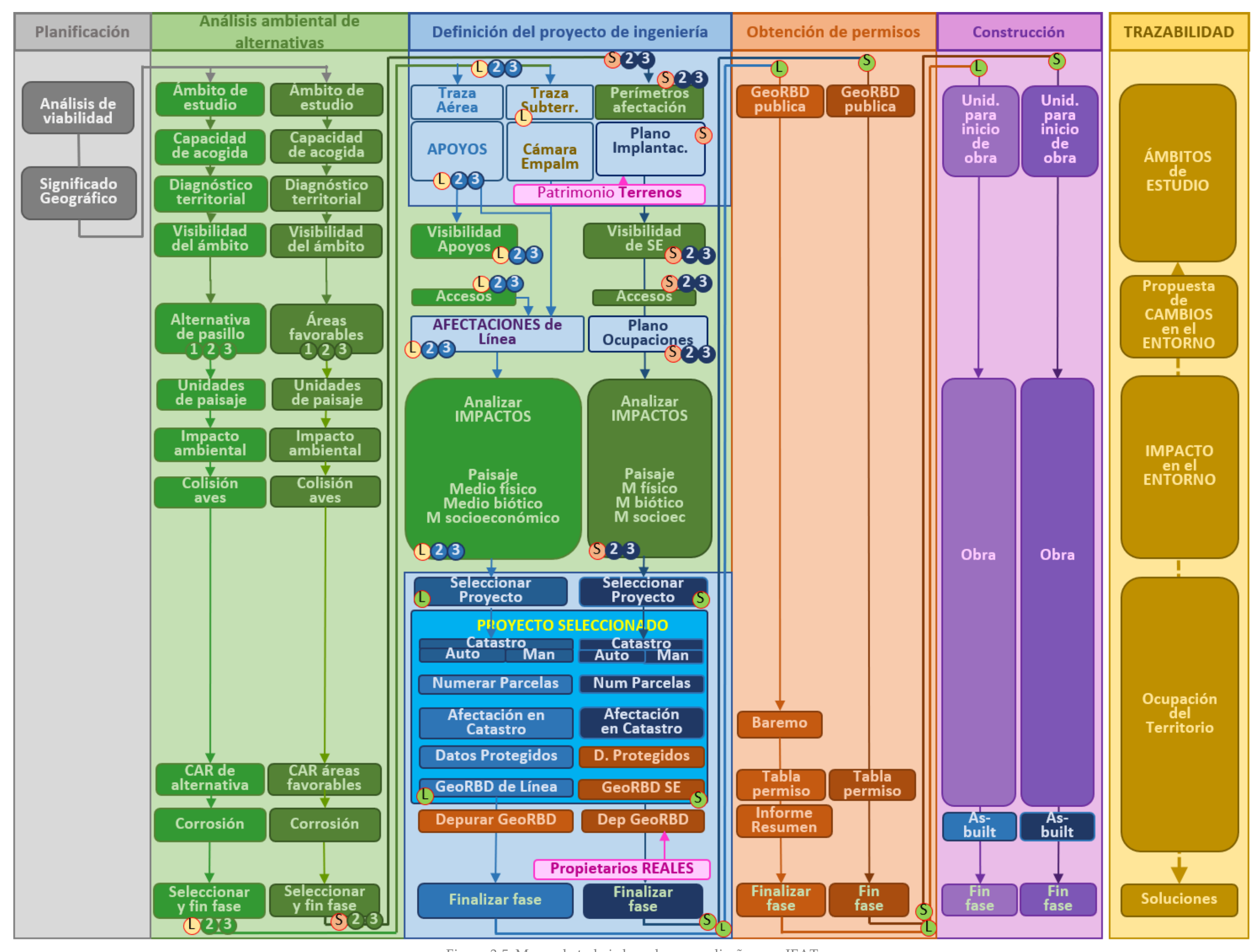

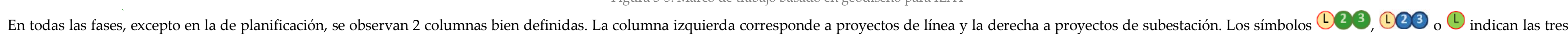

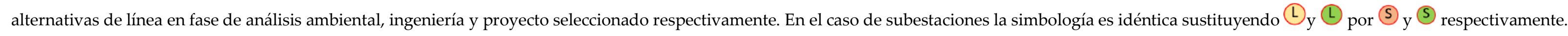


En el diseño de este marco de trabajo basado en geodiseño para proyectos de IEAT se han considerado las siguientes premisas:

1. Entorno único de gestión de información geográfica de proyectos

2. Embebido y soportado por un SIG, es nuestro caso el corporativo GeoRED, que
a. Facilite la colaboración
b. Ofrezca herramientas de análisis geográfico
c. Permita interactuar a usuarios internos y externos a la compañía
d. Utilizable en distintos tipos de dispositivos, tanto móviles como de sobremesa

3. Cuyo flujo de trabajo se base en el geodiseño, dirigiendo al usuario, automatizando la carga, gestionando el almacenamiento, y haciendo uso de la información geográfica.

4. Que implemente modelos de geo-procesamiento corporativos

5. Que audite la trazabilidad del proyecto

A continuación, se explica detalladamente cada una de las fases.

\subsubsection{Planificación}

Tradicionalmente, el resultado del ejercicio de planificación es la evolución necesaria de la red de transporte a ejecutar en los años siguientes (Planificación, 2020). Este resultado se traduce en una tabla de actuaciones y un croquis sin detalle de las mismas, no conectados o sincronizados.

En la actualidad, el marco de trabajo basado en geodiseño que se presenta provee, por un lado, las herramientas que permiten estimar automáticamente los trazados de futuras líneas y localizar la ubicación aproximada de las futuras subestaciones. En esta fase, únicamente se implementa el modelo de comprensión del ámbito de estudio (ver Figura 3-6).

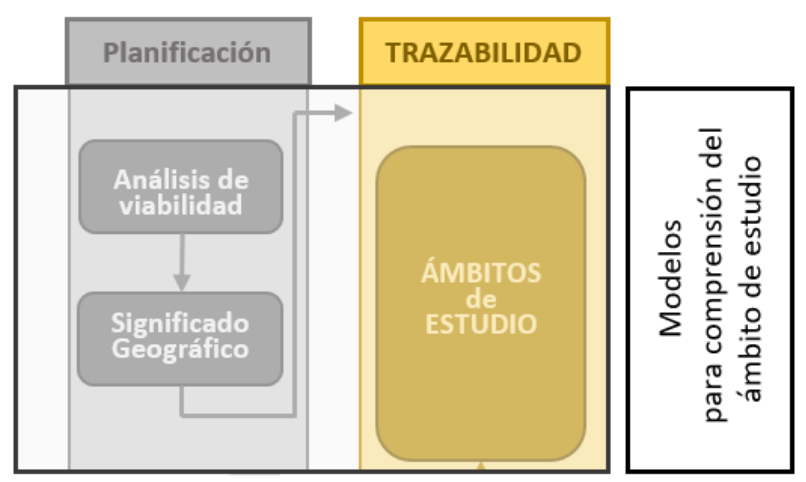

Figura 3-6. Modelos en la fase de planificación

\subsubsection{Análisis ambiental de alternativas}

Tradicionalmente esta fase ha sido la que más información geográfica ha utilizado. Sin embargo, no se contaba con una estructura de datos ni procedimientos que permitiesen una gestión corporativa, sino que dependía en gran medida de la experiencia y criterio de cada técnico. Este hecho provocaba la falta de homogeneidad tanto en los análisis como en los resultados, la falta de trazabilidad en la gestión geográfica del proyecto, la dependencia del técnico asignado y un riesgo para la imagen de la compañía. 
Con esta propuesta metodológica y de trabajo basada en geodiseño, se cuenta con modelos que ayudan a la comprensión del ámbito de estudio, modelos que proponen alternativas de cambio en el territorio, modelos que evalúan estos cambios, modelos que analizan la ocupación del territorio y, finalmente, modelos que ayudan a tomar la decisión de la alternativa de menor impacto ambiental. El tipo y secuencia de ejecución de modelos se muestra en la Figura 3-7.

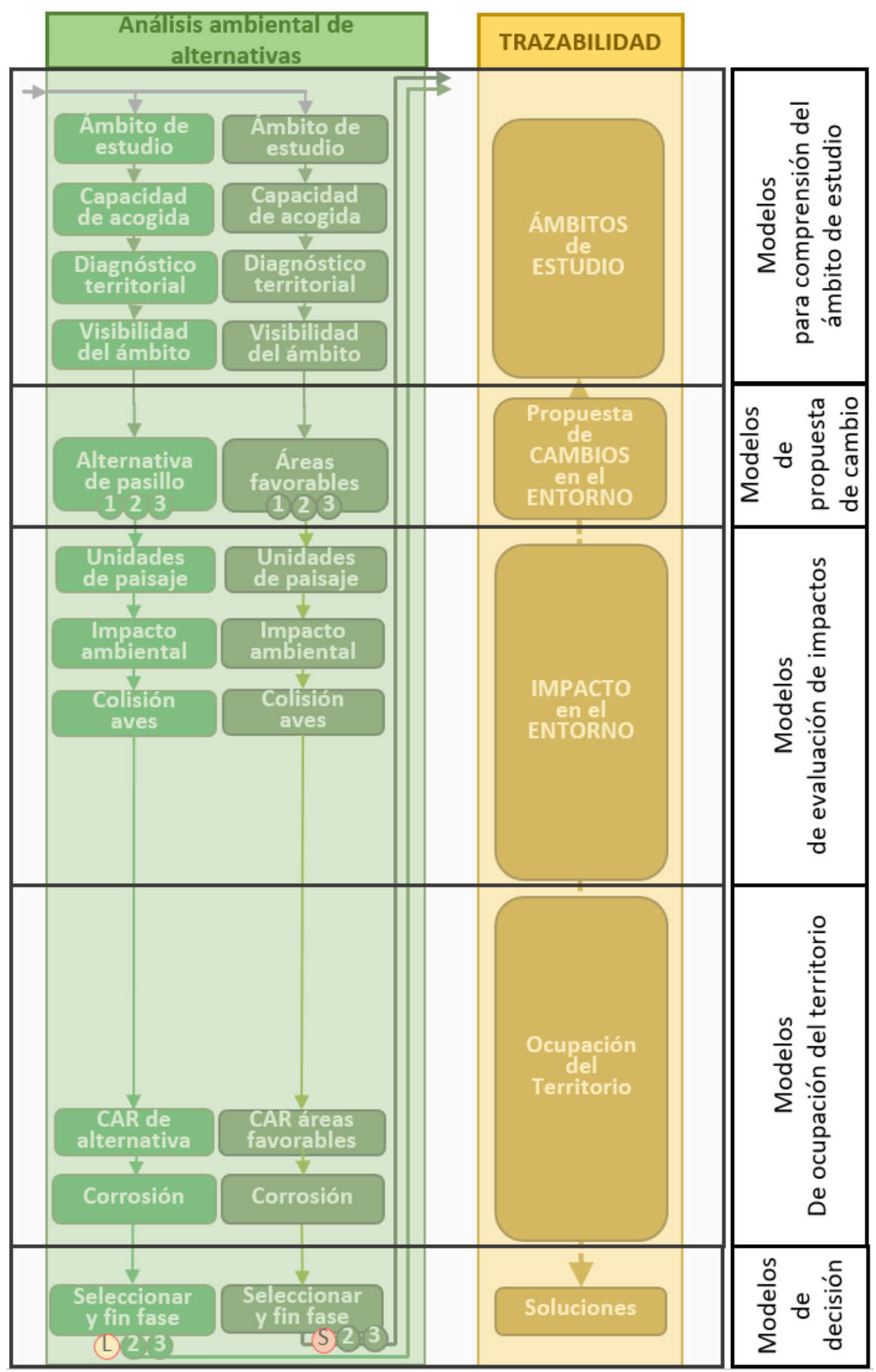

Figura 3-7. Modelos en la fase de análisis ambiental de alternativas

\subsubsection{Definición del proyecto de ingeniería}

Tradicionalmente, cada proyecto de ingeniería era definido de forma aislada sin buscar relación con otros proyectos y sin la colaboración necesaria con los técnicos de las otras fases. La propuesta 
de modelos elimina este aislamiento favoreciendo la participación y colaboración de otros equipos distintos al de la propia fase. Además, se realizaba un único proyecto en la alternativa de menor impacto resultado de la fase anterior.

La secuencia de modelos se muestra en la Figura 3-8.

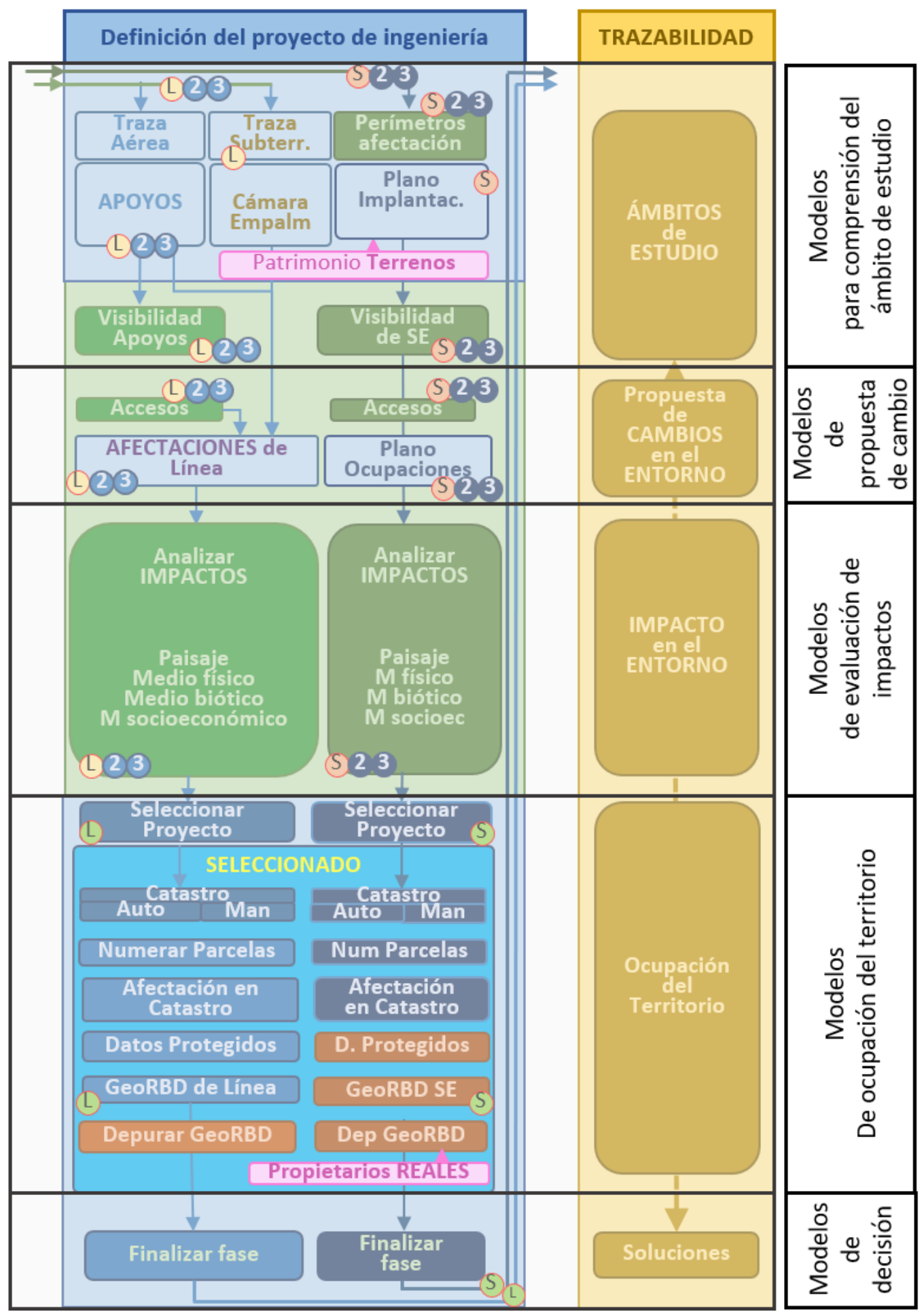

Figura 3-8. Modelos en la fase de definición del proyecto de ingeniería

En la actualidad, cuando el proyecto necesita la realización de un estudio de impacto ambiental, el marco de trabajo basado en geodiseño obliga al análisis de tres proyectos, uno por cada una de 
las tres alternativas de la fase anterior y, tras analizar los impactos en el medio físico, biótico, socioeconómico y el paisaje, se decidirá el proyecto a desarrollar. El análisis de impactos en esta fase se realiza dentro de un proceso colaborativo e iterativo entre los técnicos de la fase ambiental, los técnicos de esta fase y los técnicos encargados de gestionar a los grupos de interés. Una vez seleccionado el proyecto, se procede al análisis relativo a la ocupación del territorio proyectada. Esta ocupación del territorio, traducida a la afectación de parcelas catastrales, conlleva de nuevo un proceso colaborativo e iterativo entre los técnicos de esta fase, los técnicos de obtención de permisos $\mathrm{y}$, nuevamente, los técnicos encargados de gestionar a los grupos de interés.

\subsubsection{Obtención de permisos sobre las parcelas}

La fase de obtención de permisos sobre las parcelas afectadas únicamente participa de los modelos para comprensión de su ámbito de estudio (las parcelas afectadas), de los modelos de ocupación del territorio y los modelos de decisión. La Figura 3-9 muestra la secuencia de los modelos comentados.

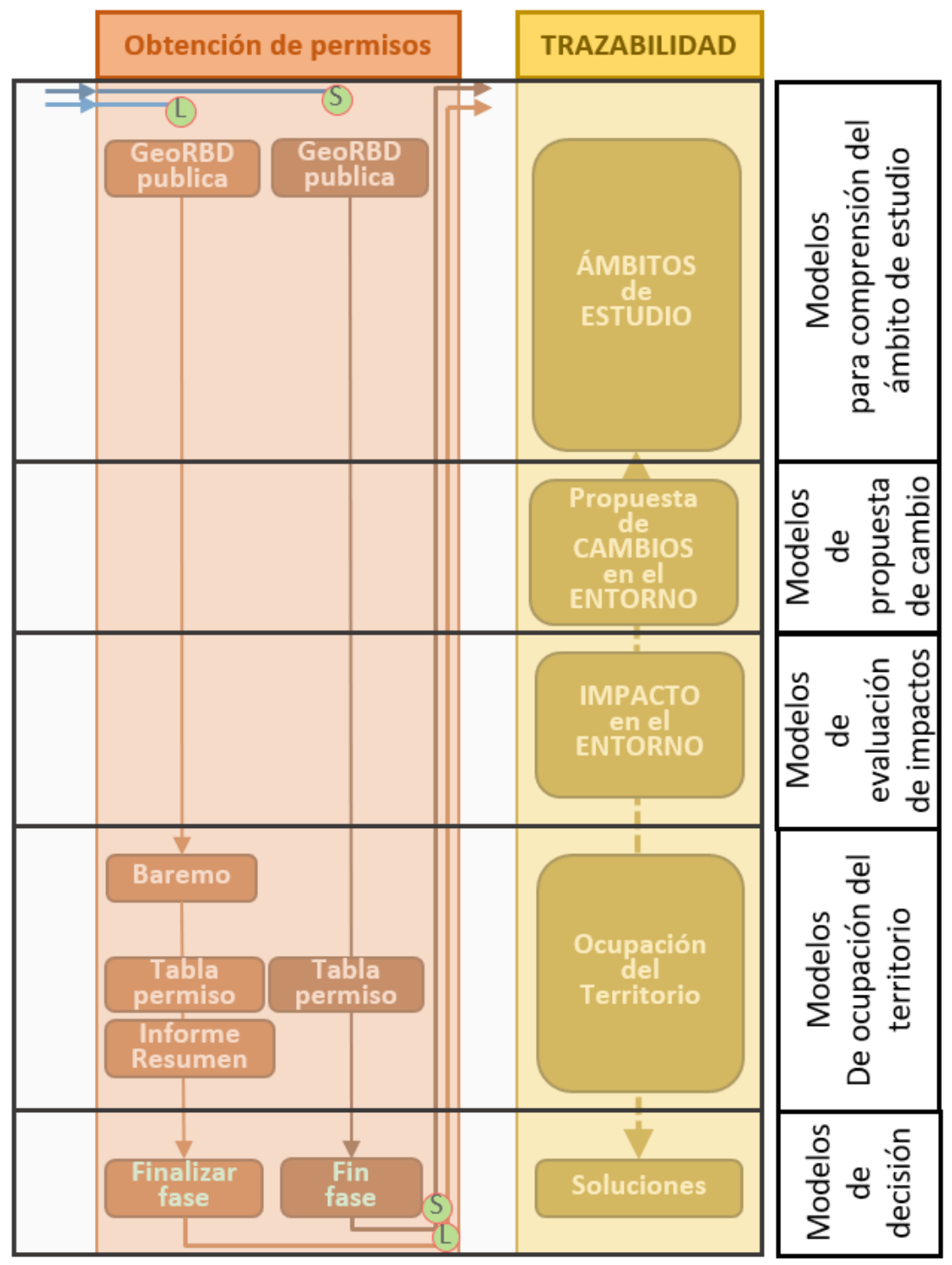

Figura 3-9. Modelos en la fase de obtención de permisos sobre las parcelas

Los cambios propuestos (las afectaciones del proyecto) y los impactos de sobre el entorno (medio físico, socioeconómico y paisaje) han sido analizados en la fase anterior y sobre los que se ha 
tomado la decisión del proyecto a construir. Este es el motivo por el que la fase de definición del proyecto de ingeniería tiene procesos colaborativos e iterativos con las fases anterior y siguiente.

\subsubsection{Construcción}

La fase de construcción materializa sobre el territorio el conjunto de decisiones tomadas en cada una de las fases anteriores. Tal como muestra la Figura 3-10 únicamente aplican, por tanto, los modelos de comprensión del ámbito de estudio y los de ocupación del territorio.

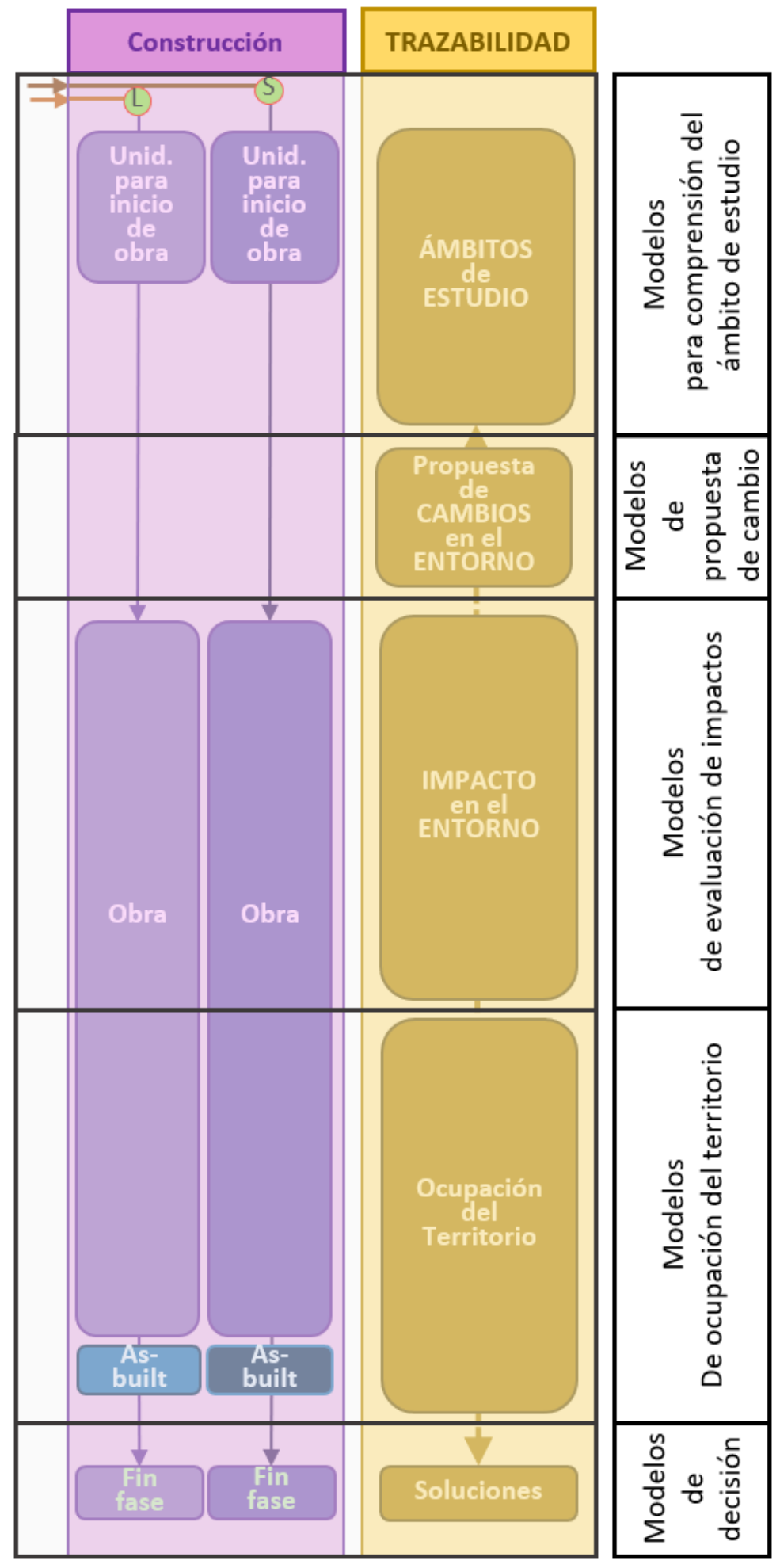

Figura 3-10. Modelos en la fase de construcción 


\subsection{Gestión de grupos de interés}

Cada proyecto, a lo largo de sus diferentes fases, reúne un gran número de grupos de interés. A menudo, estos están en desacuerdo por lo que deben celebrarse sesiones de debate y hay que diseñar y analizar diferentes alternativas. La colaboración y el entendimiento se pueden facilitar mediante el uso de mapas y herramientas visuales que sintetizan la información correspondiente del territorio. De hecho, ésta es una de las principales herramientas utilizadas por el gestor de la red de transporte para explicar los proyectos. Los técnicos del gestor de la red de transporte juegan el papel del equipo de geodiseño, pero hasta ahora no se aplica una metodología única, dando como resultado una falta de coherencia entre los proyectos, lo que significa que cada proyecto puede tener diferentes resultados dependiendo del criterio del técnico responsable.

\subsubsection{Introducción}

Tras el análisis realizado en el capítulo 2 (Antecedentes y marco de la investigación) se corrobora la necesidad de la iniciativa corporativa de dar una visión sistemática y de conjunto a la gestión de los grupos de interés de estos proyectos. Por ello, se han aplicado los conocimientos adquiridos en una propuesta concreta. Consiste en una metodología flexible para la relación con los grupos de interés que ofrece una visión conjunta de cada proyecto y una serie de acciones para la toma de decisiones sobre cada uno de ellos, teniendo en cuenta las relaciones actuales y las potenciales. Siendo el objetivo final de esta metodología la confección de un plan de acción para cada proyecto es importante conocer el carácter que cada grupo de interés tiene en el proyecto, entrando así en juego los modelos de PMBOK (PMBOK®, s.f.) que los clasifican.

La metodología que aquí se propone para gestionar los grupos de interés ha de seguir las pautas corporativas, con una visión integral y escalable. Es decir, aplicable a cualquier tipo de proyecto y para ser desarrollada e implantada gradualmente con vocación de mejora continua y que facilite la gestión de cambio.

La propuesta de incluir a los grupos de interés en las fases tempranas de los proyectos, de forma sistemática, la contempló Steinitz en 2012 en su marco de trabajo para geodiseño (Steinitz, 2012), en el que considera a "la gente del lugar" como parte fundamental del equipo de trabajo.

Como paso previo se ha realizado el análisis de situación expuesto para conocer cómo la compañía gestionaba los grupos de interés y cómo lo están haciendo otras empresas. Seguidamente se han fijado los principios básicos de sostenibilidad (Sostenibilidad-GRE, 2020) que deben guiar la metodología de gestión de grupos de interés a desarrollar. Estos principios son la coordinación interna para transmitir los mensajes de forma homogénea y con información corporativa, la escucha activa para entender las necesidades y preocupaciones de los grupos de interés, la transparencia que permita generar confianza, la anticipación que prevea dificultades posteriores y la búsqueda de alianzas con los propios grupos de interés. La comunicación es una actividad transversal necesaria en cualquier actividad de gestión de grupos de interés. Ésta requiere mensajes claros y adaptados al receptor, canales adecuados, interlocución coordinada y habilidades de comunicación. 
La propuesta combina dos líneas de actuación principales. La primera de ellas se aplica a nivel de organización de la compañía, mediante la creación de un nuevo rol que es el de gestores corporativos de grupos de interés, y la segunda es de tipo técnico, donde la implementación de la metodología se traduce en herramientas que sistematizan su gestión.

Estas dos líneas de actuación no son independientes entre sí, sino que se encuentran relacionadas en un flujo de trabajo que se incorpora, de forma paralela, al marco de trabajo basado en geodiseño para IEAT a través de los hitos de relación con los grupos de interés de cada fase.

\subsubsection{Gestor corporativo de grupos de interés}

Paralelamente a la gestión técnica de la planificación, del análisis medioambiental, de ingeniería, de obtención de los permisos o la construcción, se realiza otra labor de aproximación a los grupos de interés de cada fase. Esta labor de intermediación entre los responsables técnicos y los grupos de interés la desempeña el nuevo rol de gestores corporativos de grupos de interés. Así, dentro del flujo de trabajo basado en geodiseño para IEAT, éstos estarán siempre alineados con el desarrollo del proyecto y gestionarán los planes de acción a ejecutar con cada uno de ellos. Una de las funciones de dicho rol será velar por que la información resultante de los análisis geoespaciales llegue de forma sistemática y sea entendida de forma homogénea por todas las partes: técnicos y grupos de interés.

Estos gestores de grupos de interés se responsabilizarán de la anticipación, del diseño de los planes de acción con cada grupo de interés, de poner voz al trabajo técnico interno de forma coordinada, de generar confianza y de buscar las alianzas necesarias, así como de mantener el equilibrio necesario por medio de la comunicación con transparencia que permita anticiparse a los posibles obstáculos derivados de la relación con los grupos de interés. En definitiva, centralizan las comunicaciones entre la parte técnica y los grupos de interés.

\subsubsection{Propuesta de sistematización}

Esta propuesta aborda el diseño, y su posterior implementación, de herramientas para sistematizar la gestión de grupos de interés. Es importante adaptar los procedimientos a las tareas, enfatizando la capacidad de realizar iteraciones de prueba y error para cumplir con el proceso de retroalimentación-iteración (Eikelboom \& Janssen, 2015). Nuestra propuesta difiere de la propuesta por (Flacke \& Boer, 2017) que generan una herramienta para que las partes interesadas interactúen con la información geográfica del proyecto. En nuestro caso, los gestores de los grupos de interés utilizarán el mismo SIG que los técnicos que analizan y diseñan el proyecto y no se crea ningún instrumento diferente para abordar la aceptación social de los proyectos.

Se compone de cinco tareas secuenciales (ver Figura 3-11) y que se aplican por igual en todas las fases de un proyecto, excepto la fase de planificación que tiene una gestión más sencilla. La primera de ellas aborda la identificación de grupos de interés. Esta identificación se realiza para cada proyecto y para cada fase del mismo. La segunda tarea aborda su registro a través de su ámbito geográfico de influencia, donde se comprueba si dicho grupo se encuentra ya registrado. La tercera aborda su clasificación en cada fase de cada proyecto. La cuarta aborda la definición 
del catálogo de acciones que se han de aplicar a cada grupo de interés en cada una de las fases del proyecto y, la quinta aborda la incorporación de la gestión de grupos de interés en el flujo de trabajo basado en geodiseño para IEAT corporativo.

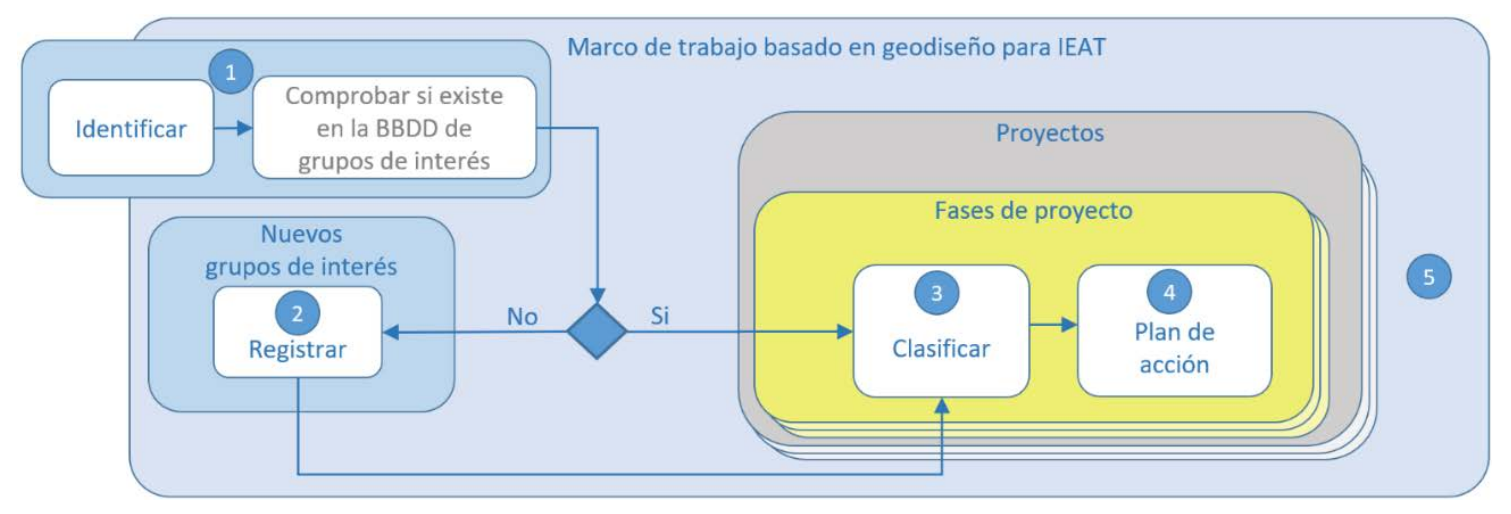

Figura 3-11. Flujo de trabajo en la gestión sistemática de grupos de interés

La propuesta metodológica de gestión de los grupos de interés en esta tesis considera a cada grupo de interés a través de su ámbito geográfico de influencia, es decir, cualquier actuación que lo altere o modifique, despierta unas preocupaciones o necesidades para un determinado grupo que pueden suponer una oposición al desarrollo del proyecto.

\subsubsection{Identificación de grupos de interés}

Según Cooper (Cooper, 2014), su análisis consiste en identificar quiénes son los grupos, tanto los que ya existen, como los futuros, así como las relaciones significativas entre ellos; cuál es su relación e intereses y puntos de vista con respecto a la empresa / acción en cuestión; cómo podría esperarse que actúen (por ejemplo, facilitando o inhibiendo el cambio), lo poderosos que son y qué impacto podrían tener sus acciones; y cuál sería el impacto de sus postura y acciones para la compañía / acción en cuestión.

En el inicio de cada fase de un proyecto, los gestores corporativos de grupos de interés identificarán a los grupos de interés que servirán para esa misma fase y las posteriores, ya que se podrán identificar también condicionantes en fases posteriores.

Tal como indica Steinitz (Steinitz, 2012) los grupos de interés locales tienen información útil que ayudará a definir soluciones, para detectar riesgos posteriores y anticipar soluciones de consenso, haciendo convivir los distintos puntos de vista.

Matizando la definición de grupos de interés de la compañía y la de Freeman (Freeman \& Mcvea, 2001), distinguimos entre grupos de interés activos y grupos de interés pasivos. Los activos son aquellos que tienen la capacidad de: organizarse, negociar, llegar a consensos y cambiar su postura respecto del proyecto de una nueva instalación a lo largo del mismo. Es un tipo de grupo de interés directamente relacionado con el medio político y socioeconómico del territorio. Los pasivos son aquellos más relacionados con el paisaje, y el medio físico y biótico del territorio, que se verán afectados por el mero hecho de estar donde están. Este tipo de grupo de interés está regulado por la legislación vigente, y que tiene una postura constante respecto al proyecto de nueva instalación. 
El proyecto INSPIRE GRID (INSPIRE-GRID-Project, 2013) ha creado un catálogo detallado de grupos de interés que, de manera general, se ven afectados por las instalaciones eléctricas. En este catálogo de grupos de interés también se desarrollan las necesidades y preocupaciones de los grupos de interés respecto de este tipo de proyectos. De la misma forma, el compromiso con la sostenibilidad en la gestión de grupos de interés de la compañía (Sostenibilidad-GRE, 2020) incorpora una lista de grupos de interés cuyas categorías de agrupación son equivalentes, por lo que el análisis realizado por el proyecto INSPIRE GRID en cuanto a preocupaciones y necesidades de los distintos grupos de interés también lo son. Esta equivalencia sirve de punto de partida para que el catálogo de acciones a aplicar a cada grupo de interés dé respuesta a sus preocupaciones y necesidades de forma alineada a las conclusiones del proyecto INSPIRE GRID.

En esta propuesta metodológica, la identificación se realiza por dos vías diferentes. La primera es automática, gracias a la coincidencia espacial entre el ámbito geográfico del proyecto y la base de datos geoespacial histórica de ámbitos geográficos de influencia de grupos de interés que hayan sido identificados para otros proyectos previos. Esta vía automática es posible gracias a la gestión global de información geoespacial que se realiza con el flujo de trabajo basado en geodiseño para IEAT. La segunda vía es manual, y que pone en valor la presencia que la compañía tiene en el territorio, también en cuanto a recursos humanos, lo que deriva en el contacto con la gente del lugar (Steinitz, 2012), advirtiendo de las necesidades y preocupaciones de los grupos de interés respecto del proyecto (Mendelow, 1981).

\subsubsection{Registro de grupos de interés}

Varios grupos de interés pueden haber sido identificados y registrados en proyectos anteriores o en fases previas de un mismo proyecto. Solo habrá que registrar los nuevos. Su registro se realizará a través de su ámbito geográfico de influencia. Este ámbito es el parámetro que permitirá relacionar su gestión con el flujo de trabajo basado en geodiseño de IEAT. También será el parámetro que sistematizará su identificación cuando en el futuro, por el mismo territorio, se proyecte una nueva IEAT. La idea de la sistematización de la identificación de grupos de interés se basa en la gestión de una base de datos geoespacial de ámbitos de influencia de grupos de interés. Esta base de datos geoespacial se relaciona, por coincidencia espacial, con el resto de las entidades geoespaciales gestionadas por el flujo de trabajo basado en geodiseño de IEAT. Un mismo ámbito geográfico de influencia podrá estar asociado a distintos grupos de interés $\mathrm{y}$, a su vez, un mismo grupo de interés podrá estar asociado a distintos proyectos y/o fases de cada proyecto. Su papel será gestionado en función del contexto "proyecto - fase de proyecto".

Una forma de simplificar su gestión en un proyecto de IEAT es agrupándolos por categorías, ya que las estrategias de gestión con los grupos de interés de la misma categoría serán similares. De la misma forma, el poder o interés de cada uno de ellos dentro de la misma categoría, también será similar.

La lista de categorías de grupos de interés propuestas en esta metodología, alineada con el proyecto INSPIRE GRID (INSPIRE-GRID-Project, 2013), se muestra en la Tabla 3-1. 


\begin{tabular}{|l|}
\hline \multicolumn{1}{|c|}{ Categorías de grupos de interés } \\
\hline Asociaciones/grupos ambientales \\
\hline Asociaciones de consumidores \\
\hline Asociaciones políticas \\
\hline Asociaciones profesionales y empresariales \\
\hline Asociaciones/agentes sociales \\
\hline Ayuntamientos \\
\hline Empresas del sector \\
\hline Empresas de otro sector \\
\hline Entidades científicas y educativas \\
\hline Medios de comunicación y otros generadores de opinión \\
\hline ONG y fundaciones \\
\hline Organismos reguladores y Administración competente \\
\hline Otras Administraciones y entes públicos \\
\hline Propietarios \\
\hline Sociedad en general \\
\hline Vecinos \\
\hline
\end{tabular}

Tabla 3-1. Categorías de los grupos de interés

El registro de grupos de interés se realiza de la siguiente forma:

- Se registra el ámbito geográfico de influencia (si no existe en la base de datos geoespacial) con los datos de la Tabla 3-2.

Datos de registro de ámbito geográfico de influencia

Geometría del ámbito geográfico de influencia

Descripción del ámbito geográfico de influencia

Tabla 3-2. Datos de registro de ámbito geográfico de influencia

- Se registra y asocia, a cada ámbito geográfico de influencia, tantos grupos de interés como haya, añadiendo para cada uno de ellos la información descrita en la Tabla 3-3.

\begin{tabular}{|l|}
\hline \multicolumn{1}{|c|}{ Asociación de grupos de interés con fase de proyecto } \\
\hline Nombre del grupo de interés \\
\hline Categoría \\
\hline Proyecto que le afecta \\
\hline Fase del proyecto (Moreno-Marimbaldo, et al., 2018) \\
\hline Poder \\
\hline Interés \\
\hline Impacto \\
\hline Estabilidad de su postura en la fase \\
\hline
\end{tabular}

Tabla 3-3. Asociación de grupos de interés con fase de proyecto

Los grupos de interés activos son complicados de modelar, entender y dar seguimiento debido a la posible volatilidad de su postura durante el proyecto, dada la dependencia de las relaciones interpersonales, o a su influencia intermitente en función de la fase en que se encuentre el proyecto. Su registro conlleva un esfuerzo de inventario en campo para poder entender sus preocupaciones y necesidades (INSPIRE-GRID-Project, 2013). El registro de los grupos de interés 
pasivos es más sencillo, pues mayoritariamente, los centros de descarga de las Administraciones Centrales o Regionales cuentan con la información geoespacial catalogada (mediante metadatos) disponible. Su registro es directo, y su clasificación y categorización inmediata y estable en el tiempo. Esto significa que gracias a estos centros de descarga se obtienen los ámbitos geográficos de influencia además del nombre y características de cada grupo de interés asociado, como por ejemplo las ZEPAS (Zonas de especial protección para las aves) que están disponibles para descarga en la página web del Ministerio para la Transición Ecológica - MITECO (https://www.miteco.gob.es/es/biodiversidad/temas/espacios-protegidos/red-natura2000/zepa.aspx).

Para implementar el registro de los grupos de interés se propone el uso del SIG corporativo GeoRED, mediante un único servicio de mapa sobre el que registrar todos los ámbitos geográficos de influencia de todas las fases de todos los proyectos. De esta forma se consigue la base de datos geoespacial de grupos de interés de la compañía. Se propone su uso ya que es el soporte lógico del flujo de trabajo de geodiseño en el que metodológicamente se plantea integrar.

\subsubsection{Clasificación de grupos de interés}

Una vez identificados y registrados los grupos de interés, se les ha de clasificar en base a sus características en cada fase de cada proyecto (Usmani, 2019), con el objetivo de disponer de la información necesaria para sistematizar su estrategia de gestión. Ésta se convierte en un problema de sistemas (Hester, et al., 2012) ya que definirán indirectamente el alcance y la funcionalidad del mismo. Una clasificación de grupos de interés basada en su nivel de cooperación (Savage, et al., 1991) es una clasificación incompleta, por tanto, una estrategia para involucrarles basada únicamente en su clasificación relativa a la potencial colaboración en el proyecto es insuficiente (Hester, et al., 2012).

Cada grupo de interés es único en cada fase de cada proyecto y, por tanto, aporta su propia perspectiva con valor agregado al conjunto, lo que es lo mismo la complementariedad (Bohr, 1928). Para determinar las estrategias de gestión de los diferentes grupos de interés hay que analizarlos considerando, por un lado, "el principio de quién o qué es lo que realmente cuenta" (Freeman, 1994) pag 413. A partir de este principio, Mitchell et al. (Mitchell, et al., 1997) pregunta, “... ¿quiénes (o qué) son los interesados de la empresa? ¿Y a quién (o qué) le prestan atención los gerentes?”. Es decir, ¿cómo identificar a los interesados y cómo decidir las estrategias para involucrarles en el apoyo de las estrategias de solución de problemas?

Tras analizar y comparar los modelos para la gestión de los grupos de interés realizado por Acuña (Acuña, 2012), se propone usar una combinación de modelos.

Uno de ellos es la matriz de Mendelow (Mendelow, 1981) que clasifica y representa grupos de interés en forma de matriz de $2 \times 2$ (matriz poder-interés, Figura 3-12) como herramienta de ayuda para su análisis. En esta clasificación, los grupos de interés se agrupan según su poder e interés hacia el proyecto y el resultado de éste (Olander \& Landin, 2005). Para ubicar a cada grupo de interés en la matriz es necesario reconocer el poder que tiene para modificar el curso del proyecto y el interés que ese grupo tiene en el mismo. 


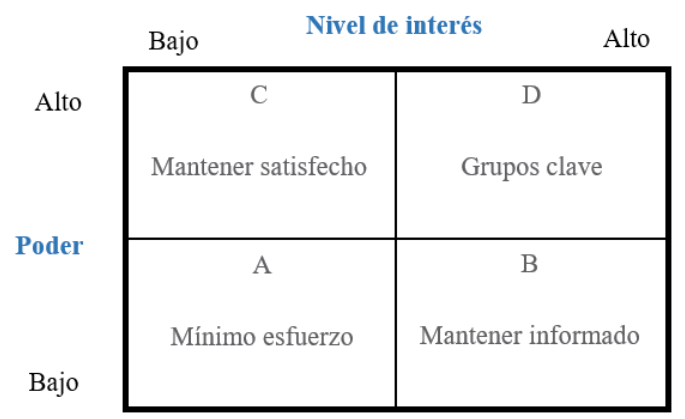

Figura 3-12. Matriz Poder - Interés (adaptada de Mendelow, 1981)

La posición que ocupen en la matriz de Mendelow (Mendelow, 1981), también estudiada por Gardner y otros (Gardner, et al., 1986) indica el tipo de acciones que se deben realizar con cada uno de ellos. Esta matriz ayudará a definir cómo se gestionará la comunicación con ellos. Los tipos de acciones se corresponden con los 4 cuadrantes de la matriz:

- Cuadrante A: Acciones para monitorizarles: grupos de interés con bajo poder y bajo interés que hay que vigilar y no aburrir con una excesiva comunicación.

- Cuadrante B: Acciones para mantenerles informados: grupos de interés con alto interés y bajo poder que habrá que tener adecuadamente informados y asegurar que no surjan problemas que hagan que cambien de cuadrante. Éstos a menudo son muy útiles con los detalles del proyecto.

- Cuadrante C: Acciones para mantenerles satisfechos: grupos de interés con alto poder y bajo interés que habrá que mantener satisfechas, pero no tanto como para aburrirse con su mensaje.

- Cuadrante D: Acciones para gestionarles atentamente: grupos de interés con alto poder y alto interés con las que debe comprometerse plenamente y hacer los mayores esfuerzos para alinear el resultado del proyecto con sus preocupaciones y necesidades (INSPIREGRID-Project, 2013).

Para gestionar el dinamismo o inestabilidad de la postura que cada grupo de interés tenga respecto del proyecto existe la matriz Poder-Dinamismo (Mendelow, 1981), véase Figura 3-13, posteriormente estudiada por Gardner (Gardner, et al., 1986). Esta matriz servirá para anticiparse a las consecuencias derivadas de un cambio de postura de grupos de interés con alto peso específico. De nuevo la matriz es de 2x2, con 4 cuadrantes que clasifican los grupos de interés en:

- Cuadrante A: grupos de interés con bajo poder y bajo dinamismo, que generarán pocos problemas.

- Cuadrante B: grupos de interés con alto dinamismo y bajo poder, que son impredecibles pero gestionables.

- Cuadrante C: grupos de interés con alto poder y bajo dinamismo, que siendo poderosos son predecibles.

- Cuadrante D: grupos de interés con alto poder y alto dinamismo, en los que se pueden encontrar mayores riesgos y oportunidades. 


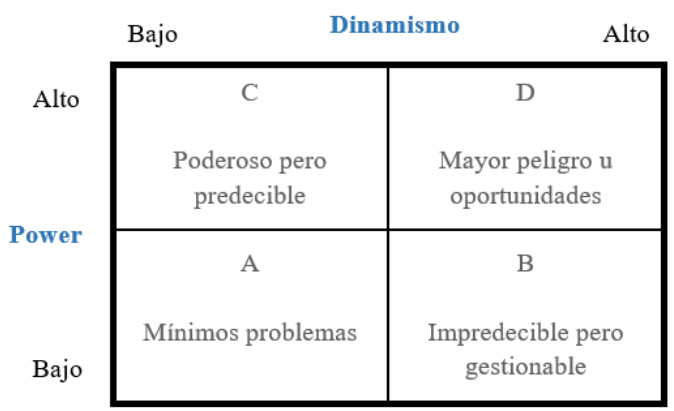

Figura 3-13. Matriz Poder - Dinamismo (adaptada de Mendelow,1981)

Los grupos de interés activos potencialmente tienen una postura más inestable respecto del proyecto que los pasivos. Estos cambios de postura han sido estudiados en los proyectos alemanes de generación de energía (Shamo, et al., 2019) con la conclusión de que existe un efecto polarizador de las actitudes a favor y en contra que amplía la brecha social entre partidarios y opositores. La agrupación de oponentes puede causar inconvenientes para cualquier proyecto.

Además, para definir una estrategia de gestión de grupos de interés más robusta, es conveniente evaluar el impacto que puede causar en el desarrollo de cualquier fase del proyecto y, por tanto, en el proyecto global, la oposición de cualquier grupo de interés.

Considerando estas cuatro variables usadas para clasificar los grupos de interés: poder, interés, impacto y la estabilidad de la postura o dinamismo (Figura 3-14) se propone una nueva matriz capaz de representarlas simultáneamente. En esta matriz la simbología que se utilizará para clasificar a los grupos de interés es (a) variables poder (eje vertical) e interés (eje horizontal) para el posicionamiento en la matriz; (b) la variable impacto que se representa con el tamaño del círculo que ayudará a distinguir cuáles tendrían mayor impacto y (c) la estabilidad de la postura o dinamismo representada por el tono, cuanto más oscuro sea éste, mayor dinamismo.

(a) Matriz poder-interés (adaptada de Mendelow, 1981)

(b) Impacto

(c) dinamismo
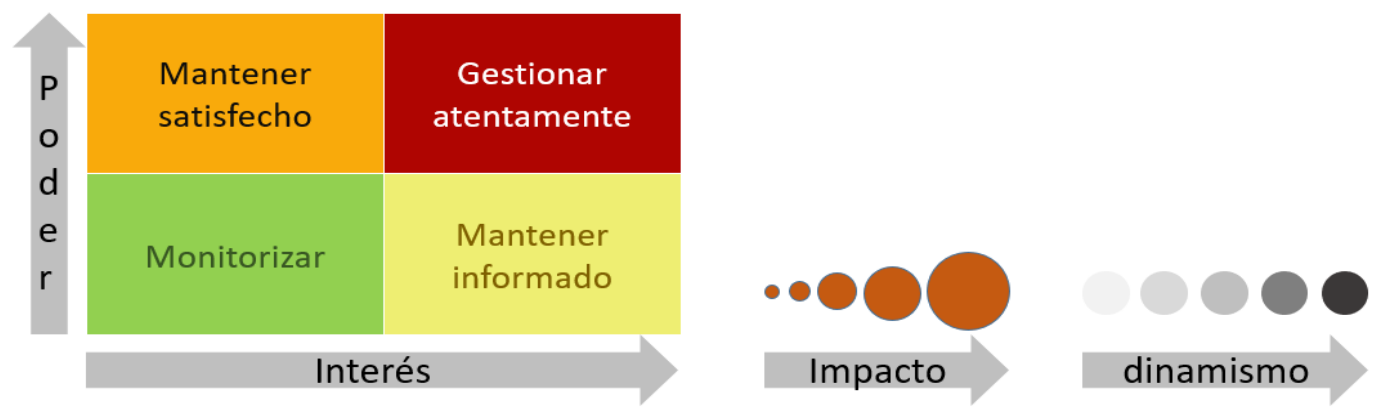

Figura 3-14. Simbología para clasificar a los grupos de interés

Considerando que se pretende gestionar los grupos de interés dentro del flujo de trabajo basado en geodiseño que gestiona datos gráficos y alfanuméricos, hay variables que dependen del análisis geoespacial y otras que son características del proyecto. Estas variables nos ayudarán a definir la importancia del proyecto y, por tanto, a matizar el impacto de cada grupo de interés en el mismo. Considerando que no todos los proyectos tienen la misma importancia, bien sea por su vertiente estratégica, técnica, económica o social, es conveniente prestar especial atención a los 
proyectos de mayor importancia. Los factores que ayudan a evaluar la importancia de cada proyecto se muestran en la Tabla 3-4.

\begin{tabular}{|c|c|c|c|c|c|c|}
\hline \multirow[b]{2}{*}{ Factores } & & \multicolumn{5}{|c|}{ Importancia del proyecto } \\
\hline & & $\begin{array}{l}\text { Muy } \\
\text { Alta }\end{array}$ & Alta & Media & Baja & $\begin{array}{l}\text { Muy } \\
\text { baja }\end{array}$ \\
\hline Imvorte (M€) & $\begin{array}{r}>50 \\
30-50 \\
10-30 \\
1-10 \\
<1 \\
\end{array}$ & $x$ & $\mathrm{x}$ & $\mathrm{x}$ & $\mathrm{x}$ & $x$ \\
\hline Alcance & $\begin{array}{r}\text { línea aérea }>30 \mathrm{~km} \\
\text { línea subterránea }>5 \mathrm{~km} \\
\text { tramo submarino } \\
\text { desfasador } \\
\text { máquina de potencia/rea } \\
\text { nueva subestación } \\
\text { almacenamiento } \\
\text { edificio } \\
\text { repotenciación }\end{array}$ & $\mathrm{x}$ & $\begin{array}{l}\mathrm{x} \\
\mathrm{x}\end{array}$ & $\begin{array}{l}\mathrm{x} \\
\mathrm{x}\end{array}$ & $\mathrm{x}$ & $\mathrm{x}$ \\
\hline Tensión & $\begin{array}{r}400 \\
220 \\
132 \\
66 \\
\end{array}$ & & $\begin{array}{l}\mathrm{x} \\
\mathrm{x} \\
\mathrm{x}\end{array}$ & $\mathrm{x}$ & & \\
\hline Comunidad Autónoma & $\begin{array}{r}\text { Galicia } \\
\text { Asturias } \\
\text { Cantabria } \\
\text { País Vasco } \\
\text { Navarra } \\
\text { La Rioja } \\
\text { Aragón } \\
\text { Cataluña } \\
\text { Murcia } \\
\text { Comunidad Valenciana } \\
\text { Andalucía } \\
\text { Castilla la Mancha } \\
\text { Castilla y León } \\
\text { Extremadura } \\
\text { Madrid } \\
\text { Baleares } \\
\text { Canarias } \\
\text { Ceuta } \\
\text { Melilla } \\
2 \text { CCAA }\end{array}$ & $\begin{array}{l}x \\
x\end{array}$ & $\begin{array}{l}x \\
x \\
x \\
x \\
x \\
x\end{array}$ & $\begin{array}{l}x \\
x \\
x\end{array}$ & $\mathrm{x}$ & $\begin{array}{l}x \\
x\end{array}$ \\
\hline Motivación Planificación & $\begin{array}{r}\text { Restricciones técnicas } \\
\text { Seguridad de suministro } \\
\text { Fiabilidad } \\
\text { Interconexiones } \\
\text { ATA } \\
\text { EvCo } \\
\text { EvRe } \\
\text { almacenamiento } \\
\text { ApD }\end{array}$ & $\mathrm{x}$ & $x$ & $\begin{array}{l}\mathrm{x} \\
\mathrm{x} \\
\mathrm{x} \\
\mathrm{x} \\
\mathrm{x} \\
\mathrm{x}\end{array}$ & & \\
\hline Ejes relacionados & $\begin{array}{r}0 \\
1 \\
2 \\
3 \\
4 \text { o más }\end{array}$ & $\mathrm{x}$ & $\mathrm{x}$ & $\mathrm{x}$ & & $\begin{array}{l}\mathrm{x} \\
\mathrm{x}\end{array}$ \\
\hline $\begin{array}{l}\text { \% superficie atravesada } \\
\text { ambientalmente protegida }\end{array}$ & $\begin{array}{r}0 \\
0-10 \\
10-30 \\
>30 \\
\end{array}$ & $\mathrm{x}$ & $\mathrm{x}$ & $\mathrm{x}$ & & $\mathrm{x}$ \\
\hline Instalación para terceros & $\begin{array}{r}\text { ADIF } \\
\text { Generación Renovable } \\
\text { Otro } \\
\end{array}$ & & & $\begin{array}{l}\mathrm{x} \\
\mathrm{x} \\
\mathrm{x}\end{array}$ & & \\
\hline Oposición previa ejes & $\begin{array}{r}\text { menos de } 5 \text { años } \\
5-10 \text { años } \\
>10 \text { años } \\
\text { nunca }\end{array}$ & $\mathrm{x}$ & $\mathrm{x}$ & $\mathrm{x}$ & & $\mathrm{x}$ \\
\hline
\end{tabular}

Tabla 3-4. Factores que ayudan a evaluar la importancia de cada proyecto 
En la representación mostrada en el ejemplo de la Figura 3-15 se utiliza la matriz poder-interés, para representar cada grupo de interés en el cuadrante que marcará la estrategia de gestión a desarrollar con él. Se utiliza el tamaño de la simbología para indicar el impacto que cada grupo de interés puede tener sobre la fase del proyecto en la que se ha identificado. Finalmente se utiliza el tono del color de la simbología para indicar el dinamismo o inestabilidad de la postura. De este modo se dispone de un cuadro de mando que permite interpretar de forma gráfica y rápidamente el tipo de grupo de interés para identificar la estrategia de gestión a aplicar.

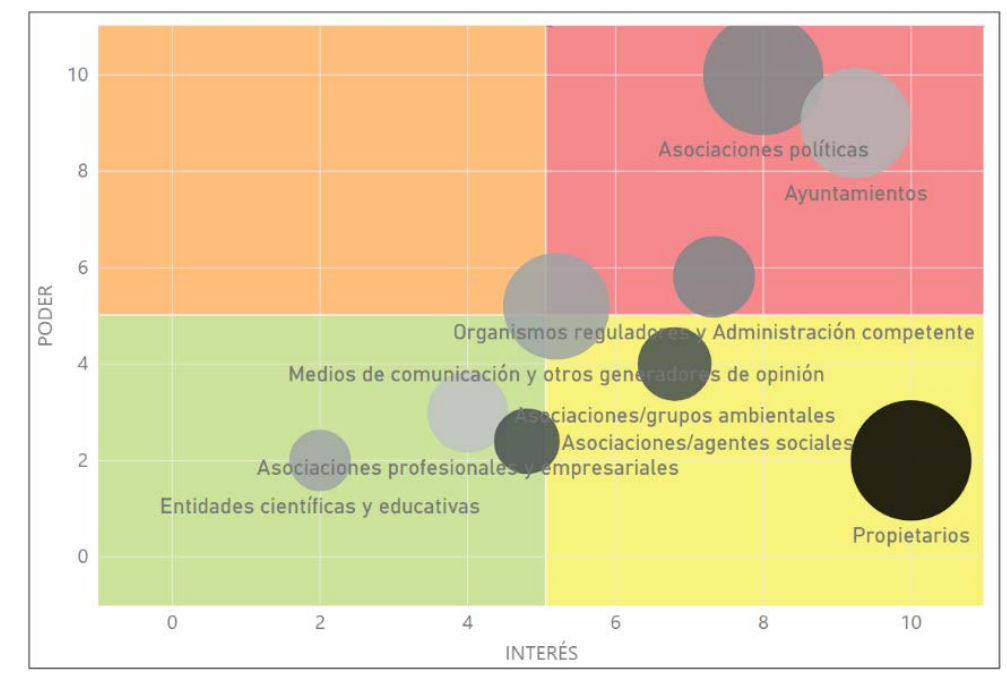

Figura 3-15. Ejemplo de uso de la nueva matriz para clasificar a los grupos de interés

Dado que durante los proyectos se produce mucha información relacionada y se generan opiniones a favor y en contra, también es conveniente considerar la estabilidad de la postura respecto al proyecto o dinamismo derivado de las influencias que unos grupos de interés pueden tener sobre otros, favoreciendo un cambio de su postura.

Para gestionar estas influencias se propone el uso de una nueva matriz de relación entre grupos de interés con moderada o alta inestabilidad en su postura respecto del proyecto. La denominaremos "matriz de influencias" e indicará qué grupos de interés puede influir en otros y, a su vez, qué grupos de interés se verán influenciados por el cambio de postura de terceros. En la Figura 3-16 se muestra un ejemplo de la matriz de influencias. De nuevo esta matriz es gestionada y actualizada por el gestor corporativo de grupos de interés, donde los actores o grupos de interés A y B se influyen mutuamente, B influye en C, D y E influyen en B y C, respectivamente. Las celdas de color gris oscuro no aplican (A no influye en A) y las celdas de color gris claro estarían repitiendo la relación en las celdas blancas (ejemplo $\mathrm{AB}=\mathrm{BA}$ ).

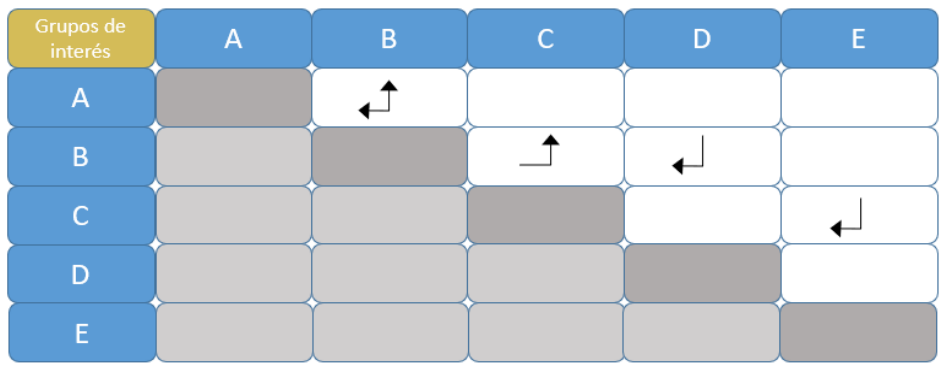

Figura 3-16. Ejemplo de matriz de influencias entre 5 grupos de interés 


\subsubsection{Catálogo de acciones}

Se definen las acciones que debe tomar la compañía hacia sus grupos de interés como actos que se realizan con un fin determinado, en un ámbito específico y que afectan, incluyen o comparten con otras entidades.

El catálogo del tipo de acciones diseñado por la compañía para la gestión sistemática de grupos de interés (ver Tabla 3-5) conlleva, no solo disponer de una lista cerrada de acciones, sino también el seguimiento de cada acción en cada fase de cada proyecto para verificar su éxito.

\begin{tabular}{|c|}
\hline Acciones \\
\hline Apariciones en medios: entrevista, reportaje, artículo de opinión \\
\hline Búsqueda de alianzas ámbito local o autonómico \\
\hline Búsqueda de alianzas (otro ámbito) \\
\hline Buzoneo a los vecinos \\
\hline Convenio/alianza de colaboración \\
\hline Convenio/alianza de tramitaciones \\
\hline Convenio/alianza de sostenibilidad \\
\hline Encuesta \\
\hline Envío de correo electrónico informativo \\
\hline Envío de correo electrónico informativo (acción masiva) \\
\hline Instalación de buzón de sugerencias \\
\hline Instalación de paneles informativos por municipios \\
\hline Jornada informativa (local o autonómica), incluidos órgano ambiental o sustantivo \\
\hline Jornada informativa otro ámbito \\
\hline Jornada de expertos (local o autonómico) \\
\hline Jornada de expertos otro ámbito \\
\hline Nota de prensa \\
\hline $\begin{array}{l}\text { Otros eventos institucionales/comunicación (puesta primera piedra, instalación exposición } \\
\text { itinerante...) }\end{array}$ \\
\hline Participación en foros organizados por el grupo de interés \\
\hline Proyectos sociales \\
\hline Publicación de información en la web de Red Eléctrica y/o RR. SS \\
\hline Publicación de una web del proyecto \\
\hline Punto de información en municipio \\
\hline Punto de información móvil \\
\hline Reunión informativa y/o para recoger aportaciones a proyecto (local o autonómica), incluidos \\
\hline Reunión informativa y/o para recoger aportaciones otro ámbito \\
\hline Reunión para asuntos de diseño e ingeniería (proyecto líneas) \\
\hline Reunión para asuntos de diseño e ingeniería (proyecto subestaciones) \\
\hline Reunión para asuntos medioambientales \\
\hline Reunión para asuntos de tramitación o permisos del proyecto \\
\hline Reunión para coordinación terceros conexiones a red \\
\hline Reunión de posicionamiento y planificación (supra proyecto) \\
\hline Rueda de prensa, encuentro con medios \\
\hline Visita de campo, a otras instalaciones de Red Eléctrica y/o Cecoel \\
\hline
\end{tabular}

Tabla 3-5. Catálogo de acciones 
Con estos fines, las acciones han de asociarse a cada grupo de interés en cada fase de cada proyecto. Un grupo de interés podrá tener asociadas tantas acciones como los gestores del proyecto estimen oportuno. Para asociar una acción a un grupo de interés se procederá de la siguiente forma: Se seleccionará el grupo de interés de entre los registrados, se asignará un nombre a la acción, se seleccionará la fase del proyecto en la que se aplica (ver Tabla 3-6),

\begin{tabular}{|l|}
\hline \multicolumn{1}{|c|}{ Fases } \\
\hline Planificación \\
\hline Análisis de alternativas \\
\hline Ingeniería \\
\hline Obtención de permisos \\
\hline Construcción \\
\hline
\end{tabular}

Tabla 3-6. Fases de los proyectos

se tendrá que seleccionar el estado de la acción de entre las posibles (Tabla 3-7),

\begin{tabular}{|l|}
\hline \multicolumn{1}{|c|}{ Estado acción } \\
\hline Planificada \\
\hline En curso \\
\hline Finalizada \\
\hline Desestimada \\
\hline
\end{tabular}

Tabla 3-7. Estado de la acción

se seleccionará el éxito de la acción (Tabla 3-8),

\begin{tabular}{|l|}
\hline \multicolumn{1}{c|}{ Éxito de la acción } \\
\hline $\mathrm{Si}$ \\
\hline $\mathrm{No}$ \\
\hline Parcial \\
\hline
\end{tabular}

Tabla 3-8. Valoración de éxito de la acción

se seleccionará el soporte documental (Tabla 3-9),

\begin{tabular}{|l|}
\hline \multicolumn{1}{|c|}{ Soporte documental } \\
\hline Argumentario \\
\hline Carta informativa \\
\hline Correo electrónico \\
\hline Cronograma \\
\hline Documentación técnica ambiental \\
\hline Documentación técnica de ingeniería \\
\hline Documentación técnica de tramitaciones y permisos \\
\hline Documento de la planificación \\
\hline Dosier de prensa \\
\hline Encuesta \\
\hline Folleto informativo \\
\hline Material audiovisual \\
\hline Nota de prensa \\
\hline Paneles y carteles informativos \\
\hline Planos \\
\hline Presentación \\
\hline Propuesta de convenio de colaboración \\
\hline Web del proyecto \\
\hline Web de Red Eléctrica \\
\hline >> Ninguno <<< \\
\hline
\end{tabular}

Tabla 3-9. Soporte documental para las acciones 
También es necesario disponer de un conjunto de evidencias de éxito para evitar la subjetividad de la clasificación y contar con un indicador de cumplimiento (Tabla 3-10).

\begin{tabular}{|l|}
\hline \multicolumn{1}{|c|}{ Evidencias cumplimiento } \\
\hline Acta de reunión \\
\hline Acuerdo/alianza \\
\hline Cartas entregadas \\
\hline Convenio firmado \\
\hline Correo enviado \\
\hline Informe de la jornada \\
\hline Informe de la visita \\
\hline Informe de los hitos principales del proyecto \\
\hline Informe del evento \\
\hline Informe del foro \\
\hline Listado de sugerencias recibidas y peticiones de información \\
\hline Número de visitas \\
\hline $\begin{array}{l}\text { Número de visitas por municipio y listado de sugerencias recibidas y peticiones de } \\
\text { información }\end{array}$ \\
\hline Número de visitas y listado de sugerencias recibidas y peticiones de información \\
\hline Número de visitas y/o seguidores \\
\hline Paneles instalados en municipio \\
\hline Repercusión mediática \\
\hline Resultados de la encuesta \\
\hline Tratamiento de la noticia \\
\hline
\end{tabular}

Y, finalmente, se seleccionará el responsable interno de liderarla que corresponde con las unidades de negocio corporativas que estarán coordinadas con el gestor corporativo de grupos de interés. Estas unidades de negocio son dependientes de la estructura que la compañía tenga en cada momento y, por tanto, cambiantes.

Además, se podrán registrar tantas observaciones o comentarios sobre la acción como se considere oportuno, tales como su ejecución, resultado o cualquier otro aspecto que añada información de utilidad.

Se ha realizado una prueba piloto con 13 proyectos de desarrollo de la red de transporte de electricidad. Estos proyectos han sido seleccionados en diferentes entornos y en diferentes estadios para detectar problemas y mejorar la metodología.

La Figura 3-17 muestra, a modo de ejemplo, los resultados de la ejecución de las cuatro tareas descritas:

a) los ámbitos geográficos de influencia de los 13 proyectos

b) lista de los grupos de interés asociados a un ámbito geográfico de influencia de uno de los proyectos

c) descripción de uno de los grupos de interés del ámbito de influencia consultado

d) descripción de una acción realizada con el grupo de interés analizado. 
(a)

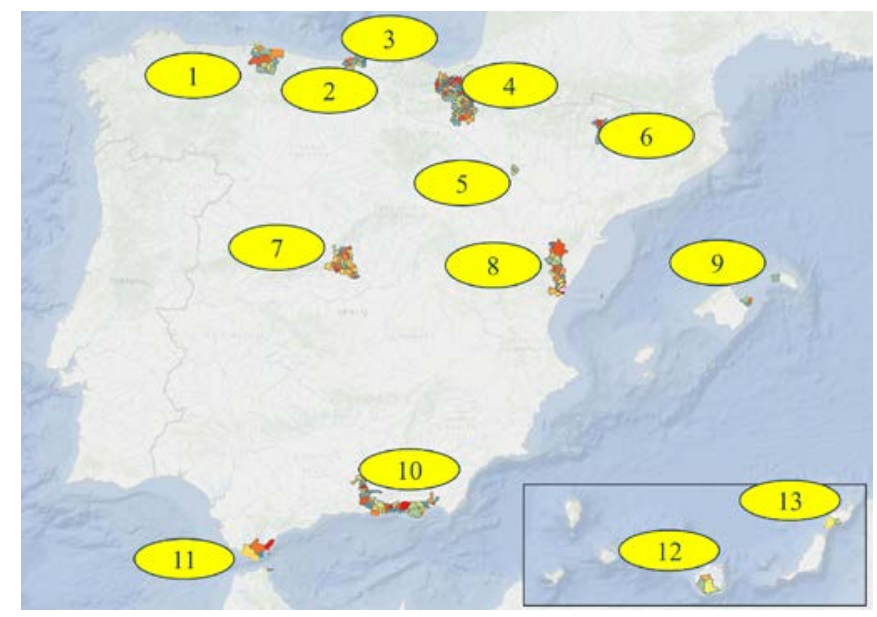

(c)

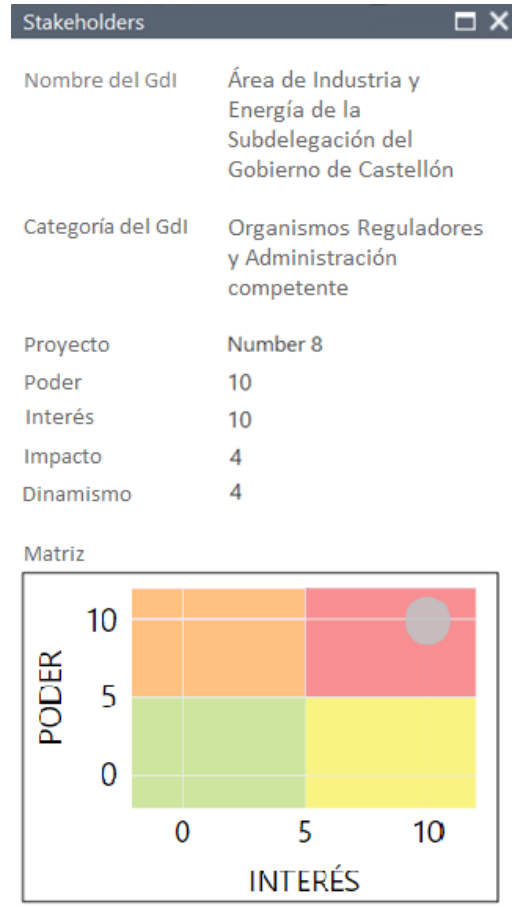

(b)

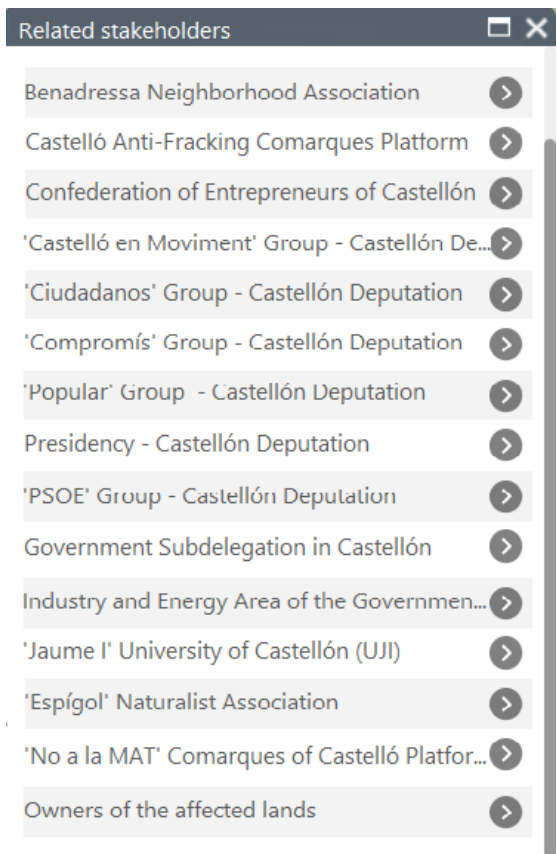

(d))

$\begin{array}{ll}\text { Actions } & \\ \text { Action Name } & \begin{array}{l}\text { Monitoring and coordination } \\ \text { meeting }\end{array} \\ \text { Project phase } & \begin{array}{l}\text { Studying alternatives } \\ \text { Planned }\end{array} \\ \text { Action Status } & \\ \text { Action's succes } & \text { Planning Document } \\ \text { Ducumentary } & \\ \text { support 1 } & \text { Engineering technical } \\ \text { Documentary } & \text { information } \\ \text { support 2 } & \text { Environmental } \\ \text { Documentary } & \text { technical information } \\ \text { support 3 } & \\ \text { Documentary } & \\ \text { support 4 } & \\ \text { Evidence of } & \text { Meeting Minutes } \\ \text { compliance } & \\ \text { Action Leader } & \text { Technical project manager } \\ \text { Collaborator 1 } & \text { Territorial delegate } \\ \text { Collaborator 2 } & \text { Environmental technician }\end{array}$

Figura 3-17. Ejemplo de resultados de prueba piloto con 13 proyectos

La quinta tarea se ejecutará por medio del flujo de trabajo basado en geodiseño en el que los resultados de la ejecución de sus modelos proveerán al gestor corporativo de grupos de interés de la información necesaria para gestionarlos. 
3.2.3.5 Gestión de grupos de interés en el flujo de trabajo basado en geodiseño para IEAT

La integración de la gestión de grupos de interés en el flujo de trabajo para las IEAT basado en geodiseño tiene un doble objetivo. Por un lado, poder relacionar espacialmente el ámbito geográfico de influencia de los grupos de interés con toda la información geográfica del flujo de trabajo de la IEAT y poder así identificar qué grupos pueden verse involucrados en cada fase del proyecto. Por otro disponer de una base de datos de grupos de interés de ámbito nacional y atemporal, que registrará los grupos de interés identificados en otros proyectos u otras fases en el pasado. De esta forma muchos grupos de interés para nuevas infraestructuras serán identificados de forma espontánea como consecuencia de su intersección espacial con la información de la fase en la que se esté estudiando cada proyecto.

El flujo de trabajo basado en geodiseño propuesto para IEAT ha estado en constante evolución. Con la propuesta metodológica para la gestión de los grupos de interés se han introducido cambios en el flujo de trabajo para identificarles, y para gestionar la colaboración y el consenso con los grupos relacionados con el proyecto. Estas modificaciones se introducen en diferentes puntos porque, al igual que en el marco de trabajo de Steinitz (Steinitz, 2012), hay que conocer el impacto sobre el territorio y poder anticiparse, y favorecer así la disposición para acometer cualquier tipo de acción con los grupos de interés. Se trata por tanto de pasar de la gestión de los grupos de interés al compromiso con ellos (Dalcher, 2016).

La gestión de los grupos de interés que tienen relevancia en el desarrollo de proyectos de la IEAT puede acometerse con diferentes enfoques. Dada la alta vinculación de estos proyectos con el territorio, se ha optado por gestionarles considerando su área geográfica de influencia como parámetro fundamental ya que se puede usar para:

i) Delimitar territorialmente su ámbito geográfico de influencia;

ii) Identificar las regiones con influencia de varios grupos de interés;

iii) Acotar territorialmente las acciones a acometer con cada grupo de interés;

iv) Automatizar la identificación de posibles grupos de interés para futuros proyectos y

v) Definir acciones más dirigidas a su gestión.

Al igual que el flujo de trabajo basado en geodiseño se ve soportado por un SIG, la gestión de los grupos de interés se realizará con él. De este modo se podrá gestionar geográficamente su área de influencia y toda la información alfanumérica descriptiva, así como las acciones a acometer para cada uno de ellos. La Figura 3-18 muestra la fusión del flujo de trabajo basado en geodiseño para IEAT, con la propuesta de su gestión geográfica. 


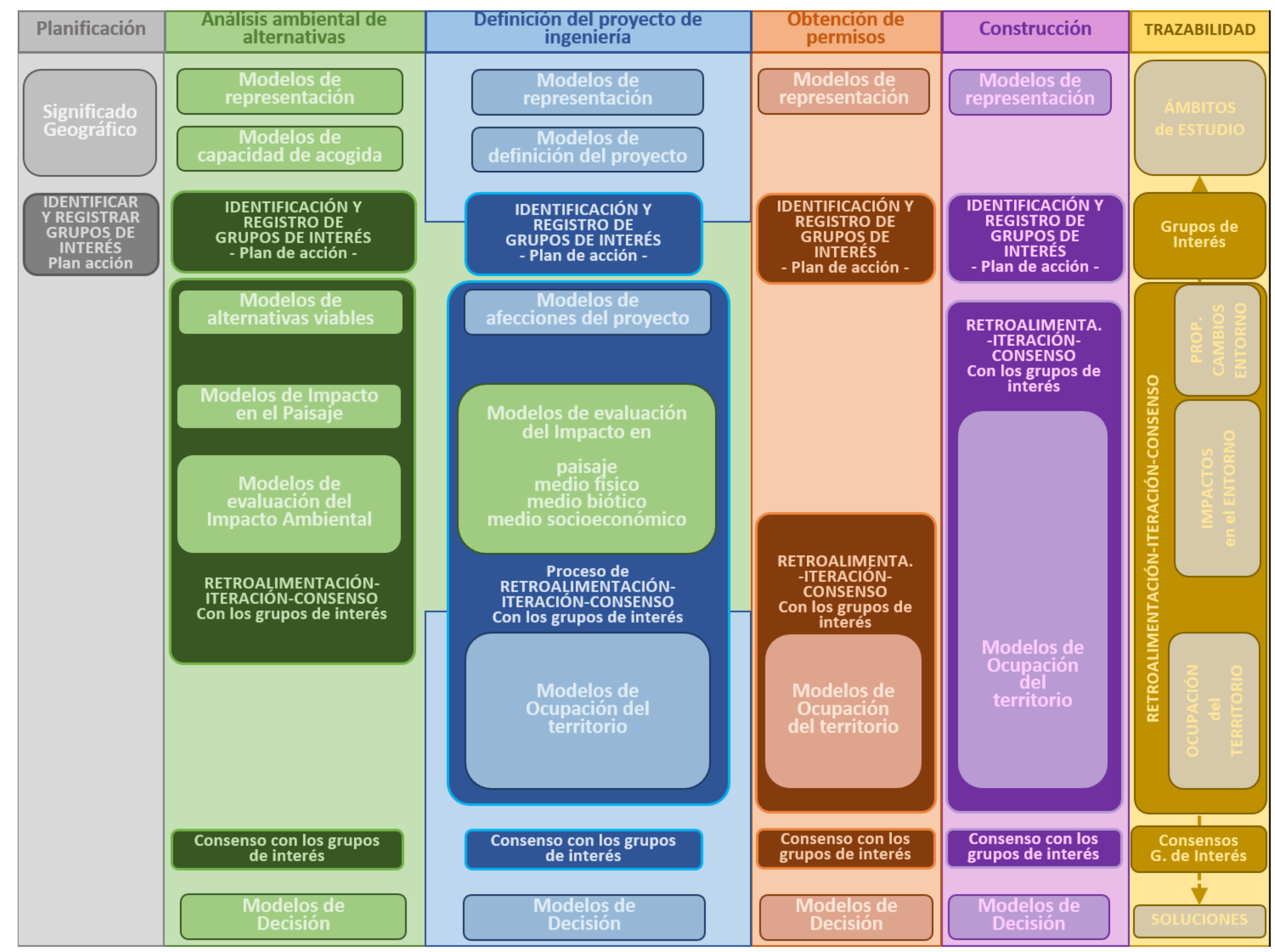

Figura 3-18. Fusión de los modelos del marco de trabajo basado en geodiseño para IEAT con la estrategia de gestión geográfica de grupos de interés 
Las cajas en color claro corresponden al marco de trabajo basado en geodiseño para IEAT y las más oscuras añaden la nueva funcionalidad de conexión con los grupos de interés.

En primer lugar, se identifican las siguientes entidades en las que se ha modelado la gestión de los grupos de interés en el SIG:

i) El ámbito geográfico de influencia: delimita el área geográfica sobre la que un grupo de interés podrá influir. Para cada ámbito geográfico de influencia puede haber $\mathrm{n}$ grupos de interés relacionados, es decir, puede haber varios grupos de interés que comparten el área de influencia. Cada uno de ellos se describe, además de por su propia geometría, por un código y un nombre que lo identifican;

ii) Grupo de interés: Se trata de un atributo que describe a cada uno de ellos. Un mismo grupo de interés puede estar en más de un ámbito o área de influencia y puede tener relacionadas tantas acciones como sean necesarias;

iii) Acción: Atributos que describen las actuaciones necesarias con cada grupo de interés en concreto. Se podrán relacionar tantas acciones a un mismo grupo de interés como sea necesario;

iv) Observación: Atributos no obligatorios que matizan o dan información adicional a cada una de las acciones registradas. Podrá haber n observaciones para cada Acción.

Utilizando como base de referencia el flujo de trabajo basado en geodiseño se establecen tres hitos de gestión de grupos de interés en cada fase, excepto en la fase de planificación.

El primero de ellos, considerando que el primero de los modelos del flujo de trabajo es el relacionado con el ámbito de estudio, aborda:

i) la identificación automática de ámbitos geográficos de influencia de grupos de interés ya registrados con anterioridad;

ii) el registro de los nuevos;

iii) la clasificación de cada grupo de interés en cada fase;

iv) el plan de acción o asignación de acciones. Es decir, el flujo de trabajo ya descrito en la Figura 3-11.

El segundo hito de gestión, considerando los resultados de los análisis que realizan los diferentes modelos de cada fase del flujo de trabajo, trata de mantener involucrado a cada grupo de interés en el avance del proyecto ya que cada modelo ejecutado añadirá más información útil para entender mejor cómo se va concretando el diseño final del proyecto. Este hito es un proceso colaborativo de retroalimentación-iteración para alinear las expectativas de todas las partes que debe gestionar el gestor corporativo de grupos de interés. Un ejemplo de este hito lo observamos en la fase de obtención de permisos, donde un camino de acceso a un futuro apoyo o torre puede estar diseñado por un lado de una parcela y, tras el proceso retroalimentación-iteración establecido con el propietario del terreno, se diseña un nuevo camino de acceso satisfactorio para ambas partes. 
El tercer hito de gestión busca el consenso en el resultado de cada fase. Es decir, en el flujo de trabajo cada fase se finaliza con un modelo de decisión, esta decisión se toma basándose en los resultados del análisis técnico y en los resultados del consenso deseado con cada grupo de interés.

De la misma forma que se registra la trazabilidad de la información geográfica de las fases del proyecto, también se registra la trazabilidad de la gestión de los grupos de interés. La Figura 3-18 muestra gráficamente las entidades que lo componen y la fusión del flujo de trabajo basado en geodiseño para IEAT, con la propuesta de gestión geográfica de grupos de interés que se presenta en este trabajo.

\subsubsection{Integración de la gestión de grupos de interés en el marco de trabajo basado en geodiseño}

Los grupos de interés no participan directamente en el proceso de toma de decisiones de los proyectos, pero es importante comprender cómo involucrarlos en los procesos de retroalimentación-iteración, combinando su participación con los diferentes modelos de propuesta de cambio y la evaluación de sus impactos teniendo en cuenta sus necesidades. Este es un punto clave para acercar el campo técnico y social, reduciendo así la distancia entre el análisis técnico y las evaluaciones no profesionales realizadas por los grupos de interés (Giuffrida, et al., 2019).

La gestión de los diferentes grupos de interés en cada fase del proyecto de IEAT, tal como lo define el flujo de trabajo basado en geodiseño se realizará de la siguiente forma:

\subsubsection{Fase de Planificación}

Las principales necesidades energéticas eléctricas nacionales son los principales desencadenantes de la fase de planificación: el dimensionado y mallado de la red de transporte de electricidad para garantizar la seguridad del suministro, la evacuación de las instalaciones donde se genera, el consumo industrial y el abastecimiento de los ferrocarriles de alta velocidad.

Se trata de una fase en la que las escalas de trabajo son pequeñas y los grupos de interés coinciden con sus promotores, por lo que el consenso es absoluto y no existen apenas puntos de fricción.

Esta metodología propone un único hito de gestión de grupos de interés que aborda su identificación y registro geográfico. Una vez registrados serán asociados a esta fase del proyecto y se diseñará un plan de acción, basado en las acciones definidas de forma corporativa (Sostenibilidad-GRE, 2020).

\subsubsection{Fase de análisis ambiental de alternativas}

En esta fase se confrontan los intereses energéticos con los condicionantes territoriales. Se plantean tres hitos de gestión para los grupos de interés. En primer lugar, su identificación y registro geoespacial asociados a esta fase. Además de los nuevos grupos de interés, los registrados en la fase de planificación pueden verse involucrados en esta fase. El plan de acción que se diseña en este hito de esta fase para cada grupo de interés estará basado en las acciones definidas en el modelo corporativo de relación con los grupos de interés que será matizado en base al histórico de éxito de las acciones llevadas a cabo con cada grupo de interés y en ese territorio. En segundo 
lugar, tras el análisis y diagnóstico territorial y durante el estudio de alternativas viables, se comenzará un proceso de retroalimentación-iteración con los grupos de interés para compatibilizar la solución técnica con sus requerimientos. Tal como está definido el flujo de trabajo basado en geodiseño para IEAT, este proceso iterativo se servirá del modelo que evalúa el posible impacto ambiental de cada alternativa y el modelo que evalúa la visibilidad de cada una de ellas. De forma intrínseca a este proceso iterativo, se ejecutarán las acciones ya comentadas, para gestionar adecuadamente a cada grupo de interés en esta fase del proyecto.

En tercer y último lugar, tras analizar los impactos ambientales y de visibilidad de los pasillos resultantes, el gestor corporativo de grupos de interés podrá convocar un encuentro en el que se revisará la información ya facilitada en el hito anterior de retroalimentación-iteración y se buscará el consenso de todas las partes, para dar por finalizada la fase de estudio de alternativas, dando como resultado al menos tres pasillos en los que se analizará las soluciones de ingeniería del proyecto. En esta fase toman mayor relevancia los grupos de interés pasivos, ya que se suelen ser las figuras de protección ambiental que están reguladas y responden a una normativa oficial. Su identificación, registro y asociación con esta fase del proyecto se puede asumir como automática.

\subsubsection{Fase de definición del proyecto de ingeniería}

La fase de ingeniería tiene como entrada los 3 pasillos o áreas favorables viables de la fase de estudio de alternativas. Se realizarán tres proyectos de ingeniería. En esta fase también se plantean tres hitos de gestión de grupos de interés. En el primero se procederá a identificar y registrar geográficamente los grupos de interés propios de esta fase, y se asociarán los grupos con esta fase. Cada grupo de interés tiene una relevancia diferente según la fase del proyecto y, por tanto, su posición en la matriz poder-interés o sus características de impacto y estabilidad en su postura respecto del proyecto será también diferente. También se establecerá el plan de acción basado en las acciones definidas en el modelo corporativo de gestión de grupos de interés, que nuevamente será matizado por el historial de éxito de las acciones llevadas a cabo con cada grupo de interés para ese mismo territorio. Se tendrán en cuenta las relaciones establecidas con los grupos en las fases anteriores de haberse visto involucrados.

El segundo hito se corresponde con el primer boceto de distribución espacial de los apoyos o torres de la línea eléctrica, con el que se iniciará de nuevo un proceso de retroalimentacióniteración sirviéndose como herramienta de análisis y comunicación del modelo de flujo de trabajo basado en geodiseño para IEAT, donde se analizan los impactos ambientales, socioeconómicos y de visibilidad de las torres. Después se ejecutarán las acciones necesarias para gestionar adecuadamente a cada grupo de interés en esta fase del proyecto. Tras este proceso iterativo se acometerá el tercer hito que se corresponde con el consenso. Al igual que en el marco de geodiseño de Steinitz (Steinitz, 2012), esta solución consensuada suele llevar asociada una negociación que satisfaga a todas las partes. La efectividad del gobierno corporativo de cualquier compañía será mayor cuando mayor sea el número de grupos de interés que se entiendan entre sí asociados a su actividad, hecho que mejorará su reputación corporativa y su productividad. Las compañías que cuiden y formen mediante sesiones de entendimiento a su personal para trabajar con los grupos de interés serán socialmente más responsables e innovadoras que aquellas corporaciones donde solo se llevan a cabo debates corporativos (Kuzmin \& Khilukha, 2016). 
Llegado este momento, tras el tercer hito, se decide qué alternativa asociada a un pasillo y fase de ingeniería será construido. Cualquier cambio en el trazado que surja a partir de este momento puede suponer rehacer gran parte del trabajo de ingeniería que consta de la afectación territorial además de la componente eléctrica y mecánica del proyecto. Por esta razón es muy importante que haya una solución consensuada entre todas las partes.

\subsubsection{Fase de obtención de permisos sobre las parcelas}

En esta fase la escala de trabajo se acerca a la resolución de las parcelas catastrales y los grupos de interés son mayoritariamente los propietarios de las parcelas afectadas. Si no existe otro proyecto de IEAT que atraviese el mismo territorio los grupos de interés serán nuevos y tendrán que ser identificados y registrados. El servicio de la Sede Electrónica del Catastro (SEC, 2020) proporciona el ámbito geográfico de influencia y el nombre de cada uno de ellos, dando cumplimiento al primer hito de gestión de grupos de interés de esta fase. El plan de acción será muy parecido para la mayoría de los grupos de interés de esta fase derivado de su perfil de propietarios de parcelas afectadas, y está definido en el modelo corporativo de gestión de grupos de interés.

El segundo hito de gestión de estos grupos de interés comenzará con la publicación en medios oficiales o medios informativos locales, de la afectación de la futura instalación eléctrica sobre las parcelas de su propiedad. Una vez informados se procederá a una reunión personal para informar más detalladamente de cómo la nueva instalación afectará a las parcelas de su propiedad, y donde se cuantificarán las dimensiones de las servidumbres necesarias para el correcto uso y mantenimiento de la futura instalación. En este proceso iterativo se utilizarán los modelos, tal como define el flujo de trabajo basado en geodiseño para IEAT, que evalúan el impacto de la futura instalación sobre las parcelas catastrales. Las acciones en esta fase son las más relacionadas con la gente del lugar (Steinitz, 2012), que será la que conviva con la instalación.

El tercer hito abordará el mutuo acuerdo con la correspondiente compensación económica por las ocupaciones y servidumbres adquiridas y cuantificadas con anterioridad.

\subsubsection{Fase de construcción}

En esta fase los grupos de interés han sido identificados y registrados previamente, por lo que el primer hito de gestión se simplifica en cuanto a las pesquisas necesarias en otras fases. Los nuevos grupos de interés están relacionados con las ocupaciones temporales necesarias para obra, que derivan de las necesidades de acceso o acopio de material no contemplados durante el proyecto. Para ellos, el plan de acción consistirá en una extensión del plan aplicado en la fase obtención de permisos. El segundo hito de gestión de los grupos de interés está asociado a la cuantificación de los daños reales causados a las parcelas, su vegetación y/o construcciones durante la construcción. Este hito no será iterativo ya que, gracias a los modelos del flujo de trabajo basado en geodiseño para IEAT, se calculará la magnitud real de los daños causados por la construcción de la instalación, pudiendo así dimensionar la compensación económica a aplicar. El tercer hito servirá para compensar económicamente por los daños causados.

Aunque en esta fase se materializa el proyecto diseñado en fases anteriores, se hace necesario gestionar a diferentes grupos de interés de todas las fases. Un problema en la fase de construcción 
podría dar como resultado altos sobrecostes (Olander \& Landin, 2005) o incumplimientos de plazos en proyectos cuya puesta en servicio puede ser estratégica.

3.2.4.6 Síntesis de la integración de la gestión de grupos de interés en el marco de trabajo

Es en este flujo de trabajo basado en geodiseño para IEAT donde se unen todas las fases anteriores del enfoque metodológico y que sirve para retroalimentar el proceso ante un nuevo proyecto que atraviese un territorio ya analizado. Es decir, un grupo previamente identificado en otro proyecto, en cualquiera de sus fases, será automáticamente identificado como potencial grupo de interés para un nuevo proyecto que solape geográficamente con él. A su vez, cualquier acción llevada a cabo en el pasado con dicho grupo de interés en ese territorio tendrá una valoración de éxito. Esto permitirá orientar la estrategia a aplicarle en el nuevo proyecto.

En esta propuesta se quiere resaltar la importancia que tiene la caracterización y categorización de cada grupo de interés (poder, interés, impacto y estabilidad de la postura de cada grupo de interés) respecto del proyecto. También se destaca la importancia de identificar las interrelaciones entre los propios grupos de interés de cada proyecto, de asociar las acciones por grupo y fase del proyecto y, además, la importancia de visualizar todo el plan de actuación en conjunto para revisiones y ajustes.

\subsection{Notificaciones automáticas}

Considerando el número de proyectos, el número de procesos, el volumen de información a gestionar y el número de usuarios interesados en el seguimiento de cada proyecto, se hace necesario el establecimiento de un sistema de notificaciones automáticas.

Este sistema de notificaciones automáticas será el encargado de, cada vez que un proceso sea ejecutado enviar un correo electrónico, con asunto y cuerpo del mensaje predefinidos, informando de este evento.

A su vez, el sistema debe establecer una configuración "por defecto" para cada tipo de usuario. Es decir, no todos los procesos son de interés para todos los usuarios. Por este motivo, en función del perfil del usuario, el sistema de notificaciones establece un conjunto de suscripciones a los procesos de interés.

Cada usuario podrá modificar la configuración "por defecto" y personalizar, para cada proyecto, la suscripción a los procesos que considere de interés.

\subsection{Conclusiones}

Los entornos colaborativos aportan unas características al flujo de trabajo de una empresa que, bien aprovechadas, permiten aumentar el rendimiento global de todas sus unidades usuarias. El concepto de geodiseño lleva implícita la colaboración, por lo que diseñar GeoRED basado en este concepto aporta la posibilidad del consenso en todas las soluciones dependientes de diferentes grupos de interés. Permiten asimismo establecer procedimientos corporativos que darán homogeneidad a todos los resultados. Por otro lado, mediante la relación contenidos-usuarios, se 
hace posible crear espacios de trabajo con contenidos y usuarios restringidos a una temática específica. Estos usuarios pueden ser internos o externos, lo que permite incorporar a los proveedores a las metodologías y criterios de la compañía sin coste de licencias de software para éstos.

Actualmente GeoRED cuenta con cerca de 700 usuarios activos por mes, cuya participación sirve para una mejora continua y desarrollo de evolutivos que mejoran la usabilidad, eficiencia y funcionalidad del sistema global, mejorando la experiencia del usuario y la imagen de la compañía.

Los modelos y el flujo de trabajo basado en geodiseño para IEAT (Moreno-Marimbaldo, et al., 2018) definidos en trabajos previos, garantizan que los proyectos se desarrollan utilizando los mismos criterios corporativos, minimizando el uso de criterios personales de los técnicos en cada fase y obteniendo resultados más homogéneos y sostenibles. Es una realidad en el GIS corporativo (GeoRED), ya que permite representar, establecer escenarios de colaboración y aplicar modelos de geoprocesamiento de forma iterativa. Estos modelos responden a procesos que, desde el punto de vista técnico, se traducen en la ejecución de geoprocesos cuyos resultados describen la futura instalación desde diferentes puntos de vista.

La gestión geográfica de grupos de interés permite tratar la información geoespacial que los representa como una más de las variables a tener en cuenta en el desarrollo de proyectos de IEAT. Permite integrar a los grupos de interés con factores estratégicos, técnicos, económicos, sociales y ambientales en la gestión, buscando el desarrollo sostenible. De este modo se puede controlar el riesgo y la reputación de la compañía ya que se da a conocer la actividad y el valor aportado al mejorar la información y el acceso a la misma para los grupos de interés, se favorece la identificación de interlocutores, las percepciones y las actitudes de los grupos de interés ante un nuevo proyecto de desarrollo de la red de transporte de electricidad.

La incorporación de la gestión de grupos de interés en paralelo a la ejecución de los geoprocesos permite compartir la información generada por los geoprocesos con los diferentes grupos de interés en el momento en que ésta se genera. De esta forma, también se sistematiza y homogeniza la gestión de grupos de interés. Se les identificará, clasificará, se les asociará un plan de acción, y serán considerados parte integrante de los procesos iterativos buscando el consenso, de acuerdo con los criterios corporativos.

Tras integrar la gestión de los grupos de interés en GeoRED, éste permite a usuarios ajenos a la organización colaborar con los técnicos responsables de los proyectos a través de sus gestores corporativos. La incorporación de la gestión de grupos de interés en el flujo de trabajo basado en geodiseño para IEAT, posibilita que los portavoces o representantes de los grupos de interés encuentren su propio espacio de trabajo en el que, de forma simultánea a la ejecución de los geoprocesos, podrán expresar sus opiniones en relación con cada uno de los resultados, formando parte del proceso iterativo en el que todas las partes interesadas colaborarán para facilitar el consenso.

Gracias a este ejercicio de transparencia y colaboración, la compañía aplica un plan de acción diseñado y supervisado por el gestor corporativo para cada uno de los grupos de interés 
identificados y clasificados al inicio de cada fase del proyecto. Este plan se ejecuta en forma de acciones que vienen inducidas por la posición que cada grupo de interés ocupe en la matriz poder-interés, el impacto que pueda tener en el proyecto, y la estabilidad de su postura. Esto impone realizar un seguimiento, más o menos intenso, para asegurar que el tipo de acciones asignadas son las más adecuadas.

La figura del gestor corporativo de grupos de interés destaca como facilitador relevante en el flujo de trabajo basado en geodiseño para IEAT, ya que materializa y centraliza la interlocución que: acompaña internamente el desarrollo técnico de los proyectos y externamente trasmite las sensaciones de los grupos de interés a medida que avanzan las fases de desarrollo del proyecto.

De este modo se asegura que la gestión de los proyectos es única tanto para la parte técnica como para los grupos de interés, ya que la ejecución de los modelos alimenta tanto a los procesos técnicos como a los argumentos que ayudan a explicar el proyecto hacia el exterior.

La metodología ha sido aplicada a 13 proyectos distribuidos por la geografía nacional y de diferentes tipos: aéreos, subterráneos, submarinos y mixtos. El ensayo con estos proyectos ha permitido mejorar la metodología y validarla, iniciando el cambio hacia una forma más sostenible de acometer los proyectos de desarrollo de la red de transporte de energía eléctrica.

Todo ello muestra un compromiso institucional firme con la sostenibilidad (social, técnicoeconómica y ambiental), encaminado a cumplir con el apoyo al desarrollo de la sociedad y de la conservación de su capital natural. 


\section{IMPLEMENTACIÓN Y RESULTADOS}

\subsection{Introducción}

El uso de la información geográfica para la gestión de activos de la red de transporte de electricidad ha experimentado un auge, todavía creciente, en los últimos 10 años. Este uso no se refiere únicamente a la visualización, sino a los productos derivados del análisis de este tipo de información y las herramientas que han automatizado los procedimientos corporativos que han sido, a su vez, interpretados como modelos de procesamiento de información geográfica o "geoprocesamiento".

Tanto la información como las herramientas deben gestionarse respondiendo a una estructura acorde al desarrollo de los proyectos de Infraestructuras Eléctricas de Alta Tensión (IEAT) que permita la recuperación y explotación rápida, la colaboración, la comunicación y la trazabilidad a lo largo de sus fases.

El marco de trabajo propuesto se implementa sobre la base tecnológica que ofrece el SIG corporativo y significando el portal único de acceso a la información geográfica de los proyectos de IEAT. Tiene la misión de gestionar la estructura de datos y las herramientas definiendo un flujo de trabajo capaz de guiar a los técnicos responsables en cada fase. También, constituye el medio por el cual se vinculan directamente los grupos de interés existentes en cada territorio con las alteraciones que un proyecto de IEAT provoca en el mismo.

Globalmente, este marco de trabajo constituye un sistema para la generación de productos para la visualización y cálculo de indicadores de afectación a los entornos que describen el territorio y que ayudarán a la toma de decisiones.

\subsection{El concepto GeoRED}

El SIG corporativo de REE, GeoRED, ha sido diseñado con la premisa de poder activar los mecanismos de retroalimentación-iteración-consenso que forman parte del concepto de geodiseño. Asimismo, considerando la importancia creciente de la interoperabilidad de información geográfica de los últimos años, se trata de un SIG que es capaz de integrar, en el mismo entorno, los diferentes SIG internos o externos a la organización.

Aunque el diseño de esta plataforma no sigue ningún marco de geodiseño, ni tiene integrados procedimientos homogéneos para cada fase de los proyectos, y los procedimientos aplicados dependen de los criterios del miembro del personal técnico responsable, aporta la base tecnológica y los mecanismos de visualización y de colaboración sobre los que construir e implementar el marco de trabajo basado en geodiseño para IEAT, además de dar soporte tecnológico a la gestión de los grupos de interés.

Dado que los flujos de información geográfica generada en las fases del proyecto de una nueva IEAT han sido ya establecidos, estos se han ido implementando, conforme se ha ido modelando y validando la metodología objeto del Enfoque metodológico, como un conjunto de procedimientos a seguir en cada nuevo proyecto. Para facilitar la gestión y el almacenamiento de 
toda la información geográfica se ha implementado el SIG corporativo de la compañía, GeoRED. Este fue diseñado también para cubrir las necesidades de la colaboración de las partes interesadas. Está respaldado por la información geográfica que facilita la colaboración y la comprensión de la realidad geográfica mediante el uso de mapas y herramientas visuales y de geoprocesamiento, posibilitando realizar ciclos iterativos de diseño hasta que los participantes alcancen un consenso (Nyerges, et al., 2016). También tiene la capacidad de representar, en un único entorno, los requisitos de las diferentes partes interesadas. Así, a través de los gestores corporativos de grupos de interés, aporta un enfoque metodológico alternativo para investigar cómo involucrar a diferentes actores, desde técnicos hasta actores locales, en un proceso abierto y participativo. Esta participación facilita la transparencia y la visibilidad en las diferentes decisiones y responsabilidades.

En este entorno colaborativo, además de las herramientas gráficas que permiten a los usuarios interactuar con el territorio, se incorporan otro tipo de herramientas que:

i) ayudan a tomar decisiones respetando la legislación vigente en distintos ámbitos (medioambientales, riesgos, urbanísticos, etc.),

ii) valorar distintas alternativas desde un punto de vista ingenieril $y$,

iii) aplicar metodologías corporativas consolidadas, ejecutando procedimientos homogéneos para todas las fases de los proyectos.

La Figura 4-1 muestra ejemplos de la interfaz gráfica de GeoRED.
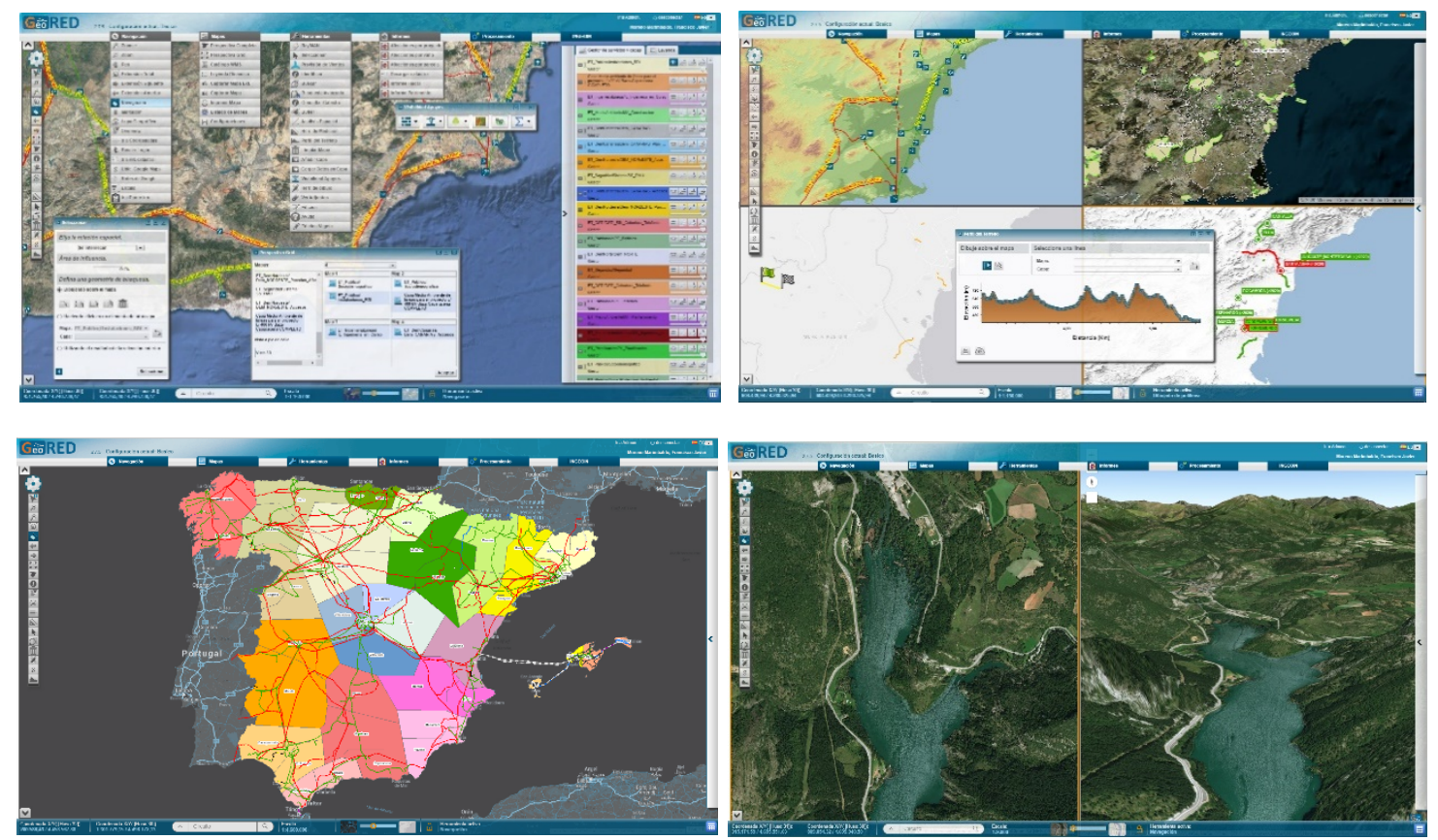

Figura 4-1. Interfaz gráfica de GeoRED

GeoRED materializa en un entorno de geodiseño (Artz, 2010) colaborativo, los procesos de colaboración existentes en cada proyecto. Se han identificado las herramientas que debe ofrecer una plataforma web, que ayude en la toma decisiones consensuadas entre todos los grupos de 
interés que intervienen en un proyecto de IEAT, y facilitar el flujo de información geográfica entre estos grupos de interés.

Permite integrar la información geográfica de las diferentes unidades organizativas de la compañía. Esta información geográfica es la representación de "cosas" que hay en el mundo real. Estas "cosas" pueden representarse gracias a la abstracción de la realidad que realizamos por medio de los modelos de datos. En GeoRED, pueden convivir tantos modelos de datos de entidades geográficas como sea necesario. De esta manera, todas las unidades organizativas tienen cabida en el sistema.

En GeoRED se realiza una gestión de contenidos (geográficos) relacionada con la gestión de usuarios. El objetivo de esta relación es la distribución de la responsabilidad de la información a los respectivos responsables, para integrarla en un mismo sistema. De esta forma, la asociación de perfiles de usuarios a los contenidos hace que se generen espacios virtuales de trabajo para cada temática o proyecto en los que un grupo reducido de personas trabaja de forma colaborativa para alcanzar soluciones de consenso. Estas personas pueden pertenecer o no a la organización, es decir, GeoRED permite la colaboración de usuarios internos con usuarios externos a la organización.

Cada servicio de mapa está compuesto por una serie de capas. Cada una de éstas representará la abstracción de una realidad que se apoyará en la simbología para facilitar su entendimiento. Se puede así entender que un servicio de mapa es una agrupación de capas, un espacio de trabajo es una agrupación de servicios de mapas y, por tanto, GeoRED es la agrupación de todos los espacios de trabajo. De cara a su relación con el exterior, GeoRED permite integrar los espacios de trabajo internos con los externos que cumplan con los estándares OGC (OGC, 2020).

Considerando que cada servicio de mapa es un SIG en sí mismo, GeoRED es un SIG que hace convivir a los diferentes SIG de las diferentes unidades organizativas entre sí, y con los SIG de los diferentes grupos de interés externos. GeoRED es, por tanto, un SIG de SIGs.

De esta manera, en cada fase del flujo de la información geográfica de una IEAT, podremos crear un espacio de trabajo para todos los grupos de interés (internos y externos) de cada instalación.

El crear un espacio de trabajo significa dar la capacidad de activar los mecanismos de retroalimentación-iteración-consenso en los que se basa el concepto de geodiseño, que ocurre cuando hay diferentes grupos de interés involucrados cuyos puntos de vista o intereses no son coincidentes. En cada una de las fases hay un conjunto de grupos de interés diferente, que deben convivir en el entorno.

En GeoRED, cada fase del proyecto contará con, al menos, un servicio de mapa que estará enmarcado en el espacio de trabajo correspondiente a la fase del proyecto en cuestión. Los servicios de mapa se identifican en el gestor de servicios y capas por medio de cajas cuyos colores pueden configurarse para una mejor gestión de estos. La Figura 4-2 muestra la convivencia de todos ellos. 


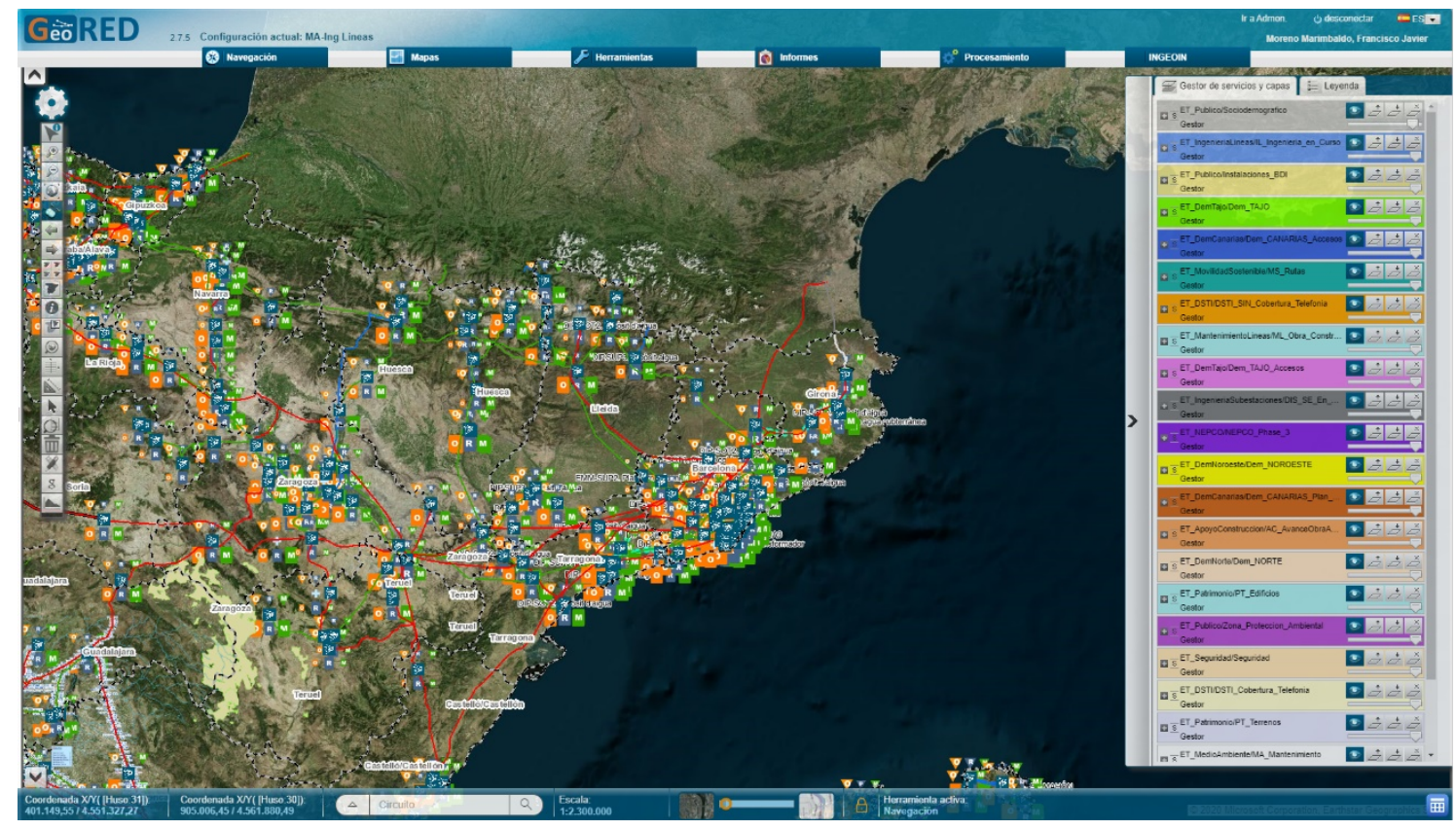

Figura 4-2. Convivencia de diferentes servicios de mapa para colaboración

Los grupos de interés se relacionan con los contenidos a través de asignación de roles. De esta forma, puede haber usuarios con capacidad de lectura o de lectura/escritura. Estos permisos son asignados por los binomios usuario-servicio de mapa. Esta posibilidad permite que un único usuario tenga diferentes roles, cada uno de ellos será asignado en función del servicio de mapa al que haya que darle acceso. Esta flexibilidad permite que un usuario pueda trabajar con diferentes servicios de mapa simultáneamente, con un permiso de acceso diferente para cada uno.

En GeoRED, los contenidos (servicios de mapa o mapas) se clasifican en carpetas o espacios de trabajo que pueden asociarse a las actividades de las unidades organizativas. Cada unidad organizativa que necesite de información geográfica para su gestión podrá contar con tantos mapas como necesite. Cada mapa contendrá una serie de capas que, por su temática, se agrupan en este y se independizan de otros mapas. Todos los usuarios de una unidad organizativa, por tanto, de su espacio de trabajo, tienen acceso de consulta a todos los mapas de este. Algún usuario de este espacio de trabajo podrá tener permisos de edición sobre uno o varios mapas de este. También, por necesidades de trabajo, usuarios de unas unidades organizativas podrán tener acceso a alguno de los mapas de otra. Aquí se establece un escenario de colaboración en el que la información geográfica de diferentes unidades organizativas coexiste en el mismo entorno, cada una con sus responsables de actualización, y donde GeoRED permite el análisis espacial de unas con otras.

También es posible que, por necesidades del trabajo, se permita la edición de un mapa a un usuario de una unidad organizativa ajena, creándose otro escenario de colaboración donde usuarios de unidades organizativas diferentes pueden actualizar el mismo mapa.

Si bien todos los usuarios de la compañía tienen acceso de consulta a todos los mapas del espacio de trabajo público, cada unidad organizativa o espacio de trabajo tiene un gestor que asigna los permisos de acceso a los mapas que gestiona. 
La Figura 4-3 muestra cómo se pueden relacionar los contenidos con los usuarios, teniendo gran flexibilidad de colaboración entre las diferentes temáticas gestionadas por GeoRED, donde las flechas rojas significan permisos de consulta y las verdes de edición.

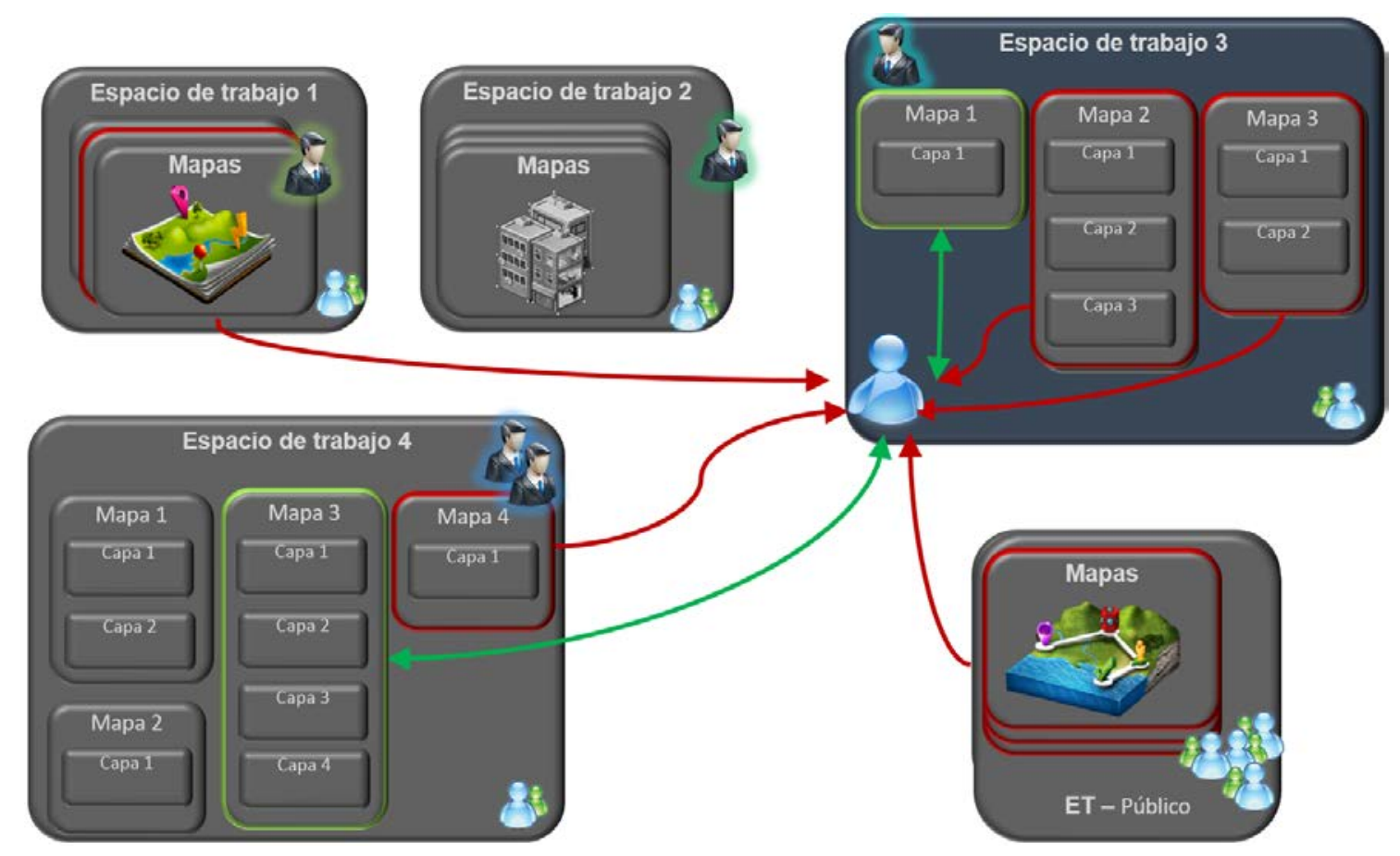

Figura 4-3. Relación de los contenidos con los usuarios

El geodiseño se hace patente en los escenarios de colaboración, de discusión, de negociación y consenso que genera GeoRED en la simultaneidad de hacer convivir diferentes servicios de mapa de los diferentes grupos de interés.

Cada proyecto tendrá sus propias características, por lo que los grupos de interés serán diferentes en cada proyecto. GeoRED permite crear tantas configuraciones de servicios de mapa como sea necesario.

Además del objetivo de gestionar, en el mismo entorno, todos los servicios de mapa necesarios en un proyecto, GeoRED tiene un objetivo más concreto en cuanto a su funcionalidad como SIG corporativo. Este objetivo es la definición y gestión de los procedimientos geográficos corporativos. De esta manera se pretende que todos los proyectos se desarrollen bajo los mismos criterios. Estos criterios deben ser corporativos con la intención de minimizar la importancia de criterios personales de los técnicos responsables, en favor del criterio corporativo, que dará homogeneidad a los resultados de todos los proyectos.

La Figura 4-4 muestra ejemplos de diferentes configuraciones en el mismo entorno GeoRED. 

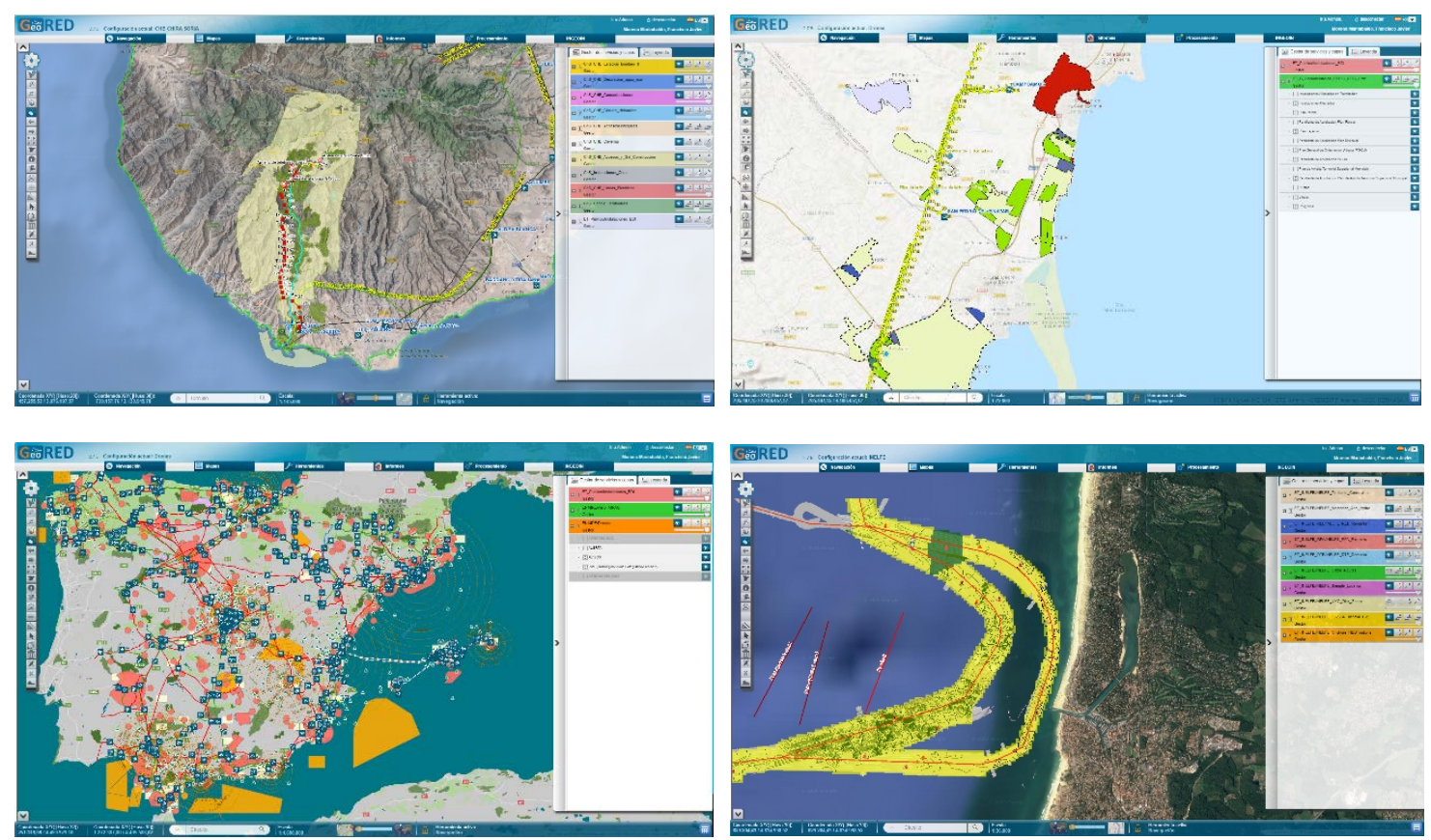

Figura 4-4. Diferentes configuraciones de servicios de mapa

Para que los mecanismos de retroalimentación-iteración-consenso se activen cuando diferentes grupos de interés trabajan de modo colaborativo, es necesario que haya un marco de trabajo que sistematice el proceso.

Las herramientas de colaboración constituyen un conjunto de soluciones que permiten a las organizaciones crear espacios de trabajo en grupo para compartir, almacenar y buscar información, mejorando la eficiencia organizativa y las relaciones de negocio. Los entornos colaborativos cada vez están más presentes en el conjunto de soluciones que las organizaciones adoptan para optimizar y mejorar las actividades derivadas de la comunicación y gestión del conocimiento de la empresa.

Uno de los factores que hay que tener en cuenta a la hora de implantar una solución colaborativa es la complejidad del entorno. Otro de los factores que hay que tener en cuenta es la cantidad de información que circula por los sistemas de una empresa. Por regla general, esta cantidad va en función de la actividad que realiza la empresa, y en el ámbito de actuación de esta.

La sensibilidad de la información juega también un papel fundamental y, en cualquier caso, la forma en que se procesa y se accede a la información debe ajustarse a la Ley Orgánica de Protección de Datos. Los administradores del sistema tienen la responsabilidad de gestionar los permisos de acceso para que únicamente los usuarios autorizados puedan visualizar la información sensible.

La gestión de usuarios y el establecimiento de una política de seguridad adecuada es garantía de buen funcionamiento de un entorno colaborativo. Los administradores del sistema deben garantizar la integridad y la confidencialidad de la información sensible. Las soluciones existentes que proporcionan un entorno colaborativo disponen de características de seguridad que permiten gestionar usuarios, establecer permisos y bloquear el acceso a cualquier información por parte de 
una persona no autorizada. Normalmente, los sistemas de autentificación basados en nombre de usuario y contraseña son los más extendidos y, en caso de ser usados de forma correcta, suponen una medida más que suficiente para garantizar los niveles de seguridad.

GeoRED ha sido concebida, también, para servir de herramienta de comunicación y para mejorar el entendimiento de los proyectos. Un ejemplo es la incorporación de un visor 3D y una sincronización con Google Earth y Google Street View. La Figura 4-5 muestra el sistema con las tres vistas sincronizadas.

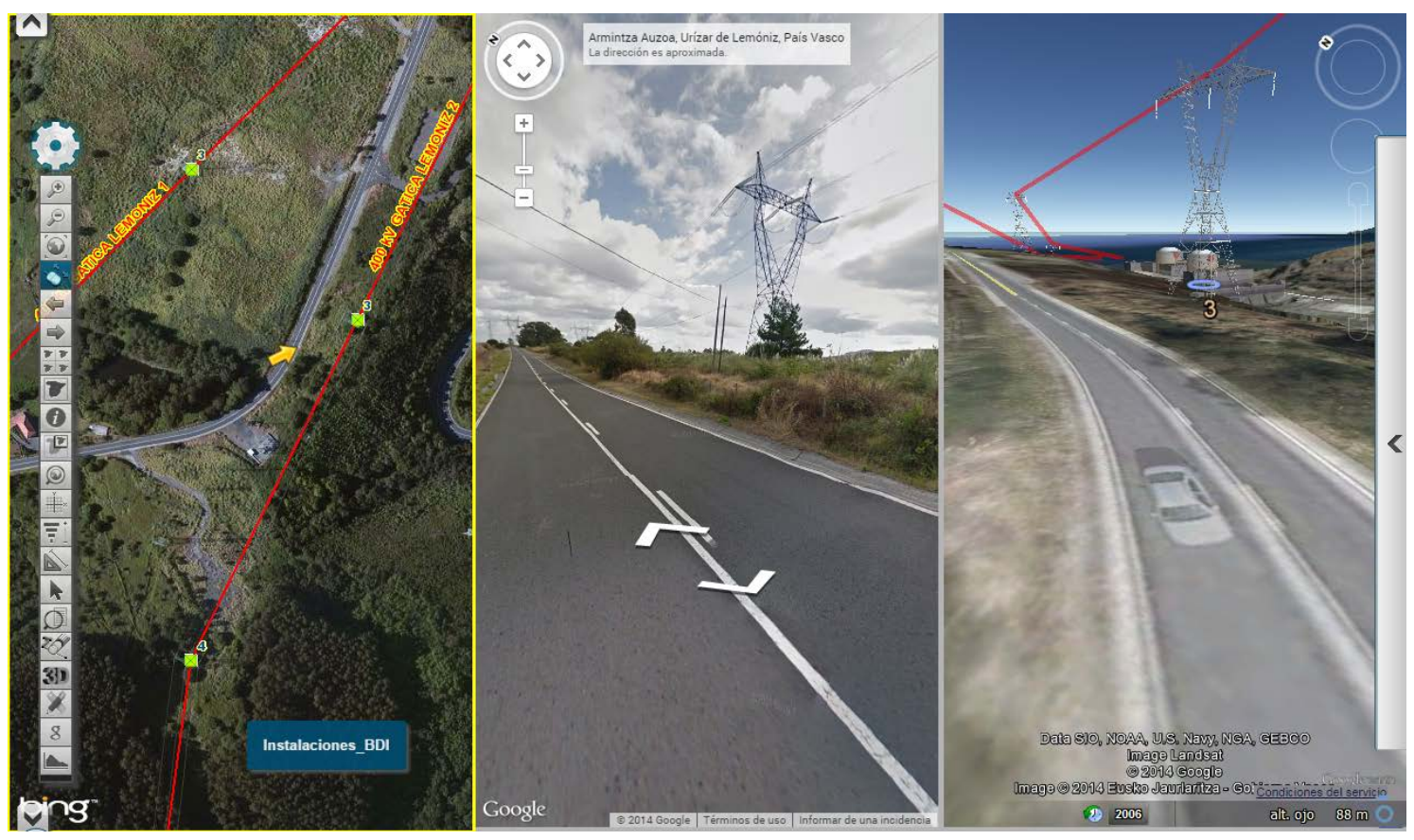

Figura 4-5. Vistas 2D, 3D y Google Street View sincronizadas

\subsubsection{Metodología de diseño de la implementación}

GeoRED nace por la necesidad de gestionar la información geográfica asociada a las infraestructuras de la Red de Transporte de energía eléctrica en España. Esta información responde a un modelo de datos diferente para cada una de las fases de los proyectos de nuevas infraestructuras y es generada, actualizada y tratada por un número elevado de técnicos que están distribuidos en el territorio.

Con el objetivo de dar soporte a todos los técnicos de todas las fases de los proyectos y a todos los técnicos usuarios de información geográfica durante la vida útil de las instalaciones, la herramienta a diseñar debía satisfacer las necesidades existentes y estar preparada para ampliaciones futuras. En este sentido, el método seguido para su diseño se compone de las siguientes fases:

- Definición del contexto

La estructura de REE es territorial, es decir, además de los técnicos de las oficinas centrales, existen técnicos de los departamentos responsables de los proyectos en el territorio y que son coordinados por los primeros. Esto provocaba una descentralización 
de la información. Se trataba de crear una herramienta que diluyese la distancia física centralizando y homogeneizando la información bajo criterios únicos.

- Análisis de requerimientos

Los requerimientos mínimos indispensables eran marcados por las necesidades ya cubiertas por los anteriores procedimientos. Se trataba entonces de, analizando las necesidades no cubiertas, dotar a REE de procedimientos y herramientas para satisfacerlas.

- Permitir identificar y registrar a los diferentes grupos de interés

En cada proyecto de infraestructuras eléctricas existen diferentes grupos de interés, tanto del ámbito energético como del ámbito social y normativo. Había, por tanto, grupos de interés internos, alineados con las necesidades e intereses de REE, como grupos de interés externos, que en algún caso pueden representar una oposición al desarrollo de la RdT.

- Modelar las relaciones entre grupos de interés

Cada grupo de interés tiene un papel determinado en cada proyecto y, por el propio desarrollo de este, se generan espontáneamente una serie de relaciones en las que estos grupos de interés tienen que colaborar, negociar y llegar a soluciones de consenso. Estas relaciones pueden ser de tipo técnico, económico, político e incluso de intereses personales. La transparencia de las partes es fundamental en el desarrollo del proyecto.

- Propuesta del marco de trabajo El marco de trabajo persigue dos objetivos complementarios. Por un lado, definir qué tipo de información se gestiona, su responsable, su formato, su origen y destino, y su precisión, y por otro lado definir procedimientos corporativos homogéneos para todos los proyectos.

- Implementación

La implementación supone la materialización de los conceptos en herramientas de trabajo alineadas con todas las fases anteriores.

\subsection{Implementación del marco de trabajo basado en geodiseño para IEAT}

La implementación del marco de trabajo basado en geodiseño para IEAT se materializa en una consola, que gestiona la información geográfica de los proyectos, cuyo objetivo es automatizar las tareas del ciclo de vida de proyectos de línea eléctrica o subestación, desde su planificación hasta su construcción.

\subsubsection{Consola o gestor de información geográfica de los proyectos}

Desde las distintas fases del proyecto, implementadas en la consola, se pueden ir ejecutando los procesos a través de un flujo predeterminado e ir visualizando los resultados. En la Figura 4-6 y, para mejor visualización, por fases en las figuras Figura 4-6 (a), Figura 4-6 (b), Figura 4-6 (c) y Figura 4-6 (d), se muestra la consola desarrollada, con todos los controles en cada cuadro de mando. 

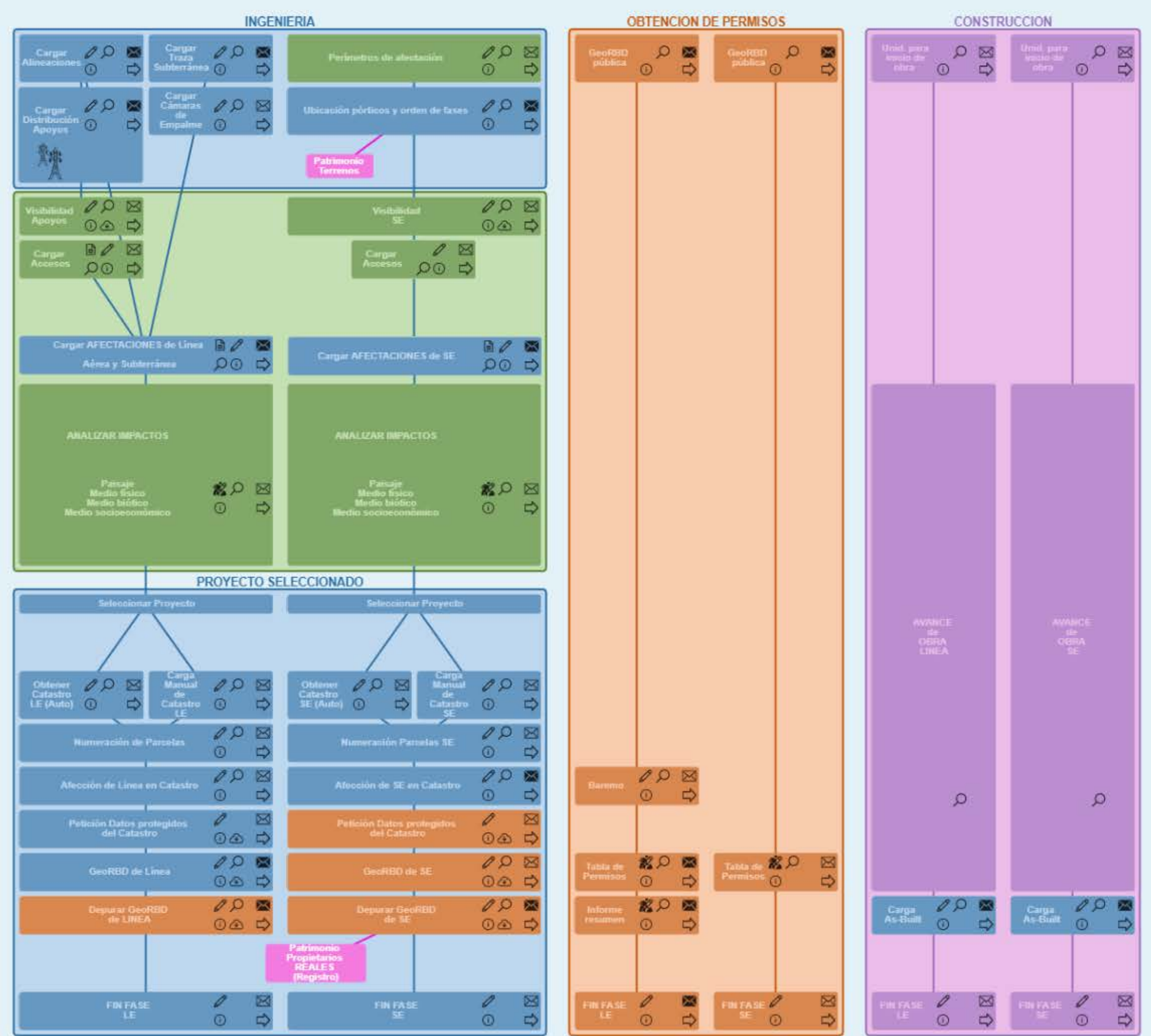

DC 220 Costa de la Luz - Puebla de Gurmán
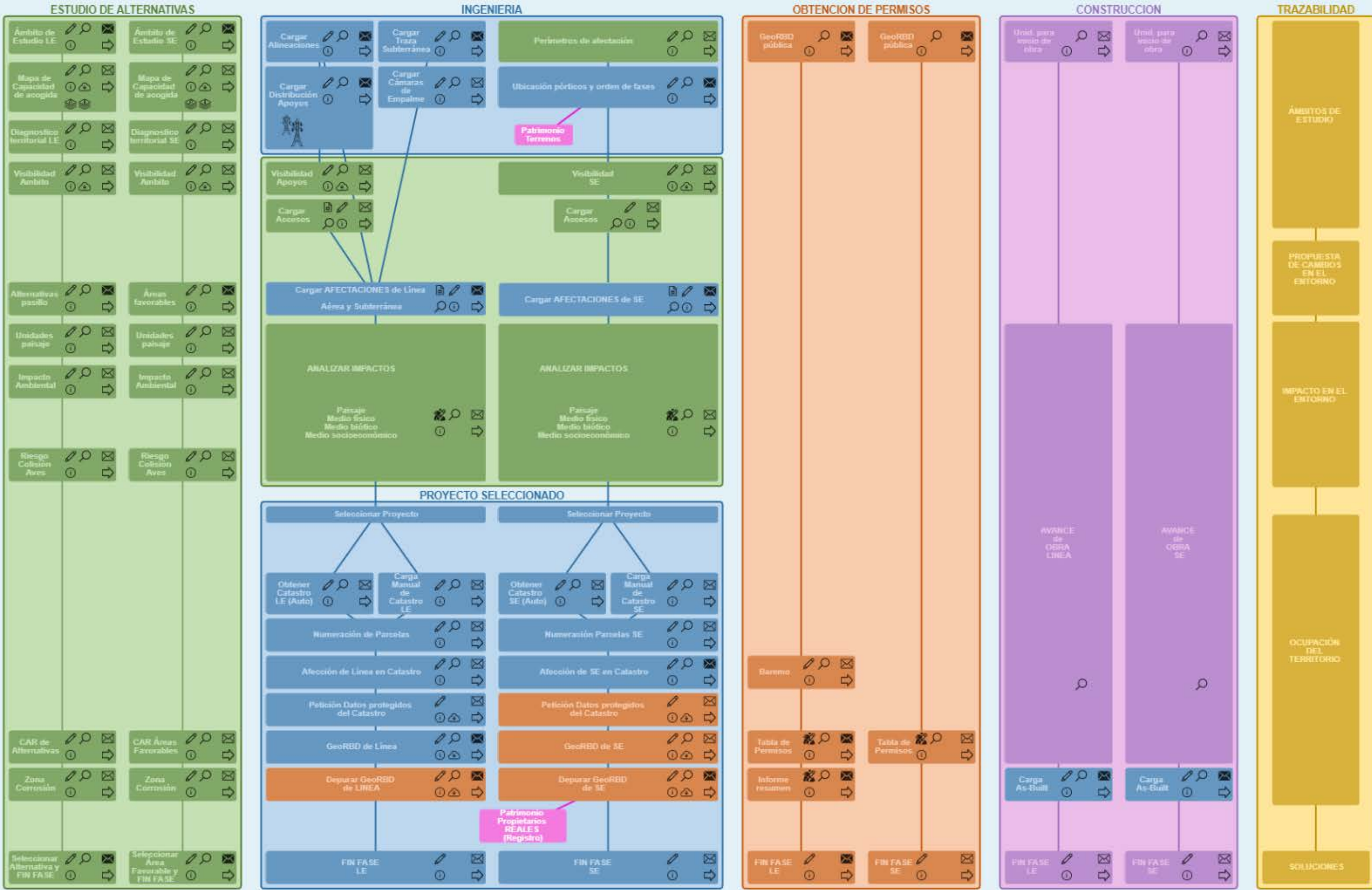

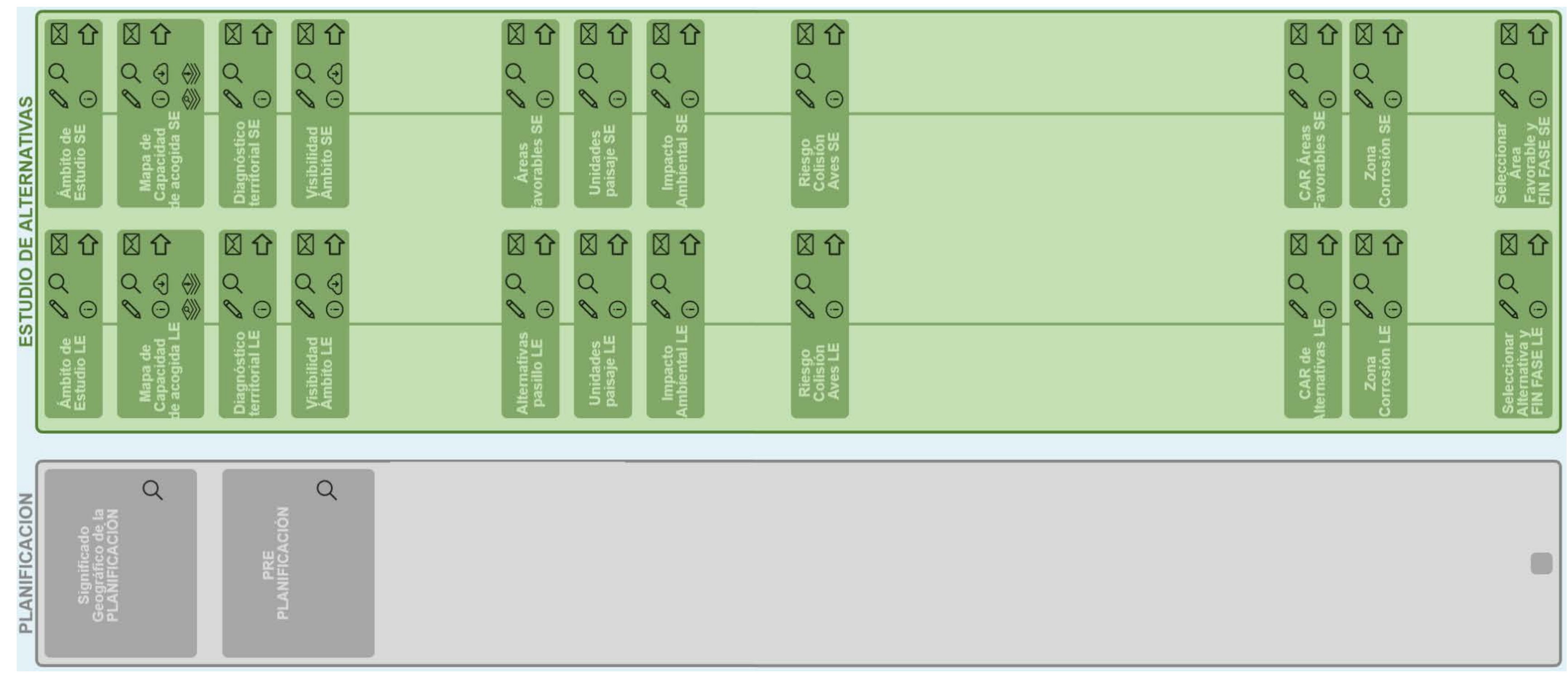

Figura 4-6 (a). Consola para gestionar la información geográfica de los proyectos (Fases Planificación y Análisis ambiental de alternativas) 


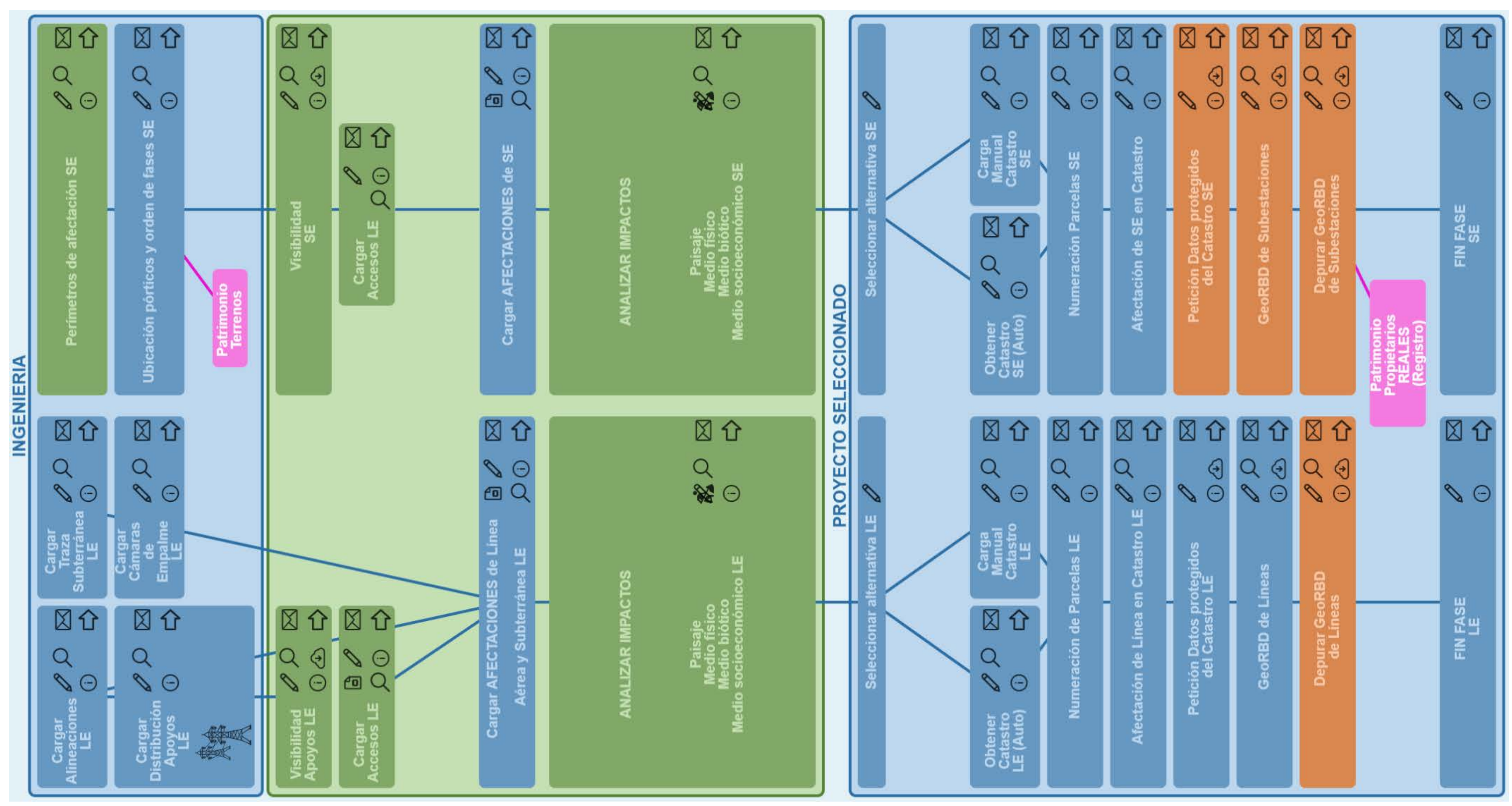

Figura 4-6 (b). Consola para gestionar la información geográfica de los proyectos (Fase Definición del proyecto de ingeniería) 


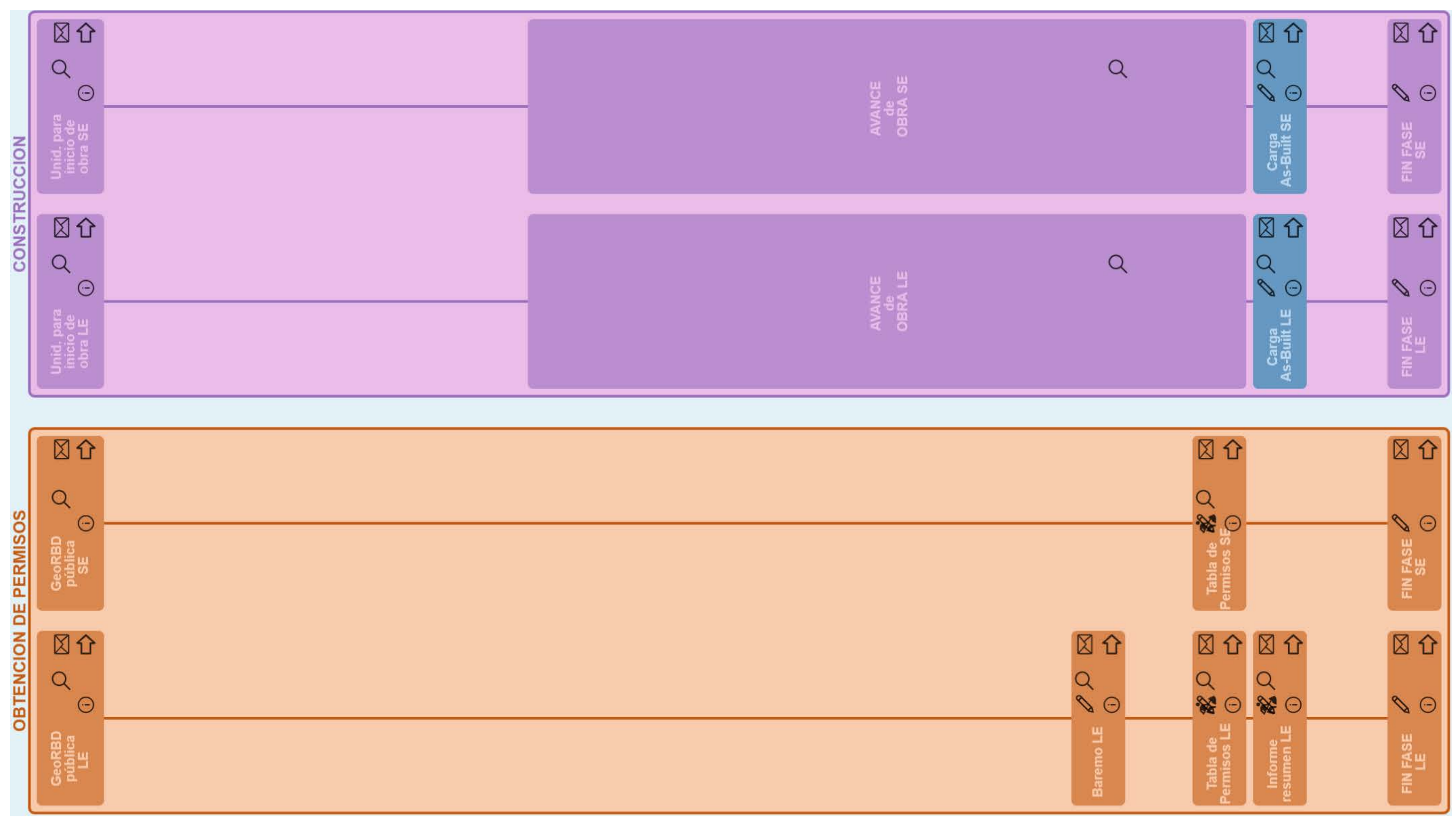

Figura 4-6 (c). Consola para gestionar la información geográfica de los proyectos (Fases Obtención de permisos sobre las parcelas y Construcción) 


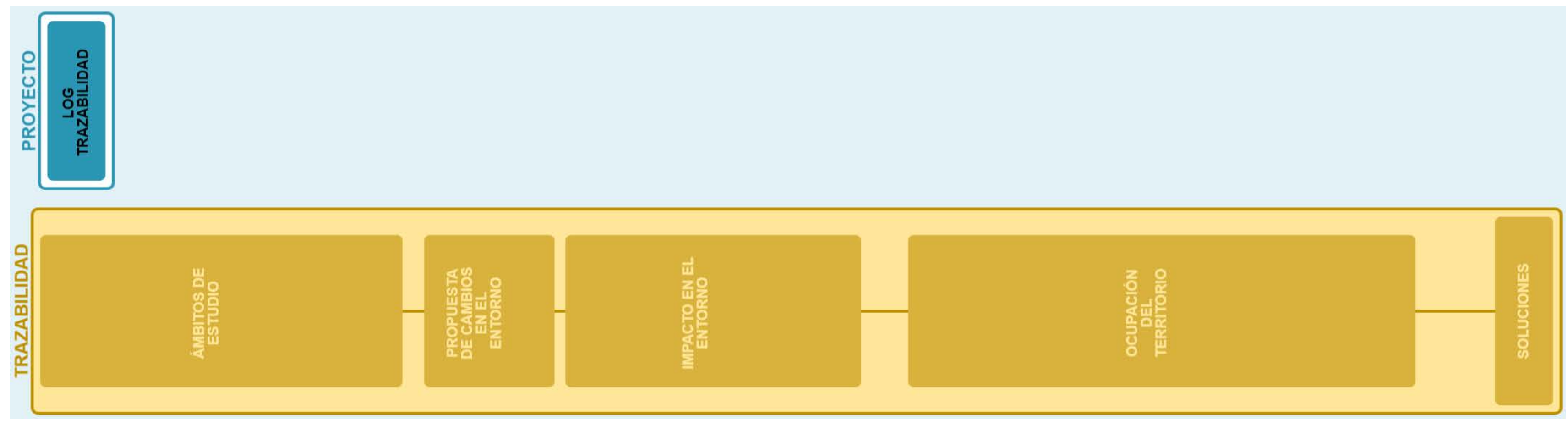

Figura 4-6 (d). Consola para gestionar la información geográfica de los proyectos (Trazabilidad de la información geográfica y de la ejecución de procesos del proyecto) 
En la consola podemos encontrar cuatro fases operativas y dos fases no operativas. Las operativas son las que contienen geoprocesos que serán ejecutados por los técnicos responsables, a diferencia de las no operativas cuyos controles se ejecutan automáticamente por el sistema. En la fase de planificación se ejecuta una sola vez cuando hay una nueva planificación eléctrica, y la fase complementaria de trazabilidad mostrará la información almacenada, por tipo de modelo, por la ejecución de los geoprocesos. Estas fases son las siguientes:

- Operativas

o Estudio de alternativas o medio ambiente (verde)

o Ingeniería (azul)

o Obtención de Permisos (naranja)

o Construcción (morado)

- No operativas:

o Planificación (gris)

o Complementaria de trazabilidad (amarilla)

En cada una de las fases operativas se observan 2 columnas bien definidas. La de la izquierda corresponde siempre a proyectos de línea y la de la derecha a proyectos de subestación.

Por último, y como columna adicional, podemos encontrar el "Log de trazabilidad" que permite el acceso a los registros de trazabilidad de todos los procesos ejecutados en el proyecto, añadiendo la fase del proyecto, el usuario que lo ejecutó, la valoración del resultado, el mensaje que el usuario escribió y la fecha de la ejecución.

\subsubsection{Acceso a la consola}

El acceso a la consola de INGeoIN (INformación Geográfica de INstalaciones) se realiza a través de la barra de herramientas "INGEOIN" de GeoRED, por medio de la opción "Selección de Proyecto". Facilita la selección del proyecto con el que se desea trabajar. La Figura 4-7 muestra el menú que despliega el acceso a la selección de proyectos a gestionar.

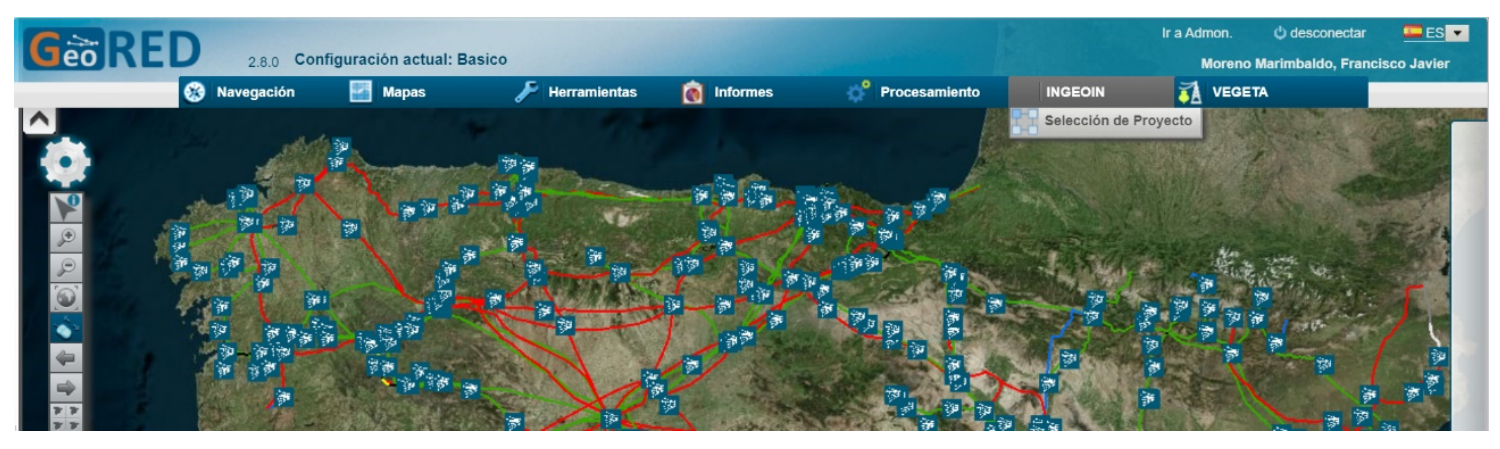

Figura 4-7. Ejemplo de cuadros de mando de la consola

La interfaz mostrada en la Figura 4-8 permite realizar un filtrado de los proyectos existente por tipo, nombre o códigos internos de gestión. Esta interfaz también permite generar proyectos nuevos para realizar estudios al margen de los planificados. 


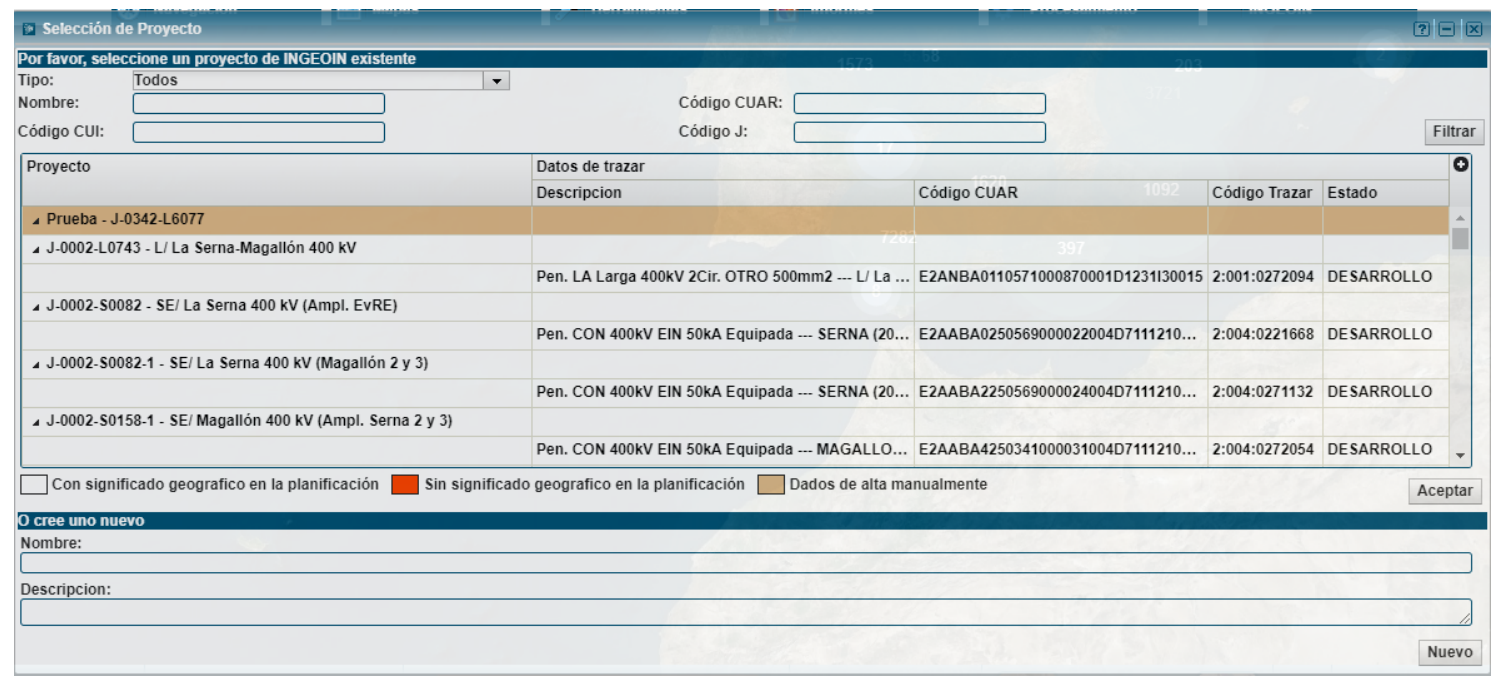

Figura 4-8. Selector de proyectos

El acceso se produce al seleccionar un proyecto y "Aceptar". En función del perfil de cada técnico, éste dispondrá en INGeoIN acceso a la ejecución de las herramientas que le correspondan según esté configurado.

\subsubsection{Funcionalidades comunes}

El significado de la simbología de los controles de los procesos se muestra en la Tabla 4-1.

\begin{tabular}{|c|c|}
\hline \multirow{2}{*}{ Icono } & Descripción \\
\hline & Controles comunes a todos los cuadros de mando \\
\hline & $\begin{array}{l}\text { Ejecuta el proceso Python asociado a cada proceso. Se pueden pedir parámetros de entrada o activar la } \\
\text { herramienta de dibujo de GeoRED }\end{array}$ \\
\hline & Visualiza los resultados de la ejecución del proceso en un servicio de mapa \\
\hline & $\begin{array}{l}\text { Descarga en un archivo zip los resultados de la ejecución del proceso: mapas ráster y datos protegidos } \\
\text { de Catastro }\end{array}$ \\
\hline & $\begin{array}{l}\text { Muestra en una ventana el log de trazabilidad de cada proceso, qué usuario lo ha ejecutado, si se ha } \\
\text { ejecutado correctamente o no, el mensaje que el usuario puede añadir y la fecha de la ejecución }\end{array}$ \\
\hline$\overline{\Delta x}$ & El usuario se suscribe o deja de suscribirse a las notificaciones automáticas tras la ejecución del proceso \\
\hline & $\begin{array}{l}\text { Permite enviar aviso del resultado de la ejecución del proceso a un usuario o lista de usuarios. } \\
\text { Complementa el envío de notificaciones automáticas }\end{array}$ \\
\hline & Controles específicos \\
\hline & $\begin{array}{l}\text { Mapa de capacidad de acogida: se muestra en un servicio de mapa las capas vectoriales que participan } \\
\text { en el cálculo del mapa de capacidad de acogida }\end{array}$ \\
\hline & $\begin{array}{l}\text { Mapa de capacidad de acogida: se descarga comprimida una geodatabase-gdb con las capas vectoriales } \\
\text { que han participado en el cálculo del mapa de acogida }\end{array}$ \\
\hline 回 & Descarga de plantilla para ejecutar los procesos de Carga de accesos y Carga de Afectaciones de línea \\
\hline & Se visualiza la distribución de apoyos en 3D una vez cargada \\
\hline$n$ & Herramienta que formará parte del flujo y que se encuentra en fase de desarrollo \\
\hline
\end{tabular}

Tabla 4-1. Significado de simbología de controles 


\subsubsection{Procesos}

Cada proceso perteneciente a una fase se encuentra representado en la consola como un pequeño cuadro de mando que contiene controles (botones) que lo dotan de funcionalidad. Los geoprocesos o conjunto de geoprocesos que se ejecutan son transparentes para el usuario y el color indica el tipo de perfil de usuario que podrá ejecutarlo. Además, cuando un proceso ha sido ejecutado mantiene su color, pero oscurece el tono, por lo que rápidamente se detecta en qué estado concreto se encuentra el desarrollo del proyecto. La Figura 4-9 (a) muestra ejemplos de cuadros de mando antes de su ejecución y la Figura 4-9 (b) después de la ejecución.

(a)

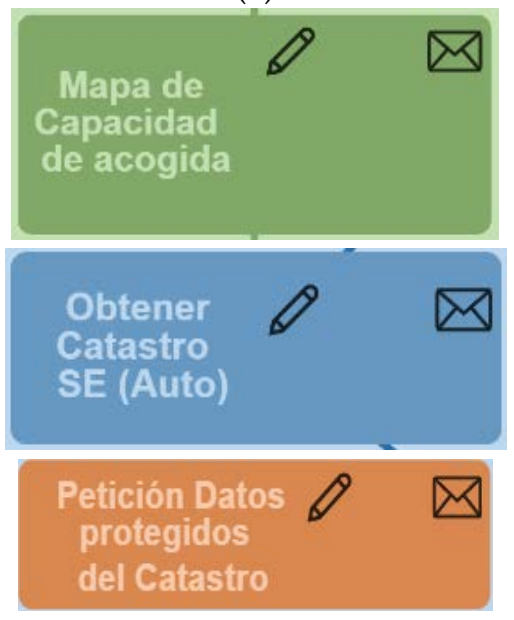

(b)

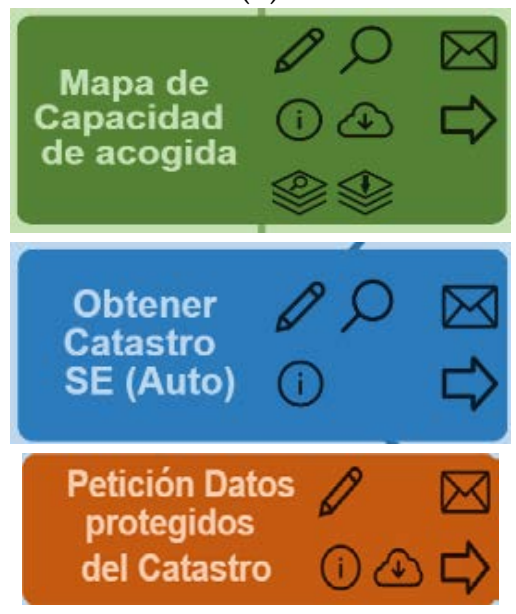

Figura 4-9. Ejemplo de cuadros de mando de la consola antes y después de su ejecución

Los procesos de una fase se ejecutan de manera secuencial a través de un flujo definido.

La única funcionalidad que está disponible al iniciar por primera vez una fase será el lápiz de ejecución. Al ejecutar un proceso, el sistema mostrará al usuario el modo Mapa de GeoRED donde, a través de un formulario o widget, se le solicitarán los parámetros de entrada necesarios para la ejecución del geoproceso, si los necesitara: archivos en formato Shapefile, cuadros de texto o geometrías, (en este último caso estará disponible el widget de edición de GeoRED).

Como norma general, la ejecución de unos procesos habilitará la ejecución del siguiente en la secuencia de cada fase, consiguiendo así homogeneidad en la ejecución de los proyectos.

En cualquier cuadro de mando, si se ejecuta nuevamente el proceso de carga o generación de resultados, la información cargada o generada con anterioridad será sobrescrita, siendo necesario justificar esta acción que quedará registrada en la trazabilidad del proyecto.

Una vez realizada la ejecución aparecerá, en el cuadro de mandos del proceso, la siguiente funcionalidad:

1. Botón Lupa: Visualizar resultados en GeoRED

2. Botón Información: Ver log de ejecución de esa herramienta

3. Botón Descarga: Descarga de resultados, si el cuadro de mando lo permite

4. Además, según la caja aparecerán otros botones específicos de cada proceso. 


\subsubsection{Gestión de usuarios}

La gestión de información geográfica que realiza GeoRED está basada en la estructura de contenidos definida por los siguientes conceptos:

- Capa de información geográfica: geometrías con un modelo de datos asociado que se utiliza para representar entidades con significado geográfico.

- Servicio de mapa o, simplemente, mapa: conjunto de capas que, por su contenido, se agrupan para ser gestionadas de forma agrupada. Cada servicio de mapa responde a una temática concreta.

- Espacio de trabajo: Contenedor de servicios de mapa de una unidad organizativa.

Los roles definidos en GeoRED para el acceso a los contenidos geográficos son los siguientes:

- Gestor de espacio de trabajo: Con capacidad para gestionar el acceso de usuarios a los mapas de su espacio de trabajo. Los usuarios dados de alta en un espacio de trabajo tienen acceso a todos los mapas de este.

El gestor puede otorgar acceso, a alguno de los mapas del espacio de trabajo, a usuarios de otras unidades organizativas

- Editor de mapa: Con capacidad para editar cualquier capa del mapa sobre el que gestor le ha otorgado permiso de escritura.

- Lectura de mapas: Con capacidad de consulta de todas las capas del mapa sobre el que tiene permiso de lectura.

La gestión de usuarios de este gestor de información geográfica de proyectos se basa en la funcionalidad que aporta GeoRED.

Los espacios de trabajo definidos son los siguientes:

- INGEOIN Planificación $\rightarrow$ fase Planificación

- INGEOIN Medio ambiente $\rightarrow$ fase Análisis ambiental de alternativas

- INGEOIN Ingeniería $\rightarrow$ fase Definición del proyecto de ingeniería

- INGEOIN Permisos $\rightarrow$ fase Obtención de permisos

- INGEOIN Construcción $\rightarrow$ fase Construcción

El acceso a las funcionalidades de la consola se gestiona según el perfil y el rol que cada usuario tenga. Los perfiles, mostrados en la Tabla 4-2, están asociados a las fases de proyecto y, lógicamente, a la especialidad de cada usuario.

\begin{tabular}{|l|c|c|}
\hline \multirow{2}{*}{ Fase del proyecto } & \multicolumn{2}{|c|}{ Perfil } \\
\cline { 2 - 3 } & Línea & Subestación \\
\hline Análisis ambiental de alternativas & MA-LE & MA_SE \\
\hline Definición del proyecto de ingeniería & IN-LE & IN_SE \\
\hline Obtención de permisos & PE-LE & PE-SE \\
\hline Construcción & CO-LE & CO-SE \\
\hline
\end{tabular}


Los roles de usuario gestionarán lo que cada usuario pude realizar dentro del perfil con el que haya sido dado de alta:

- Rol Lectura: el usuario que esté dado de alta en cualquier espacio de trabajo INGEOIN con rol de lectura podrá visualizar los resultados de los procesos de todas las fases que hayan sido ejecutados en el proyecto y podrá suscribirse a las notificaciones de cualquier proceso.

- Rol Lectura/Escritura: El usuario que este dado de alta en un espacio de trabajo concreto de INGEOIN, tendrá chequeado el permiso de escritura en uno de los mapas de escritura (líneas o subestaciones) y tendrá permisos para ejecutar los procesos correspondientes a su fase de líneas o subestaciones.

Los cuadros de mando que todavía no han generado un resultado únicamente podrán ejecutarse por los técnicos cuyo perfil les habilite para ello:

- Los cuadros de mando de color gris podrán ser ejecutados por todos los técnicos con acceso a la consola de proyectos.

- Los cuadros de mando de color verde únicamente podrán ser ejecutados por los técnicos con perfil MA_LE o MA_SE, es decir, los técnicos responsables del análisis ambiental del proyecto de línea o subestación respectivamente.

- Los cuadros de mando de color azul únicamente podrán ser ejecutados por los técnicos con perfil IN_LE o IN_SE, es decir, los técnicos responsables de la ingeniería del proyecto de línea o subestación respectivamente.

- Los cuadros de mando de color naranja únicamente podrán ser ejecutados por los técnicos con perfil PE_LE o PE_SE, es decir, los técnicos responsables de la obtención de los permisos sobre las parcelas afectadas por el proyecto de línea o subestación respectivamente.

- Finalmente, los cuadros de mando de color morado podrán ser ejecutados por todos los técnicos con acceso a la consola, ya que esta fase no genera resultados, sino que permite visualizar el avance de obra.

Una vez que ya tienen resultado, su consulta, su descarga o la consulta del log de trazabilidad están abiertas a cualquier usuario con acceso a la consola.

\subsubsection{Sistema de notificaciones automáticas}

La consola de INGeoIN posee un sistema de notificaciones automáticas que permite avisar a los usuarios, mediante el envío de un e-mail, cuando un proceso ha finalizado.

Cada perfil de usuario tiene configurado unas notificaciones automáticas por defecto. Las notificaciones por defecto establecen una comunicación entre técnicos de un mismo proyecto, pero de diferentes fases, para poder iniciar procesos de colaboración sin la necesidad de que el técnico que ejecuta un proceso tenga que, de forma manual, informar a todos los técnicos que pudieran estar interesados en dicho resultado.

Al abrir la consola, el sistema carga automáticamente la lista de suscripciones del usuario para el proyecto activo y configura el interfaz de usuario conforme a esta lista. Posteriormente el usuario 
puede modificar la configuración por defecto y establecer su propia configuración de notificaciones para cada proyecto.

Adicionalmente, se puede enviar una notificación a demanda. Esta funcionalidad es útil para informar, por ejemplo, al equipo directivo que no está en el día a día de los proyectos.

La Figura 4-10 muestra un ejemplo de las herramientas de suscripción y envío de notificaciones:

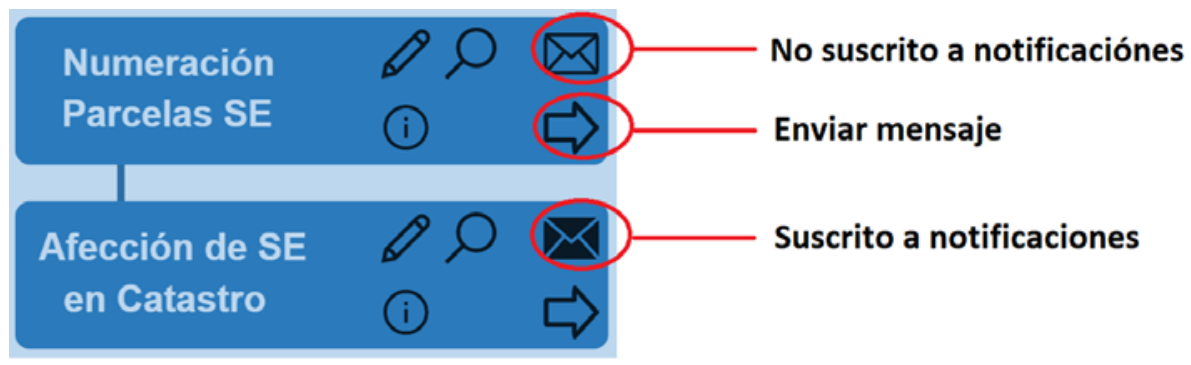

Figura 4-10. Ejemplo de suscripción y envío de notificaciones

4.3.3.1 Configuración de notificaciones según perfil de usuario

La configuración de notificaciones por defecto para cada perfil viene especificada en la Tabla 4-3:

\begin{tabular}{|c|c|c|c|c|c|c|c|}
\hline \multicolumn{2}{|c|}{ Medio Ambiente } & \multicolumn{2}{|c|}{ Ingeniería } & \multicolumn{2}{|c|}{ Permisos } & \multicolumn{2}{|c|}{ Construcción } \\
\hline Líneas & SE & Líneas & SE & Líneas & SE & Líneas & SE \\
\hline $\begin{array}{l}\text { Carga } \\
\text { alineaciones }\end{array}$ & $\begin{array}{l}\text { Cargar plano } \\
\text { implantación } \\
\text { SE }\end{array}$ & $\begin{array}{l}\text { Ámbito de } \\
\text { estudio LE }\end{array}$ & $\begin{array}{l}\text { Ámbito de } \\
\text { estudio SE }\end{array}$ & $\begin{array}{l}\text { Alternativas } \\
\text { pasillo }\end{array}$ & $\begin{array}{l}\text { Áreas } \\
\text { favorables }\end{array}$ & $\begin{array}{l}\text { Fin de fase } \\
\text { IN LE }\end{array}$ & $\begin{array}{l}\text { Depurar } \\
\text { GeoRBD de } \\
\text { SE }\end{array}$ \\
\hline $\begin{array}{l}\text { Carga } \\
\text { distribución } \\
\text { apoyos }\end{array}$ & $\begin{array}{l}\text { Fin de fase } \\
\text { Permisos SE }\end{array}$ & $\begin{array}{l}\text { Alternativas } \\
\text { pasillo LE }\end{array}$ & $\begin{array}{l}\text { Alternativas } \\
\text { pasillo LE }\end{array}$ & $\begin{array}{l}\text { Cargar } \\
\text { alineaciones }\end{array}$ & $\begin{array}{l}\text { Cargar plano } \\
\text { ocupación } \\
\text { RBD }\end{array}$ & $\begin{array}{l}\text { Tabla de } \\
\text { permisos }\end{array}$ & $\begin{array}{l}\text { Fin de fase } \\
\text { Permisos SE }\end{array}$ \\
\hline $\begin{array}{l}\text { Carga } \\
\text { afectaciones } \\
\text { de línea }\end{array}$ & & $\begin{array}{l}\text { Cargar plano } \\
\text { ocupaciones } \\
\text { para RBD }\end{array}$ & $\begin{array}{l}\text { Áreas } \\
\text { favorables }\end{array}$ & $\begin{array}{l}\text { Carga } \\
\text { distribución } \\
\text { apoyos }\end{array}$ & $\begin{array}{l}\text { Afectación } \\
\text { de SE en } \\
\text { catastro } \\
\end{array}$ & $\begin{array}{l}\text { Informe } \\
\text { resumen }\end{array}$ & $\begin{array}{l}\text { Fin de fase } \\
\text { Construcción } \\
\text { SE }\end{array}$ \\
\hline \multirow[t]{7}{*}{$\begin{array}{l}\text { Fin de fase } \\
\text { Permisos } \\
\text { LE } \\
\end{array}$} & & $\begin{array}{l}\text { Cargar plano } \\
\text { implantación } \\
\text { SE } \\
\end{array}$ & $\begin{array}{l}\text { Cargar } \\
\text { alineaciones }\end{array}$ & $\begin{array}{l}\text { Cargar traza } \\
\text { subterránea }\end{array}$ & $\begin{array}{l}\text { Fin de fase } \\
\text { MA SE }\end{array}$ & \begin{tabular}{|l} 
Fin de fase \\
Permisos \\
LE \\
\end{tabular} & \\
\hline & & $\begin{array}{l}\text { Fin de fase } \\
\text { MA LE }\end{array}$ & $\begin{array}{l}\text { Carga } \\
\text { distribución } \\
\text { apoyos }\end{array}$ & $\begin{array}{l}\text { Cargar } \\
\text { afectaciones } \\
\text { de línea } \\
\end{array}$ & $\begin{array}{l}\text { Fin de fase } \\
\text { IN SE }\end{array}$ & & \\
\hline & & $\begin{array}{l}\text { Depurar } \\
\text { GeoRBD de } \\
\text { líneas } \\
\end{array}$ & $\begin{array}{l}\text { Cargar traza } \\
\text { subterránea }\end{array}$ & $\begin{array}{l}\text { Fin de fase } \\
\text { MA LE }\end{array}$ & \begin{tabular}{|l} 
Fin de fase \\
Construcción \\
SE \\
\end{tabular} & & \\
\hline & & \begin{tabular}{|l|} 
Fin de fase \\
Permisos LE \\
\end{tabular} & $\begin{array}{l}\text { Fin de fase } \\
\text { MA SE } \\
\end{array}$ & $\begin{array}{l}\text { GeoRBD de } \\
\text { Líneas }\end{array}$ & & & \\
\hline & & $\begin{array}{l}\text { Fin de fase } \\
\text { Construcción } \\
\text { LE } \\
\end{array}$ & $\begin{array}{l}\text { Depurar } \\
\text { GeoRBD de } \\
\text { subestaciones } \\
\end{array}$ & $\begin{array}{l}\text { Fin de fase } \\
\text { IN LE }\end{array}$ & & & \\
\hline & & & $\begin{array}{l}\text { Fin de fase } \\
\text { Permisos SE }\end{array}$ & $\begin{array}{l}\text { Fin de fase } \\
\text { Construcción } \\
\text { LE }\end{array}$ & & & \\
\hline & & & $\begin{array}{l}\text { Fin de fase } \\
\text { Construcción } \\
\text { SE }\end{array}$ & & & & \\
\hline
\end{tabular}

Tabla 4-3. Configuración de notificaciones por defecto según perfil de usuario 


\subsubsection{Envío de notificaciones}

Un usuario con permiso para ejecutar el proceso también tiene permisos para enviar notificaciones. Al seleccionar "Enviar notificación" se abre el gestor de correo electrónico predeterminado del sistema del usuario (normalmente Outlook) y el sistema rellena de forma automática:

- La lista de destinatarios. Serán los usuarios que se han suscrito a las notificaciones del proceso para el proyecto en cuestión.

- El asunto y el cuerpo del correo electrónico. Se carga con un mensaje "tipo" configurado para el proceso. A diferencia de las notificaciones automáticas, tanto el asunto como el cuerpo del correo electrónico pueden ser modificados.

\subsubsection{Suscripción a notificaciones}

La primera vez que un usuario accede al proyecto se añadirá de forma automática una lista de suscripciones a procesos en función de su perfil.

Un usuario puede voluntariamente darse de alta/baja en la lista de destinatarios de las notificaciones de los procesos para cada proyecto.

\subsubsection{Modelos de geoprocesamiento}

A continuación, se detallan cada una de las 5 fases del enfoque metodológico propuesto para el diseño de las IEAT concretando cómo el modelo define la información geográfica a utilizar y la que se genera en cada una de ellas.

\subsubsection{Fase de planificación}

El modelo de representación de la información geográfica para esta fase está basado en los tipos de líneas: tensiones y su condición (aérea, subterránea o submarina).

\subsection{Modelos para comprensión del ámbito de estudio}

El objetivo de este tipo de modelos en esta fase es, por un lado, el de analizar geográficamente la viabilidad de las instalaciones que se pretende proponer -etapa de preplanificación-, por otro lado, dar significado geográfico a la planificación ya aprobada por el Consejo de Ministros. Estos modelos se muestran en la Figura 4-11.

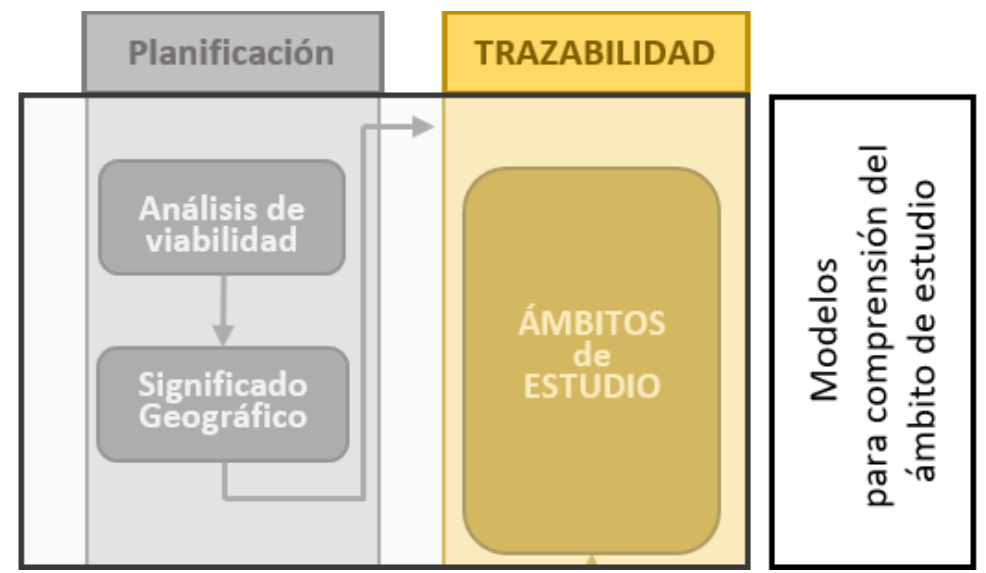

Figura 4-11. Procesos para comprensión de ámbitos de estudio en fase de planificación 
a) El análisis geográfico de la viabilidad se basa en un mapa ya generado, de ámbito nacional, en el que se han fusionado con diferentes pesos los condicionantes territoriales más relevantes. Este mapa es, en su concepción, un mapa de coste. El geoproceso analiza este mapa de coste para cada instalación de tipo línea propuesta y da como resultado un trazado con vocación de croquis a la escala de esta fase.

Este mapa se ha generado adaptando la metodología propuesta en el proyecto 'TPropongo' (López, 2014), que dará como resultado la información geográfica básica requerida. La adaptación ha consistido en la reducción del número de mapas que formará parte del modelo a ponderar y en la re-parametrización de todos los demás, quedando finalmente ocho mapas categorizados por temática y nivel de aceptabilidad de una nueva línea. Cada uno de los ocho mapas tiene su correspondencia con los condicionantes territoriales a tener en cuenta. A cada pixel (resolución del análisis) se le aplicará un valor de aceptabilidad para cada uno de los factores territoriales considerandos. La escala de valores de aceptabilidad se ha definido de acuerdo al criterio técnico de REE y representa la dificultad para la acogida de una línea eléctrica en el rango de 0-10. Siendo el valor cero como el valor de mayor capacidad de acogida del territorio y diez el valor de menor.

Los condicionantes territoriales son:

- Infraestructuras lineales existentes

Se pretende obtener las zonas en las que ya existe impacto por instalaciones eléctricas con el fin de agrupar el impacto de la nueva línea eléctrica con las existentes, evitando así fragmentar nuevamente el territorio por la apertura de otros corredores de infraestructuras.

Por criterios basados en la experiencia, se realizan buffers (áreas de influencia) de $250 \mathrm{~m}$ alrededor de las infraestructuras lineales existentes (líneas eléctricas, carreteras y líneas de ferrocarril) para delimitar las zonas favorables. Por otro lado, también se realiza un buffer de los primeros $25 \mathrm{~m}$ alrededor de dichas instalaciones lineales para respetar las servidumbres de estas infraestructuras. Los criterios de dificultad de acogida quedan registrados en la Tabla $4-4$.

\begin{tabular}{|l|c|}
\hline Áreas de influencia & Valor \\
\hline Primeros $25 \mathrm{~m}$ alrededor de infraestructuras lineales & 10 \\
\hline Siguientes $250 \mathrm{~m}$ alrededor de infraestructuras lineales & 0 \\
\hline
\end{tabular}

Tabla 4-4. Valores de dificultad para la acogida de áreas de influencia de infraestructuras lineales

- Accesibilidad

La accesibilidad al territorio, además de minimizar los costes y plazos de ejecución de obra, permite también reducir los impactos derivados de la construcción de nuevos accesos. Se pretende generar un mapa con las áreas del territorio más accesibles, las menos accesibles y de las que no disponen de caminos para acceder. Por criterios basados en la experiencia 
en este tipo de proyectos, se realizan buffers de vías asfaltadas y vías no asfaltadas a 250 y $500 \mathrm{~m}$. También se realiza un buffer de $25 \mathrm{~m}$ alrededor de las vías asfaltadas por respetar sus servidumbres. Los valores de dificultad de acogida se presentan en la Tabla 4-5.

\begin{tabular}{|l|c|}
\hline Áreas de influencia & Valor \\
\hline Primeros $25 \mathrm{~m}$ alrededor de vías asfaltadas & 10 \\
\hline Primeros $250 \mathrm{~m}$ alrededor de vías asfaltadas & 0 \\
\hline Siguientes $250 \mathrm{~m}$ alrededor de vías asfaltadas & 2 \\
\hline Primeros $250 \mathrm{~m}$ alrededor de vías no asfaltadas & 0 \\
\hline Siguientes $250 \mathrm{~m}$ alrededor de vías no asfaltadas & 2 \\
\hline
\end{tabular}

Tabla 4-5.Valores de dificultad para la acogida de accesibilidad

- Orografía

Se pretende obtener un mapa del ámbito de estudio que represente las zonas con mayor y menor pendiente. Los valores de dificultad de acogida asignados en función de la pendiente son los que se presentan en la Tabla 4-6.

\begin{tabular}{|l|c|}
\hline Rango de pendientes & Valor \\
\hline Entre 0 y $\%$ & 0 \\
\hline Entre 2 y $5 \%$ & 3 \\
\hline Entre 5 y $10 \%$ & 6 \\
\hline Mayor de $10 \%$ & 10 \\
\hline
\end{tabular}

Tabla 4-6. Valores de dificultad para la acogida por pendiente del terreno

\section{- Valor Natural}

En el territorio se encuentran diferentes figuras de ocupación con valor natural. Estas figuras deben tenerse en cuenta para evitar su degradación, en la medida de lo posible. Los valores de dificultad de acogida asignados se presentan en la Tabla 4-7.

\begin{tabular}{|l|c|}
\hline Zona natural & Valor \\
\hline Arboles altos (35-50 m) y arboledas singulares & 6 \\
\hline Vegetación de interés & 8 \\
\hline Viñedo & 6 \\
\hline Hábitats de interés comunitario & 7 \\
\hline Bosques & 6 \\
\hline Zonas de actuación de aves de humedales, esteparias y necrófagas & 8 \\
\hline Cultivos & 1 \\
\hline
\end{tabular}

Tabla 4-7. Valores de dificultad para la acogida por existencia de Valor Natural

- Figuras de protección ambiental

Las zonas de protección ambiental deben respetarse y el objetivo en este caso es obtener un mapa que represente los Espacios Naturales Protegidos (ENP), dando mayor valor a las zonas que se superpongan con ellas. 
Los valores de dificultad de acogida asignados a los espacios protegidos son los que se presentan en la Tabla 4-8.

\begin{tabular}{|l|c|}
\hline Zona de Figuras de Protección Ambiental & Valor \\
\hline Figura de Protección Ambiental & 6 \\
\hline Superposición de 2 Figuras de Protección Ambiental & 8 \\
\hline Superposición de 3 o más Figuras de Protección Ambiental & 10 \\
\hline
\end{tabular}

Tabla 4-8. Valores de dificultad para la acogida por existencia de Figuras de Protección Ambiental

- Núcleos de población

La proximidad a los núcleos de población influye dificultando el desarrollo de nuevas instalaciones. Este mapa representa los núcleos de población, así como distintas zonas cercanas o alejadas. Por un lado, en las alejadas las instalaciones tendrán un menor impacto de visibilidad, pero tendrán peores posibilidades de acceso. Se plantea asignar distintos niveles de dificultad en base a anillos de buffers o áreas de influencia a diferentes distancias para categorizar el territorio, para los que se plantean los siguientes pesos de dificultad que se muestran en la Tabla 4-9.

\begin{tabular}{|l|c|}
\hline Distancia a núcleos de población & Valor \\
\hline Núcleos de población a distancia d $<450 \mathrm{~m}$ & 10 \\
\hline Núcleos de población a distancia $450 \mathrm{~m}<\mathrm{d}<650 \mathrm{~m}$ & 4 \\
\hline Núcleos de población a distancia $650 \mathrm{~m}<\mathrm{d}<850 \mathrm{~m}$ & 2 \\
\hline Núcleos de población a distancia $850 \mathrm{~m}<\mathrm{d}<1000 \mathrm{~m}$ & 1 \\
\hline Núcleos de población a distancia d $>1000 \mathrm{~m}$ & 0 \\
\hline Edificaciones aisladas a distancia d $<50 \mathrm{~m}$ & 9 \\
\hline Edificaciones aisladas a distancia $50 \mathrm{~m}<\mathrm{d}<100 \mathrm{~m}$ & 5 \\
\hline Edificaciones aisladas a distancia $\mathrm{d}>100 \mathrm{~m}$ & 0 \\
\hline
\end{tabular}

Tabla 4-9. Valores de dificultad para la acogida por proximidad de núcleos de población

\section{- Medio social}

De un modo similar se clasifican las distintas zonas de interés social clasificadas por su tipo de acuerdo a los valores de la Tabla 4-10 siendo valores de dificultad altos en general.

\begin{tabular}{|l|c|}
\hline Interés social & Valor \\
\hline Aeropuertos & 10 \\
\hline Zonas arqueológicas & 10 \\
\hline Zonas militares & 10 \\
\hline Concesiones mineras & 10 \\
\hline Bienes de interés cultural & 10 \\
\hline Otras infraestructuras (Gasoductos, acueductos, carreteras) & 10 \\
\hline Zonas de recreo (parques acuáticos, campos de golf) & 8 \\
\hline
\end{tabular}


- Medio Físico

Los accidentes físicos del territorio imponen restricciones evidentes relacionadas con la hidrología y la geología. Para considerarlas se realizan buffers de $25 \mathrm{~m}$ alrededor de la red hidrográfica con el fin de respetarla. También se realizan buffers de $200 \mathrm{~m}$ alrededor de los elementos puntuales como son los lugares de interés hidrogeológico.

Los valores asignados a los distintos tipos de accidentes físicos y distancias son los que se muestran en la Tabla 4-11.

\begin{tabular}{|l|c|}
\hline \multicolumn{1}{|c|}{ Medio físico } & Valor \\
\hline Red hidrográfica a distancia d $<25 \mathrm{~m}$ & 4 \\
\hline Embalses & 8 \\
\hline Lugares de interés hidrogeológico & 8 \\
\hline Geo-recursos a distancia d $<200 \mathrm{~m}$ & 8 \\
\hline
\end{tabular}

Tabla 4-11.Valores de dificultad para la acogida por existencia de elementos físicos del terreno

En función de la particularidad de cada Región, REE podrá generar para cada uno de los factores territoriales tantos mapas como se precisen modificando los valores de aceptabilidad aplicables a cada variable de cada condicionante territorial. De esta forma, para cada proyecto de nueva línea eléctrica, se podrán generar de forma iterativa diferentes escenarios para cada condicionante territorial.

El objetivo de este modelo es la generación de un mapa de capacidad de acogida del territorio con posibilidades de acoger una nueva línea eléctrica.

Una vez generados los mapas anteriores (formato ráster) que representan cada uno de los factores territoriales a considerar, el mapa de capacidad de acogida se obtiene de la superposición ponderada de todos ellos. Cada mapa ha sido generado considerando los valores de aceptabilidad de sus variables, y cada mapa tiene un peso diferente para la generación del mapa de acogida final. Los pesos utilizados pueden verse en la Tabla 4-12:

\begin{tabular}{|l|c|}
\hline \multicolumn{1}{|c|}{ Mapa } & Peso (\%) \\
\hline Figuras de Protección Ambiental & 20 \\
\hline Núcleos de población & 20 \\
\hline Orografía & 18 \\
\hline Accesibilidad & 15 \\
\hline Valor natural & 12 \\
\hline Infraestructuras lineales existentes & 5 \\
\hline Medio social & 5 \\
\hline Medio físico & 5 \\
\hline
\end{tabular}

Tabla 4-12. Valores de ponderación para la generación de los mapas de capacidad de acogida

El resultado de la superposición ponderada de los diferentes mapas es el mapa de capacidad de acogida, en el que cada pixel (a la resolución del estudio) tendrá un valor de capacidad de 
acogida, siendo los pixeles con menor valor los que tienen mayor capacidad de acogida para una nueva línea.

Modificando los pesos de cada mapa, se obtendrán diferentes escenarios. Esto posibilita iterar y aproximar el mapa de capacidad de acogida a las condiciones particulares de cada Región.

Este modelo se compone de dos pasos. En el primero se acotará el ámbito del análisis, con el que se realizará un recorte del mapa de acogida. En el segundo paso se realizará el análisis que permitirá obtener las alternativas. De esta forma se podrá, de forma iterativa, definir tantos ámbitos de análisis como sea necesario y generar alternativas de pasillo para cada uno de ellos.

En el primer paso (ver Figura 4-12) se genera la máscara para recortar el mapa de capacidad de acogida considerando una envolvente de la línea recta que une los puntos origen y destino de la siguiente forma:

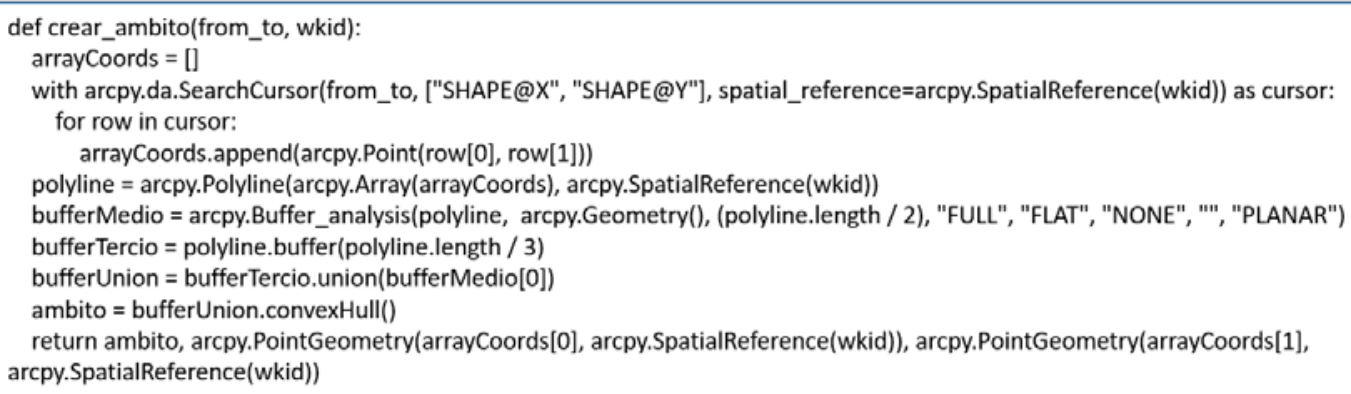

Figura 4-12. Modelo de cálculo del ámbito del análisis

En base al mapa de capacidad de acogida recortado por la máscara anterior, este modelo permite generar corredores, o pasillos dentro de los cuales se proyectará la línea eléctrica. Una línea eléctrica siempre tiene un origen y un destino que pueden ser subestaciones eléctricas (nuevas o existentes) o entronques en otras existentes. Estos pasillos representan las zonas de mayor capacidad de acogida para unir el origen y destino.

El flujo de información de este modelo se muestra de forma gráfica en la Figura 4-13:

(a)

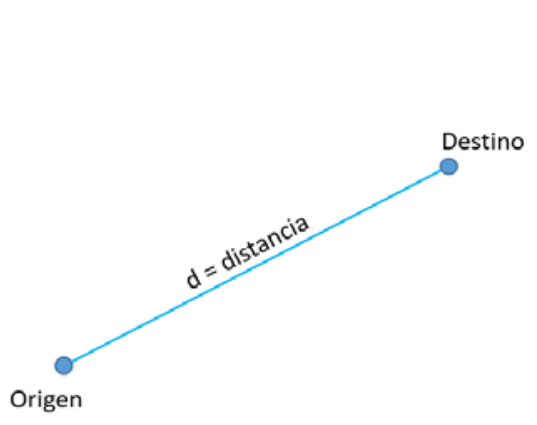

(b)

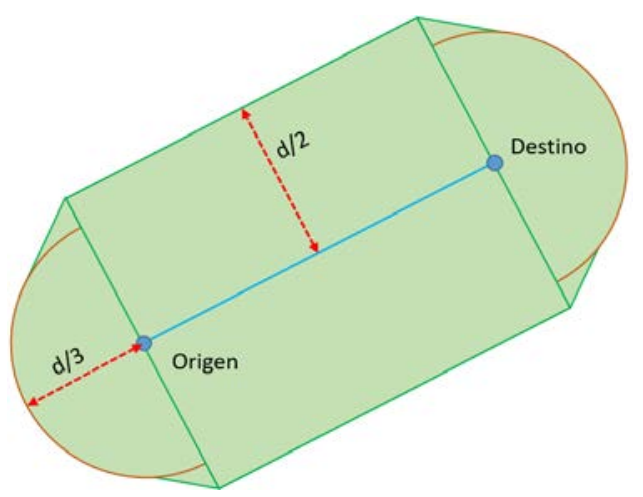


Para facilitar que todas las alternativas de pasillos posibles puedan ser consideradas, la delimitación del ámbito de análisis debe ser variable en función de la distancia de los puntos origen y destino. A mayor distancia de separación entre los puntos origen y destino mayores deberá ser las dimensiones del ámbito de estudio. Es decir, el ancho del ámbito de análisis se determina como una función de la distancia entre los puntos origen y destino. Por criterios empíricos basados en la experiencia, se considera que el ancho es de 1/3 de la distancia y es un valor que puede ser modificado de manera iterativa.

El recorte del ráster que se acaba de generar servirá en el modelo como ráster de superficie de coste para, a partir de los puntos de origen y destino generar un ráster de Coste de Distancia para cada uno de los puntos. Estos ráster de Coste de Distancia representan la distancia de menor coste acumulativo para cada celda al punto más cercano teniendo en cuenta el mapa de capacidad de acogida como superficie de coste.

El segundo paso, basado en el modelo de la Figura 4-14, se generan las alternativas de pasillo tras haber restringido el ámbito de análisis del paso anterior.

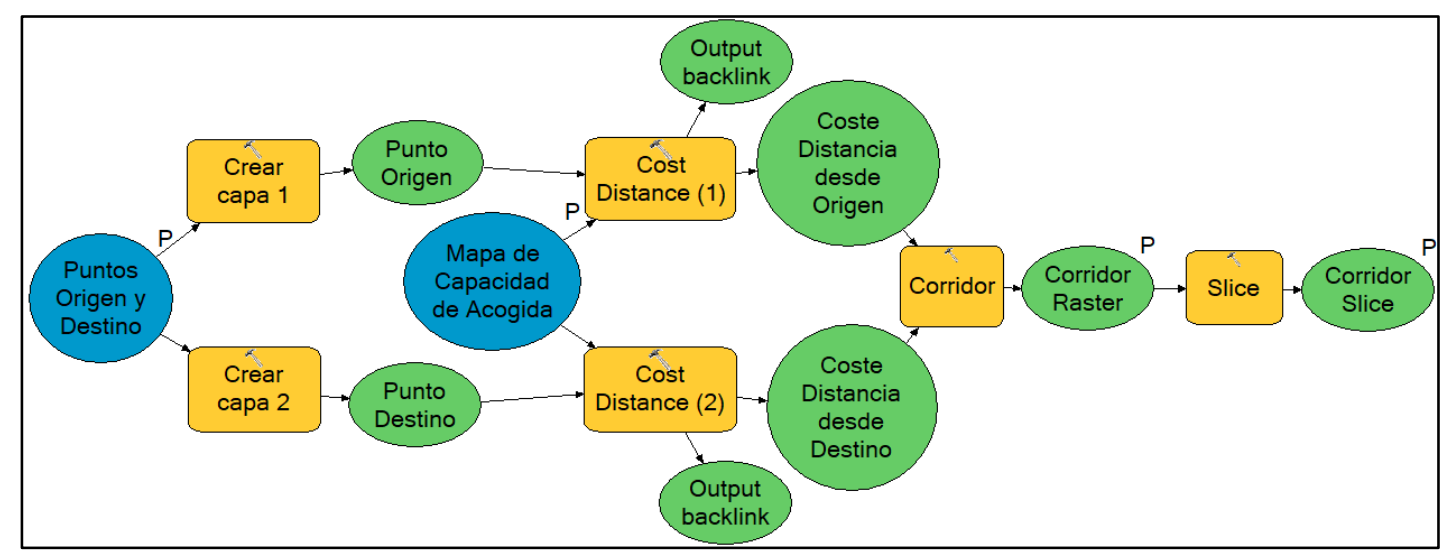

Figura 4-14. Modelo de geoprocesamiento para la generación de alternativas de pasillo

Con estos dos ráster de Coste de Distancia se obtiene la suma de los costes ambientales acumulativos. Del ráster resultante se extraen las zonas de menor coste ambiental acumulativo. El eje de estas zonas de menor coste ambiental es la traza propuesta para el análisis de viabilidad.

Este modelo genera de forma automática el eje de cada alternativa de pasillo. Este eje será una propuesta que por diseño es la más alejada de los límites del pasillo, buscando que las afectaciones provocadas por el desplazamiento de los cables conductores por el viento transversal y por el trazado de los futuros caminos de acceso a los apoyos, queden fuera del pasillo.

Para poder realizar este cálculo, el modelo que propone el eje o alineación genera los vértices que delimitan el polígono del pasillo (ver Figura 4-15 (a)). Con éstos se generan los polígonos de Thiessen (ESRI, 2018) (ver Figura 4-15 (b)) y, tras convertirlos a polyline, se seleccionan las líneas que están íntegramente dentro del ámbito, mostrado en la Figura 4-15 (c). 
(a)

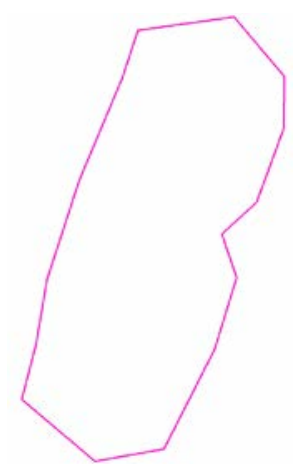

(b)

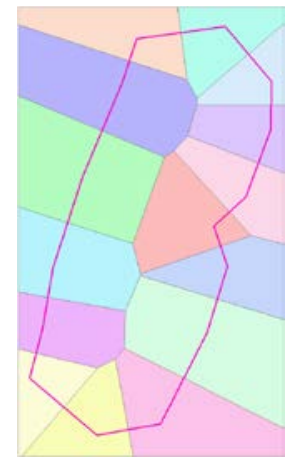

(c)

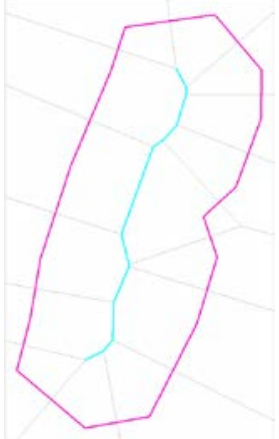

Figura 4-15. Ejemplo gráfico de la aplicación de los polígonos de Thiessen para la generar alineaciones.

En la Figura 4-16 se presenta el geoproceso que genera las alineaciones.

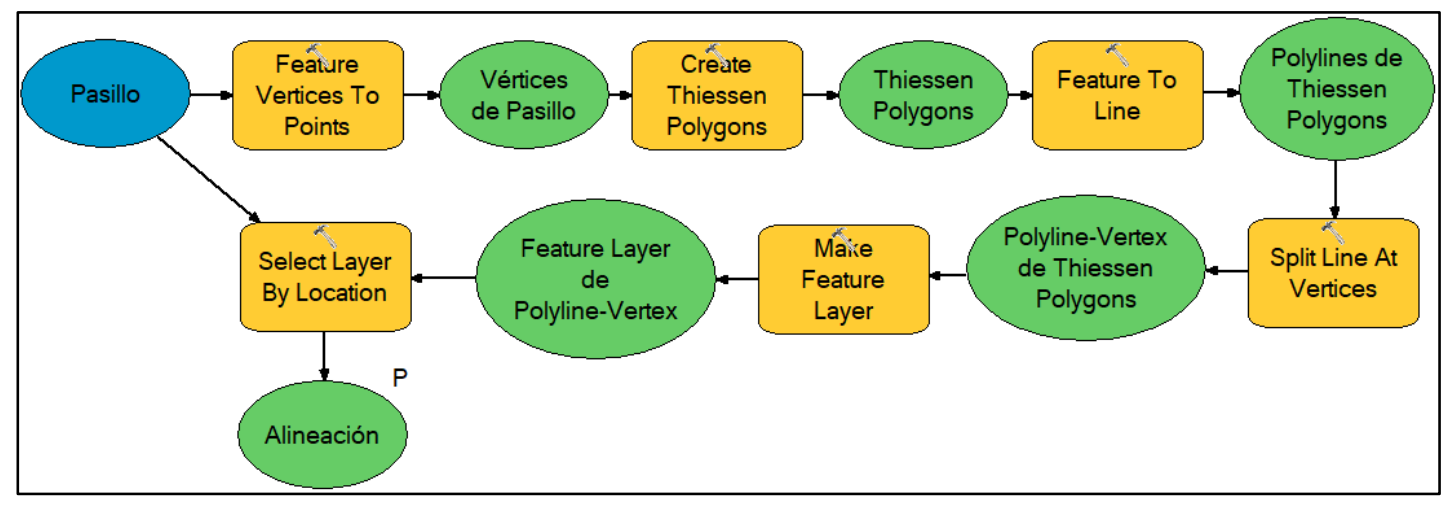

Figura 4-16. Modelo que genera la alineación dentro de cada pasillo

a) Tras los análisis de viabilidad geográfica y técnica, el proceso que da significado geográfico, a fecha de esta redacción (Figura 4-17) a la planificación aprobada muestra sobre un mismo mapa todas las instalaciones (líneas y subestaciones) que la componen.

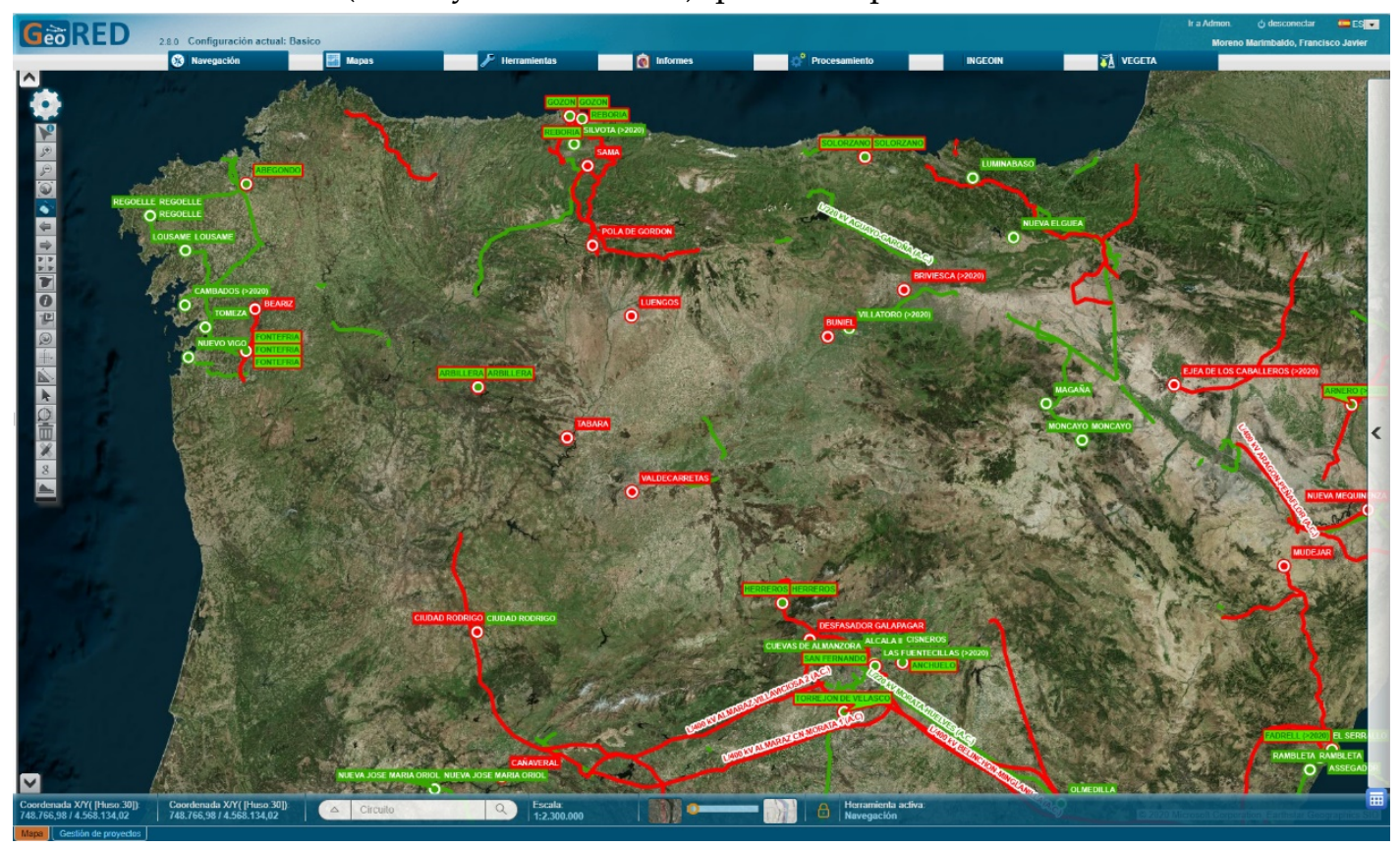

Figura 4-17. Significado geográfico de la planificación 
4.3.4.2 Fase de análisis ambiental de alternativas

Una vez aprobada por el Consejo de Ministros la planificación de la red de transporte de energía eléctrica, la principal contribución a la planificación que se realiza en esta fase, viene de la mano de la información geográfica. En ella se tienen en cuenta los condicionantes y restricciones del medio físico y el medio biótico. Se realizan un conjunto de análisis que dan como resultado al menos tres alternativas viables de pasillo como solución para poder albergar el estudio del proyecto de línea eléctrica. La obligatoriedad de evaluar ambientalmente tres alternativas de proyecto en España está establecida por la Ley 21/2013, de 9 de diciembre de 2013 (BOE, 2013).

En esta fase se produce un cambio cualitativo en el detalle de la información geográfica utilizada, cambiando de la escala 1:1.000.000 a escalas del intervalo 1:25.000 a 1:10.000, y será soportada por los siguientes modelos que ayudarán a la toma de decisiones y justificación de las soluciones:

\subsection{Modelos para comprensión del ámbito de estudio (Fase análisis ambiental)}

El objetivo es, no solo representar, sino poder analizar la información geográfica con el criterio que REE establece para cada fase. Este criterio se establece bajo dos requisitos, que son: la información geográfica básica requerida y la simbología de representación corporativa; dando así homogeneidad a los estudios de nueva IEAT.

Los procesos de este tipo de modelos se muestran en la Figura 4-18.

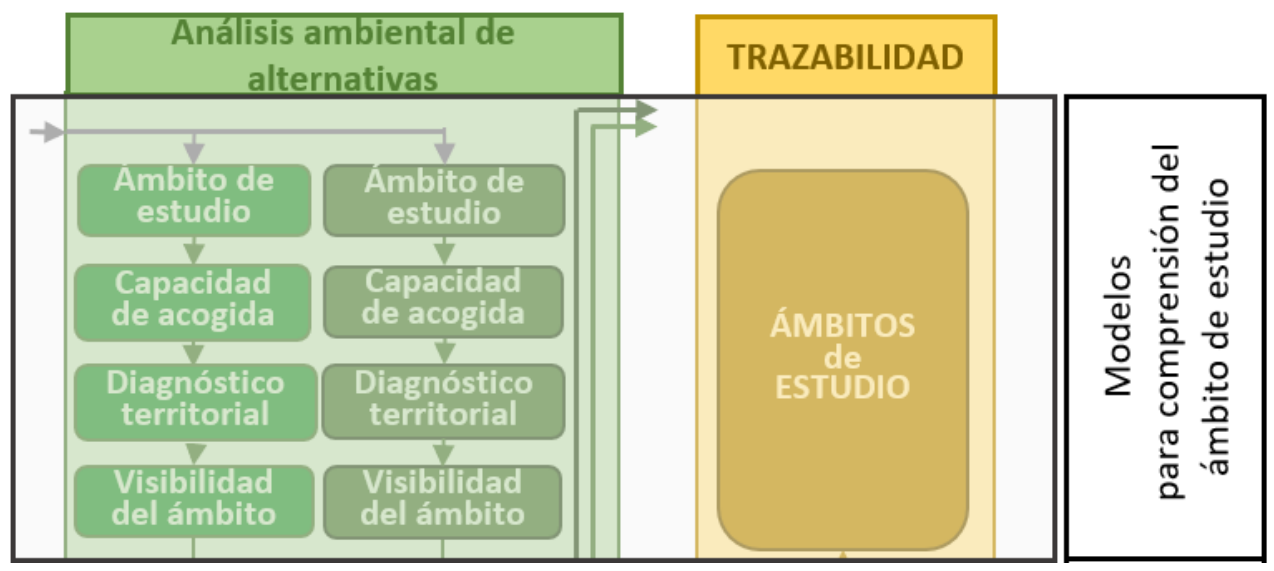

Figura 4-18. Procesos de los modelos para comprensión del ámbito de estudio de análisis ambiental

a) El proceso para establecer los ámbitos de estudio en proyectos de línea y subestaciones se describe a continuación:

i. $\quad$ Proyecto de línea:

El proceso permite dibujar polígonos sobre el mapa de GeoRED o añadir un archivo en formato shapefile. Estos definen el ámbito de estudio que delimitará el análisis ambiental de alternativas donde proyectar la futura línea eléctrica. Este proceso se realiza a través de un widget que utiliza la herramienta de edición de GeoRED que se muestra en la Figura 4-19. 


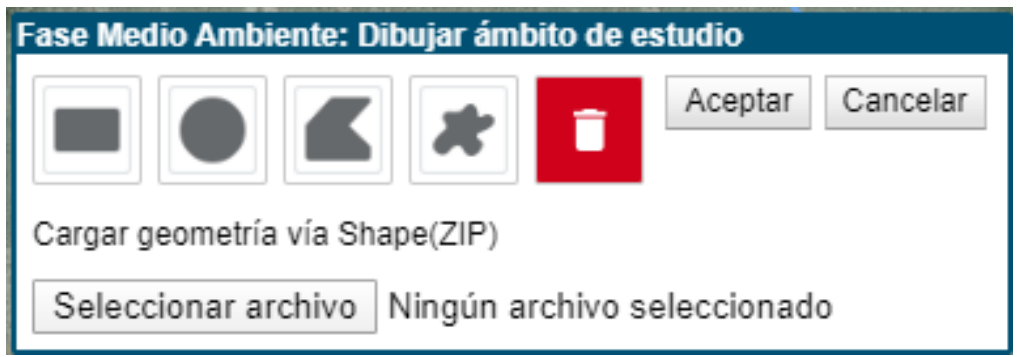

Figura 4-19. Widget para definir el ámbito de estudio de línea o subestación

ii. Proyecto de subestación:

Proceso que permite dibujar polígonos sobre el mapa base de GeoRED, o añadir un archivo en formato shapefile, con el ámbito de estudio que delimitará geográficamente el análisis ambiental de áreas favorables donde proyectar la futura subestación eléctrica.

El widget utilizado en este proceso es idéntico al de línea, aunque el dato dibujado o cargado se almacenará en su tabla correspondiente.

En ambos tipos de proyecto, líneas o subestaciones, el proceso trata el polígono que se inserta y lo guarda en base de datos intersecando con el mapa de Regiones Biogeográficas que se utilizará en procesos posteriores. Este mapa de Regiones Biogeográficas elaborado por el Instituto Geográfico Nacional se muestra en la Figura 4-20, siendo la fuente de este (RivasMartínez, 2017).

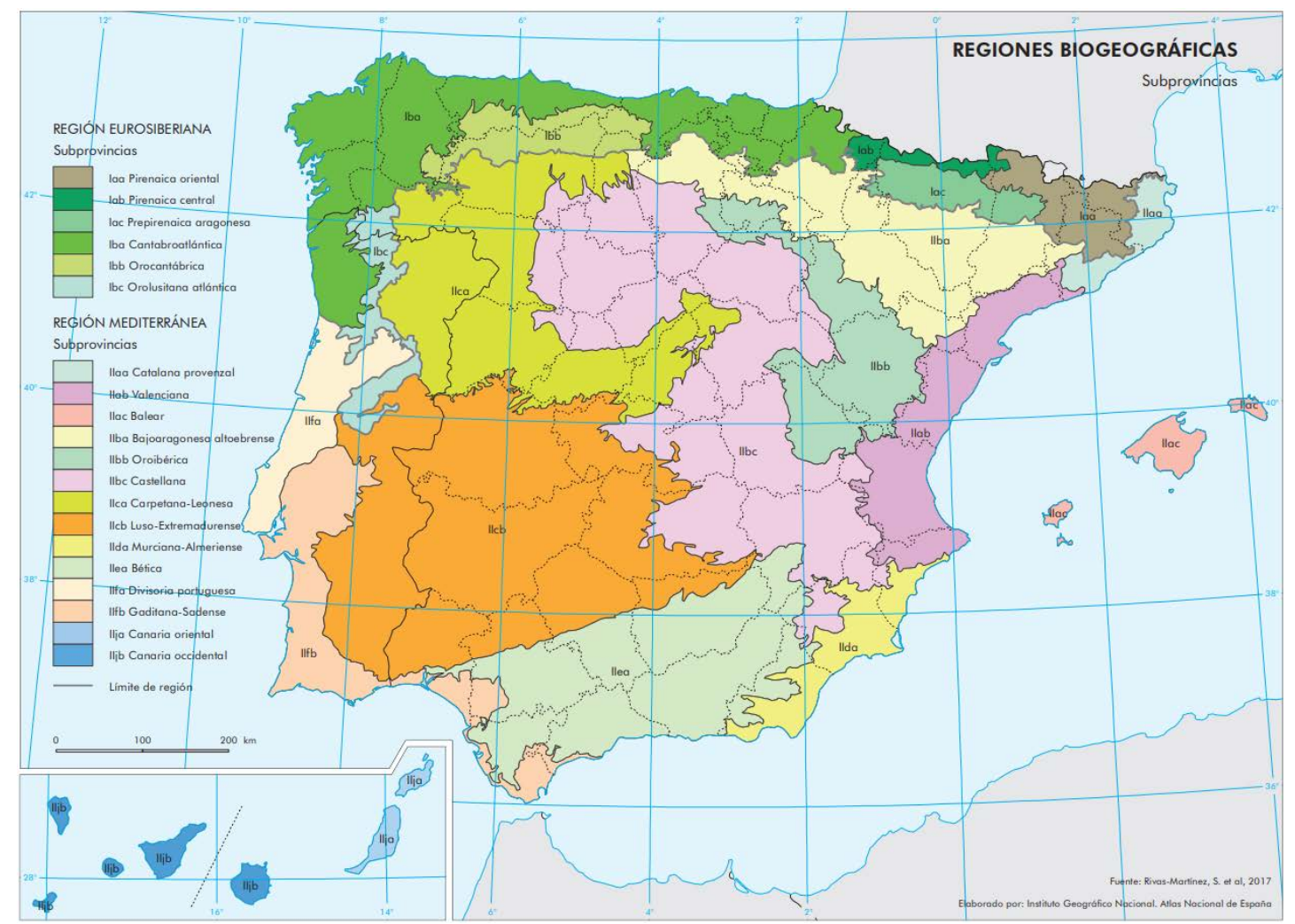

Figura 4-20. Mapa de Regiones Biogeográficas (fuente Rivas-Martínez et al. 2017) 
b) El proceso para generar el mapa de capacidad de acogida se describe a continuación:

El objetivo de este modelo es la generación de un mapa de capacidad de acogida del territorio, delimitado por el ámbito de estudio, con posibilidades de acoger una nueva IEAT. Una vez generadas las capas ráster que representan cada uno de los factores territoriales a considerar (capas/entidades), el mapa de capacidad de acogida se obtiene de la superposición ponderada de todos ellos. Cada capa ráster ha sido generada considerando los valores de aceptabilidad de sus variables, y cada una tiene un peso diferente según las regiones afectadas en el ámbito de estudio para la generación del mapa de acogida final.

A diferencia con el mapa de capacidad de acogida utilizado en el análisis de viabilidad, en el que el número de condicionantes era reducido y donde los usuarios no tenían ninguna capacidad de configuración, en este que está delimitado por el ámbito definido en el proceso anterior, el usuario podrá modificar pesos, utilizar sus propias capas de información geográfica y añadir condicionantes no considerados por defecto.

Para este mapa de capacidad de acogida se consideran condicionantes territoriales agrupados en: medio físico, medio biótico, medio socioeconómico, paisaje, zonas de prohibición y otros condicionantes que el propio usuario puede personalizar si el proyecto lo requiere. Dentro de cada uno de estos grupos hay diferentes categorías como se muestra en la Tabla 4-13.

\begin{tabular}{|l|l|l|l|}
\hline \multicolumn{1}{|c|}{ Medio físico } & \multicolumn{1}{|c|}{ Medio biótico } & \multicolumn{1}{|c|}{ Medio socioeconómico } & Paisaje \\
\hline \multirow{2}{*}{ Orografía } & $\begin{array}{l}\text { Figuras de protección } \\
\text { ambiental }\end{array}$ & Núcleos de población & $\begin{array}{l}\text { Zonas de especial } \\
\text { importancia } \\
\text { paisajística }\end{array}$ \\
\hline Hidrografía & Vegetación & Medio social & \\
\hline Accesibilidad & Avifauna & Infraestructuras lineales eléctricas & \\
\cline { 1 - 2 } Suelos & Hábitats & \multirow{2}{*}{ Otras infraestructuras lineales } & \\
\cline { 2 - 3 } & Usos del suelo & &
\end{tabular}

Tabla 4-13. Categorías de los condicionantes territoriales para mapa de capacidad de acogida

Las categorías de los condicionantes territoriales para proyectos de línea son iguales a las utilizadas en proyectos de subestación. Difiere, sin embargo, el uso que se hace de las capas que componen cada categoría. Por ejemplo, la pendiente del terreno es más restrictiva en proyectos de subestación que en proyectos de línea, debido al movimiento de tierras y la huella en el terreno que dejaría la construcción de una subestación en terreno de pendiente acusada. Los pesos asignados a cada categoría también se adecúan al tipo de proyecto. También posibilita que el usuario utilice la información existente en el repositorio de la compañía o que utilice información diferente si el proyecto así lo requiere. Como ejemplo de la interfaz gráfica se muestra uno de los formularios en la Figura 4-21. 


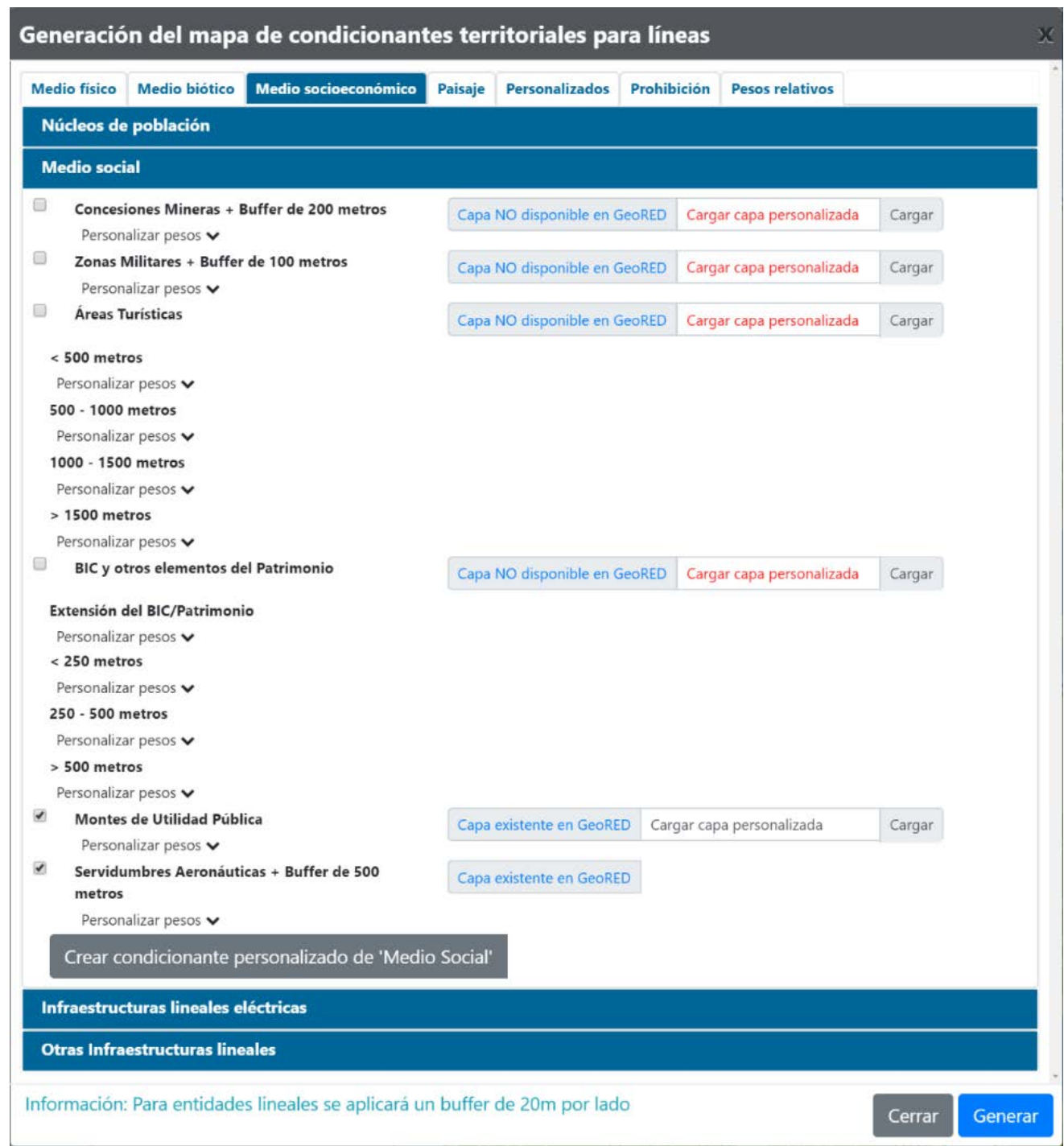

Figura 4-21. Ejemplo de interfaz gráfica para generar mapa de capacidad de acogida del ámbito

Cada categoría tiene un peso asignado de forma corporativa que puede ser modificado por el técnico responsable justificadamente $\mathrm{y}$, sumando todos los pesos de todas ellas, deberán completar el 100\% para cada Región Biogeográfica intersecada. La Figura 4-22 muestra la interfaz que permite gestionar los pesos.

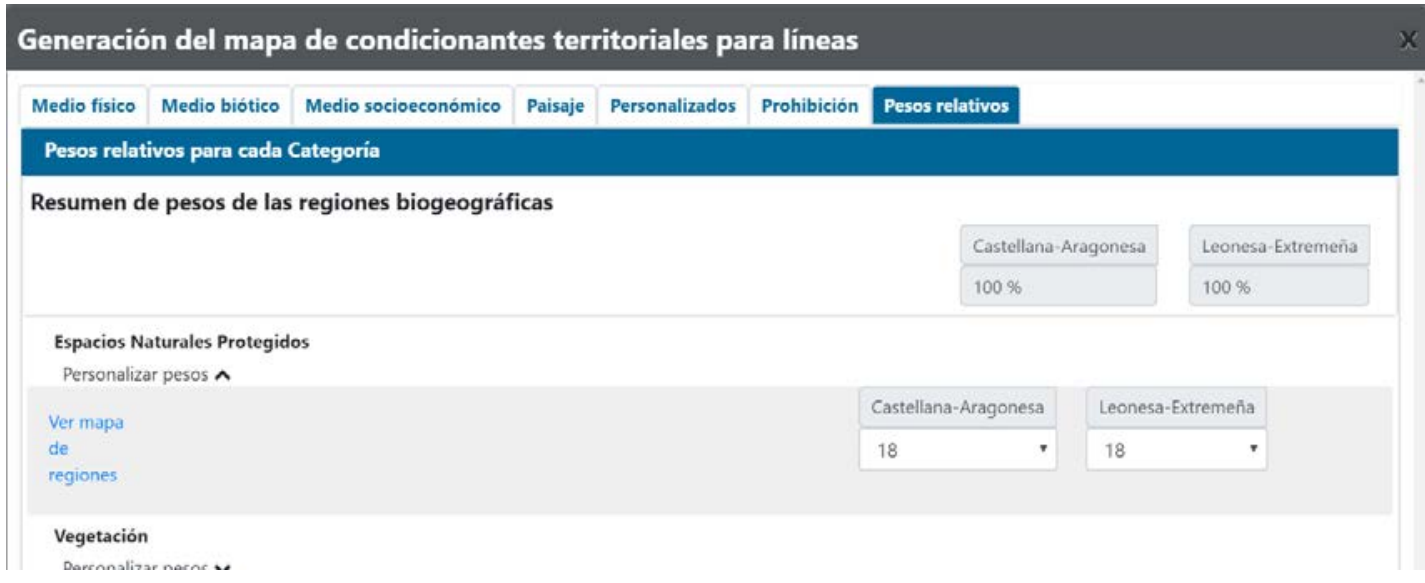

Figura 4-22. Interfaz para gestión de pesos de categorías de condicionantes territoriales 
El tratamiento sobre la información de cada capa y categoría para generar el mapa de capacidad de acogida del ámbito de estudio es idéntico al descrito en los modelos para comprensión del ámbito de estudio en la fase de planificación, es decir, se genera un mapa ráster para cada categoría donde cada capa ha sido ponderada y, sobre la suma de todos los mapas resultantes es ponderada según la categoría. La principal diferencia es que este mapa se genera a demanda y se dispone de la capacidad de interactuar con la información geográfica y los pesos que se asignan a cada caso. Un ejemplo de mapa de capacidad de acogida de línea se muestra en la Figura 4-23 (a), en el que las zonas coloreadas en tono más claro son las de menor coste ambiental, y las no coloreadas las zonas prohibidas o fuera del ámbito. La Figura 4-23 (b) muestra un ejemplo de mapa de capacidad de acogida de subestación.

(a)

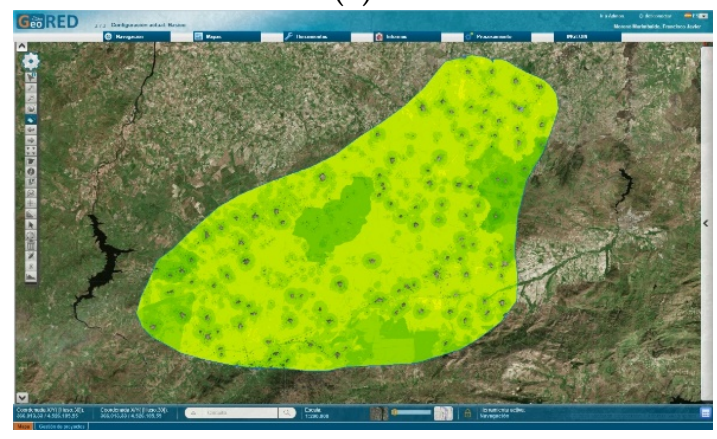

(b)

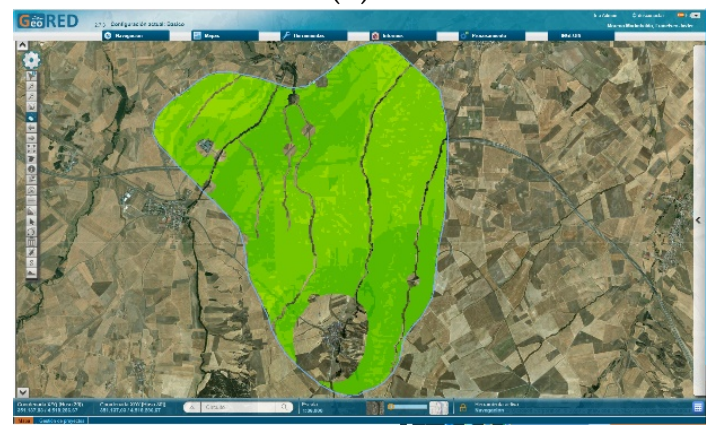

Figura 4-23. Ejemplo de mapa de capacidad de acogida de línea

Al finalizar el proceso, además de poder visualizar el resultado, el control mostrará opciones de descarga del ráster resultado, la visualización de todas las capas vectoriales utilizadas en el proceso o la descarga de la información vectorial utilizada. Al tratase de uno de los que más funcionalidad tiene se muestra en la Figura 4-24 el cuadro de mando implementado antes y después de su ejecución.
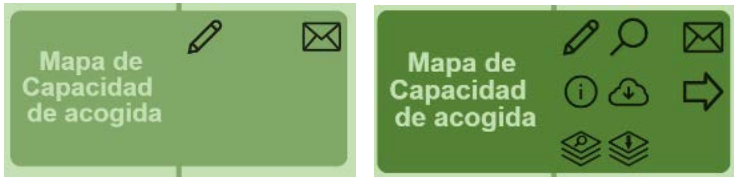

Figura 4-24. Proceso de generación de mapa de capacidad de acogida

c) El proceso de realizar un diagnóstico territorial que indique las zonas de menor impacto dentro del ámbito de estudio se describe a continuación:

i. $\quad$ Proyecto de línea:

Su objetivo es obtener una serie de pasillos de idoneidad medio ambiental para ajustar el recorrido de la futura línea eléctrica.

El proceso se basa en el mapa de capacidad de acogida generado en el proceso anterior. La Figura 4-25 muestra el widget para introducir sobre el mapa las coordenadas origen y destino de la futura línea para su análisis. 


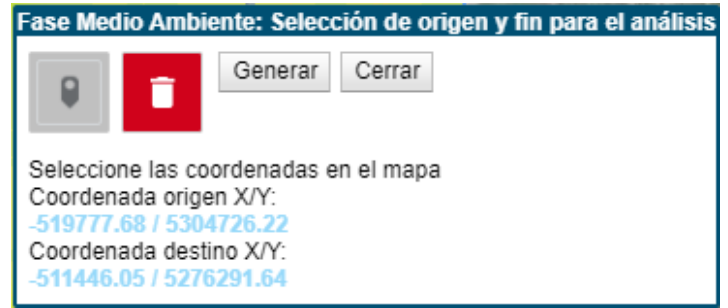

Figura 4-25. Proceso de generación de diagnóstico territorial de línea

El proceso selecciona el ámbito de estudio, calcula la línea de corte de análisis, para que no haya pasillos circulares, y sus respectivos pasillos a través de las herramientas de análisis espacial costDistance y Corridor de ESRI, dando como resultado un mapa ráster cuyo valor de píxel se guarda en el campo gridcode. Este ráster se transforma en vectorial y, dentro del ámbito, se clasifica el territorio en 50 valores de gridcode, de los que se desprecian los peores 20. En la Figura 4-26 (a) se muestran los 30 valores mantenidos y se simbolizan del verde oscuro (menor coste y por tanto más favorable) al rojo (mayor coste y menos favorable). En la Figura 4-26 (b), al filtrar y mantener los 10 valores más favorables se adivinan los posibles pasillos que ayudarán a los técnicos a definir las alternativas.

(a)

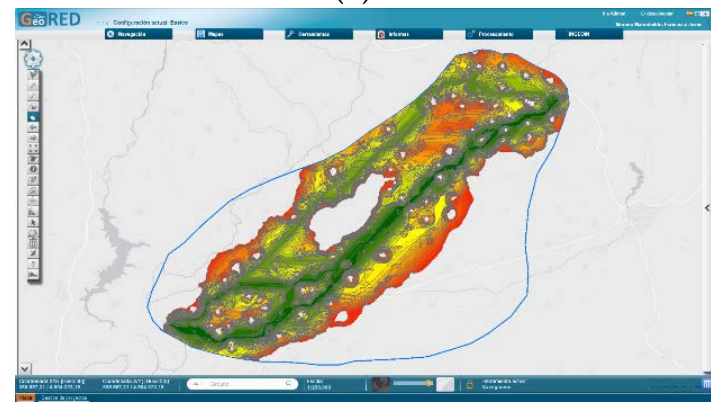

(b)

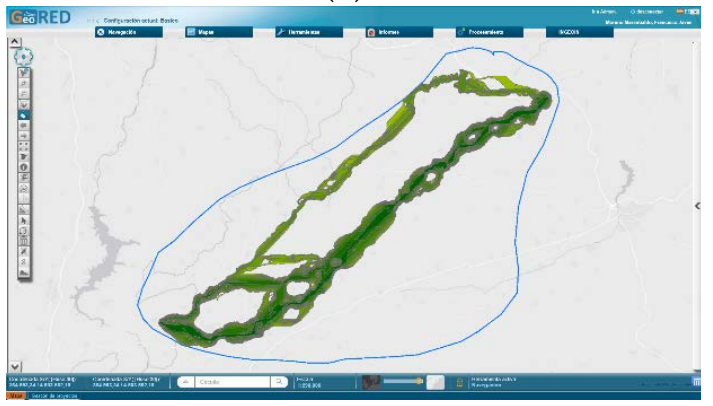

Figura 4-26. Ejemplo de diagnóstico territorial de proyecto de línea

\section{ii. Proyecto de subestación}

Este proceso se basa en el mapa de capacidad de acogida generado en el proceso anterior, permitirá al usuario introducir las dimensiones aproximadas de la futura subestación para analizar el espacio necesario para su posible ubicación.

El proceso selecciona el ámbito de estudio, calcula las pendientes y la distancia euclídea a los núcleos de población y pondera ambos con el mapa de condicionantes. Este ráster se convierte a vectorial para obtener las áreas óptimas y generar las zonas gridcode. Por último, se seleccionan las zonas donde tendría cabida una subestación con las dimensiones indicadas dentro de las áreas favorables, dando como resultado dos mapas vectoriales, uno con los gridcode general de las áreas favorables y otro con el análisis de la ubicación idónea de las subestaciones también clasificadas por gridcode. Ambos resultados se almacenan en la base de datos. 
La Figura 4-27 (a) muestra el resultado de las áreas, clasificadas por gridcode y simbología, para colocar una nueva subestación, y la Figura 4-27 (b) muestra, clasificadas por gridcode y simbología, aquellas áreas con capacidad de acogida para una subestación con las dimensiones indicadas.

(a)

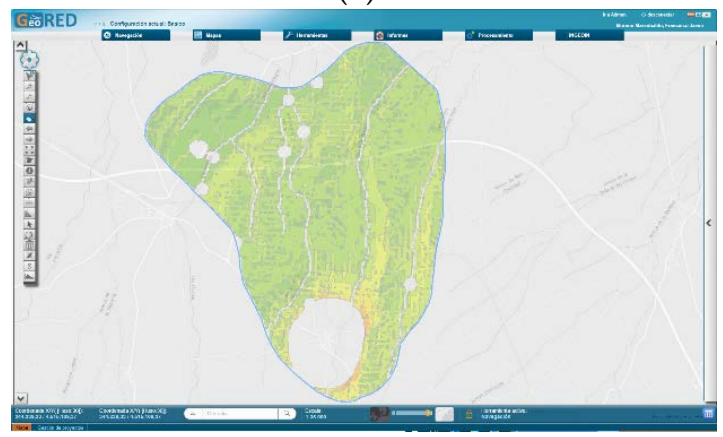

(b)

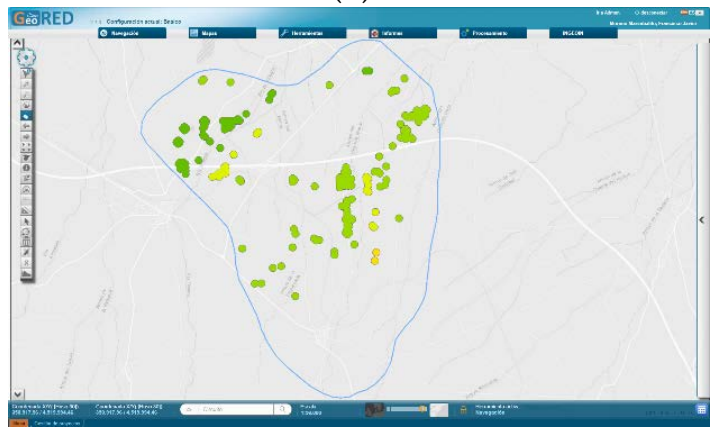

Figura 4-27. Ejemplo de diagnóstico territorial de proyecto subestación

La Figura 4-28 muestra cómo el proyecto de línea y el de subestación trabajan simultáneamente y se establece un escenario de colaboración para que los técnicos de ambos proyectos puedan tomar la mejor decisión de conjunto.

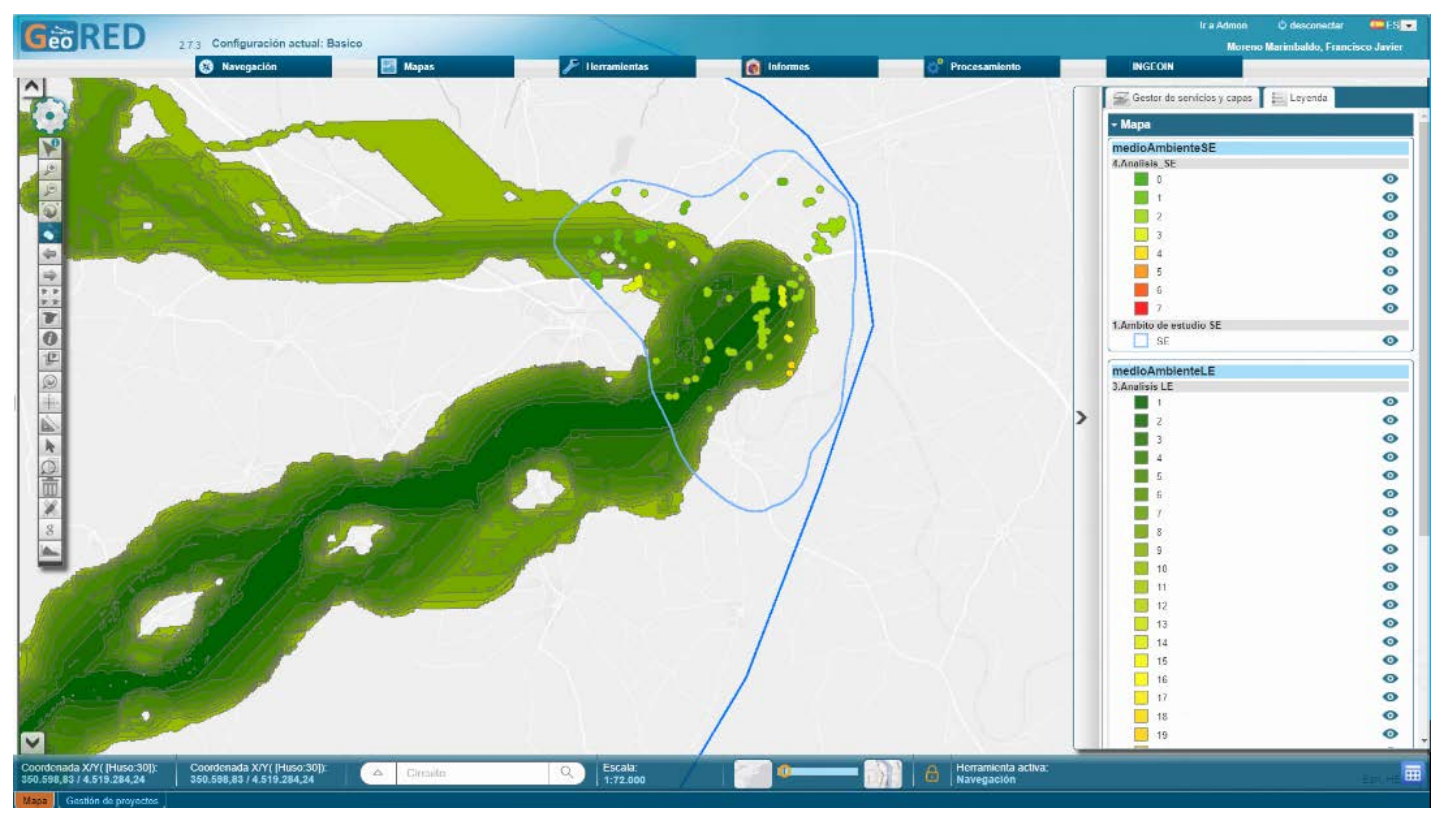

Figura 4-28. Superposición de proyectos de línea y subestación para colaboración de los equipos

d) Proceso de análisis de la visibilidad del ámbito de estudio:

Este modelo añade un atributo más a cada alternativa de pasillo o área favorable realizando un análisis de visibilidad para cada una de ellas. La visibilidad, en esta fase, no es una característica que condicione de manera estricta el trazado de la futura línea eléctrica o ubicación de una subestación, pero sí informará de la superficie de la visibilidad de cada alternativa. 
Se utilizará, además del Modelo Digital del Terreno (MDT) del ámbito de estudio, un conjunto de puntos relevantes de observación como son los núcleos de población y todos aquellos puntos que el técnico que realice el estudio considere interesantes, como los paradores, rutas turísticas, carreteras, etc., y se calculará la cuenca visual de todos ellos en el ámbito de estudio.

Posteriormente se realizará una intersección entre cada alternativa con la cuenca de visibilidad general de la zona para comparar las alternativas de pasillo o área favorable de subestación, desde el punto de vista de la visibilidad.

En esta comparación se valorará la superficie de visibilidad de cada alternativa y el peso que cada punto relevante de observación tenga en el territorio. En la Figura 4-29 (a) se muestra el Modelo Digital de Terreno, en la Figura 4-29 (b) el Modelo Digital de Terreno con puntos de observación y en la Figura 4-29 (c) el Mapa de visibilidad (Visible = verde / No visible = rojo).

(a)

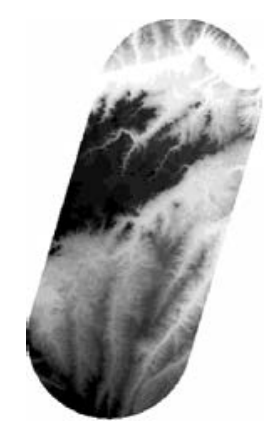

(b)

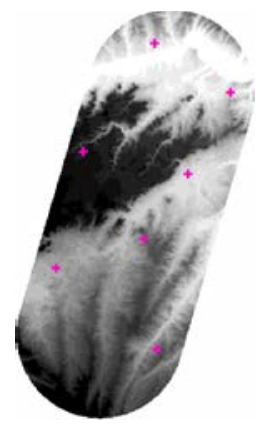

(c)

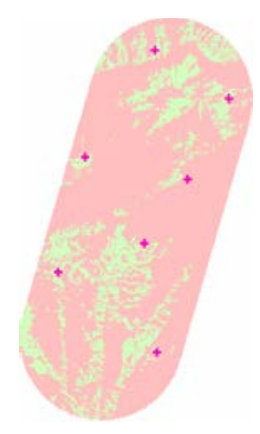

Figura 4-29. Ejemplo gráfico del cálculo de visibilidad general en el ámbito de análisis.

La Figura 4-30 (a) muestra el análisis de visibilidad general del ámbito del proyecto de línea, y la Figura 4-30 (b) el análisis de visibilidad general del ámbito del proyecto de subestación. En ambos casos se aplica una simbología que va desde los verdes oscuros (menor visibilidad) a los rojos (mayor visibilidad), siendo la ausencia de color de visibilidad nula desde los puntos de observación considerados.

(a)

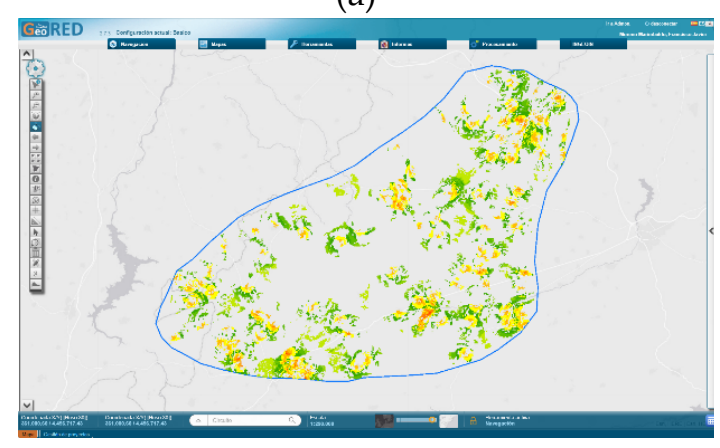

(b)

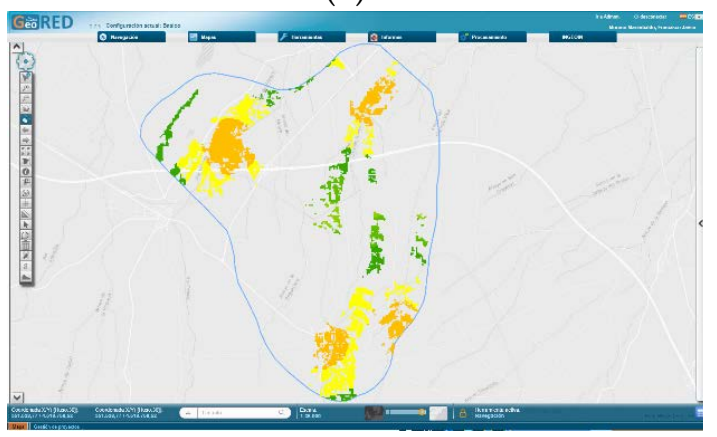

Figura 4-30. Ejemplo de análisis de visibilidad de los ámbitos de estudio de línea y subestación 


\subsection{Modelos de propuesta de cambios (Fase análisis ambiental)}

El objetivo de estos modelos es concretar, dentro del ámbito de estudio, las áreas en las que se analizará el proyecto de ingeniería.

Con la información previa de los modelos, que han permitido comprender el territorio dentro de cada ámbito de estudio y, complementado con el ineludible trabajo de campo, los técnicos podrán dibujar las alternativas de pasillo o áreas favorables.

Los procesos de este tipo de modelos se muestran en la Figura 4-31.

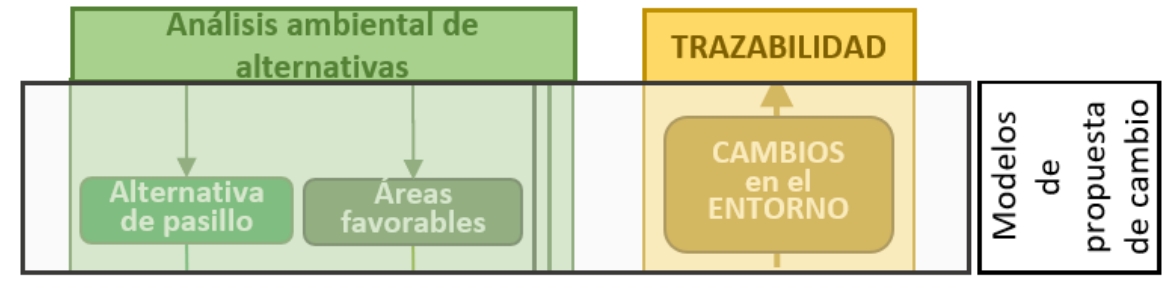

Figura 4-31. Procesos que dan soporte a los modelos de propuesta de cambio en la fase medioambiental

Para ambos tipos de proyecto, línea y subestación, la herramienta es idéntica. El único cambio se produce en la capa en la que se almacena cada geometría. El objetivo de esta herramienta es dibujar las alternativas de pasillo, con geometría de tipo polígono, más idóneas según los análisis medioambientales realizados en los procesos anteriores.

Al ejecutar la herramienta, el sistema muestra el modo mapa de GeoRED, y a través del widget de edición se podrán dibujar sobre el mapa las alternativas de pasillo o áreas favorables. La herramienta de edición también permite modificar objetos previamente dibujadas, tanto su geometría como sus atributos.

Figura 4-32 muestra el widget de edición representativo de ambos casos.

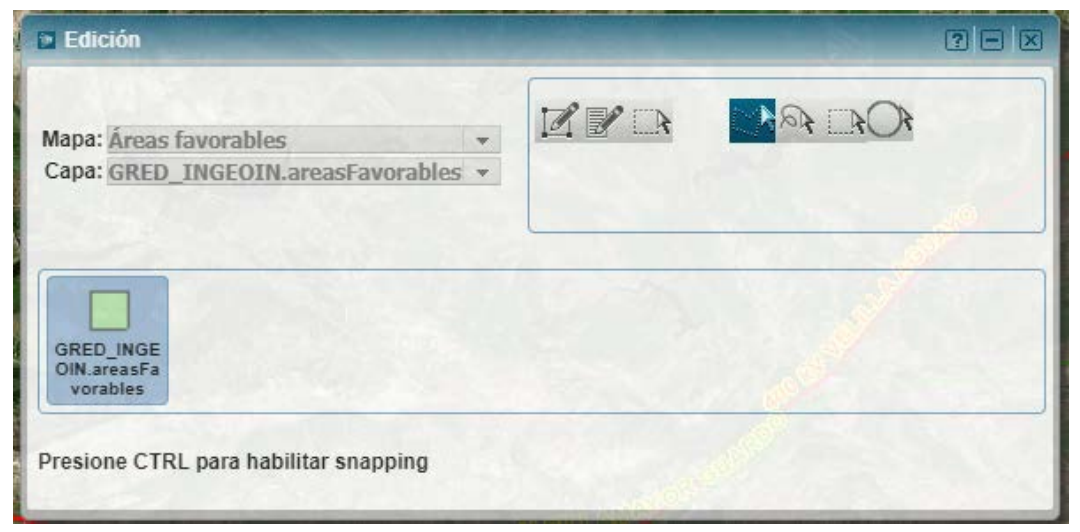

Figura 4-32. Widget de edición para alternativas de pasillo y áreas favorables

Un ejemplo de alternativas de pasillo se muestra en la Figura 4-33 (a) y un ejemplo de áreas favorables se muestra en la Figura 4-33 (b). 
(a)

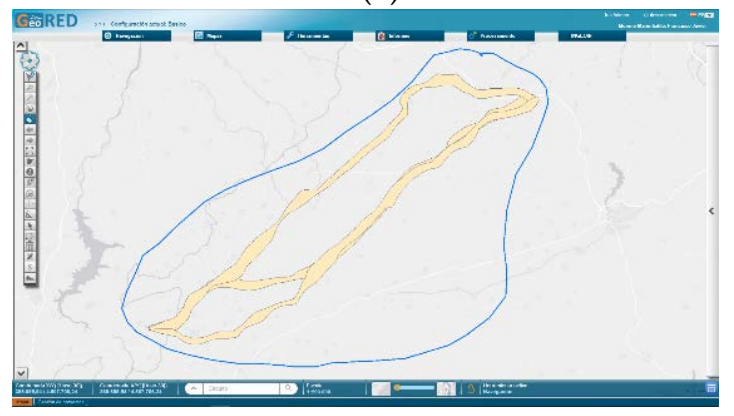

(b)

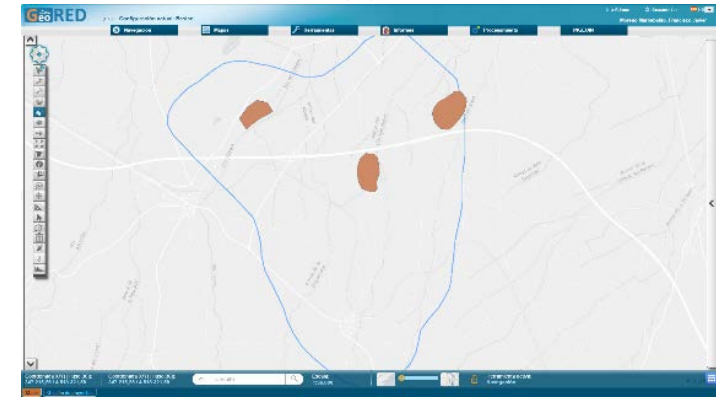

Figura 4-33. Ejemplo de alternativas de pasillo y de áreas favorables

La Figura 4-34 muestra, nuevamente como los equipos técnicos tienen que colaborar y tomar decisiones técnicas para que el proyecto de línea finalice en donde se localice el proyecto de subestación y viceversa.

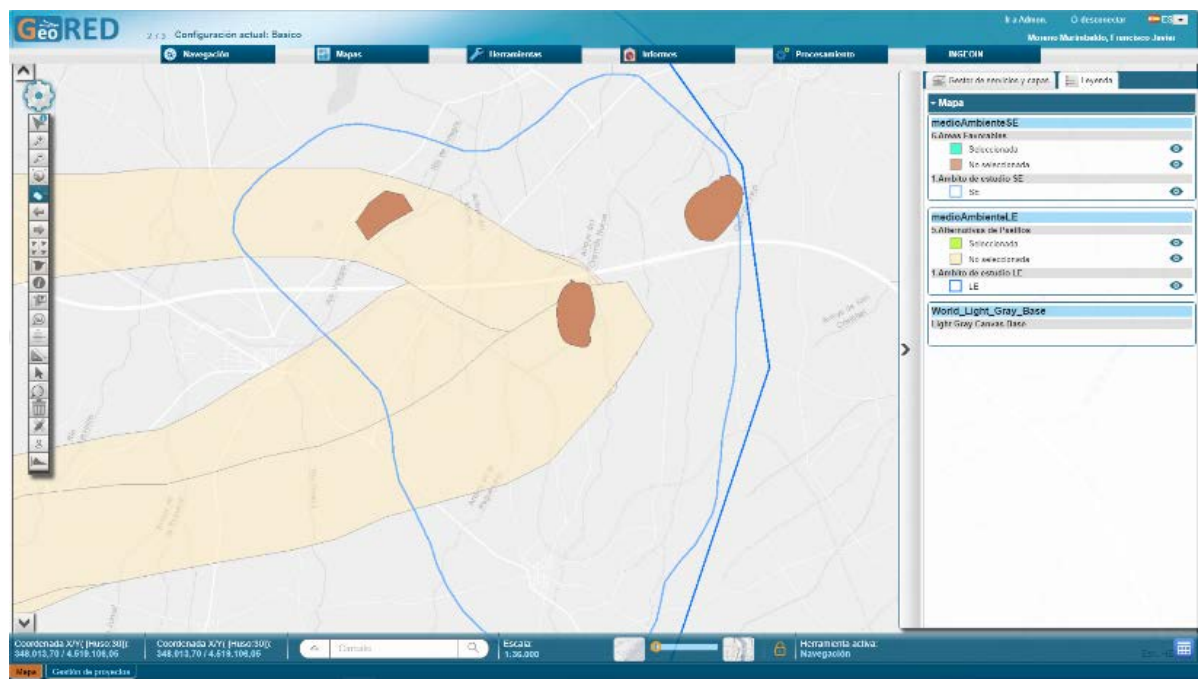

Figura 4-34. Ejemplo de coincidencia geográfica de los proyectos de línea y subestación

\subsection{Modelos de evaluación de impactos en el entorno (Fase análisis ambiental)}

El objetivo de estos modelos es evaluar, desde el punto de vista ambiental, cada una de las alternativas de pasillo o áreas favorables propuestas con el modelo anterior. La Figura 4-35 muestra los procesos de este tipo de modelos.

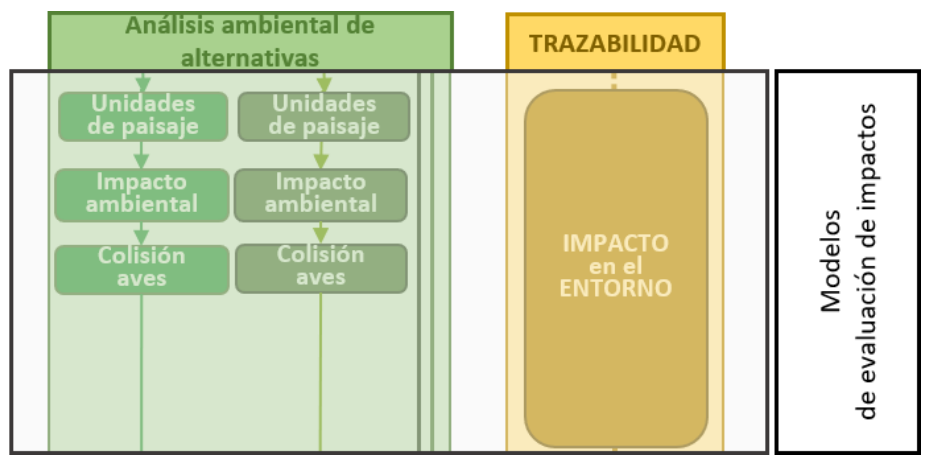

Figura 4-35. Procesos para evaluar el posible impacto de las alternativas y áreas favorables propuestas 
Concretamente, se analizarán los posibles impactos: en el paisaje, ambiental y de la avifauna.

a) Evaluación del impacto en el paisaje:

El objetivo de este proceso es calcular el porcentaje de afectación de las alternativas de pasillo o áreas favorables sobre los Parques Naturales.

La Figura 4-36, muestra un ejemplo de resultado de evaluación de afectación a las unidades del paisaje.

D Resultado del Análisis de Unidades de Paisaje
\begin{tabular}{|l|l|l||}
\hline Porcentaje de Afección de Unidades de Paisaje & AFECCION PARQUES NATURALES & Fecha ejecución \\
\hline Alternativa & 0 & $11 / 5 / 202012: 30: 47$ \\
\hline Alternativa 2 & 0 & $11 / 5 / 202012: 30: 47$ \\
\hline Alternativa 3 & 0 & $11 / 5 / 202012: 30: 47$ \\
\hline Alternativa 1 & & ( \\
\hline
\end{tabular}

Figura 4-36. Ejemplo de resultado de evaluación de afectación a las unidades del paisaje

b) Evaluación del impacto en el medio ambiente:

Tanto las alternativas de pasillo como las áreas favorables generadas, incluso con las consideraciones realizadas en la generación del mapa de acogida, han generado alguna afectación en el entorno. En esta fase se considerarán las afectaciones sobre el medio ambiente. Éstas deben ser identificadas, cuantificadas y ordenadas para poder seleccionar la de menor impacto. Para ello se generará una capa que será la suma de todas las figuras de protección ambiental y se realizará una intersección de cada una de las alternativas de pasillo sobre las figuras de protección obteniendo para cada alternativa: qué figuras atraviesa, su importancia y en qué magnitud son afectadas. De esta forma se podrá seleccionar la alternativa de pasillo de menor impacto ambiental.

En ambos tipos de proyectos se cuantifica el porcentaje de superficie de cada alternativa o cada área favorable que interseca con diferentes figuras de protección ambiental. Una vez ejecutada, clicando en el control lupa de visualización del cuadro de mando, se abrirá una tabla en el visor de GeoRED con los resultados, informando de los siguientes atributos: Alternativa (nombre o descripción alternativa), la afectación de Figuras de Protección (ZEPA, ENP, ZEPIM, LIC, RAMSAR) en porcentaje y la fecha de ejecución del proceso.

La Figura 4-37 muestra un ejemplo del resultado de la ejecución de esta herramienta.

\begin{tabular}{|c|c|c|c|c|c|c|c|}
\hline Resultado de & Inálisis de & o ambien & & & & ? & 凶 \\
\hline \multicolumn{8}{|c|}{ Porcentaje de Afección de figuras de protección } \\
\hline Alternativa & $\%$ ZEPA & $\%$ ENP & $\%$ ZEPIM & $\%$ LIC & $\%$ RAMSAR & Fecha ejecución & ๑ \\
\hline Alternativa 1 & 0 & 0.57 & 0 & 0.65 & 0 & $12 / 5 / 202017: 0 \ldots$ & $\Delta$ \\
\hline Alternativa 2 & 0 & 0.07 & 0 & 0.01 & 0 & $12 / 5 / 202017: 0 \ldots$ & \\
\hline Alternativa 3 & 0 & 0.07 & 0 & 0.01 & 0 & $12 / 5 / 202017: 0 \ldots$ & \\
\hline
\end{tabular}

Figura 4-37. Ejemplo del resultado del proceso de impacto ambiental de alternativas o áreas favorables

c) Evaluación del impacto sobre la avifauna:

El objetivo de este proceso es calcular el porcentaje de afectación de cada alternativa de pasillo o área favorable sobre las zonas de riesgo de colisión de aves del Mapa de Sensibilidad de REE 
que se muestra en la Figura 4-38. Este mapa sintetiza el riesgo de colisión de aves en ámbitos geográficos y clasifica el riesgo en función de nidificación de especies, rutas migratorias y colisiones detectadas con instalaciones eléctricas.

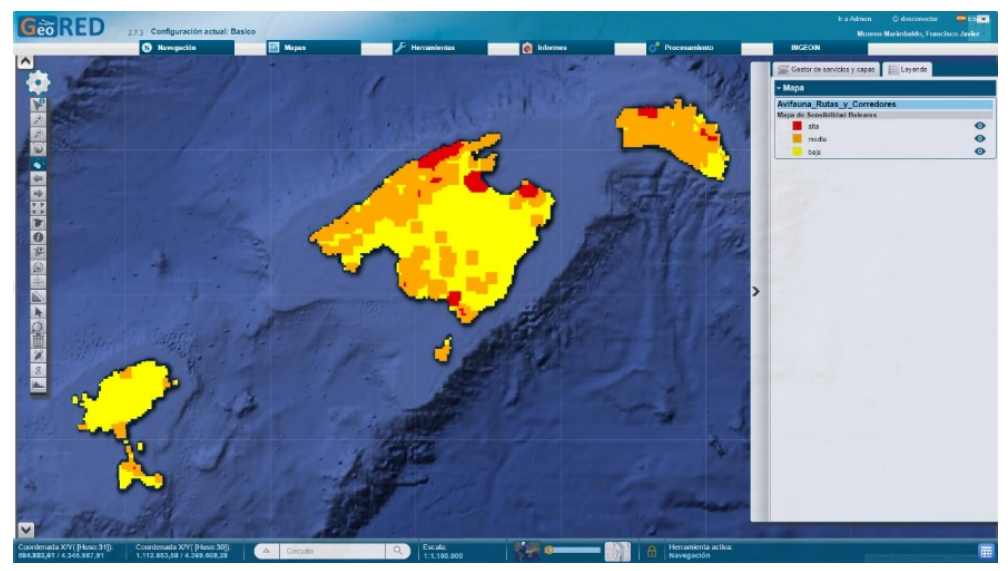

Figura 4-38. Mapa de sensibilidad de riesgo de colisión de aves

Realizado el proceso, seleccionando un elemento mostrará una tabla con los valores porcentuales de los riesgos en cada alternativa como se puede ver en la Figura 4-39.

\begin{tabular}{|c|c|c|c|c|c|}
\hline Desultado d & de Riesgo de Cc & Aves & & & 凶 \\
\hline \multicolumn{6}{|c|}{ Porcentaje de Afección de Riesgo de Colisión de Aves } \\
\hline Alternativa & RIESGO ALTO & RIESGO MEDIO & RIESGO BAJO & Fecha ejecución & () \\
\hline Alternativa 1 & 0 & 23.59 & 76.41 & $12 / 5 / 202017: 05: 31$ & $\Delta$ \\
\hline Alternativa 3 & 0 & 21.16 & 78.84 & $12 / 5 / 202017: 05: 31$ & \\
\hline Alternativa 2 & 0 & 24.58 & 75.42 & $12 / 5 / 202017: 05: 31$ & \\
\hline
\end{tabular}

Figura 4-39. Ejemplo del resultado del proceso que calcula el riesgo de colisión de aves

\subsection{Modelos de ocupación del territorio (Fase análisis ambiental)}

En esta fase los distintos modelos aplicados van constriñendo el proyecto de ingeniería, podría decirse que lo que se analiza es cómo el territorio afectará al proyecto.

Se analiza si las alternativas de pasillo o áreas favorables están o atraviesan zonas con alta probabilidad de caída de rayos o zonas con una corrosión superior a la media en España sobre los materiales de las instalaciones eléctricas.

La Figura 4-40 muestra los procesos de este tipo de modelos.

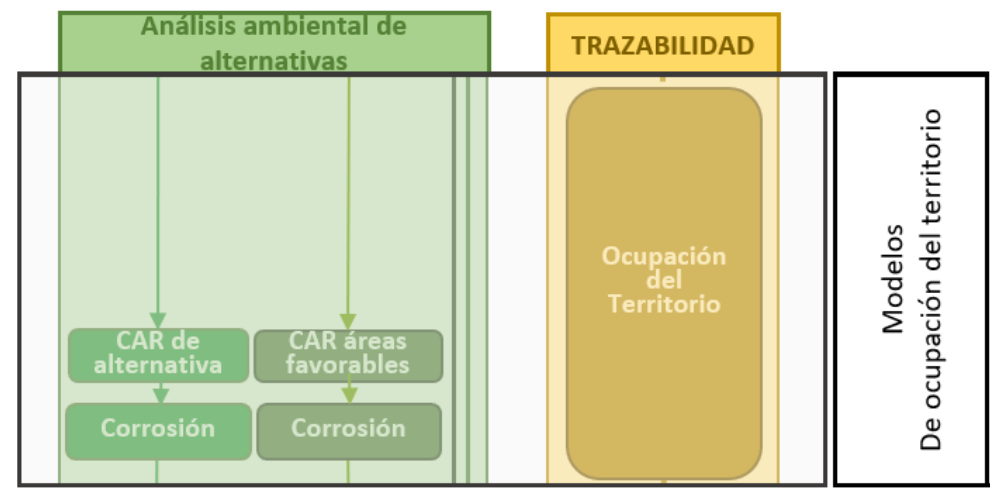

Figura 4-40. Procesos de los modelos de ocupación del territorio 
a) Análisis de la densidad de caída de rayos en las alternativas del proyecto:

La caída de rayos sobre las instalaciones o cerca de ellas provoca a menudo incidencias que se intentan solventar con medidas de protección automática que, en muchos casos, no son suficientes y es necesaria una actuación manual o comprobación visual, por lo que una zona de alta densidad de rayos provoca mayores costes de mantenimiento y mayor probabilidad de indisponibilidad de la instalación.

La Figura 4-41 muestra el mapa de densidad de caída de rayos de AEMET junto con la división administrativa de España para su interpretación.

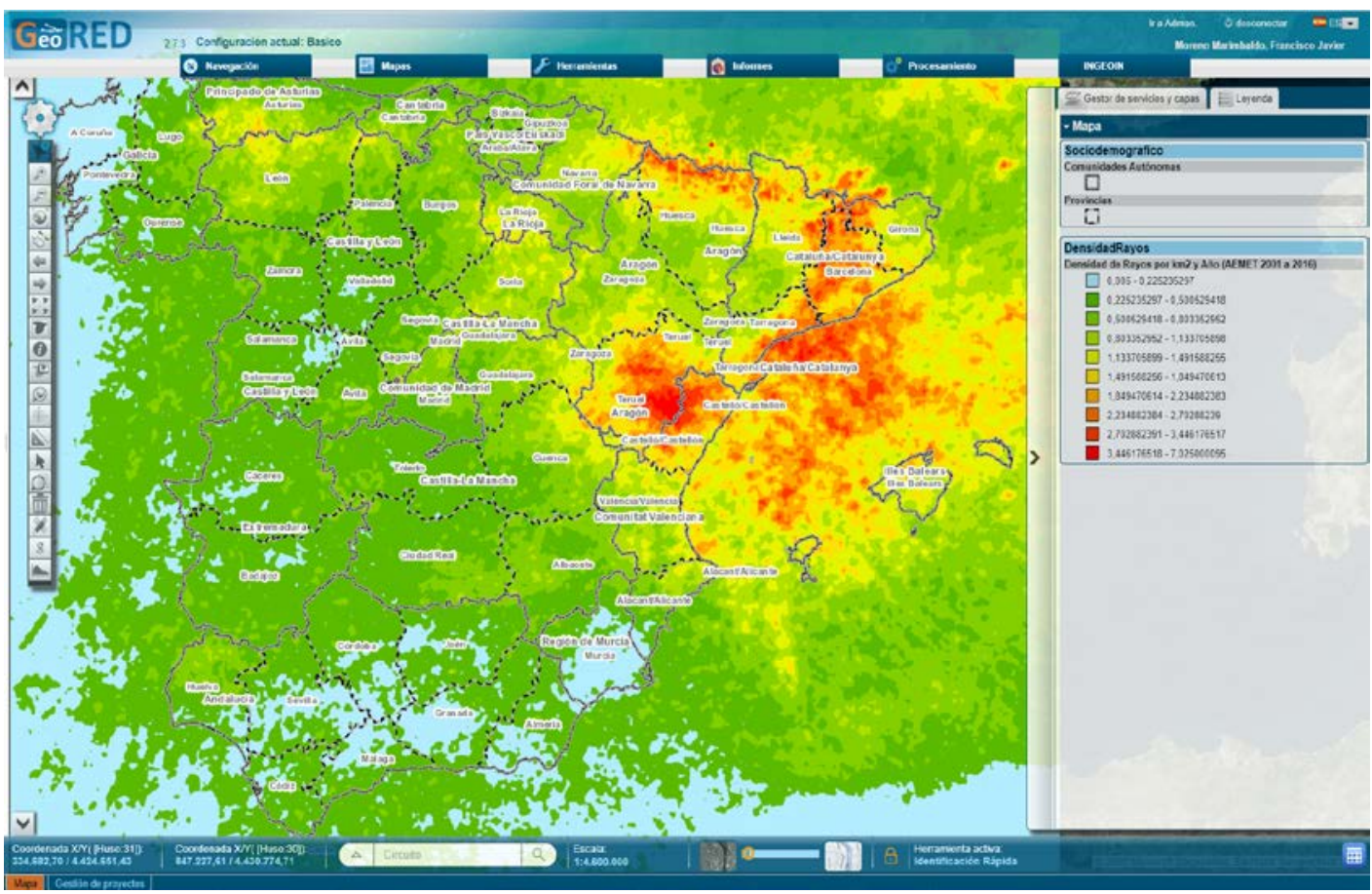

Figura 4-41. Mapa de densidad de caída de rayos por km² y año. Datos 2001-2016 de AEMET

A partir del mapa de densidad media de rayos por kilómetro cuadrado y año publicado por AEMET con datos entre 2001 a 2016, este proceso analiza las alternativas de pasillo y las áreas favorables del proyecto y calcula por intersección de ambas capas las afectaciones en porcentaje de superficie derivadas de este fenómeno meteorológico.

La Figura 4-42 muestra un ejemplo del resultado de este proceso.

\begin{tabular}{|c|c|c|c|c|c|}
\hline Resultado d & de Riesgo de Co & Rayos & & & 区 \\
\hline \multicolumn{6}{|c|}{ Porcentaje de Afección de Riesgo de Colisión de Rayos } \\
\hline Alternativa & RIESGO ALTO & RIESGO MEDIO & RIESGO BAJO & Fecha ejecución & (†) \\
\hline Alternativa 2 & 0 & 4.69 & 95.31 & $11 / 5 / 202012: 54: 46$ & - \\
\hline Alternativa 3 & 0 & 0 & 100 & $11 / 5 / 202012: 54: 46$ & \\
\hline Alternativa 1 & 0 & 3.25 & 96.75 & $11 / 5 / 202012: 54: 46$ & \\
\hline
\end{tabular}

Figura 4-42. Ejemplo del resultado del proceso que calcula la zona de riesgo de caída de rayos

b) Evaluación de la corrosión acusada sobre las instalaciones:

A partir del mapa de zonas de corrosión de REE, este proceso analiza las alternativas de pasillo y las áreas favorables del proyecto y calcula, realizando una intersección de ambas capas, 
cómo se verán afectadas en porcentaje de superficie, por este fenómeno que afecta al mantenimiento de las instalaciones.

La Figura 4-43 muestra el mapa de zonas de corrosión de REE.

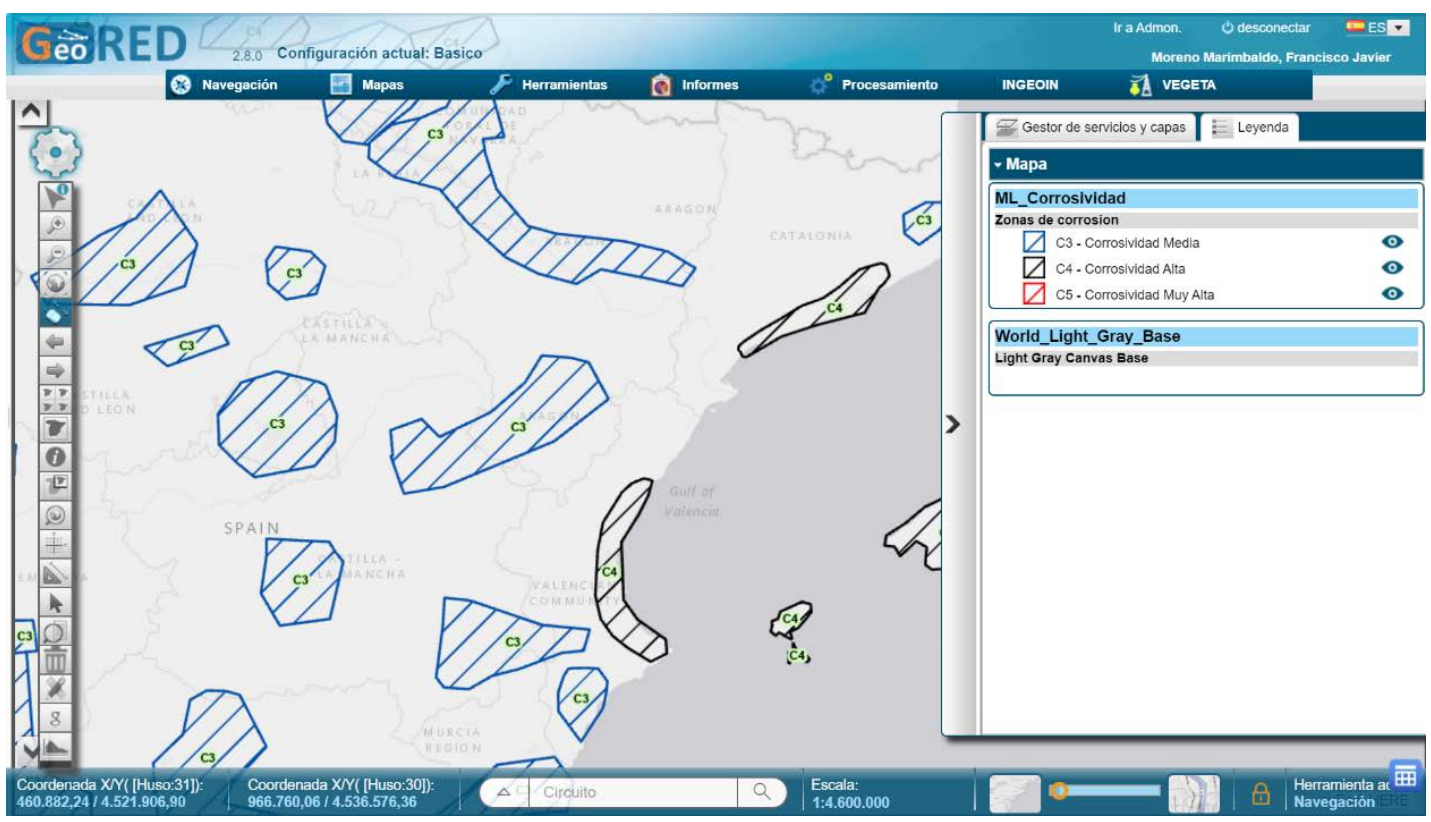

Figura 4-43. Mapa de zonas de corrosión de REE

La Figura 4-44 muestra un ejemplo del resultado de ejecución de este proceso.

\begin{tabular}{|c|c|c|c|c|c|c|c|c|}
\hline Desultado d & $\mathrm{Ar}$ & álisis de Zonas de & Corrosión & & & & ? & 凶 \\
\hline Porcentaje de & fece & Eión de Zonas de & prrosión & & & & & \\
\hline Alternativa & $\Delta$ & C1 - MUY BAJA & C2 - BAJA & C3 - MEDIA & C4 - ALTA & C5 - MUY ALTA & Fecha ejecución & $\boldsymbol{\oplus}$ \\
\hline Alternativa 1 & & 0 & 0 & 14.37 & 0 & 0 & $13 / 5 / 2020$ 8:35:26 & $\triangle$ \\
\hline Alternativa 2 & & 0 & 0 & 13.32 & 0 & 0 & 13/5/2020 8:35:26 & \\
\hline Alternativa 3 & & 0 & 0 & 21.37 & 0 & 0 & $13 / 5 / 20208: 35: 26$ & \\
\hline
\end{tabular}

Figura 4-44. Ejemplo del resultado de ejecución del proceso de zonas de corrosión

\subsection{Modelos de decisión (Fase análisis ambiental)}

Para poder identificar la alternativa de pasillo o área favorable de menor impacto se analizarán en conjunto los resultados de los modelos de evaluación antes descritos: de impacto ambiental, de unidades del paisaje, del riesgo de colisión de aves (avifauna), del modelo de visibilidad general y las zonas con necesidad de un mayor mantenimiento, a los que se sumarán los criterios de coste económico y de longitud de cada alternativa.

La Figura 4-45 muestra los procesos de este tipo de modelos.

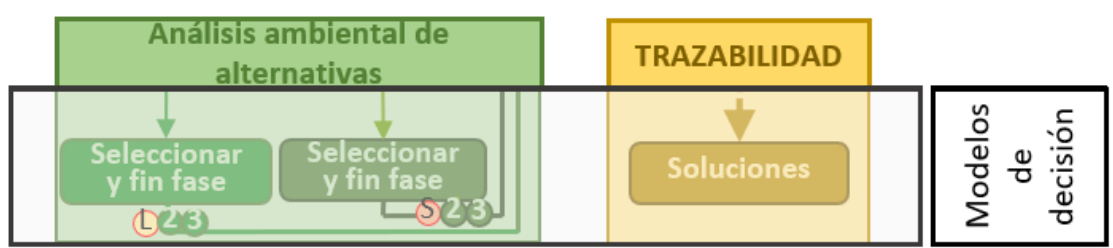

Figura 4-45. Procesos del modelo de decisión 
Esta decisión tiene un alto componente humano, por tanto, más subjetivo y basado en la experiencia, que incluso podrá matizar cualquiera de las alternativas estudiadas. Un ejemplo del resultado de este proceso para proyecto de línea se muestra en la Figura 4-46 (a), y de proyecto de subestación en la Figura 4-46 (b).

(a)

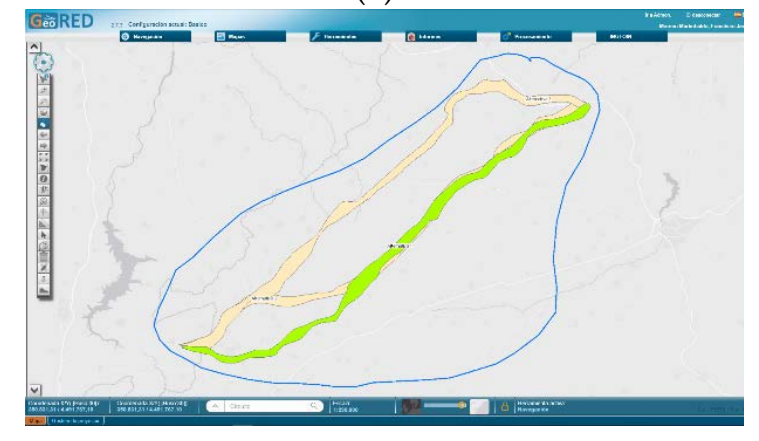

(b)

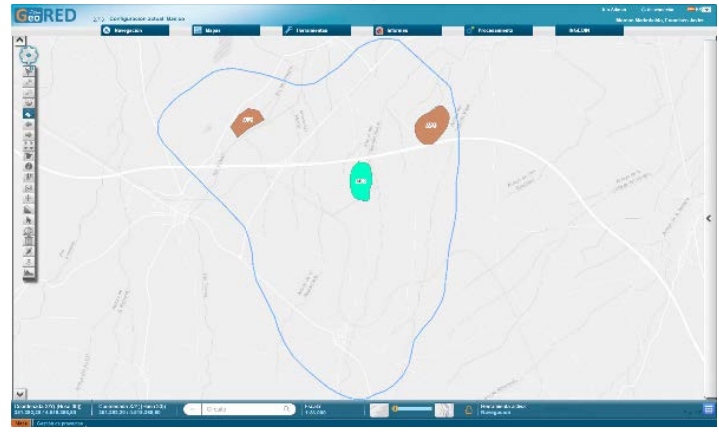

Figura 4-46. Ejemplo gráfico de selección de alternativas de pasillo y áreas favorables

La ejecución de este proceso significa el fin de la fase de análisis ambiental de alternativas. Una vez ejecutado, permitirá comenzar el proceso de ingeniería.

\subsubsection{Fase de diseño del proyecto de ingeniería}

En esta fase se diseña un proyecto para cada una de las tres alternativas propuestas en la fase anterior. El ámbito de estudio de ingeniería queda restringido a los pasillos para líneas o áreas favorables para subestaciones que las alternativas ambientales han propuesto en la fase anterior.

El diseño de un proyecto tendrá diferentes pasos dentro de esta fase, dejando al margen los aspectos eléctricos, los mecánicos consecuencia de los esfuerzos generados por los cables conductores y soportados por los apoyos y la obra civil en cuanto a construcción de accesos y cimentaciones.

La Figura 4-47 muestra la evolución de la información geográfica en la fase de ingeniería:

a) el primer paso (Figura 4-47 (a)) es el diseño de las alineaciones que se convierte en el trazado viable de la nueva línea eléctrica que obligatoriamente estará dentro del pasillo generado previamente.

b) El segundo paso es la consolidación de los vértices de la alineación como apoyos (ver Figura 4-47 (b)).

c) El tercero es la distribución de apoyos, en la que todos los vértices del paso anterior suponen un apoyo. Entre dos vértices habrá tantos apoyos como sean necesarios (ver Figura 4-47 (c)).

d) El cuarto paso es el diseño de accesos a los apoyos (Figura 4-47 (d)).

e) Por último, el quinto paso es la generación de todas las superficies de afectación de la futura línea eléctrica (Figura 4-47 (d)). 
(a)

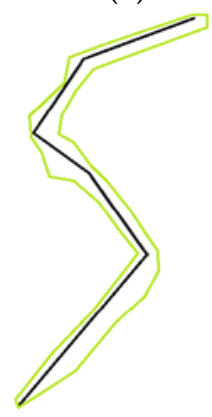

(b)

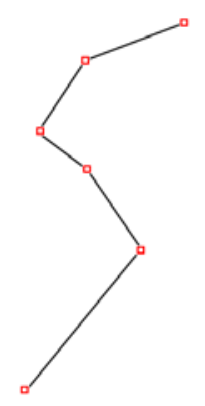

(c)

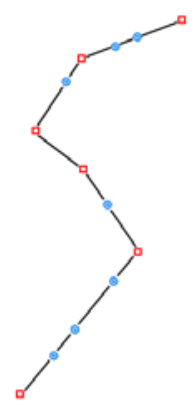

(d)

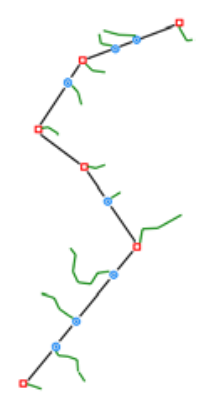

(e)

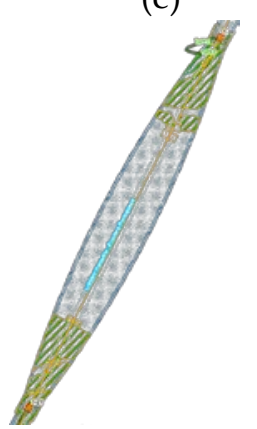

Figura 4-47. Ejemplo gráfico de la evolución de la información geográfica en fase de ingeniería

Para llevar a cabo estos pasos se ejecutan los siguientes modelos:

\subsection{Modelos para comprensión del ámbito de estudio (Fase ingeniería)}

Para analizar la información geográfica dentro de cada pasillo en este modelo se van a gestionar datos a una escala mucho más precisa que en las fases anteriores, entre 1:5.000 y 1:2.000. Destacan el de un MDT con una resolución mínima de $5 \mathrm{~m}$, la longitud de los vanos (distancia entre 2 torres eléctricas o apoyos consecutivos), la existencia de caminos transitables y las preferencias y restricciones para la ubicación de vértices y apoyos. Estas preferencias y restricciones vienen definidas mayoritariamente por la geomorfología del terreno, intentando evitar cauces de ríos o zonas inundables, carreteras y su servidumbre, zonas de difícil acceso con maquinaria sobre ruedas, vías pecuarias, etc.

Se analizará una propuesta por cada alternativa de pasillo o área favorable, siendo los procesos de este tipo de los modelos que se muestran en la Figura 4-48.

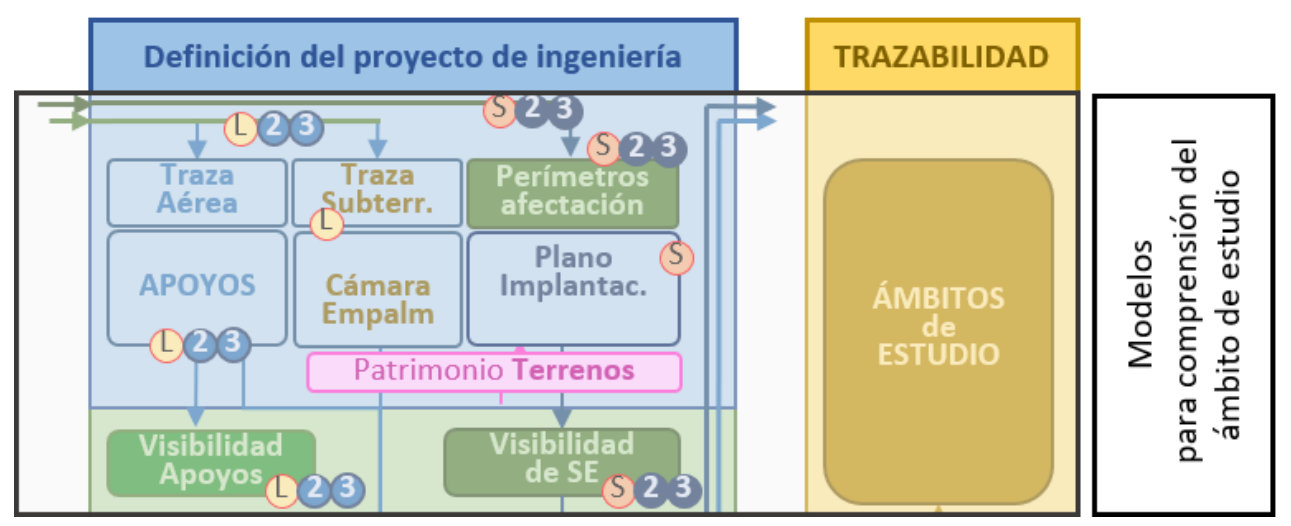

Figura 4-48. Procesos del modelo para comprensión del ámbito de estudio de ingeniería

a) Estimación de trazas de línea y huella de la subestación en el terreno

Estos procesos no generan ningún resultado, únicamente se utilizan para cargar las primeras aproximaciones del proyecto de ingeniería. Estas aproximaciones, aun estando definidas dentro de las alternativas de pasillo o las áreas favorables, establecen una colaboración entre los técnicos de la fase ambiental y los de ingeniería para garantizar que cada fase que se avance en el proyecto cumpla también con los requisitos de la fase anterior. 
También sirven para hacer colaborar a los técnicos de ambas ingenierías (línea y subestación) y adecuar sus estudios técnicos a la confluencia geográfica de ambas instalaciones, es decir, la traza de la línea se inicia o finaliza en la subestación.

i. Proyecto de línea:

La traza aérea o subterránea cargada servirán para comprender y explicar cuál será el terreno concreto que sobre el que podría implantarse la futura línea. Se cargarán tantas trazas de proyecto como alternativas de pasillo haya establecido la fase ambiental del proyecto para poder compararlas posteriormente.

ii. Proyecto de subestación:

El perímetro de afectación servirá para comprender y explicar cuál será el terreno concreto sobre el que podría implantarse la subestación, es decir, la huella que se materializaría en el territorio. Se cargarán tantos perímetros de afectación o huellas de la subestación como áreas favorables que haya establecido la fase ambiental del proyecto.

b) Estimación de la implantación de las instalaciones en el terreno

Estos procesos sirven para facilitar la toma de decisiones en uno de los puntos más críticos de los proyectos ya que de no existir una coordinación y sincronización precisa de los técnicos de ambas ingenierías puede acarrear retrabajos de alto coste económico y dilatación de plazos que pueden causar incumplimientos de las necesidades de la red de transporte.

Una instalación eléctrica de alta tensión tiene 3 fases eléctricas, cada una de ellas corresponde a un cable o conductor. La Figura 4-49 (a) muestra en 3D y la Figura 4-49 (b) en 2D, la llegada de una línea de dos circuitos a una subestación donde cada conductor conecta al punto correspondiente a su fase.

(a)

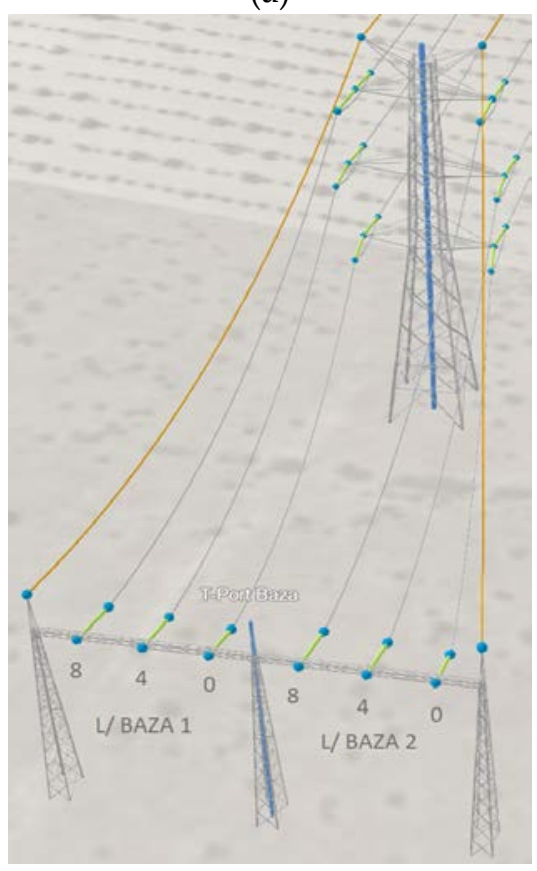

(b)

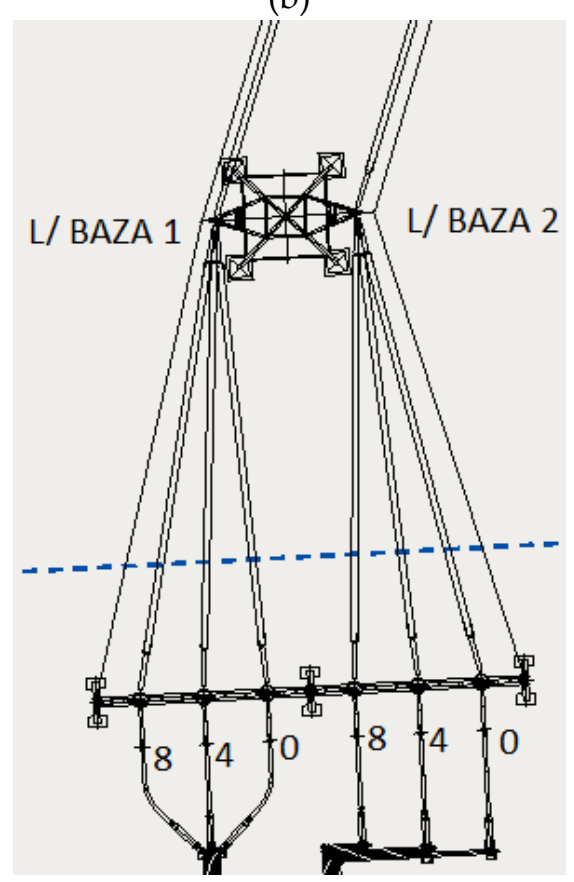

Figura 4-49. Ejemplo de encuentro de proyecto de línea y subestación 
La parte de la subestación (pórticos) donde se conectan la línea y la subestación deben coincidir, pero no únicamente en cuanto a localización geográfica, sino en cuanto al orden o puntos de conexión de las fases eléctricas de ambas ingenierías.

En este proceso se cargan, para el proyecto de línea, los archivos generados (XML y KMZ) por el software específico de diseño técnico de líneas eléctricas PLS-CADD (PLS-CADD ${ }^{\mathrm{TM}}$, s.f.) que incorpora la librería de tipos de torre en 3D y, para el proyecto de subestaciones, el archivo en formato $d w g$ incluyendo la superficie de la subestación, los pórticos y el orden de fases.

Este proceso añade la particularidad de la visualización 3D del proyecto, gracias a la interpretación de estos archivos siendo el proceso el siguiente:

1. Generación de los apoyos: carga los datos de los apoyos

2. Generación de la geometría de entidades 2D

3. Generación de puntos de enganche: puntos azules en la Figura 4-50

a. Entre apoyo y cables (para cables de tierra)

b. entre apoyo y cadenas de aisladores

c. entre aisladores y cables

4. Generación de cadenas de aisladores (Líneas verdes en la Figura 4-50)

5. Procesado de vanos y cabes de tierra. Con la colección de apoyos y sus puntos de enganche se generan los cables (líneas curvas en la Figura 4-50)

a. Cables de tierra en naranja

b. Cables conductores en gris

6. Procesado del KMZ. Se carga la celosía del apoyo que está en el KMZ asociado al fichero PLS-CADD (Celosía del apoyo en la Figura 4-50).

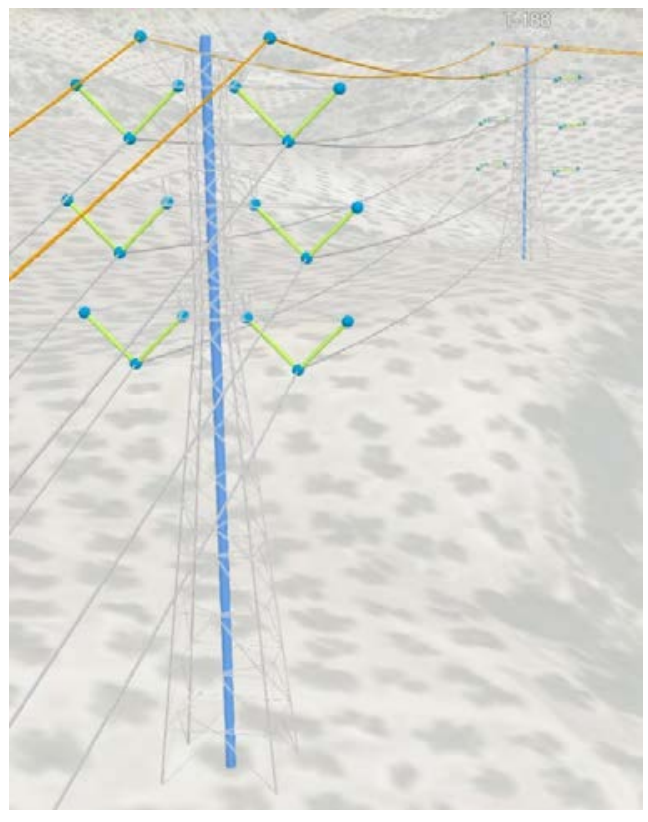

Figura 4-50. Ejemplo 3D de las entidades que tienen geometría en el entorno.

También es necesario consensuar con los técnicos encargados de la gestión patrimonial de la compañía sobre la viabilidad de adquisición de las parcelas sobre las que construirá la subestación. 


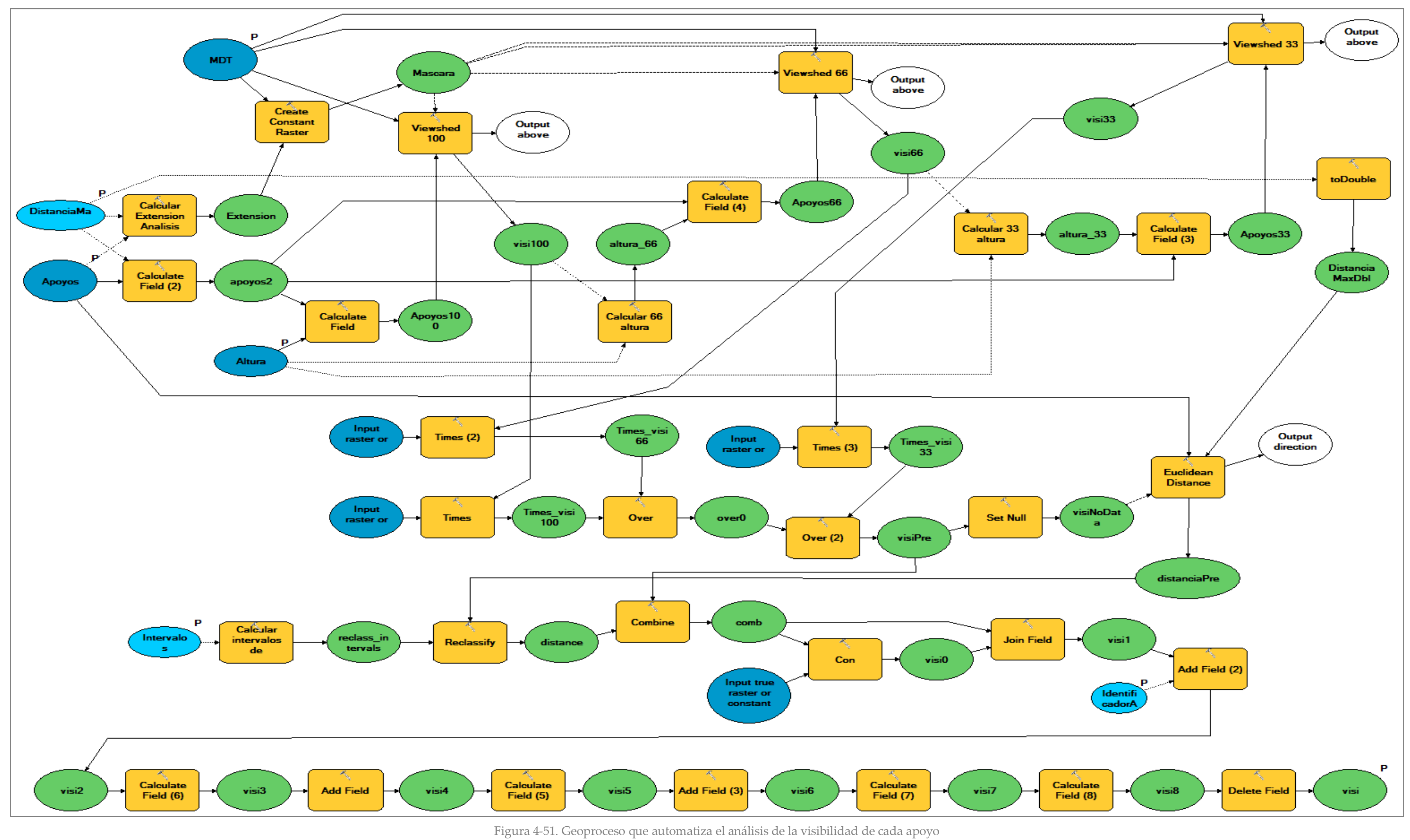


Se realiza con las herramientas ya desarrolladas en el sistema corporativo GeoRED. La Figura 4-52 (a) muestra la herramienta de visibilidad de apoyos y la Figura 4-52 (b) la herramienta de visibilidad de subestaciones.

(a)

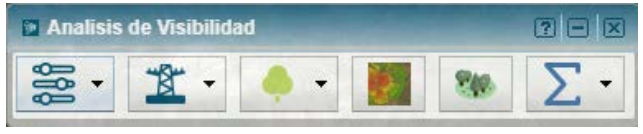

(b)

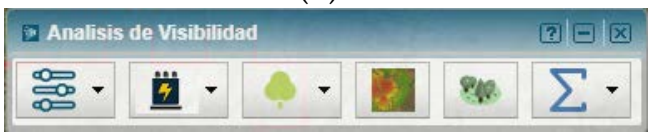

Figura 4-52. Herramientas de análisis de visibilidad de GeoRED

i. $\quad$ Proyecto de línea:

Este modelo analiza únicamente la visibilidad de los apoyos ya que su visibilidad crea más impacto que la de los conductores. Su objetivo es valorar de forma cuantitativa y cualitativa la visibilidad de los apoyos, (Moreno, 2017). Cuantitativamente calculando la superficie de la cuenca de visibilidad para cada apoyo de forma independiente y en conjunto con el resto de los apoyos del análisis. Cualitativamente al considerar como parámetros de ponderación la distancia entre cada punto del territorio estudiado y cada apoyo, y la parte vista de cada apoyo (parte alta, parte media-alta, apoyo completo).

Este modelo de geoprocesamiento, de forma resumida, realiza 2 tareas fundamentales. La primera de ellas es la modificación del modelo digital del terreno añadiendo la vegetación como apantallamientos de visibilidad naturales. La segunda consiste en un análisis triple para cada apoyo, es decir, se calcula la cuenca de visibilidad de cada apoyo con su altura total, con el $66 \%$ de su altura y con el 33\% de la altura. De esta forma se puede determinar qué parte de cada apoyo es vista (cabeza del apoyo, parte media alta o apoyo completo) desde cada punto del ámbito de estudio.

Para cada alternativa se realiza una combinación de los resultados del análisis de visibilidad de cada apoyo. El modelo de combinación de resultados queda representado en la Figura 4-53. Este modelo de geoprocesamiento combina los resultados de la ejecución del modelo anterior. Así, a cada punto del territorio se le asignará la información alfanumérica del análisis de visibilidad de todos los apoyos considerados, dando como resultado un análisis de visibilidad de cada alternativa.

El resultado concreto para un punto del ámbito de estudio viene definido por los siguientes atributos: el número de apoyos que se ven desde ese punto, la distancia a la que está cada uno de ellos y qué parte de cada apoyo es vista. La importancia de la visibilidad está directamente relacionada con la ponderación que se realiza por la distancia a cada apoyo y la parte visible del mismo. 


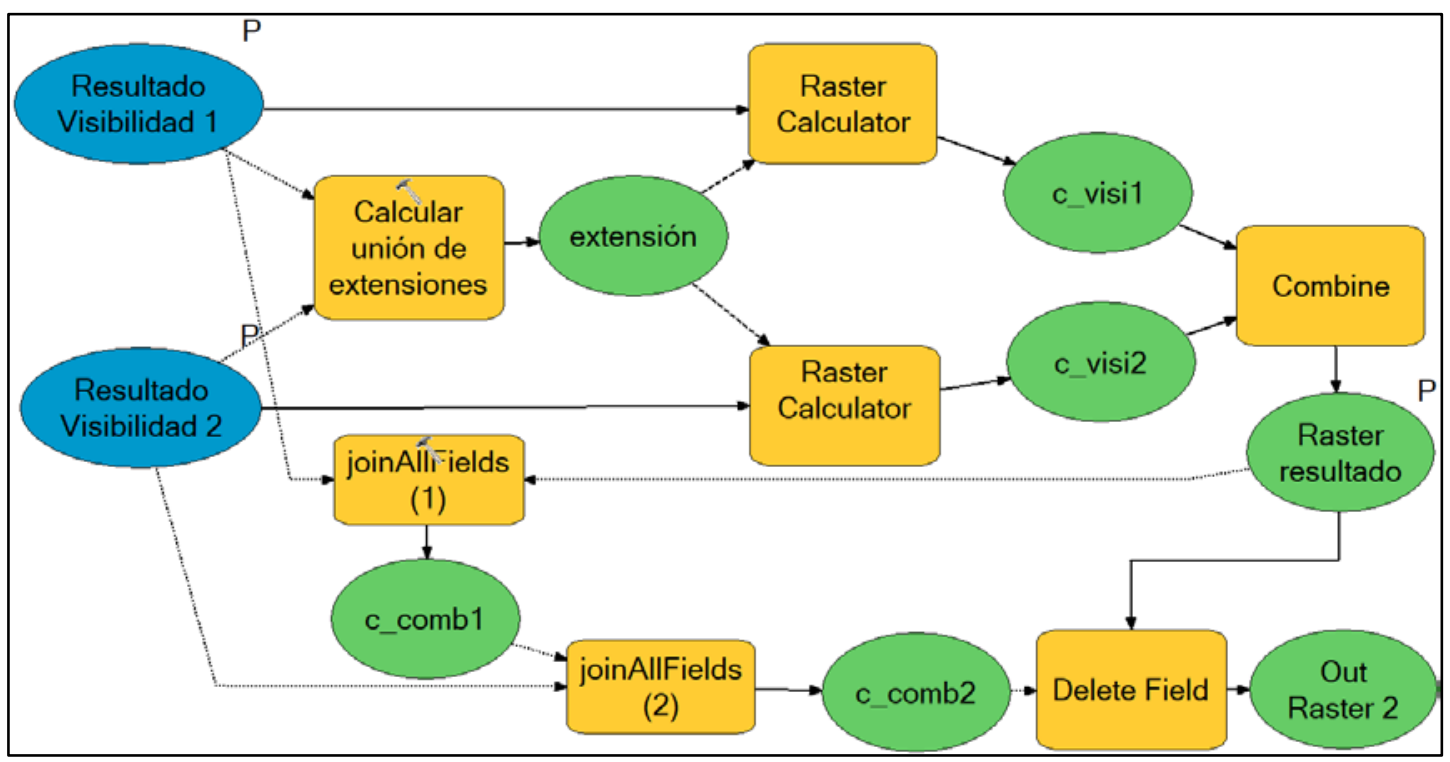

Figura 4-53. Geoproceso que combina los resultados de visibilidad de cada apoyo analizado

En la Figura 4-54 se presenta como ejemplo el resultado de aplicar este modelo, donde se muestra el detalle de visibilidad en un punto del ámbito, que informa del detalle de la visibilidad de los apoyos analizados. Siendo el color verde el que indica menor visibilidad y el color rojo el que indica mayor visibilidad. La ausencia de color indica visibilidad nula o fuera del rango del análisis.

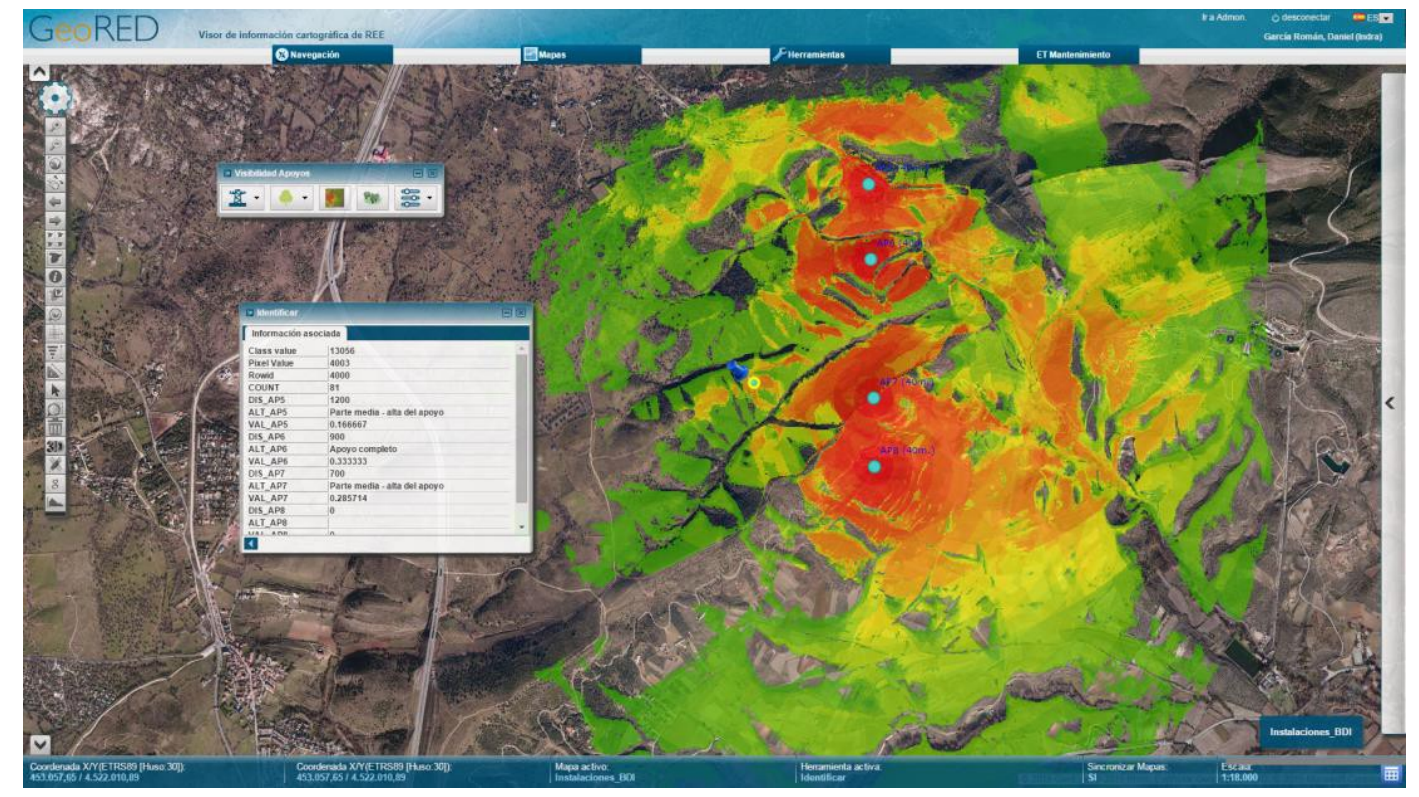

Figura 4-54. Ejemplo gráfico del resultado del análisis de la visibilidad

Como resultado adicional se genera un escenario 3D (ver Figura 4-55) conteniendo el mapa de visibilidad, los apoyos analizados y las zonas de arbolado consideradas en el análisis, con su especie y altura. La representación 3D de los apoyos es obtenida de la librería de tipos de torre que incorpora PLS-CADD y la representación 3D de la vegetación se realiza a partir de archivo en formato dae (Digital Asset Exchange basados en el formato XML COLLADA, abreviatura 
de Collaborative Design Activity) que se compone con dos imágenes montadas perpendicularmente de cada especie de árbol o arbusto.

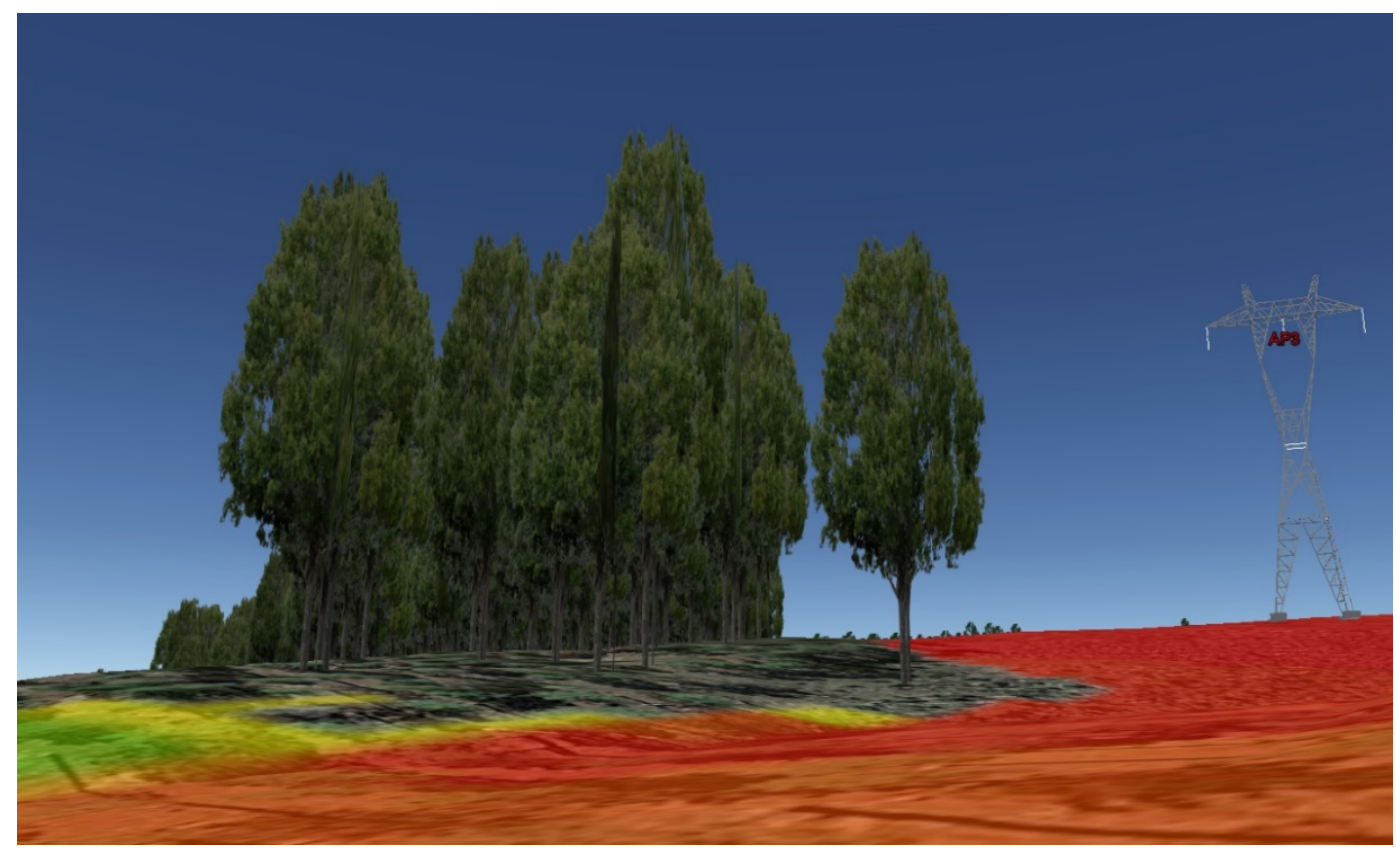

Figura 4-55. Ejemplo de escenario 3D de análisis de visibilidad

ii. Proyecto de subestación:

Para calcular la visibilidad de subestaciones, el modelo es el mismo que en proyectos de línea, con la diferencia de que se analizarán los vértices de la superficie que delimita la futura subestación como elementos a calcular su visibilidad.

\subsection{Modelos de propuesta de cambios (Fase ingeniería)}

Tras haber analizado diferentes propuestas de proyecto, tanto de línea como de subestación, dentro de las alternativas de pasillo o las áreas favorables, este tipo de modelos concreta la propuesta de cambios sobre el territorio en forma de afectaciones. Estas afectaciones reflejan exactamente cómo se materializará el proyecto sobre el territorio y serán de dos tipos, por un lado, los caminos de acceso para la construcción y el mantenimiento de las futuras instalaciones y, por otro lado, las afectaciones de la propia instalación eléctrica. Se analizará una propuesta por cada alternativa de pasillo o área favorable.

Los procesos de este tipo de modelos se muestran en la Figura 4-56.

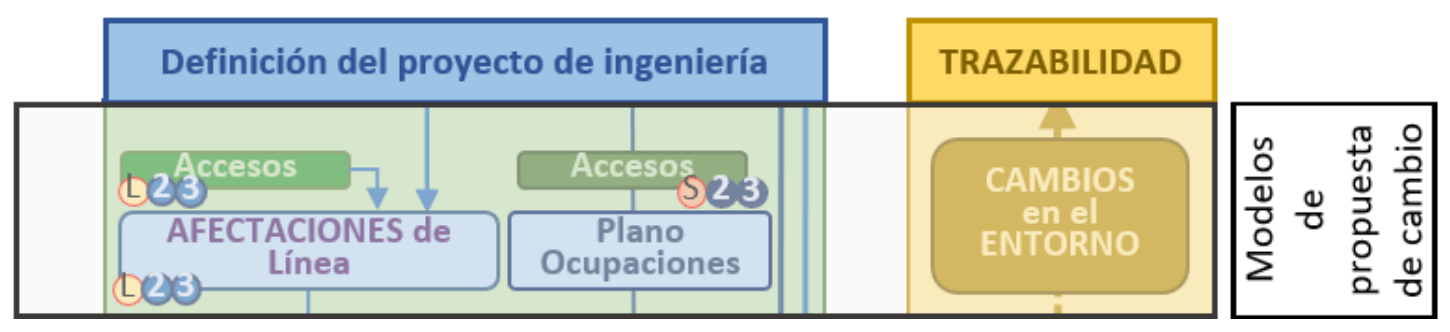

Figura 4-56. Procesos de los modelos de propuesta de cambio en fase de ingeniería 
a) Carga de caminos de acceso

Los caminos de acceso son una de las entidades que, sin ser una instalación eléctrica, son indispensables para la construcción y futuro mantenimiento de estas. Aunque forman parte del proyecto de ingeniería, serán los técnicos de medio ambiente los encargados de su diseño, codificación y carga en el sistema, por este motivo el color de sus cuadros de mando es verde.

Los procesos de carga de caminos de acceso no generan resultado adicional. Su función es la de permitir su visualización y la comprobación de la estructura de datos para los procesos de análisis espacial posteriores.

i. $\quad$ Proyecto de línea:

Se considera camino de acceso susceptible de considerarse en el proyecto a cualquier recorrido a partir del último camino público transitado. También es posible, por el tipo de maquinaria, que haya que acondicionar algún camino público, por lo que habrá que considerar la afectación que suponga dicha acción. Los caminos de acceso a los apoyos de la futura línea pueden ser de diferentes tipos:

- Nuevo a construir

- Existente en buen estado

- Campo a través

- Existente a acondicionar

- Tramo con actuación (necesidad de actuar sobre cualquier tipo de construcción)

Para cualquiera de los tipos anteriores, como norma general, se consideran las siguientes superficies de afectación:

- Ancho en firme

- Desmonte

- Terraplén

El ancho en firme se establece en 4 metros, sin embargo, en zonas de pendientes muy acusadas puede variar para permitir la maniobra de giro de las máquinas.

La Figura 4-57 (a) muestra la superficie de afectación del ancho en firme resaltada y la Figura 4-57 (b) la superficie de afectación resaltada del desmonte necesario por la pendiente lateral del camino a construir.

(a)

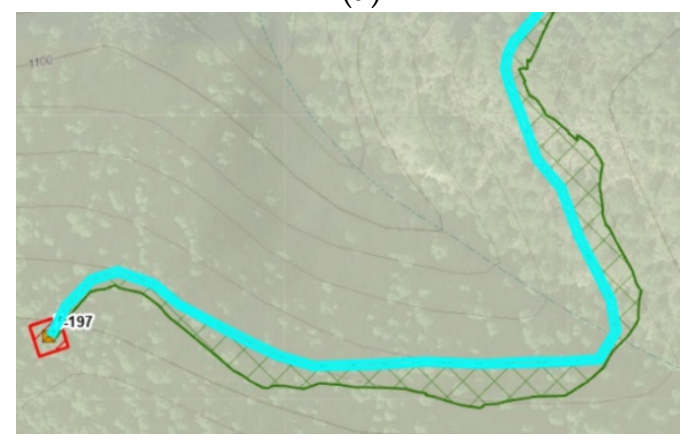

(b)

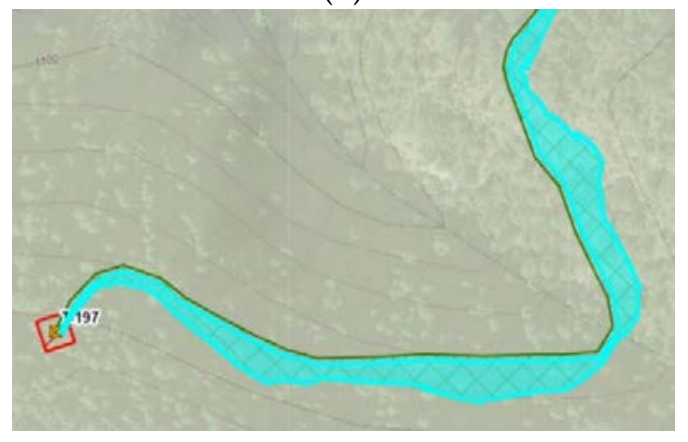

Figura 4-57. Ejemplo de superficies de afectación de un camino de acceso 
Además de la carga de información, esta herramienta ofrece la posibilidad de descargar la plantilla y poder así poblar el archivo de carga (file geodatabase) con la estructura de campos necesaria. Esta descarga, además de la plantilla de accesos incorporará la distribución de apoyos cargada previamente, lo que servirá de guía a los técnicos de diseño de caminos de acceso. La Figura 4-58 (a) muestra el cuadro de mando antes de su ejecución en el que se ofrece la posibilidad de descarga de la plantilla de accesos y la Figura 4-58 (b) muestra el cuadro de mando después de haber cargado los accesos.

(a)

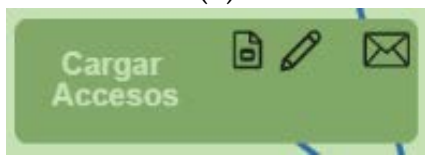

(b)

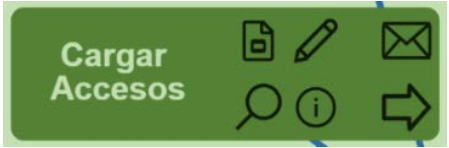

Figura 4-58. Cuadro de mando de carga de caminos de acceso de línea

ii. Proyecto de subestación:

Las subestaciones suelen construirse próximas a viales o carreteras públicas, por lo que su camino de acceso será una prolongación de estos y serán construidos para soportar el tráfico de vehículos pesados.

Al igual que en proyectos de línea, serán los técnicos de medio ambiente los encargados de, tras comprobar en campo el cumplimiento ambiental del diseño del futuro acceso, realizar la carga de este.

La Figura 4-59 muestra un ejemplo, en verde, de un camino de acceso a una subestación.

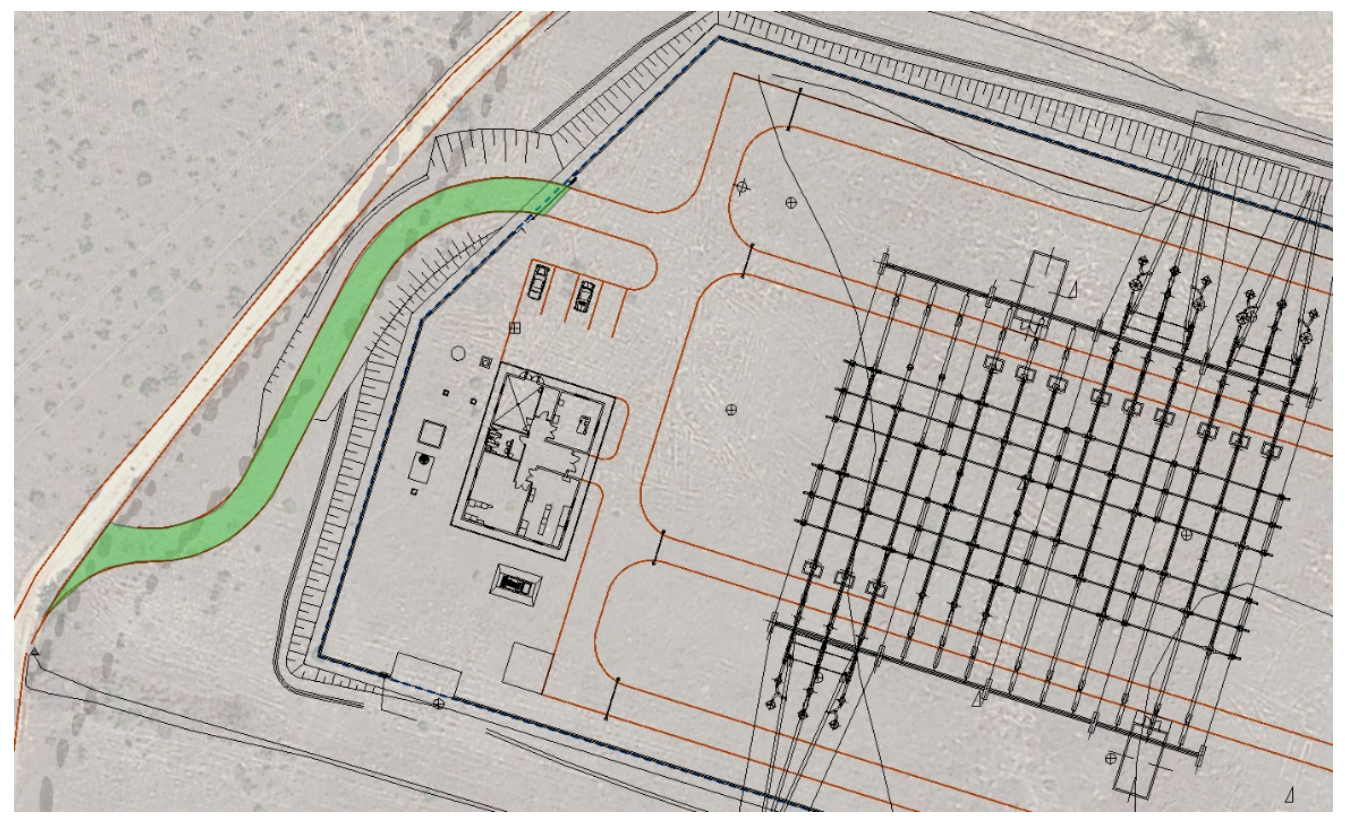

Figura 4-59. Ejemplo de camino de acceso a una subestación

b) Carga de afectaciones

Estos procesos, al igual que los anteriores procesos de esta fase, no generan resultado, sino que permiten cargar en el sistema las afectaciones de las instalaciones eléctricas y comprobar que las estructuras de datos son correctas para la ejecución de los procesos posteriores. 
i. Proyecto de línea:

Con la distribución de apoyos se pueden calcular las afectaciones que conlleva la futura línea eléctrica, pudiendo ser permanentes o temporales mientras se construye.

Las afectaciones de un proyecto de línea se dividen en dos grupos, las de línea aérea y las de línea subterránea y la carga en el sistema se realizará de forma simultánea.

Al igual que en la carga de accesos, esta herramienta permite descargar una plantilla que servirá de apoyo para cumplir con la estructura de datos necesaria para cada una de las afectaciones. La Figura 4-60 (a) muestra el cuadro de mando antes de su ejecución y la Figura 4-60 (b) después de su ejecución.

(a)

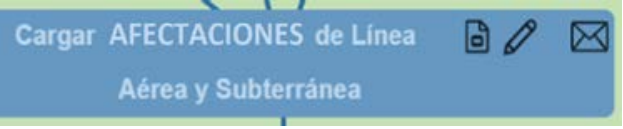

(b)

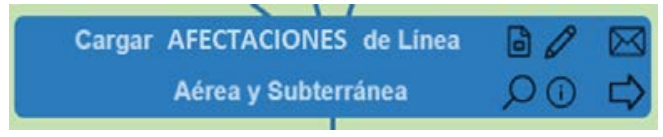

Figura 4-60. Cuadro de mando de carga de afectaciones de línea

Las afectaciones de línea aérea suponen ocupaciones permanentes, ocupaciones temporales y servidumbres de paso o servidumbres del tendido de cables. La Figura 4-61 (a) muestra un ejemplo de afectaciones de línea aérea y la Figura 4-61 (b) muestra la leyenda correspondiente.

(a)

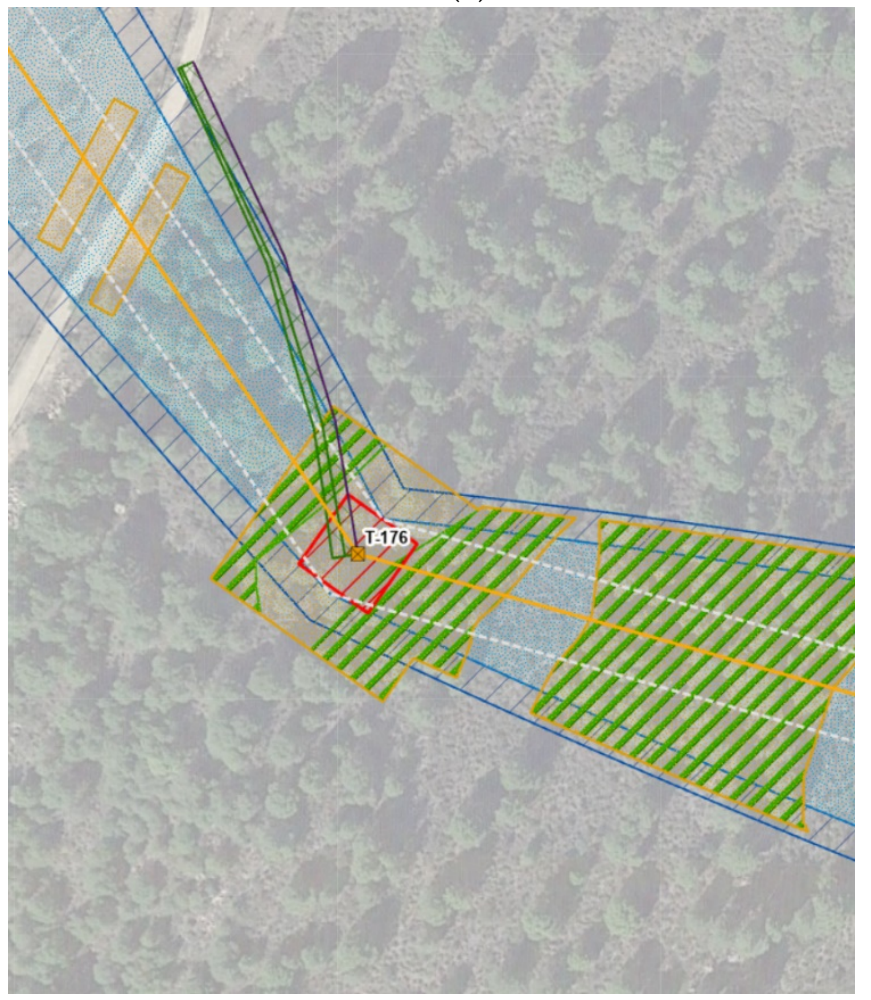

(b)

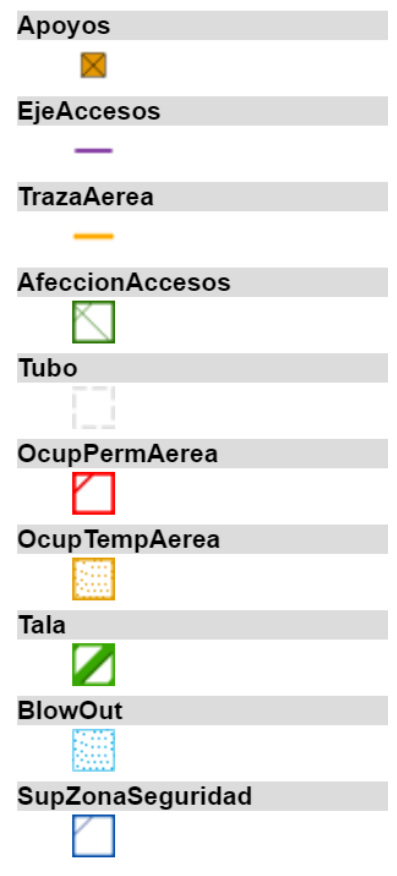

Figura 4-61. Ejemplo de afectaciones de línea aérea

En cuanto a las afectaciones de línea subterránea, únicamente suponen ocupaciones temporales y permanentes. La Figura 4-62 (a) muestra un ejemplo de afectaciones de línea aérea y la Figura 4-62 (b) muestra la leyenda correspondiente. 
(a)

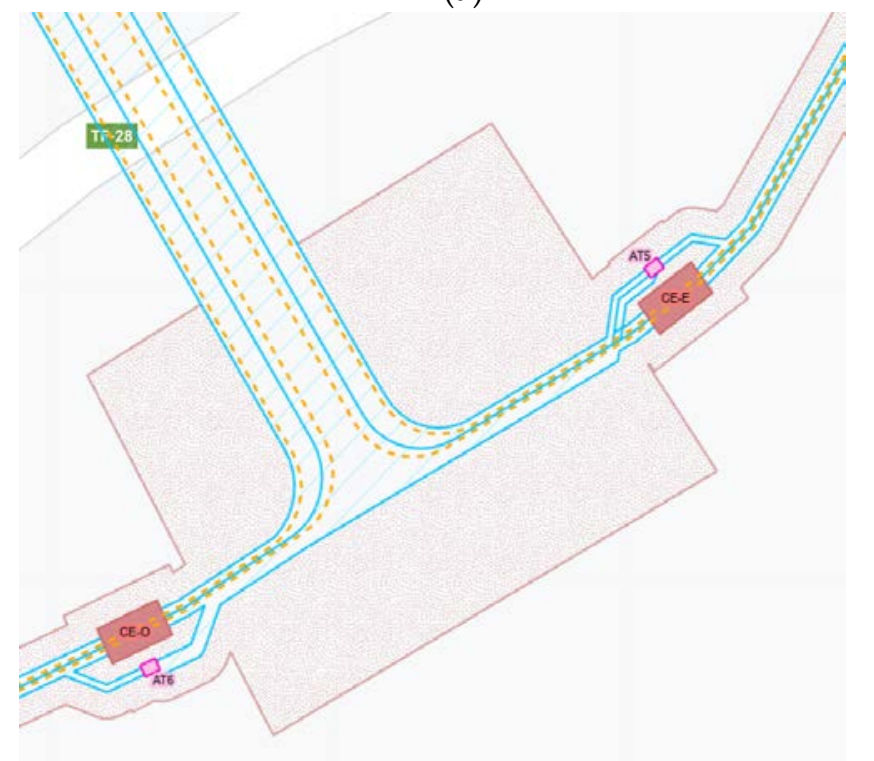

(b)

TrazaSubterranea

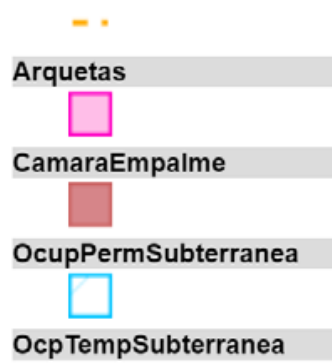

Figura 4-62. Ejemplo de afectaciones de línea subterránea

ii. Proyecto de subestación:

En las afectaciones de un proyecto de subestación no se consideran el conjunto de equipos, máquinas y cables que componen la instalación eléctrica, sino que se engloban en lo que significa la ocupación del territorio en su conjunto, es decir, lo que hay dentro de una subestación, ya no tiene significado geográfico desde el punto de vista de ocupación del terreno. La Figura 4-63 (a) muestra un ejemplo de afectaciones de una subestación y la Figura 4-63 (b) muestra su leyenda correspondiente.

(a)

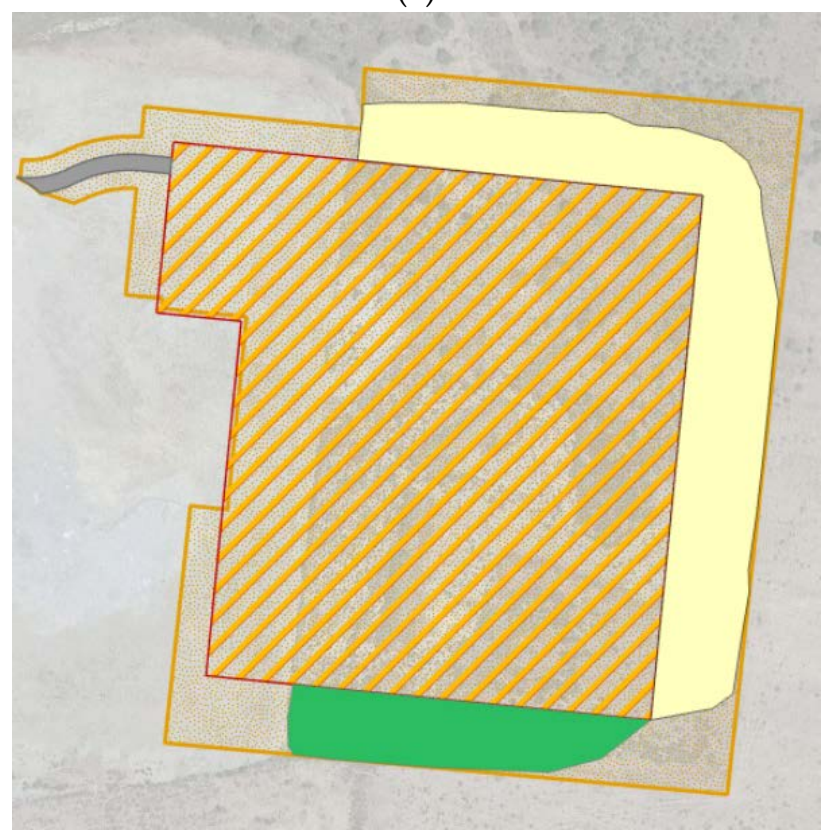

(b)

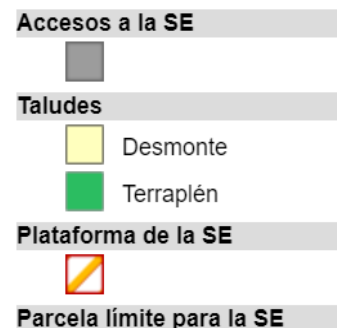

Parcela límite para la SE

Figura 4-63. Ejemplo de afectaciones de un proyecto de subestación 


\subsection{Modelos de evaluación de impactos en el entorno (Fase ingeniería)}

Este tipo de modelos tienen como objetivo la comparación de las alternativas de proyecto de línea y de subestación de los modelos anteriores. Esta comparación se realizará desde el punto de vista del impacto sobre el paisaje, el medio físico, el biótico y el socioeconómico.

Los procesos de este tipo de modelos se muestran en la Figura 4-64.

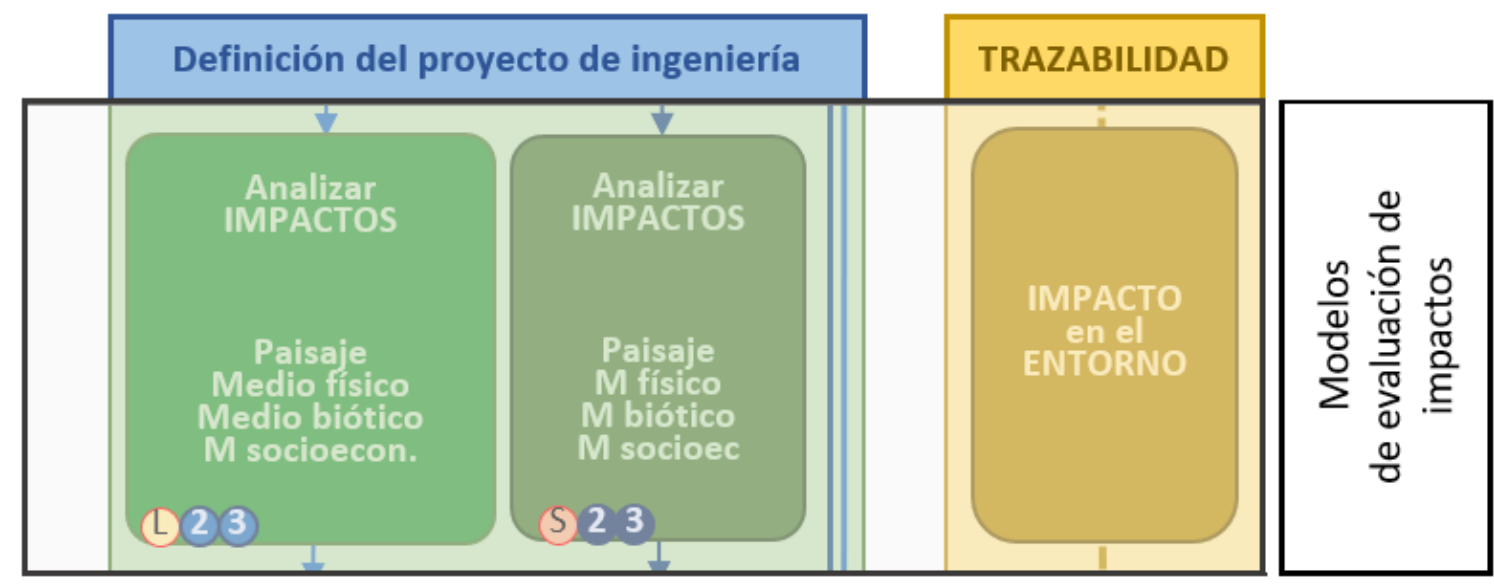

Figura 4-64. Procesos de los modelos de evaluación de impactos en fase de ingeniería

La ejecución de estos procesos pone de manifiesto uno de los objetivos perseguidos desde el diseño de GeoRED y mantenido durante el diseño e implementación del marco de trabajo basado en geodiseño. Se trata del almacenamiento único y centralizado de la información geográfica del proyecto.

Para el análisis de los posibles impactos se utilizará, además de la información geográfica de las afectaciones del proyecto de línea y de subestación, toda la información geográfica cargada en el proceso de generación del mapa de capacidad de acogida de la fase de análisis ambiental de alternativas, pudiendo el usuario actualizar o añadir información geográfica adicional a la considerada en la generación de dicho mapa.

La interfaz, por tanto, es la misma que en el proceso de generación del mapa de capacidad de acogida, con la diferencia de haber eliminado la ponderación de cualquiera de sus entidades. Tampoco se tendrán en cuenta las regiones biogeográficas en las que se vaya a implantar el proyecto. La Figura 4-65 muestra un ejemplo de la interfaz. 


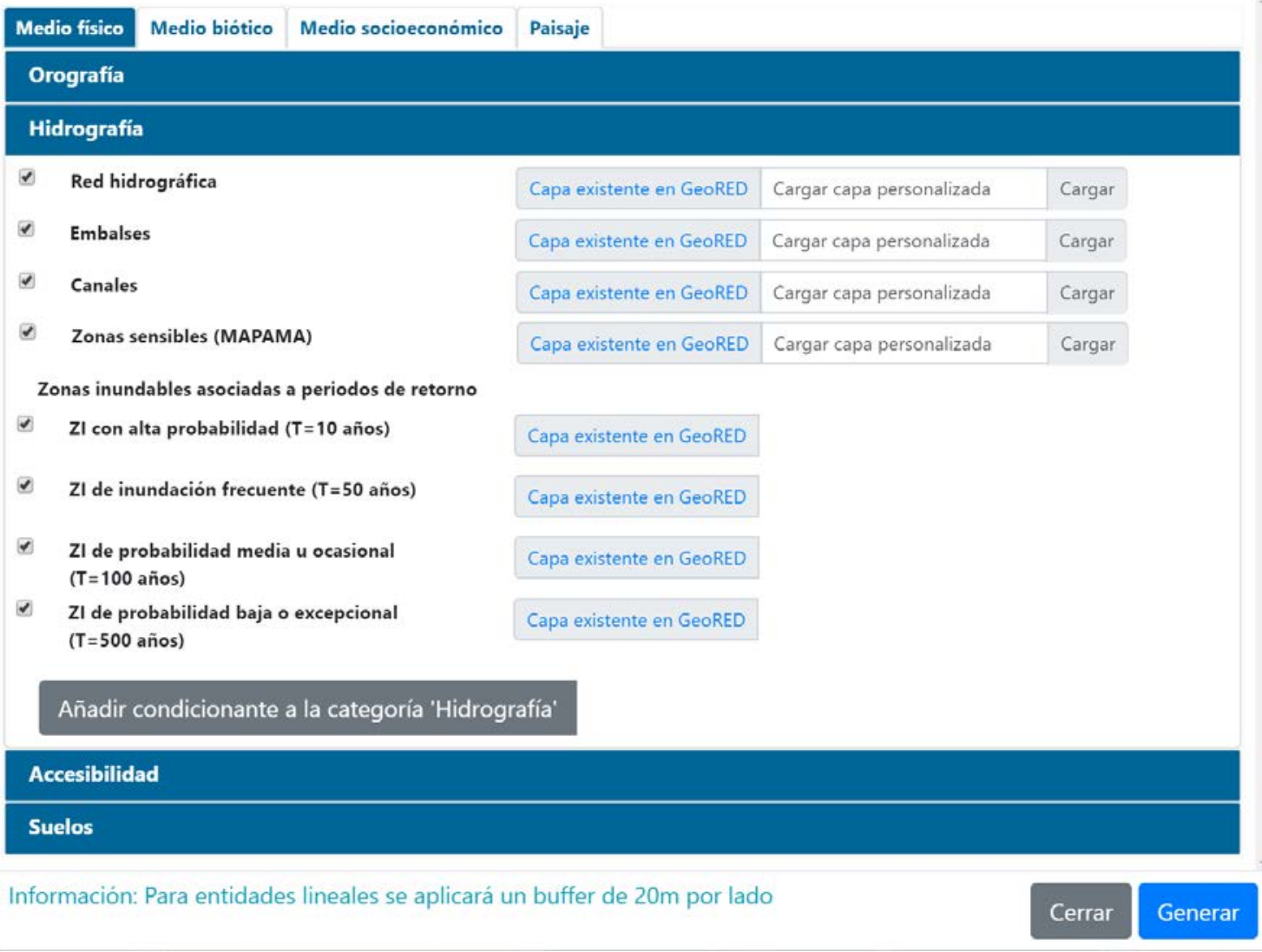

Figura 4-65. Ejemplo de interfaz para el cálculo de indicadores de afectación de proyecto de línea

El resultado es un informe que permitirá comparar cómo cada alternativa de proyecto de línea o de proyecto de subestación afecta a los aspectos considerados.

La Tabla 4-14 muestra un ejemplo de aspectos a analizar en proyectos de líneas aéreas respecto del medio físico.

\begin{tabular}{|c|c|c|c|}
\hline $\begin{array}{l}\text { Aspecto a } \\
\text { analizar }\end{array}$ & Indicador & Unidad & Magnitud \\
\hline \multirow{2}{*}{ Accesibilidad } & $\begin{array}{l}\text { Superficie nuevo acceso a } \\
\text { construir }\end{array}$ & $\mathrm{m}^{2}$ & Accesos (nuevo a construir ) \\
\hline & Superficie accesos existentes & $\mathrm{m}^{2}$ & $\begin{array}{l}\text { Accesos (existente en buen estado y existente a } \\
\text { acondicionar) }\end{array}$ \\
\hline \multirow[b]{3}{*}{ Suelo } & Superficie en zonas de riesgo & $\mathrm{m}^{2}$ & Accesos (nuevo a construir) + campa \\
\hline & № apoyos en pendientes $>30 \%$ & $\mathrm{n}^{\mathrm{o}}$ & Apoyos \\
\hline & $\begin{array}{l}\text { Distancia a elementos interés } \\
\text { geológico }\left(\mathrm{n}^{\mathrm{o}} \text { elementos a menos }\right. \\
\text { de } 100 \mathrm{~m})\end{array}$ & $\mathrm{n}^{\mathrm{o}}$ & Apoyos + accesos (nuevo a construir) + campa \\
\hline \multirow{4}{*}{ Agua superficial } & Cruzamiento cauces eje línea & $\mathrm{n}^{\mathrm{o}}$ & Traza \\
\hline & Cruzamiento cauces accesos & $\mathrm{n}^{\mathrm{o}}$ & $\begin{array}{l}\text { Accesos (nuevos a construir, campo a través y } \\
\text { existente a acondicionar) }\end{array}$ \\
\hline & Apoyos a menos $100 \mathrm{~m}$ cauces & $\mathrm{n}^{\mathrm{o}}$ & Apoyos \\
\hline & Accesos a menos $100 \mathrm{~m}$ cauces & $\mathrm{n}^{\mathrm{o}}$ & $\begin{array}{l}\text { Accesos (se tiene en cuenta el conjunto, no los } \\
\text { tramos por tipo) }\end{array}$ \\
\hline $\begin{array}{c}\text { Agua } \\
\text { subterránea }\end{array}$ & $\begin{array}{l}\text { Distancia a } \\
\text { fuente/captación/manantial/pozo }\end{array}$ & $\mathrm{m}$ & Apoyos \\
\hline
\end{tabular}

Tabla 4-14. Ejemplo de indicadores a calcular para evaluación de impactos de proyecto de línea 
A fecha de redacción de este documento, aunque el diseño ha finalizado, la generación de estos informes está en fase de implementación, por lo que no pueden mostrarse ejemplos.

\subsection{Modelos de ocupación del territorio (Fase ingeniería)}

Los modelos de ocupación del territorio tienen como objetivo el cuantificar la afectación del proyecto sobre el terreno y concretamente sobre la propiedad privada. Esta propiedad privada se representa por las parcelas catastrales como unidad de mínima de cálculo. Es decir, cualquier tipo de afectación de un proyecto de línea o de subestación será cuantificada para cada parcela catastral en particular.

Los procesos de este tipo de modelos se muestran en Figura 4-66.

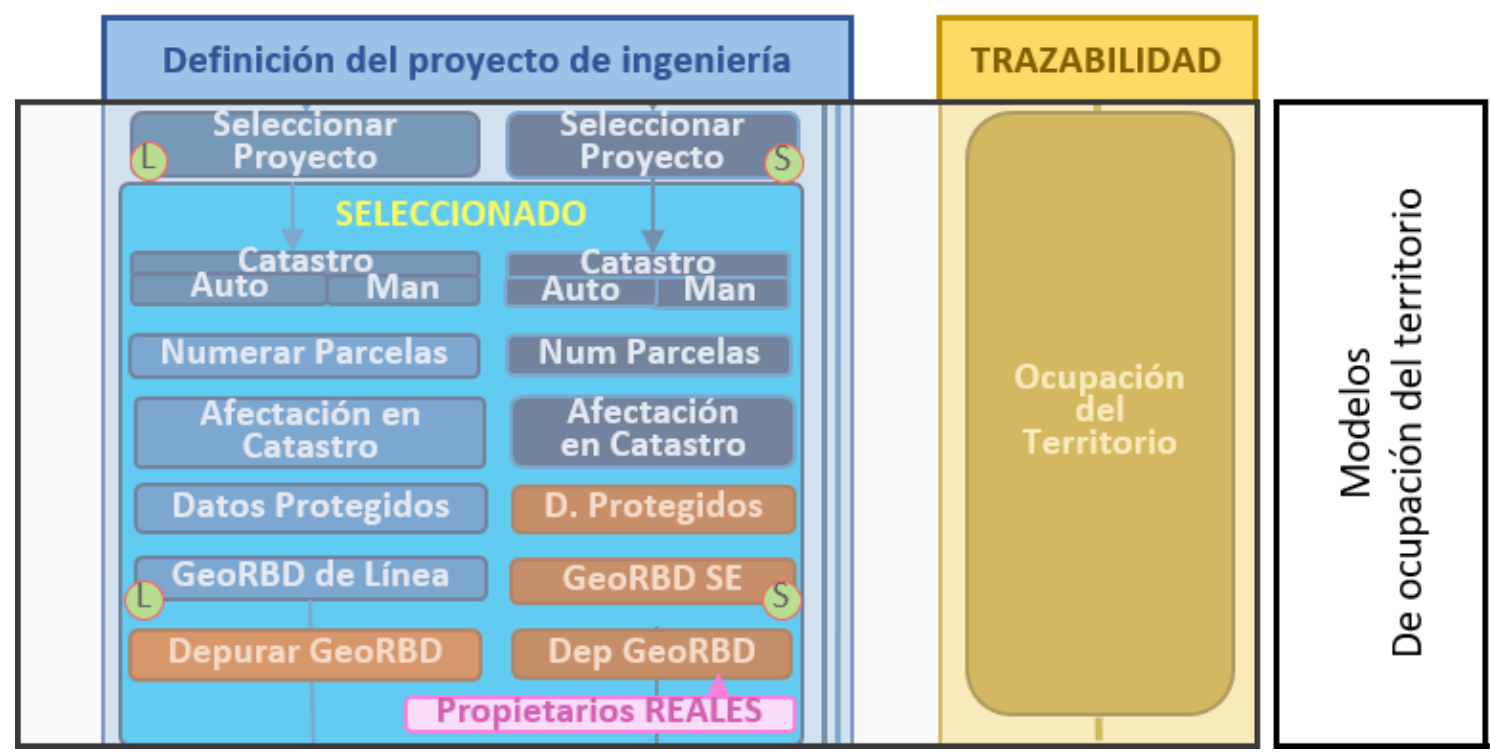

Figura 4-66. Procesos de los modelos de ocupación del territorio en fase de ingeniería

a) Selección de alternativa de proyecto

Desde el proceso de dibujo de alternativas de pasillo para proyectos de línea o áreas favorables para proyectos de subestación, se han considerado tres alternativas para cada caso. En este proceso y, tras analizar desde el punto de vista técnico, ambiental y socioeconómico se seleccionará la alternativa de proyecto a construir. Se trata de un proceso que añade un atributo, seleccionado o no seleccionado, a las alternativas de proyecto analizadas.

A partir de este proceso, cualquier acción posterior estará únicamente referida al proyecto seleccionado.

b) Gestión de las parcelas catastrales afectadas por el proyecto

Tanto para proyectos de línea como de subestación se procede a unir todas las afectaciones para calcular la extensión del catastro a gestionar en el proyecto.

Excepto para País Vasco y Navarra, que tienen sus propios servicios catastrales, se utilizarán los servicios que ofrece la Sede Electrónica del Catastro (SEC, 2020).

Las parcelas catastrales pueden obtenerse de dos formas diferentes:

- De forma automática 
Se ha desarrollado un geoproceso que, gracias al WFS - Web Feature Service de la SEC, se obtienen las geometrías de las parcelas catastrales realizando diferentes peticiones hasta completar la extensión definida por la unión de todas las afectaciones. Las respuestas a estas peticiones son gestionadas para que no haya parcelas duplicadas ni terreno sin representación catastral.

- De forma manual

Para los proyectos del País Vasco y Navarra y, para los del resto de España que se requiera, podrá obtenerse la cartografía catastral de forma manual y, tras ser gestionada para que cumpla con la estructura de datos necesaria, podrá ser cargada en el sistema.

Para este procedimiento la SEC establece como unidad mínima de descarga el municipio, es decir, independientemente de la extensión afectada en un municipio, la descarga del catastro del mismo contendrá todas sus parcelas catastrales.

Estas descargas cuentan con la desventaja de una posible falta de actualización ya que la SEC establece actualizaciones trimestrales.

La gestión de estas parcelas que realiza el proceso es, además de comprobar la estructura de datos, la selección de las parcelas que formarán parte del proyecto.

c) Codificación o numeración de las parcelas del proyecto

i. Numeración de parcelas afectadas por la instalación

En este proceso se asigna un nuevo código que es secuencial, llamado "Parcela de Proyecto", que se inicia para cada municipio afectado, ya que el código de referencia catastral no permite una localización visual rápida y tampoco una ordenación lógica.

El geoproceso diseñado realiza una operación de proyección del centroide de cada parcela catastral sobre la traza de la línea. A continuación, se recorre la línea y se asigna un número secuencial a cada parcela catastral en el mismo orden que su centroide ha sido proyectado. Al cambiar de municipio, este código vuelve a iniciarse. El técnico responsable seleccionará el origen de la numeración tal como se muestra en la Figura 4-67.

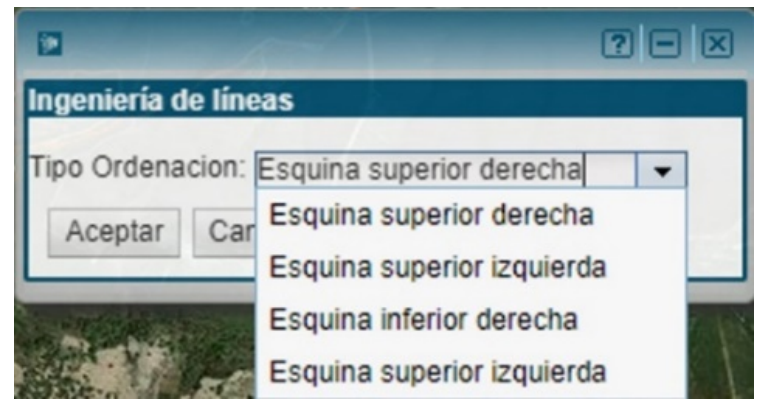

Figura 4-67. Formulario de selección del origen de numeración de parcelas 
En el caso de proyectos de subestación, considerando el reducido número de parcelas que se afectan, se utiliza el método de ordenación proporcionado por ESRI, tras utilizar el mismo selector de origen de numeración.

ii. Numeración de parcelas afectadas por los caminos de acceso

La numeración de las parcelas afectadas por los caminos de acceso se basa en la numeración de parcelas afectadas por cualquiera del resto de afectaciones de la propia instalación.

A diferencia de las parcelas afectadas por la instalación, la numeración de parcelas afectadas por caminos de acceso se configura por medio de un número con parte entera y parte decimal.

Considerando que un camino de acceso es para llegar a un apoyo concreto, la parte entera será el código asignado a la parcela que contiene al apoyo. La parte decimal es secuencial y se parte de la parcela afectada más alejada del apoyo e irá creciendo hasta llegar al mismo.

Si una parcela ya ha sido numerada por afectación de la instalación, no será renumerada por la afectación del acceso, sino que mantendrá su código.

De esta forma, al visualizar en formato tabla la lista de parcelas afectadas por el proyecto, habrá una ordenación, por municipio, coherente entre las parcelas que contienen un apoyo y las que contienen su camino de acceso. La Tabla 4-15 muestra un ejemplo de esta visualización.

\begin{tabular}{|c|c|c|}
\hline Parcela de Proyecto & Código de apoyo & Referencia Catastral \\
\hline 1 & & $18180 \mathrm{~A} 00100145$ \\
\hline 2 & & $18180 \mathrm{~A} 00100132$ \\
\hline$\cdots$ & & $\ldots$ \\
\hline 15 & $\mathrm{~T}-135$ & $18180 \mathrm{~A} 00100113$ \\
\hline 16 & & $18180 \mathrm{~A} 00100118$ \\
\hline 16,001 & & $18180 \mathrm{~A} 00100126$ \\
\hline 16,002 & & $18180 \mathrm{~A} 00100127$ \\
\hline 16,003 & & $18180 \mathrm{~A} 00100125$ \\
\hline 16,004 & & $18180 \mathrm{~A} 00100112$ \\
\hline 17 & & $18180 \mathrm{~A} 00100119$ \\
\hline 18 & & \\
\hline
\end{tabular}

Tabla 4-15. Ejemplo de ordenación de parcelas de proyecto en formato tabla

La numeración de parcelas afectadas por camino de acceso a una subestación no se realiza con este criterio, sino que se numeran como el resto de las parcelas afectadas por esta. La Figura 4-68 muestra un ejemplo de parcelas de proyecto numeradas por afectación de línea y de caminos de acceso, donde se resalta la parcela número 16 que contiene al apoyo T-135. 


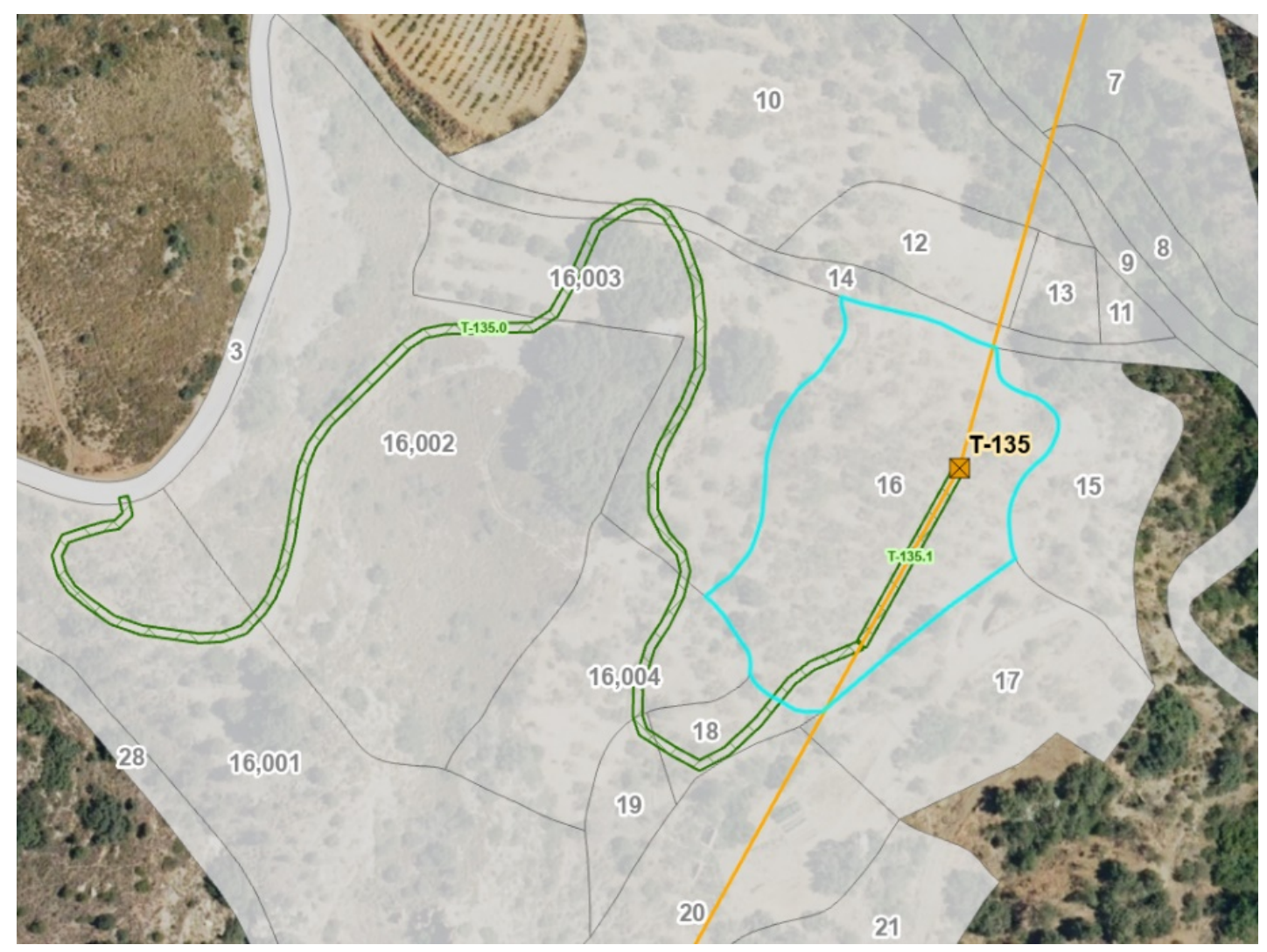

Figura 4-68. Ejemplo de numeración de parcelas de proyecto

En el caso de caminos de acceso que se encuentren en municipios que no tienen afectación de la futura instalación, la numeración corresponderá a una parte alfanumérica compuesta por secuencia de letras (comenzando por la A) y una parte coincidente con la secuencia decimal comentada. Es decir, el formato sería A.001, A.002 y, para otros accesos en otro municipio que tampoco tiene afectación de la instalación sería B.001, B.002, etc...

d) Cálculo de la magnitud de la afectación del proyecto sobre las parcelas catastrales

Estos procesos son los encargados de cuantificar la magnitud de cada tipo de afectación sobre cada parcela catastral afectada. Para este análisis se realiza una intersección de la entidad de geometrías de las parcelas catastrales con cada una de las entidades de geometrías que describen las afectaciones. Algunas de las afectaciones, como las ocupaciones permanentes de los apoyos, sus caminos de acceso, las cámaras de empalme, las arquetas de telecomunicaciones, los hitos o los elementos auxiliares, tienen un código que las diferencia, por lo que el cálculo de magnitud de su afectación se particularizará para cada una y también se obtendrá la suma total por parcela. Además de calcular la magnitud de cada tipo de afectación, para alguna de ellas se calcula una serie de indicadores que ayudan a entender la relevancia de la afectación en la parcela y permite una toma de decisiones más precisa en cuanto a mantener o eliminar dicha afectación en el informe final.

La lista de afectaciones que se calculan y el indicador que se utilizará con posterioridad en la toma de decisiones se muestra en la Tabla 4-16. 


\begin{tabular}{|c|c|}
\hline Tipo de afectación & Indicador \\
\hline \multicolumn{2}{|l|}{ Longitud de traza aérea } \\
\hline Superficie de servidumbre de vuelo & Servidumbre de vuelo \\
\hline Superficie de zona de seguridad & Zona de seguridad \\
\hline Superficie de zona de seguridad de tala de arbolado & Zona de seguridad de tala de \\
\hline Superficie de zona de seguridad de construcciones & Zona de seguridad de construcciones \\
\hline Superficie de calle de seguridad & Superficie de calle de seguridad \\
\hline Superficie de ocupación temporal aérea & Ocupación temporal aérea \\
\hline Código de apoyos (ocupación permanente aérea) & Ocupación permanente aérea \\
\hline \multicolumn{2}{|l|}{ Superficies de ocupación permanente aérea } \\
\hline \multicolumn{2}{|l|}{ Suma Total Superficies de ocupación permanente aérea } \\
\hline \multicolumn{2}{|l|}{ Número de apoyos (ocupación permanente aérea) } \\
\hline \multicolumn{2}{|l|}{ Códigos de caminos de acceso } \\
\hline Superficies de caminos de acceso & Camino de acceso \\
\hline \multicolumn{2}{|l|}{ Suma Total Superficies de caminos de acceso } \\
\hline \multicolumn{2}{|l|}{ Número de caminos de acceso } \\
\hline \multicolumn{2}{|l|}{ Superficies de caminos de acceso Nuevos a construir } \\
\hline \multicolumn{2}{|l|}{ Superficies de caminos de acceso Existentes en buen estado } \\
\hline \multicolumn{2}{|l|}{ Superficies de caminos de acceso Campo a través } \\
\hline \multicolumn{2}{|l|}{ Superficies de caminos de acceso Existente a acondicionar } \\
\hline \multicolumn{2}{|l|}{ Superficies de caminos de acceso Tramo con actuación } \\
\hline \multicolumn{2}{|l|}{ Observaciones sobre los caminos de acceso } \\
\hline Superficie de zona a talar & Superficie de Tala \\
\hline \multicolumn{2}{|l|}{ Superficie de seguridad de tala de arbolado } \\
\hline \multicolumn{2}{|l|}{ Superficie de seguridad de construcciones } \\
\hline \multicolumn{2}{|l|}{ Longitud de traza subterránea } \\
\hline Superficie de Ocupación temporal subterránea & Ocupación temporal subterránea \\
\hline Superficie de ocupación permanente subterránea (zanja) & Ocupación permanente subterránea \\
\hline \multicolumn{2}{|l|}{ Códigos de Cámaras de empalme } \\
\hline Superficies de Cámaras de empalme & Cámaras de empalme \\
\hline \multicolumn{2}{|l|}{ Suma Total Superficies de Cámaras de empalme } \\
\hline \multicolumn{2}{|l|}{ Número de Cámaras de empalme } \\
\hline \multicolumn{2}{|l|}{ Códigos de Arquetas de telecomunicaciones } \\
\hline Superficies de Arquetas de telecomunicaciones & Arquetas de telecomunicaciones \\
\hline \multicolumn{2}{|l|}{ Suma Total Superficies de Arquetas de telecomunicaciones } \\
\hline \multicolumn{2}{|l|}{ Número de Arquetas de telecomunicaciones } \\
\hline \multicolumn{2}{|l|}{ Códigos de Hitos de cable subterráneo } \\
\hline Superficies de Hitos de cable subterráneo & Hitos \\
\hline \multicolumn{2}{|l|}{ Suma Total Superficies de Hitos de cable subterráneo } \\
\hline Número de Hitos de cable subterráneo & \\
\hline Códigos de elementos auxiliares 1 & \\
\hline Superficies de elementos auxiliares 1 & Elementos auxiliares 1 \\
\hline Suma Total Superficies de elementos auxiliares 1 & \\
\hline Número de elementos auxiliares 1 & \\
\hline Códigos de elementos auxiliares 2 & \\
\hline Superficies de elementos auxiliares 2 & Elementos auxiliares 2 \\
\hline Suma Total Superficies de elementos auxiliares 2 & \\
\hline Número de elementos auxiliares 2 & \\
\hline
\end{tabular}

Tabla 4-16. Lista de afectaciones e indicadores que se calculan en proyectos de línea 
La Tabla 4-17 muestra un ejemplo incompleto, por sus dimensiones, las afectaciones calculadas.

\begin{tabular}{|c|c|c|c|c|c|c|c|c|c|c|c|c|c|c|c|c|c|c|c|c|c|c|c|c|}
\hline Referencia catastral & 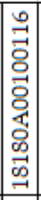 & 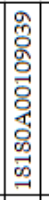 & 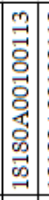 & 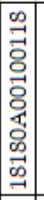 & 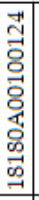 & 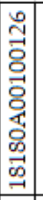 & 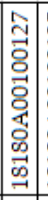 & 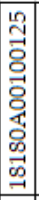 & 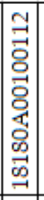 & 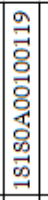 & 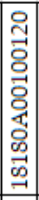 & 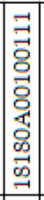 & 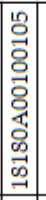 & 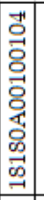 & 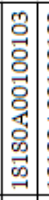 & 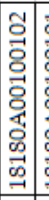 & 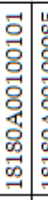 & 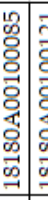 & 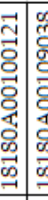 & 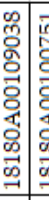 & 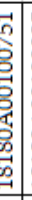 & 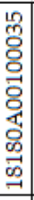 & 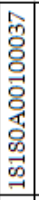 & 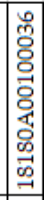 \\
\hline Código Parcela de proyecto & $\stackrel{m}{\rightarrow}$ & 五 & $\stackrel{20}{-1}$ & $\stackrel{-1}{-1}$ & $\begin{array}{l}\overrightarrow{8} \\
0 \\
0\end{array}$ & 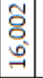 & $\begin{array}{l}0 \\
8 \\
0 \\
0 \\
-1\end{array}$ & $\begin{array}{l}7 \\
8 \\
0 \\
0 \\
-1\end{array}$ & $\approx$ & $\stackrel{\infty}{\rightarrow}$ & 2 & 요 & $\vec{\lambda}$ & สี & $\ddot{2}$ & స゙! & $\stackrel{2}{2}$ & บ1! & حิ & ำ & & ஜి & $\vec{m}$ & ले \\
\hline Longitud de traza aérea & & 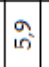 & & 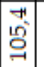 & & & & & \begin{tabular}{|c|}
0 \\
$\infty$ \\
$\infty$
\end{tabular} & & & 志 & & $\stackrel{\Omega}{\sigma}$ & $\mid \begin{array}{l}10 \\
0 \\
0 \\
2\end{array}$ & $\frac{7}{-1}$ & & \begin{tabular}{ll}
$\infty$ \\
\multirow{-}{*}{}
\end{tabular} & \begin{tabular}{c|c}
$\mathrm{m}^{\prime}$ & \\
\end{tabular} & \begin{tabular}{l}
0 \\
\multirow{\Omega}{*}{}
\end{tabular} & & $\overrightarrow{7}$ & $\begin{array}{l}\text { 엄 } \\
\text { a }\end{array}$ & تै \\
\hline Superficie de servidumbre de vuelo & 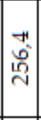 & 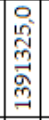 & $\begin{array}{l}m \\
0 \\
0 \\
2\end{array}$ & $\overrightarrow{\mid}$ & & & & & 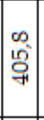 & 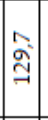 & & $\mid \begin{array}{c}\hat{\sigma} \\
\stackrel{2}{ } \\
\text { స్ }\end{array}$ & 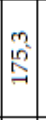 & $\begin{array}{l}0 \\
0 \\
0 \\
0\end{array}$ & : & 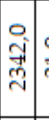 & $\stackrel{\sigma}{m}$ & 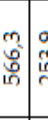 & 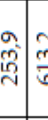 & 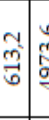 & & 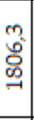 & $\begin{array}{l}\overrightarrow{1} \\
\text { के } \\
0\end{array}$ & 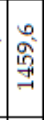 \\
\hline Superficie de zona de seguridad & 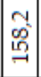 & $\begin{array}{l}7 \\
\text { ते }\end{array}$ & $\begin{array}{l}0 \\
6 \\
0\end{array}$ & 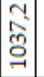 & & & & & $\begin{array}{l}0 \\
\text { oे } \\
\text { ले }\end{array}$ & $\begin{array}{c}\infty \\
\text { fే } \\
-1 \\
\end{array}$ & 壳 & 우 & $\begin{array}{l}0 \\
0 \\
\stackrel{0}{2} \\
\sim\end{array}$ & 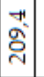 & 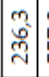 & $\begin{array}{l}n \\
n \\
n \\
n \\
n\end{array}$ & $\begin{array}{ll}\infty & 0 \\
10 & \end{array}$ & 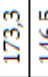 & 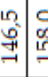 & 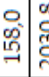 & & $\begin{array}{l}\stackrel{n}{*} \\
\stackrel{n}{n}\end{array}$ & & 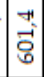 \\
\hline Superficie de calle de seguridad & $\begin{array}{l}\overrightarrow{0} \\
0 \\
\overrightarrow{-}\end{array}$ & $\begin{array}{c}\overrightarrow{2} \\
2\end{array}$ & $\begin{array}{l} \\
0 \\
0\end{array}$ & 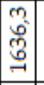 & & & & & 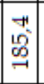 & గ̂. & & 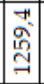 & 웅 & $\begin{array}{c}\overrightarrow{1} \\
\vec{m}\end{array}$ & \begin{tabular}{|l|} 
\\
0 \\
0 \\
के \\
\end{tabular} & $\begin{array}{l}\circ \\
\text { ๙ } \\
\text { ू }\end{array}$ & & 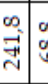 & \begin{tabular}{l|l}
$\infty$ \\
$00^{\circ}$ \\
\end{tabular} & 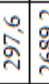 & & \begin{tabular}{l}
$n$ \\
\multirow{2}{N}{} \\
$\curvearrowright$
\end{tabular} & 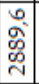 & $\begin{array}{c}\mathrm{N} \\
\stackrel{\vec{J}}{\mathrm{~J}} \\
\end{array}$ \\
\hline Superficie de ocupación temporal aérea & & & सु & 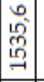 & & & & & & & & & & & & & & & & 要 & & $\begin{array}{l}0 \\
\stackrel{0}{0} \\
\stackrel{0}{0}\end{array}$ & & \\
\hline $\begin{array}{r}\text { Código de apoyos (ocupación permanente } \\
\text { aérea) }\end{array}$ & & & & 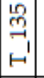 & & & & & & & & & & & & & & & & ch & 总 & & & \\
\hline Superficies de ocupación permanente aérea & & & & హ్ & & & & & & & & & & & & & & & & "ृ & & & & \\
\hline $\begin{array}{r}\text { Suma Total Superficies de ocupación } \\
\text { permanente aérea }\end{array}$ & & & & $\begin{array}{c}m \\
\text { के } \\
\infty \\
\end{array}$ & & & & & & & & & & & & & & & & 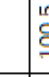 & & & & \\
\hline $\begin{array}{r}\text { Número de apoyos (ocupación permanente } \\
\text { aérea) }\end{array}$ & & & & $\rightarrow$ & & & & & & & & & & & & & & & & c & 욱. & & & \\
\hline Códigos de caminos de acceso & & 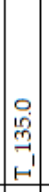 & & 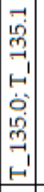 & 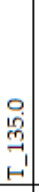 & 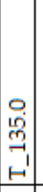 & $\begin{array}{c}0 \\
10 \\
10 \\
-1 \\
-1 \\
1\end{array}$ & 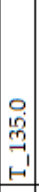 & & 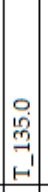 & $\begin{array}{c}0 \\
\stackrel{0}{1} \\
\stackrel{1}{2} \\
-1 \\
-1\end{array}$ & & & & & & & & & \begin{tabular}{|l}
5 \\
1 \\
-1
\end{tabular} & & 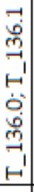 & & \\
\hline Superficies de caminos de acceso & & $\mid \begin{array}{l}2 \\
\tilde{7} \\
7\end{array}$ & & 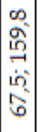 & 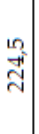 & 瓷 & 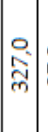 & 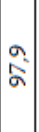 & & 旾 & $\begin{array}{l}0 \\
\stackrel{\circ}{0}\end{array}$ & & & & & & & & & $\underline{7}$ & & 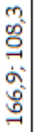 & & \\
\hline Suma Total Superficies de caminos de acceso & & 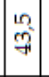 & & $\begin{array}{c}m \\
\vdots \\
a\end{array}$ & בֶ: & 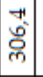 & 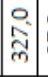 & $\stackrel{\Omega}{\alpha}$ & & $\stackrel{n}{-2}$ & ำ & & & & & & & & & $\exists$ & & $\begin{array}{c}m \\
\mathrm{~s} \\
\mathrm{~N}\end{array}$ & & \\
\hline Número de caminos de acceso & & $\rightarrow$ & & N & -1 & $\rightarrow$ & -1 & $\rightarrow$ & & -1 & -1 & & & & & & & & & - & & N & & \\
\hline $\begin{array}{r}\text { Superficies de caminos de acceso Nuevos a } \\
\text { construir }\end{array}$ & & & & & & & & & & & & & & & & & & & & $\exists$ & & $\begin{array}{c}m \\
\tilde{o}^{\prime} \\
\stackrel{-}{-}\end{array}$ & & \\
\hline $\begin{array}{r}\text { Superficies de caminos de acceso Existentes } \\
\text { en buen estado }\end{array}$ & & 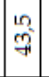 & & 这 & $\begin{array}{l}\stackrel{n}{ \pm} \\
\stackrel{1}{N}\end{array}$ & 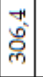 & $\begin{array}{l}0 \\
\hat{2} \\
\text { m. }\end{array}$ & $\stackrel{a}{\alpha}$ & & $\underset{n}{-2}$ & ำ & & & & & & & & & & & $\stackrel{\circ}{10}$ & & \\
\hline $\begin{array}{r}\begin{array}{r}\text { Superficies de caminos de acceso Campo a } \\
\text { través }\end{array} \\
\end{array}$ & & & & $\begin{array}{l}\infty \\
\Omega \\
\stackrel{\infty}{-1} \\
\end{array}$ & & & & & & & & & & & & & & & & & & & & \\
\hline \multicolumn{25}{|l|}{$\begin{array}{r}\text { Superficies de caminos de acceso Existente a } \\
\text { acondicionar }\end{array}$} \\
\hline \multicolumn{25}{|l|}{$\begin{array}{r}\text { Superficies de caminos de acceso Tramo con } \\
\text { actuación }\end{array}$} \\
\hline Observaciones sobre los caminos de acceso & & 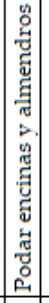 & & 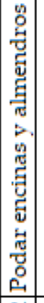 & 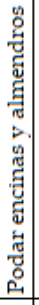 & 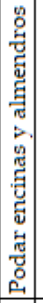 & 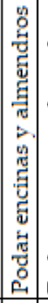 & 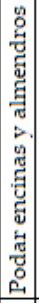 & & 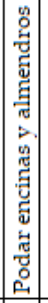 & 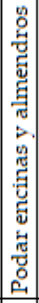 & & & & & & & & & 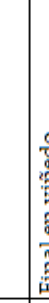 & 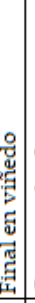 & 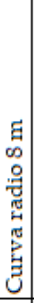 & & \\
\hline Suverficie de tala & & & & ऊु & & & & & & & & & & & & & & & & & & & & \\
\hline
\end{tabular}

Tabla 4-17. Ejemplo de tabla de afectaciones de línea 
En las de tipo permanente se contemplan la ocupación de los apoyos y sus accesos, las servidumbres de vuelo con viento transversal o sin él, además de las distancias de seguridad.

En las de tipo temporal se incluyen las superficies necesarias para acopio de material, maniobra de vehículos y maquinaria de obra o de protección por cruces de carreteras, ferrocarriles u otras líneas aéreas como las telefónicas o eléctricas.

Como resultado de esta fase se obtiene una entidad de geometrías de las parcelas catastrales afectadas y su correspondiente tabla de afectaciones vinculada, con tantos registros o filas como parcelas catastrales sean afectadas y cuyos campos o columnas contienen los datos que explican cómo la nueva instalación afectará a cada parcela.

Esta tabla de afectaciones es la base de la ocupación del territorio de cada proyecto a partir de la cual se obtendrá la Relación de Bienes y Derechos afectados - RBD.

La tabla de afectaciones de un proyecto de subestación incorporará, de la misma forma, la lista de parcelas afectadas y la magnitud de cada tipo de afectación de este tipo de instalaciones.

e) Obtención de los datos protegidos del catastro

Gracias a los permisos que la Sede Electrónica del Catastro (SEC, 2020) facilita a sus usuarios registrados, Red Eléctrica tiene la capacidad de realizar consultas masivas de los datos protegidos de las parcelas afectadas por cada proyecto.

La respuesta de la SEC a la consulta masiva es la posibilidad de descarga de un archivo con los datos protegidos solicitados.

f) Generación de la Relación de Bienes y Derechos afectados - GeoRBD

Históricamente se ha nombrado RBD a la tabla de afectaciones con los datos protegidos asociados. Esta tabla necesitaba de una colección de planos, en papel, para complementar la información de esta.

El proceso implementado genera la misma RBD per sustituyendo la colección de planos en papel, que siempre podrán imprimirse, por las geometrías de las parcelas afectadas constituyendo una capa SIG para cada tabla de afectaciones. Por este motivo se asigna el nuevo nombre de GeoRBD.

Este proceso, idéntico para proyectos de líneas y subestaciones, realiza una unión (join) a través del código de referencia catastral de la capa de geometrías con los datos protegidos obtenidos de la SEC para generar una única tabla con los datos de afectación y los datos protegidos de cada parcela.

g) Depuración de la Relación de Bienes y Derechos afectados - GeoRBD.

La parte alfanumérica de la GeoRBD será publicada en el BOE o en las publicaciones de tirada regional o local para informar a los propietarios de las parcelas afectadas de cómo el proyecto de una nueva instalación eléctrica afectará a las parcelas de su propiedad. Por ello debe ser revisada y depurada para eliminar afectaciones insignificantes tanto para el proyecto como para los propietarios. stación. 
Para realizar esta tarea de revisión y depuración se ha implementado un proceso en que se sincronizan la parte alfanumérica con la parte gráfica. La Figura 4-69 muestra la herramienta del proceso implementado.

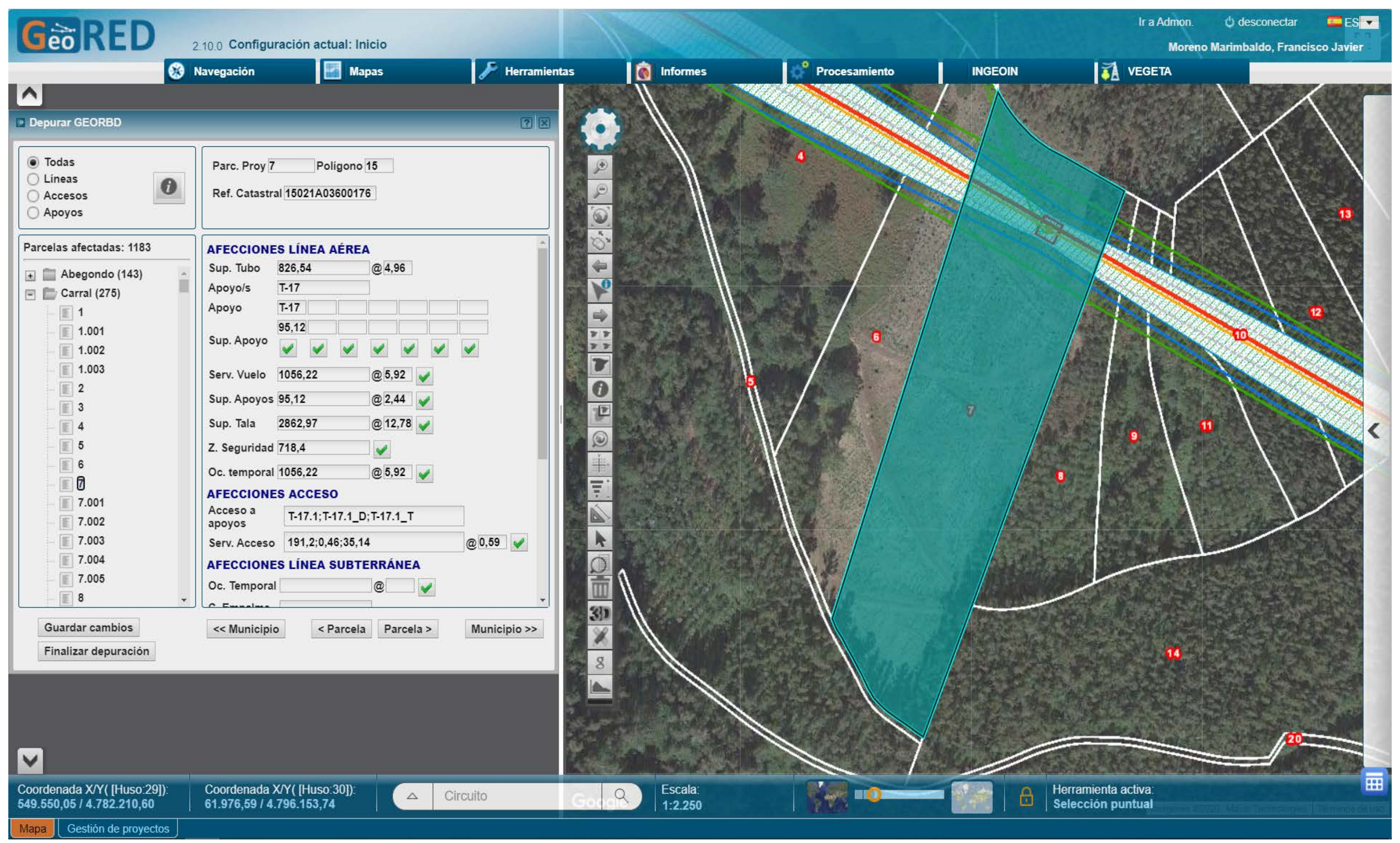

Figura 4-69. Ejemplo de la herramienta de depuración de GeoRBD 
Se analizará la forma de la afectación en cada parcela para localizar aquellas con una forma muy alargada y estrecha (p.e. 50 metros $x 1$ centímetro respectivamente) que sean irrelevantes tanto para el proyecto como para el propietario de la parcela afectada. En cualquier caso, debe ser revisada y, si procede, eliminada.

Las parcelas, se mostrarán ordenadas ascendentemente por su código "Parcela de Proyecto", dentro de cada nodo-municipio del árbol de la interfaz GeoRBD.

Al seleccionar cualquiera de las parcelas que cuelgan de cada nodo-municipio, se consigue una sincronización con el mapa, haciendo automáticamente zoom sobre la parcela y mostrando los atributos de esta en la ventana de depuración.

Del mismo modo, se permite la consulta inversa logrando una sincronización bidireccional, al activar el botón de información sobre la parcela.

Esta depuración no modifica la tabla de afectaciones, ésta quedó guardada en su proceso de generación correspondiente, sino que se realiza una copia y en el proceso de depuración se marcarán las afectaciones a eliminar de la GeoRBD depurada.

En el caso de proyectos de subestación, la interfaz será idéntica a la de proyectos de línea, pero mostrando las afectaciones correspondientes a este tipo de proyectos.

Considerando que en el transcurso del proyecto las parcelas afectadas por un proyecto de subestación pueden haber cambiado de propietario, y la SEC no haya tenido tiempo para actualizar los propietarios de estas, se procederá a una actualización manual de la GeoRBD.

Los procesos de depuración de GeoRBD, aunque forma parte de las tareas de la fase de ingeniería, serán realizados por los técnicos especialistas en obtención de permisos de forma colaborativa con los técnicos de ingeniería.

\subsection{Modelos de decisión (Fase ingeniería)}

Los modelos de decisión tienen por objetivo consolidar el trabajo previo realizado en esta fase, dando por finalizada esta.

En esta fase hay tareas de colaboración con los técnicos de una fase anterior y con los de una fase posterior, dando así mayor robustez a las soluciones que se van concretando a lo largo del proyecto.

Los procesos de este tipo de modelos se muestran en la Figura 4-70.

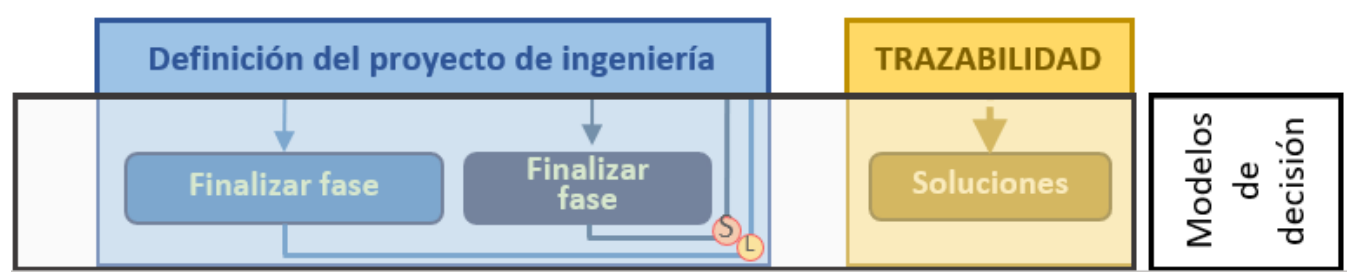

Figura 4-70. Procesos de decisión en la fase de ingeniería 


\subsubsection{Fase de obtención de permisos}

El proyecto de ingeniería diseñado tendrá una serie de afectaciones sobre la propiedad privada que esta fase se encarga de gestionar.

\subsection{Modelos para comprensión del ámbito de estudio (fase permisos)}

Los modelos para comprensión del ámbito de estudio en esta fase tienen por objetivo restringir cualquier tarea a las parcelas existentes en la GeoRBD depurada y las afectaciones reflejadas en ella, que se corresponde con lo sometido a información pública. Se trata de una representación, gráfica y alfanumérica, de la GeoRBD depurada sin posibilidad de modificación.

Cualquier actuación fuera de estas parcelas conlleva trámites adicionales y si se trata de actuaciones de envergadura pueden llevar a la modificación del proyecto de ingeniería.

Los procesos de este tipo de modelos se muestran en la Figura 4-71.

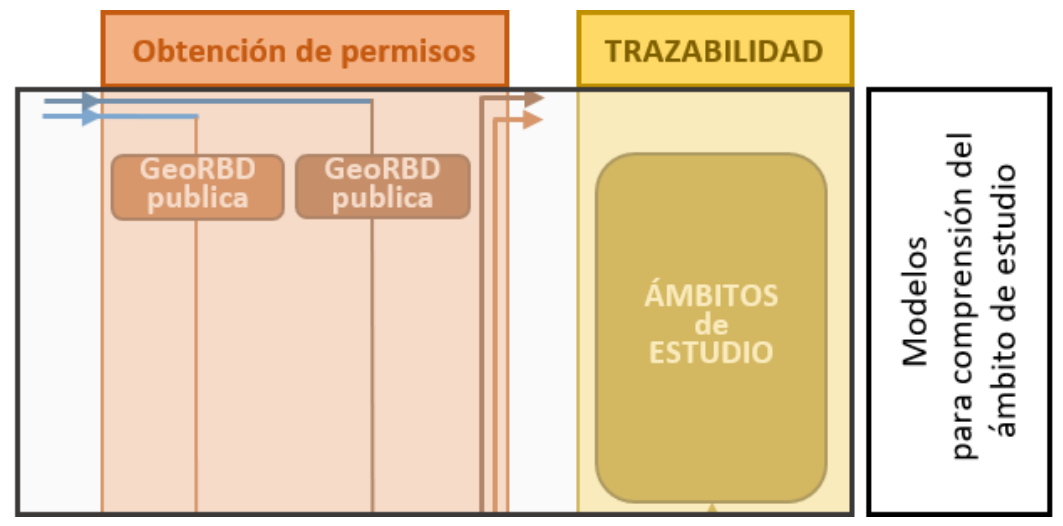

Figura 4-71. Procesos para comprensión del ámbito de estudio en fase de obtención de permisos

Estos procesos son idénticos para proyectos de línea y de subestación, cada uno mostrando su correspondiente GeoRBD.

\subsection{Modelos de ocupación del territorio (fase permisos)}

Los modelos de ocupación del territorio en esta fase tienen como objetivo obtener los permisos de paso, de servidumbre o de ocupación sobre las parcelas indicadas en la GeoRBD.

Los procesos de este tipo de modelos se muestran en la Figura 4-72.

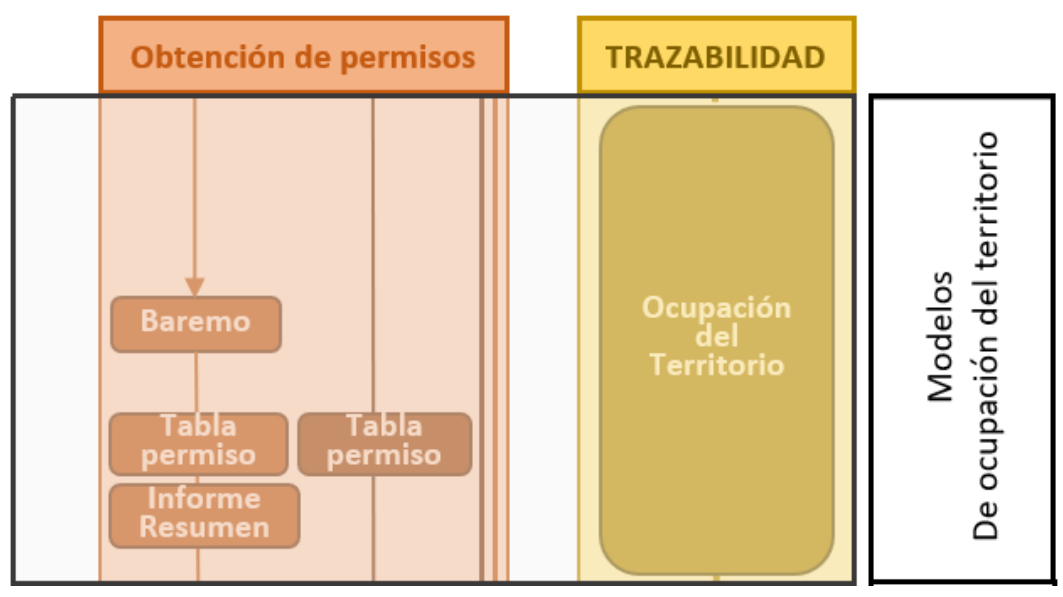

Figura 4-72. Procesos de los modelos de ocupación del territorio en fase de obtención de permisos 
a) Configuración del baremo

El baremo establece, para cada proyecto, una estimación del valor económico a compensar por metro cuadrado de ocupación.

Cada proyecto transita un territorio y en cada uno de ellos el valor del suelo y sus cultivos es diferente. Por este motivo, cada proyecto contará con su propio baremo. Como ejemplo de baremo la Tabla 4-18 muestra un ejemplo de línea subterránea.

\begin{tabular}{|c|c|c|c|c|c|}
\hline Cultivo según Catastro & $\begin{array}{c}\text { Servidumbre } \\
\text { de vuelo } \\
\left(€ / \mathrm{m}^{2}\right)\end{array}$ & $\begin{array}{c}\text { Ocupación } \\
\text { permanente } \\
\text { Aérea } \\
\text {-Apoyo- } \\
\text { (€/Ud.) }\end{array}$ & $\begin{array}{c}\text { Ocupación } \\
\text { permanente } \\
\text { Subterránea } \\
\left(€ / \mathrm{m}^{2}\right)\end{array}$ & $\begin{array}{c}\text { Cámara } \\
\text { empalme o } \\
\text { Arqueta } \\
\text { teleco } \\
(€ / \text { Ud.) }\end{array}$ & $\begin{array}{c}\text { Ocupación } \\
\text { temporal } \\
\left(€ / \mathrm{m}^{2}\right)\end{array}$ \\
\hline Labor o Labradío secano & 0 & 0 & 6 & 1800 & 0,6 \\
\hline Improductivo & 0 & 0 & 3,8 & 1500 & 0,38 \\
\hline Almendro secano & 0 & 0 & 8 & 2000 & 0,8 \\
\hline Labor o labradío regadío & 0 & 0 & 8 & 2000 & 0,8 \\
\hline Matorral & 0 & 0 & 3,5 & 1500 & 0,35 \\
\hline Higueras secano & 0 & 0 & 10 & 2500 & 1 \\
\hline Algarrobo secano & 0 & 0 & 8 & 2000 & 0,8 \\
\hline Encinar & 0 & 0 & 8 & 2000 & 0,8 \\
\hline Pastos & 0 & 0 & 3,8 & 1500 & 0,38 \\
\hline Arboles de ribera & 0 & 0 & 8 & 2000 & 0,8 \\
\hline Frutales, regadío & 0 & 0 & 10 & 2500 & 1 \\
\hline Pinar maderable & 0 & 0 & 10 & 2500 & 1 \\
\hline Olivos secano & 0 & 0 & 8 & 2000 & 0,8 \\
\hline Urbano. Suelo sin edificar & 0 & 0 & 40 & 2500 & 4 \\
\hline Urbano. Ocio y hostelería & 0 & 0 & 40 & 2500 & 4 \\
\hline $\begin{array}{l}\text { Vía de comunicación de } \\
\text { dominio público }\end{array}$ & 0 & 0 & 3,8 & 1500 & 0,38 \\
\hline Urbano. Deportivo & 0 & 0 & 40 & 2500 & 4 \\
\hline
\end{tabular}

Tabla 4-18. Ejemplo de baremo para obtención de permisos en línea subterránea

Con él se calcula la compensación económica a pagar a cada propietario estimada en función del tipo de afectación, su magnitud y el tipo de uso del suelo.

En proyectos de subestación no existe baremo, puesto que el número de parcelas es reducido y se realiza de forma manual.

b) Obtención de permisos

Se trata de una tarea de comunicación y de consenso con todos los propietarios de las parcelas afectadas.

El técnico explicará cómo la nueva instalación afectará a cada parcela y cuál será la compensación económica por este hecho. El mutuo acuerdo se registrará en un documento firmado por ambas partes que se almacenará en el sistema de gestión documental de la compañía. 
Antes de implantar la nueva metodología la comunicación de las RBD se realizaba sobre plano impreso con las afectaciones y se le proponía la compensación económica. Actualmente la nueva metodología ha sustituido el papel por el soporte digital con capacidad de interactuar para mostrar las afectaciones sobre la cartografía, ayudando a entender mejor el proyecto por parte de los propietarios.

El resultado buscado, que a fecha de la redacción de este documento está en fase de implementación, tiene la estructura de campos mostrados en la Tabla 4-19.

\begin{tabular}{|c|c|}
\hline № & Nombre Campo \\
\hline 1 & Municipio \\
\hline 2 & Parcela Proyecto \\
\hline 3 & Propietario \\
\hline 4 & Gestor o representante \\
\hline 5 & Dirección \\
\hline 6 & NIF \\
\hline 7 & Teléfono \\
\hline 8 & Polígono \\
\hline 9 & Parcela \\
\hline 10 & Referencia Catastral \\
\hline 11 & Paraje \\
\hline 12 & Longitud Aérea \\
\hline 13 & Servidumbre de Vuelo \\
\hline 14 & Zona de Seguridad \\
\hline 15 & Apoyos \\
\hline 16 & Superficie Apoyos. \\
\hline 17 & Superficie Tala \\
\hline 18 & Ocupación Temporal \\
\hline 19 & Ocupación Permanente \\
\hline 20 & Acceso al apoyo \\
\hline 21 & Superficie Acceso \\
\hline 22 & Longitud Subterránea \\
\hline 23 & Servidumbre subterránea $\left(\mathrm{m}^{2}\right)$ \\
\hline 24 & CE AT \\
\hline 25 & Naturaleza del Terreno \\
\hline 26 & Cultivo Significativo \\
\hline 27 & Acceso $\left(€ / \mathrm{m}^{2}\right)$ \\
\hline 28 & Vuelo $\left(€ / \mathrm{m}^{2}\right)$ \\
\hline 29 & Aроуо (€/Aроуо) \\
\hline 30 & Tala $\left(€ / \mathrm{m}^{2}\right)$ \\
\hline 31 & Servidumbre Subterránea $\left(€ / \mathrm{m}^{2}\right)$ \\
\hline 32 & $\mathrm{CE} / \mathrm{AT}(€ / \mathrm{CE} \mathrm{AT})$ \\
\hline 33 & Importe Apoyos \\
\hline
\end{tabular}

\begin{tabular}{|c|c|}
\hline Cont & Nombre Campo \\
\hline 34 & Importe Vuelo \\
\hline 35 & Importe Zona Seguridad \\
\hline 36 & Importe Tala \\
\hline 37 & Importe Acceso \\
\hline 38 & № Permisos Apoyo \\
\hline 39 & Importe Ocupación Temporal \\
\hline 40 & Importe Servidumbre Subterránea \\
\hline 41 & Importe CE / AT \\
\hline 42 & № Permisos Apoyo \\
\hline 43 & Importe estimado \\
\hline 44 & Importe Pagado \\
\hline 45 & Fecha Permiso \\
\hline 46 & № Apoyos parcela \\
\hline 47 & № Apoyos Con Permiso \\
\hline 48 & № Vuelos parcela \\
\hline 49 & № Vuelos con Permiso \\
\hline 50 & № accesos \\
\hline 51 & № accesos con permiso \\
\hline 52 & № Ocupaciones Temporales \\
\hline 53 & № Ocupaciones Temporal con Permiso \\
\hline 54 & № Servidumbres Subterráneas \\
\hline 55 & № Servidumbres Subterráneas con Permiso \\
\hline 56 & № CE y AT \\
\hline 57 & № CE y AT Con Permiso \\
\hline 58 & Metros Lineales Pagados (Aérea) \\
\hline 59 & Metros Lineales Pagados (Subterránea) \\
\hline 60 & ID Apoyos con permiso \\
\hline 61 & ID Ce y AT con permiso \\
\hline 62 & Estado permiso \\
\hline 63 & Tipología de la parcela \\
\hline 64 & Histórico de contactos con la propiedad \\
\hline 65 & Observaciones \\
\hline 66 & Depósitos $(€)$ \\
\hline
\end{tabular}

Tabla 4-19. Estructura de campos para tabla de permisos 
Sin embargo, sí se han implementado los procesos del primer contacto con cada propietario, registrándose en medios digitales la percepción sobre la posibilidad del mutuo acuerdo. Este primer contacto se inicia de forma paralela a la depuración de la GeoRBD con dos objetivos, por un lado, que al finalizar dicha depuración cuente con la información lo más actualizada y fiable posible y, por otro lado, cuando se inicie el proceso de obtención de permisos se evite el dilatar los plazos de esta tarea.

La Figura 4-73 muestra un ejemplo del resultado de esta primera reunión con un propietario y las observaciones realizadas.

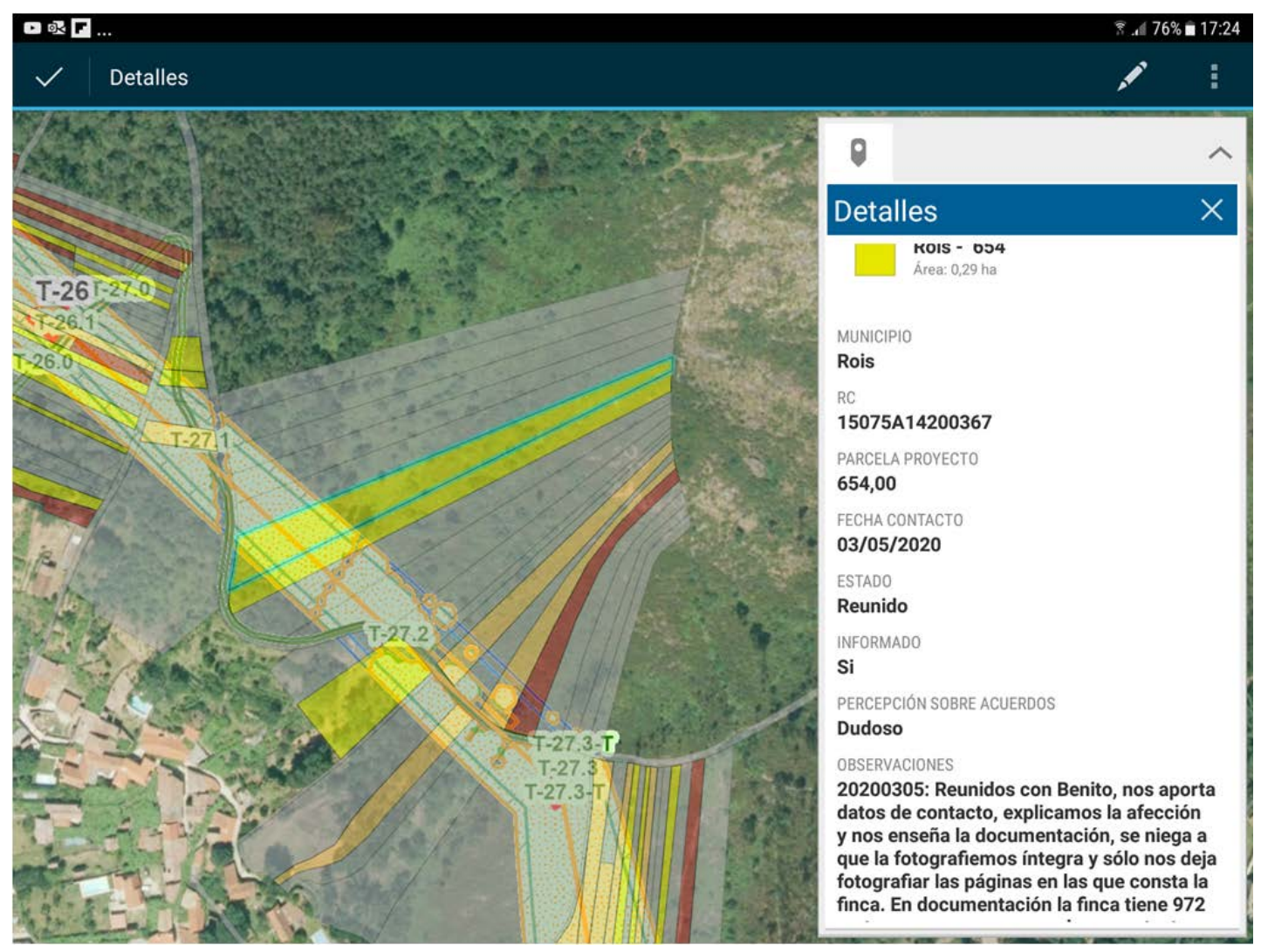

Figura 4-73. Ejemplo de registro en campo del primer contacto con propietarios

c) Generación del informe resumen

El informe resumen tiene la finalidad de dar soporte al seguimiento de la obtención de permisos, el control presupuestario por municipio, e indicar qué partes de la futura línea eléctrica puede iniciar la construcción.

Esta información es realmente relevante para poder comenzar la fase de construcción de forma paralela a la obtención de permisos. Se establece aquí otro escenario de colaboración entre ambas fases, lo que optimiza los plazos globales del proyecto.

La Tabla 4-20 muestra un ejemplo de informe resumen. 


\begin{tabular}{|c|c|c|c|c|c|c|c|c|c|}
\hline Municipio & $\begin{array}{c}\text { № } \\
\text { Apoyos } \\
\text { Total }\end{array}$ & $\begin{array}{c}\mathrm{N}^{\circ} \\
\text { Apoyos } \\
\text { con } \\
\text { permiso }\end{array}$ & $\begin{array}{c}\text { ID } \\
\text { Apoyos } \\
\text { con } \\
\text { permiso }\end{array}$ & $\begin{array}{c}\text { № } \\
\text { Vuelos }\end{array}$ & $\begin{array}{c}\mathrm{N}^{\mathrm{o}} \\
\text { Vuelos } \\
\text { con } \\
\text { permiso }\end{array}$ & $\begin{array}{c}\text { No }^{\mathbf{0}} \\
\text { tramos } \\
\text { de } \\
\text { Acceso }\end{array}$ & $\begin{array}{c}\mathrm{N}^{\mathbf{0}} \\
\text { tramos } \\
\text { de } \\
\text { Acceso } \\
\text { con } \\
\text { Permiso } \\
\end{array}$ & $\begin{array}{c}\text { Importe } \\
\text { estimado } \\
(€)\end{array}$ & $\begin{array}{c}\text { Importe } \\
\text { pagado } \\
(€)\end{array}$ \\
\hline Güeñes & 6 & 0,1 & T_4; & 29 & 2 & 9 & 1 & 460170,2 & 20507,5 \\
\hline Okondo & 1 & 0 & & 16 & 1 & 5 & 0 & 142970,55 & 1476,85 \\
\hline Alonsotegi & 6 & 0,86 & T_11; & 24 & 7 & 9 & 1 & 590022,48 & 88626,88 \\
\hline Arrankudiaga & 0 & & & 1 & 0 & 1 & 0 & 12980,3 & 0 \\
\hline Muxika & 1 & 1 & T_58; & 1 & 1 & 1 & 1 & 5946,3275 & 5946,33 \\
\hline Iurreta & 3,5 & 3,5 & $\begin{array}{l}\text { T_59; } \\
\text { T_60; } \\
\text { T_61; } \\
\text { T_62; }\end{array}$ & 26 & 19 & 12 & 10 & 293784,26 & 281987,1 \\
\hline Garai & 4,5 & 0 & & 27 & 2 & 31 & 6 & 345573,15 & 9825,2 \\
\hline Bergara & 13 & 1 & T_100; & 99 & 27 & 45 & 8 & 866597,6 & 191244,7 \\
\hline$\ldots$ & $\cdots$ & $\cdots$ & $\ldots$ & $\cdots$ & $\ldots$ & $\ldots$ & $\ldots$ & $\ldots$ & $\ldots$ \\
\hline TOTAL & 132 & 7,08 & & 1.028 & 90 & 712 & 46 & 9.787 .221 & 718702,9 \\
\hline
\end{tabular}

Tabla 4-20. Ejemplo de informe resumen

\subsection{Modelos de decisión (fase permisos)}

Los modelos de decisión en esta fase tienen por objeto registrar su finalización, es decir, que ya no se añadirá ni modificará ninguna información relativa a la obtención de permisos en esta fase.

Los procesos de este tipo de modelos se muestran en la Figura 4-74.

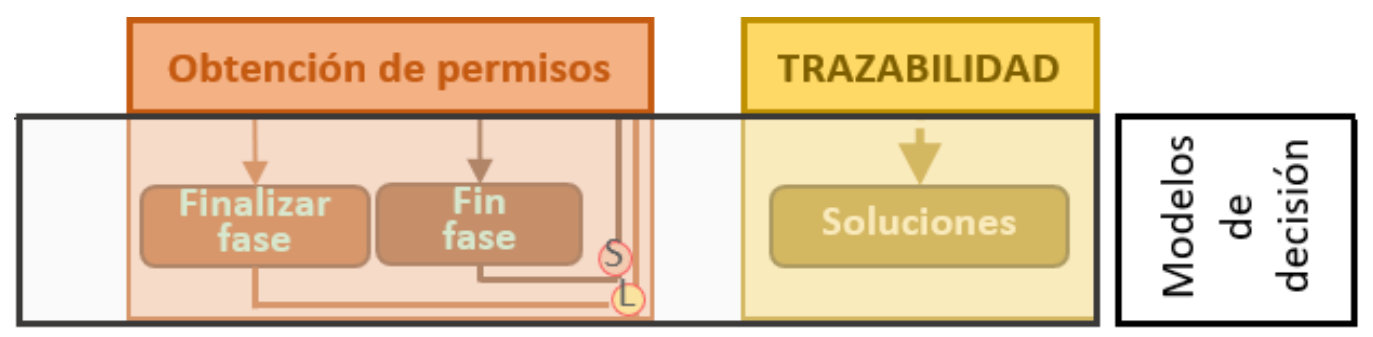

Figura 4-74. Procesos de los modelos de decisión en fase obtención de permisos

Al igual que en otros procesos de finalización de fase, el técnico responsable podrá registrar algún comentario que considere relevante.

\subsubsection{Fase de construcción}

Las fases anteriores han ido concretando una solución de proyecto construible, desde el punto de vista ambiental, técnico y legal. Es decir, el proyecto se ha ido diseñando para llegar a esta fase con garantías de poder ser construido.

\subsection{Modelos para comprensión del ámbito de estudio (Fase construcción)}

El ámbito de estudio de la fase constructiva viene marcado por el informe resumen que se apoya en la información geográfica para su mejor entendimiento. Este informe resumen indica qué apoyos pueden ser construidos y qué cables pueden ser tendidos en base a los permisos obtenidos. Es decir, un apoyo puede ser construido si se han firmado los permisos de las parcelas 
afectadas por la ocupación temporal y permanente del apoyo, pero también son necesarios los permisos de todas las parcelas afectadas por su camino de acceso. Solo en ese momento podrá comenzar la obra. Se trata de un proceso de consulta de cómo avanza la obtención de permisos que ayuda a planificar la construcción.

La Figura 4-75 muestra los procesos de este tipo de modelos.

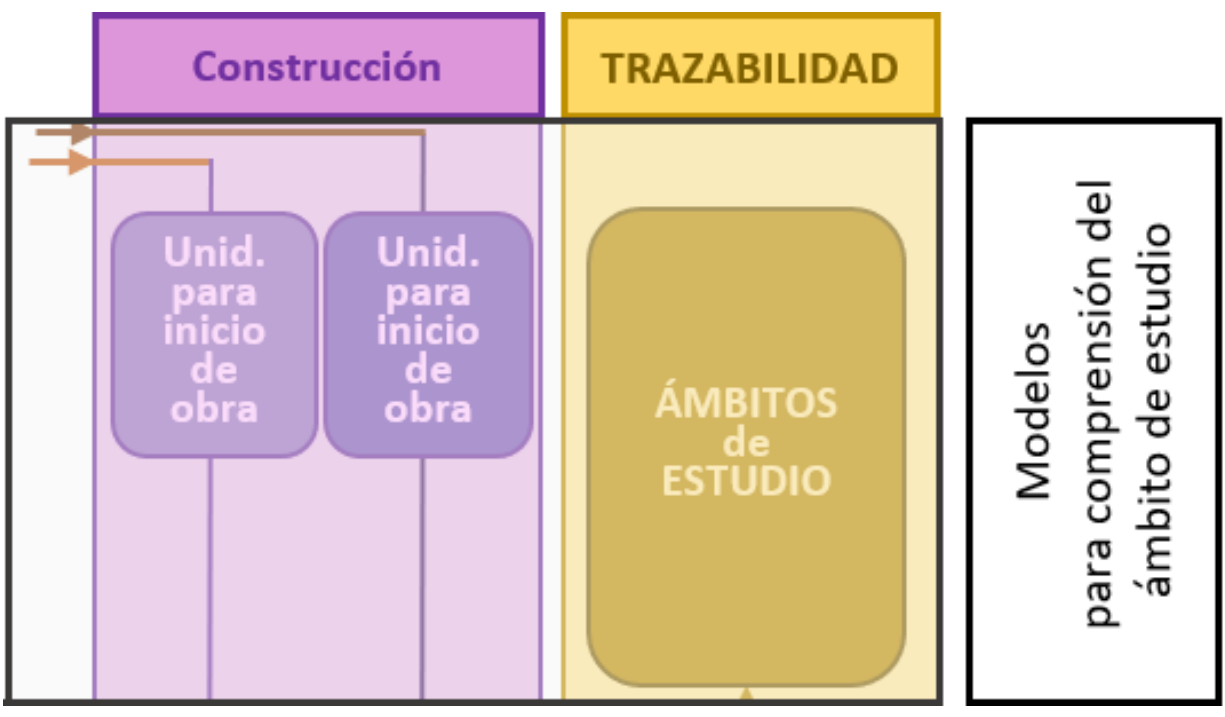

Figura 4-75. Procesos de los modelos para comprensión del ámbito de estudio de la fase constructiva

La Figura 4-76 muestra gráficamente el avance de la obtención de permisos que, junto al informe resumen indican qué partes del proyecto de línea pueden ser construidas. Donde el color verde indica permiso firmado y el rojo permiso pendiente.

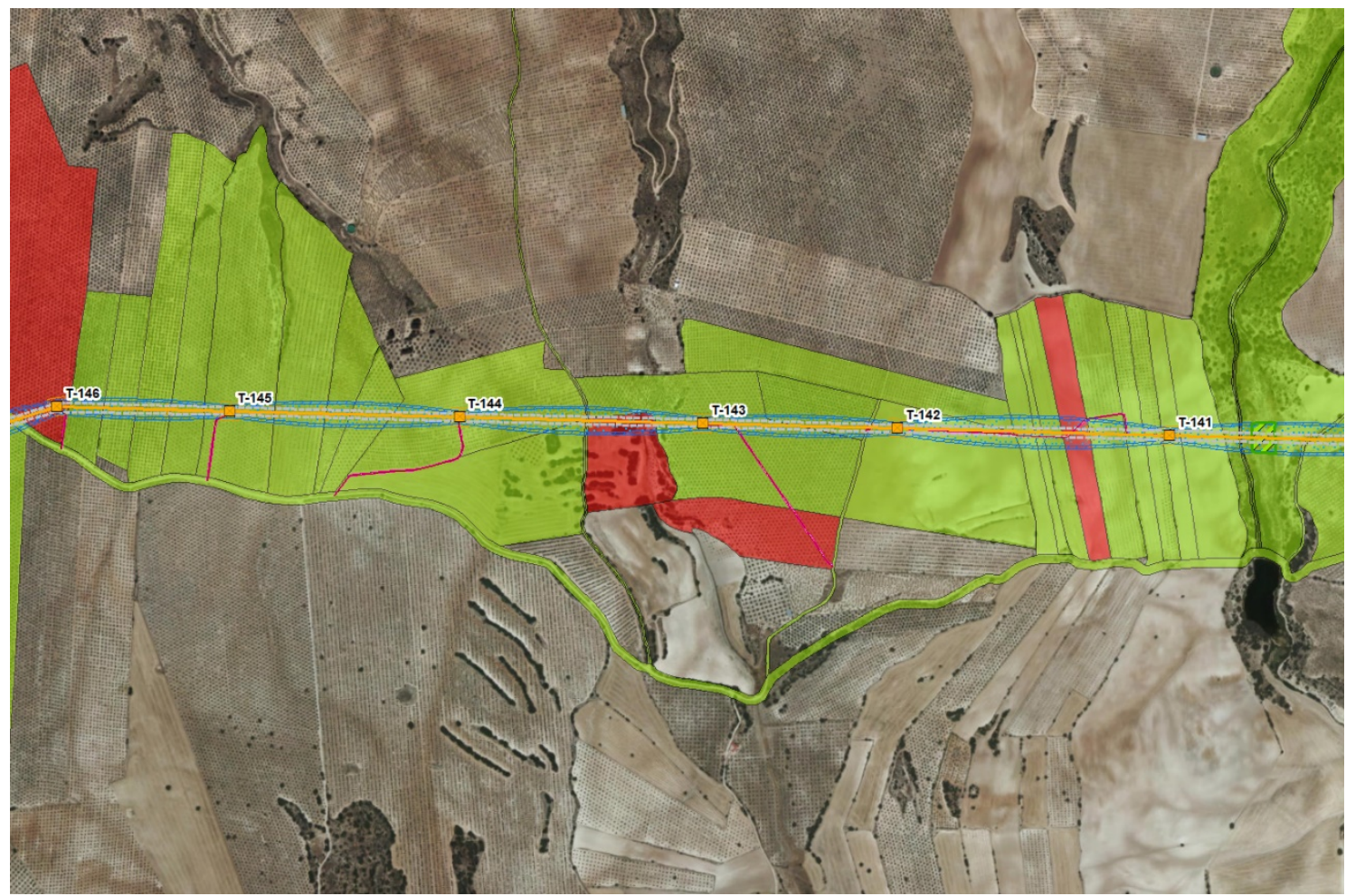

Figura 4-76. Ejemplo de avance de obtención de permisos a las parcelas afectadas 
Para proyectos de subestación, aunque el proceso es mucho más simple y no se necesita informe resumen, también se puede visualizar gráficamente el avance de obtención de permisos.

\subsection{Modelos de evaluación de impactos (Fase construcción)}

En este tipo de modelos no hay procesos que puedan automatizarse. La evaluación de impactos en esta fase se refiere a la vigilancia ambiental de la obra en cuanto a gestión de residuos y respeto al medio ambiente.

\subsection{Modelos de ocupación del territorio (Fase construcción)}

La Figura 4-77 muestra los procesos de este tipo de modelos.

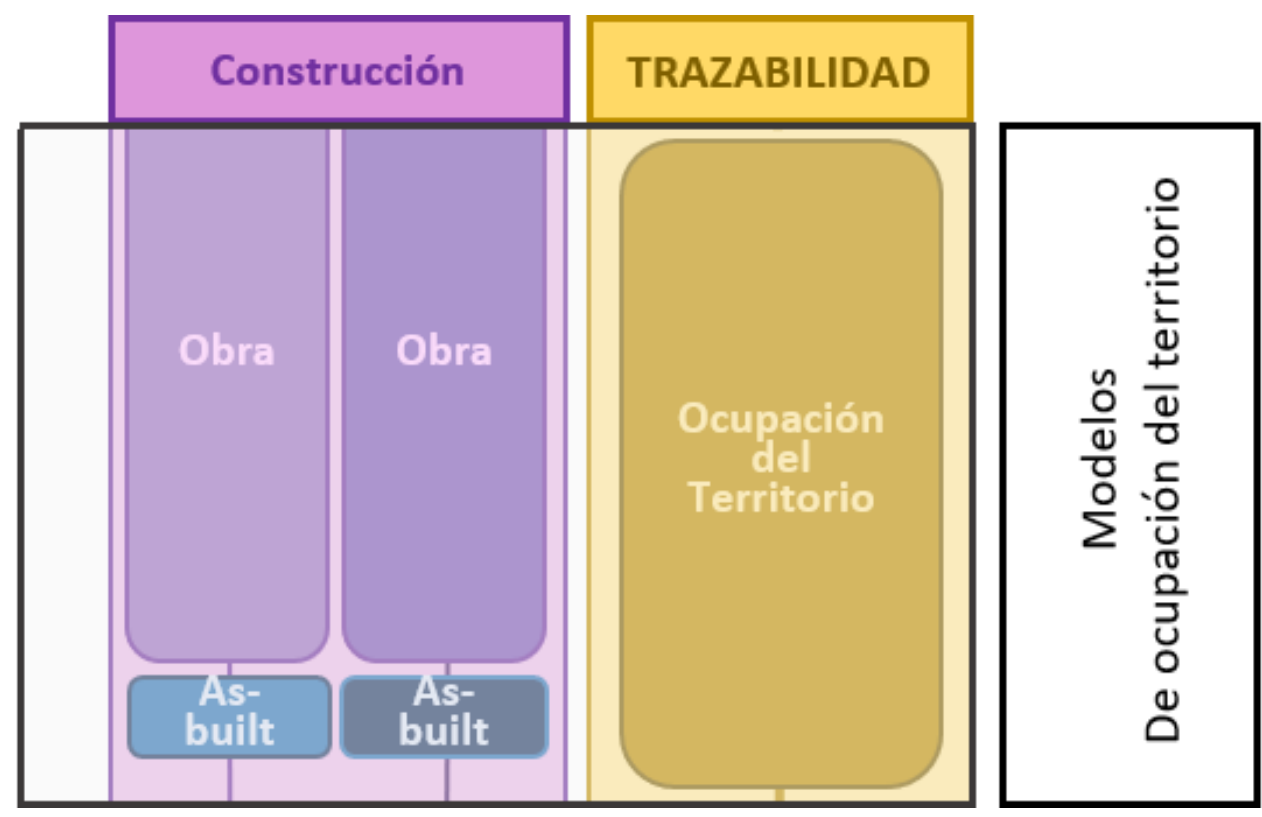

Figura 4-77. Procesos de los modelos de ocupación del territorio en fase de construcción

a) Seguimiento de obra

Con independencia de las superficies teóricas de ocupación temporal que se establecen en la fase de ingeniería, y cuantificada su afectación en fase de obtención de permisos, a menudo surgen variaciones de estas superficies durante la ejecución de la obra. Estas variaciones pueden deberse a las necesidades que generan la orografía, de la maquinaria a utilizar e incluso por la propia solicitud del propietario de la parcela.

Un ejemplo de estas nuevas superficies de ocupación temporal son las relativas al izado de los apoyos. Por defecto se considera una superficie de $1600 \mathrm{~m}^{2}$ centrada en el apoyo y orientada según la línea.

La Figura 4-78 (a) se muestra un ejemplo de la ocupación temporal propuesta por defecto, que paralizaría una vía pública de comunicación, y la Figura 4-78 (b) la establecida finalmente en la ejecución de la obra. 
(a)

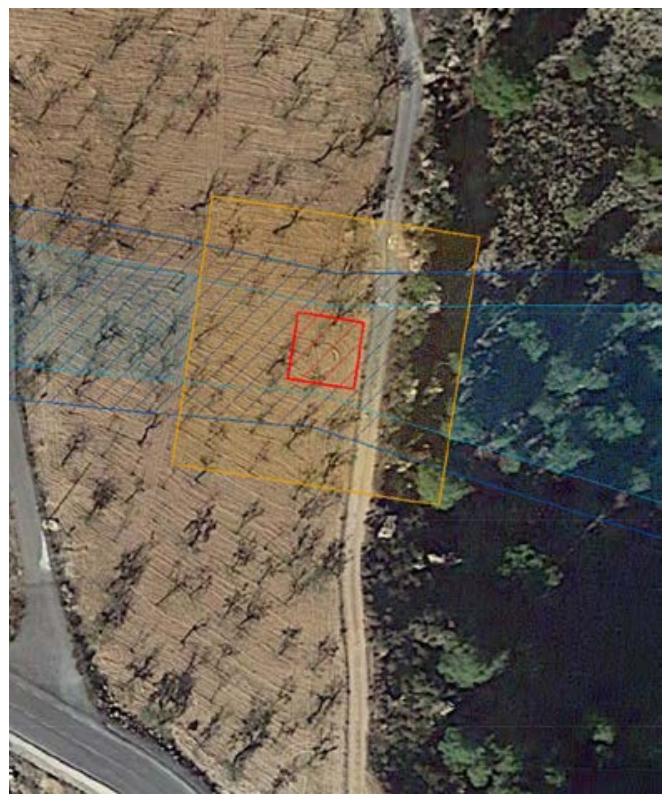

(b)

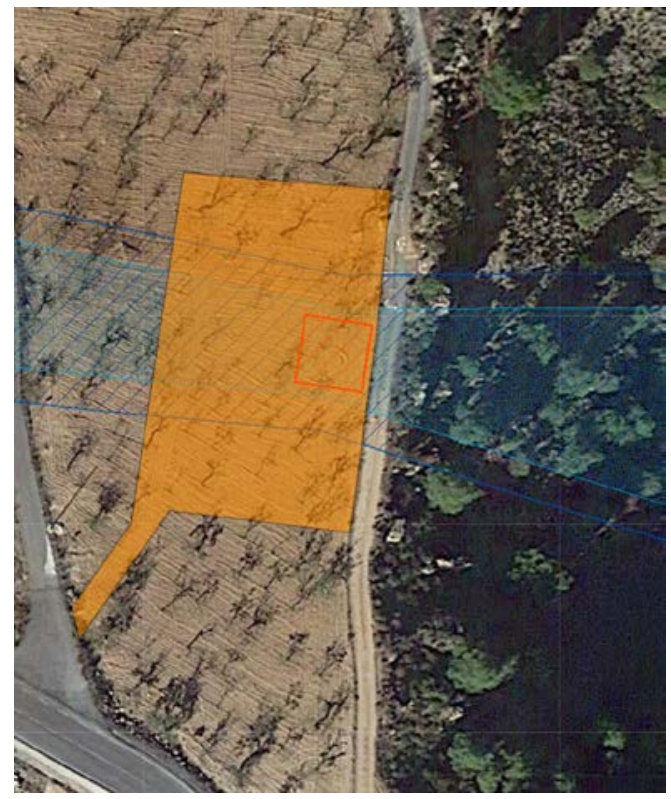

Figura 4-78. Ejemplo de diferencia entre ocupación temporal de proyecto y de construcción.

Dentro de la fase de obtención de permisos se establece el pago por los daños causados a cada parcela: por deterioro de cultivos, construcciones derribadas, vallas o alambradas cortadas, etc. En este caso, al generarse nuevas afectaciones no contempladas previamente, se establece un sistema de compensación a medida en función de los daños causados.

Paralelamente, se podrá consultar el avance de obra de forma geográfica. El proceso seguimiento del avance de obra mostrará el mapa cuya simbología ayudará a comprender de forma rápida el estado de la construcción de la instalación. La Figura 4-79 muestra un ejemplo de este proceso.

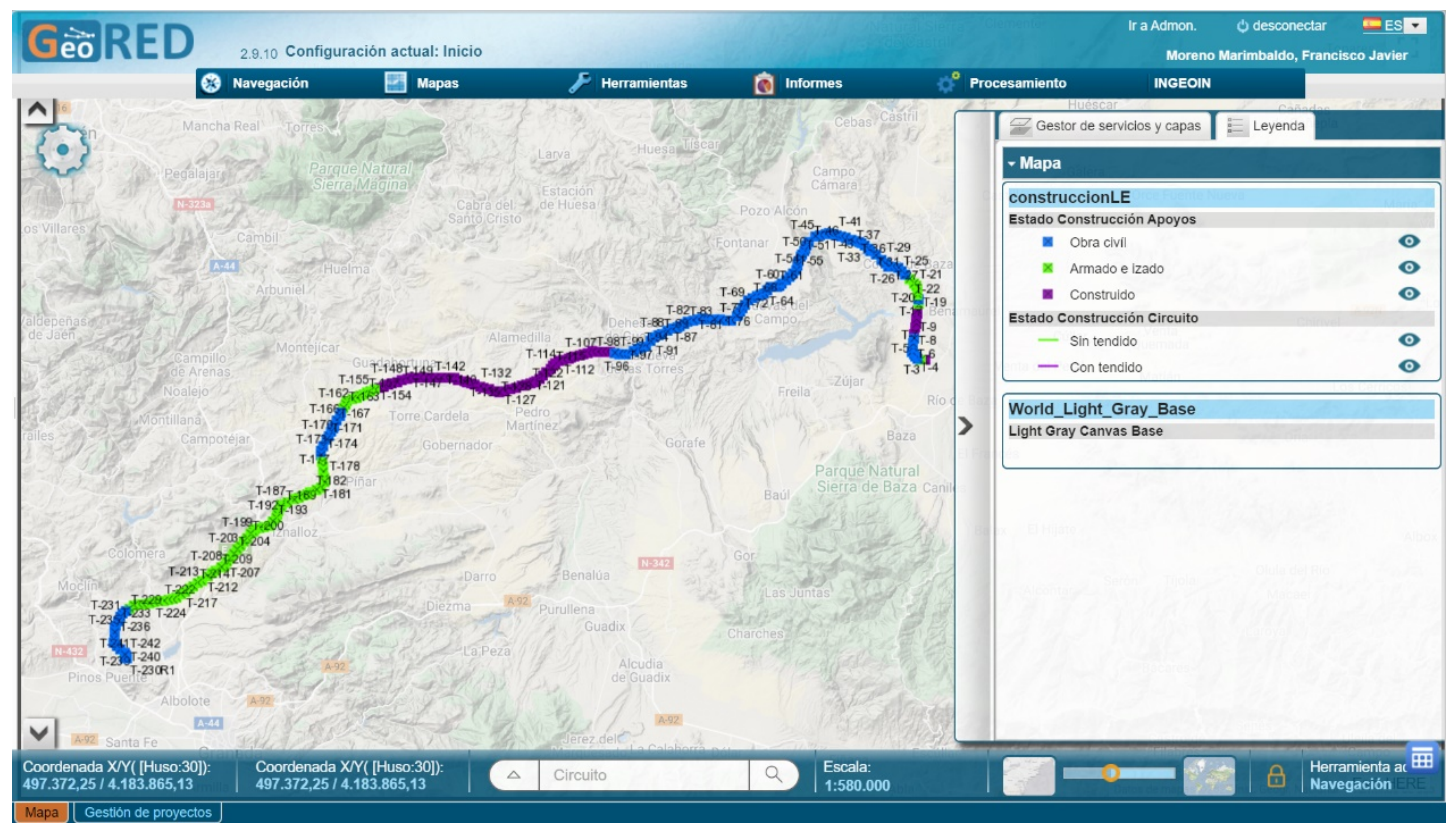

Figura 4-79. Ejemplo gráfico del estado de avance de la construcción de un proyecto de línea 
En la construcción de proyectos de subestación no existirá este tipo de avance debido a que dentro del cerramiento de la subestación el significado geográfico no es relevante.

b) Carga de planos as-built

En la construcción de grandes infraestructuras como éstas puede haber imprevistos o peticiones de los propietarios que afectan a la construcción haciendo que difiera del proyecto diseñado en detalles asumibles por la parte técnica. Los mayores cambios suelen producirse en la construcción de los caminos de acceso. Para documentar estos cambios es necesario registrar el proyecto construido, ya que el diseñado ya lo está

Este tipo de procesos automatiza la carga en el sistema de los planos que reflejan la construcción real de la instalación.

\subsection{Modelos de decisión (Fase construcción)}

Este tipo de modelos, significando la finalización de la fase y también del proyecto, son el último paso antes de proceder a la transferencia de la instalación a la unidad organizativa encargada de del mantenimiento de la misma.

La unidad organizativa encargada del mantenimiento debe recibir la instalación en perfectas condiciones técnicas y administrativas, en cuanto a tala de arbolado, permisos, etc... Para poder finalizar esta fase, se realiza una revisión exhaustiva de todos estos aspectos.

La Figura 4-80 muestra los procesos de este tipo de modelos.

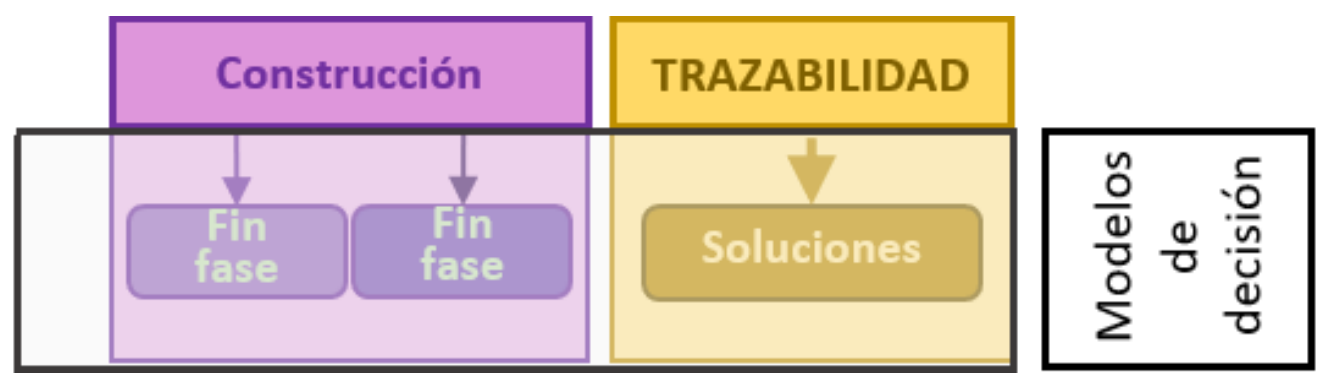

Figura 4-80. Procesos de decisión de la fase de construcción

\subsubsection{Trazabilidad de la información geográfica del proyecto}

Para garantizar la trazabilidad de la información geográfica cargada, la generada, los análisis y la ejecución de los procesos se realiza un registro automático por la ejecución de cada proceso.

La Figura 4-81 muestra los procesos de este tipo de modelos, siendo la Figura 4-81 (a) los procesos de trazabilidad de información geográfica y la Figura 4-81 (b) el proceso de registro de ejecución de procesos del proyecto. 
(a)

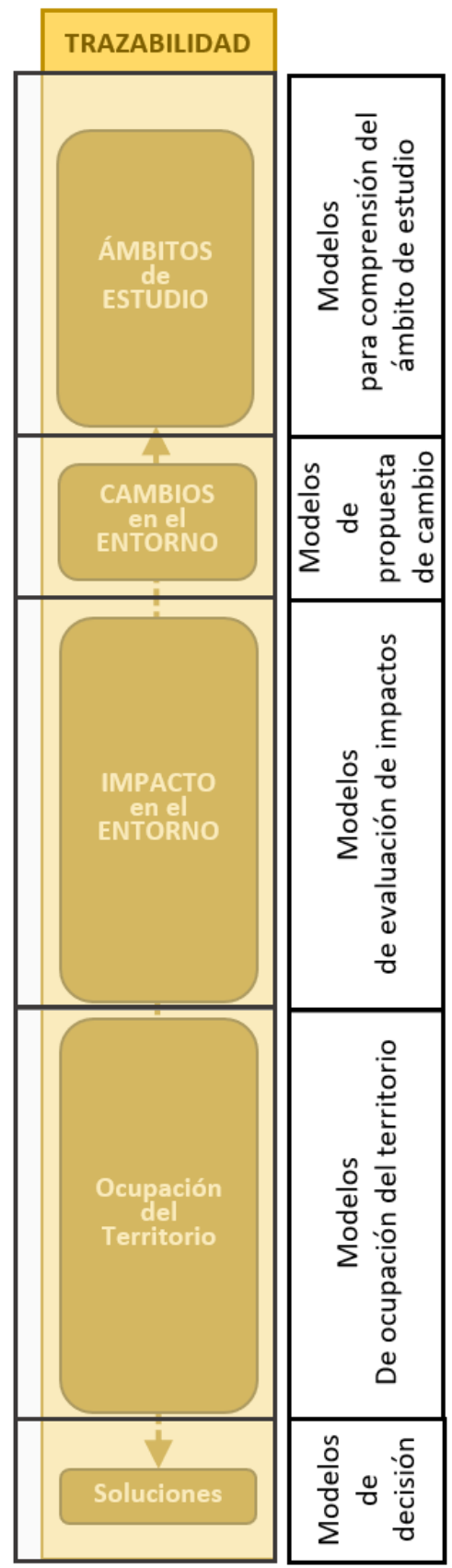

(b)

\section{LOG}

TRAZABILIDAD

Figura 4-81. Procesos de los modelos de trazabilidad

a) Trazabilidad de la información geográfica

A través de la materialización de los modelos definidos y por medio de la ejecución de los diferentes procesos se van almacenando en el sistema, de forma organizada, los resultados de todos ellos.

Al ejecutar cualquiera de los procesos de trazabilidad, el sistema realiza una llamada transversal a los resultados de los procesos, de todas las fases, del tipo de modelos seleccionado, y mostrará toda su información geográfica. La Figura 4-82 muestra un ejemplo de la ejecución de proceso de trazabilidad de los modelos para comprensión del ámbito de 
estudio, donde puede apreciarse el diagnóstico territorial, la alineación y distribución de apoyos y las parcelas afectadas

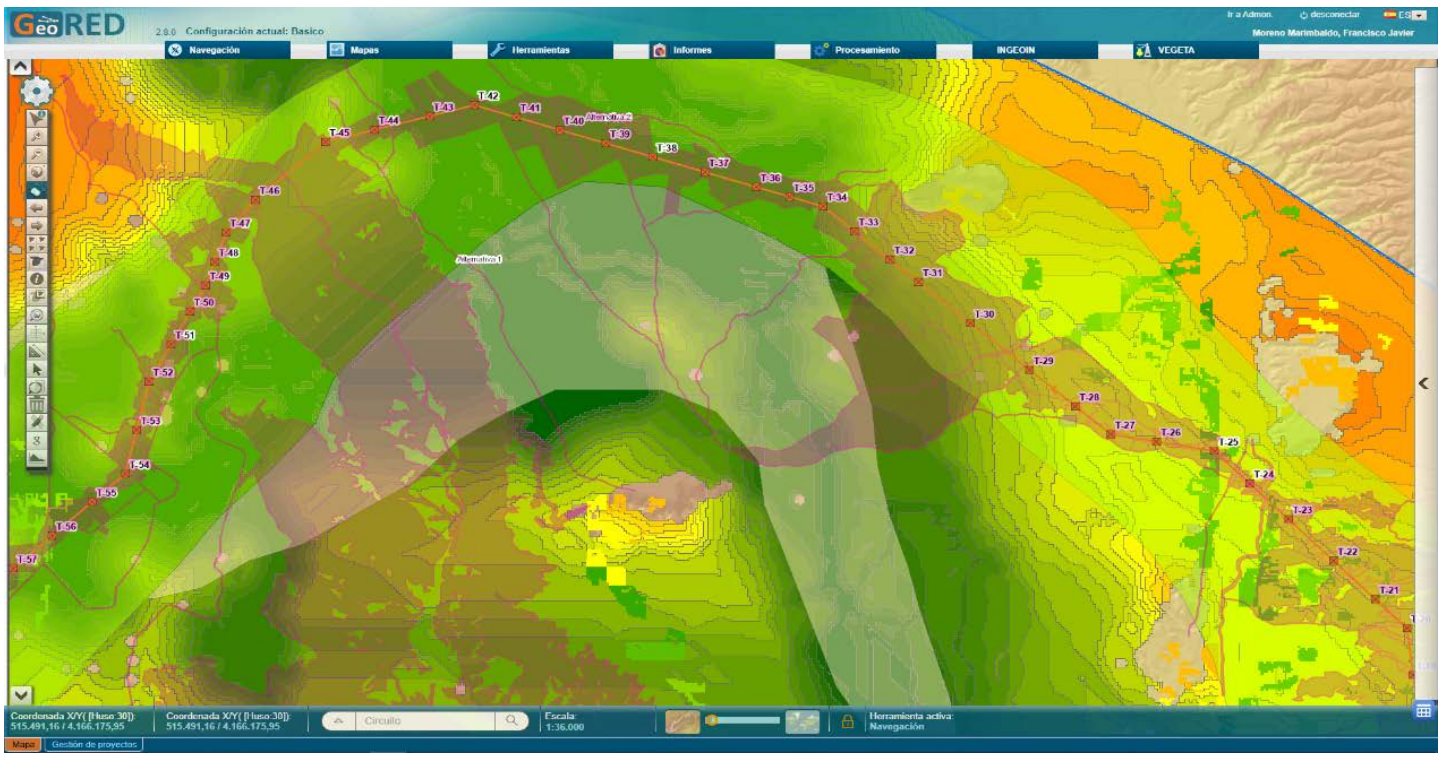

Figura 4-82. Ejemplo de trazabilidad de la información geográfica

b) Registro de ejecución de procesos

Paralelamente a la ejecución de los procesos se registra en una tabla la información de cada proceso con la siguiente información:

- Fase del proyecto

- Usuario que la ha ejecutado

- Estado de la ejecución (correcta o ha habido algún error)

- Mensaje del usuario al ejecutar el proceso

- Fecha de ejecución.

La Figura 4-83 muestra un ejemplo del log de trazabilidad de la ejecución de procesos de un proyecto de línea. Permite la ordenación por cualquiera de sus campos, la búsqueda de un registro concreto y la exportación en formato csv para explotación fuera del sistema.

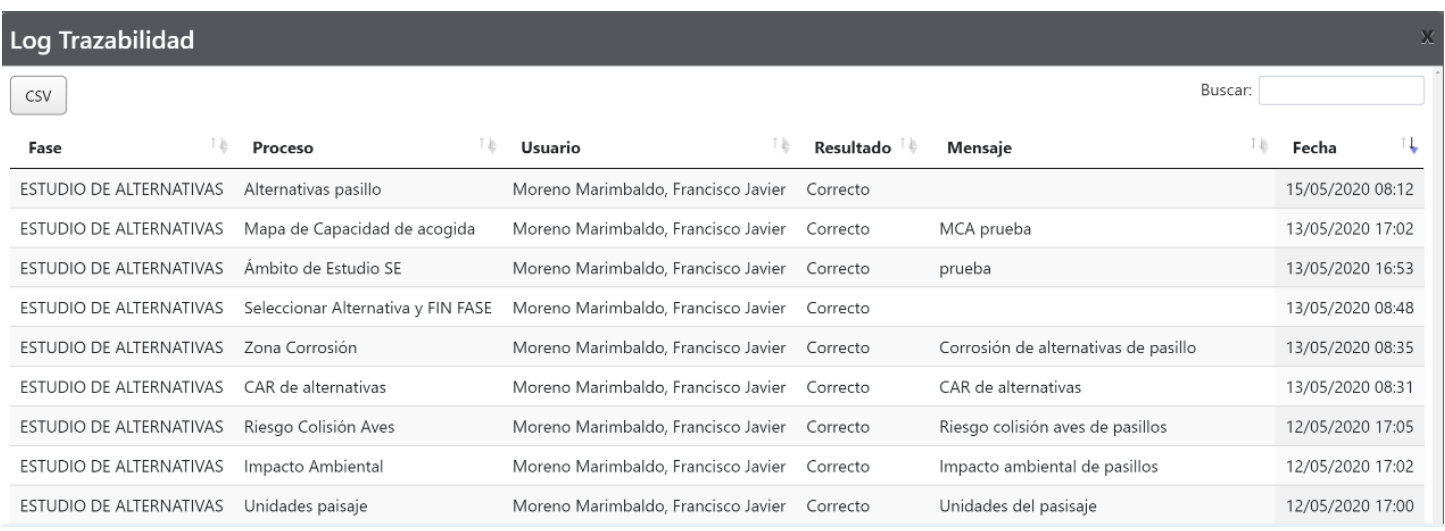

Figura 4-83. Ejemplo de log de trazabilidad de un proyecto 


\subsubsection{Gestión de grupos de interés}

\subsubsection{Base de datos geográfica de grupos de interés}

De la misma forma que se utiliza una base de datos para almacenar y explotar la información geográfica de cada fase de los proyectos, los ámbitos geográficos de influencia de los grupos de interés también serán registrados con su propio modelo de datos.

Este modelo de datos permite, además de registrar ámbitos geográficos de influencia, su asociación con los grupos de interés, la asignación de proyecto, la definición del plan de acción a través de las acciones a acometer y las observaciones sobre las acciones. La Figura 4-84 muestra el esquema-resumen del modelo de datos de grupos de interés.

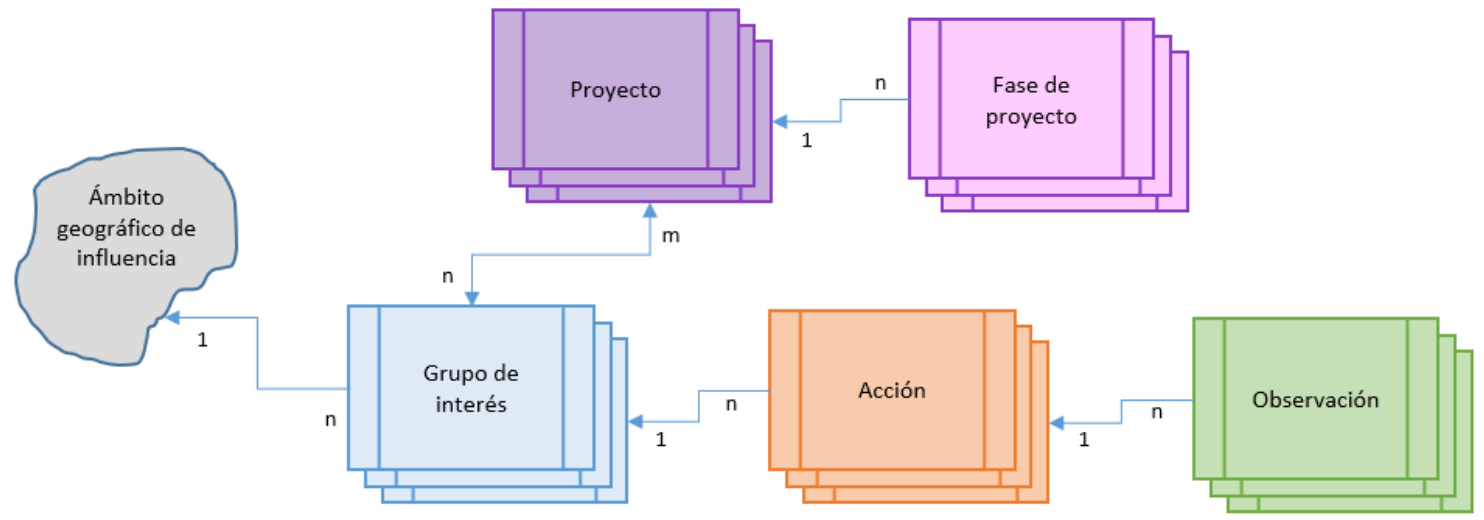

Figura 4-84. Esquema-resumen del modelo de datos de grupos de interés

Esta base de datos permitirá conocer, a nivel territorial, las relaciones entre REE y los grupos de interés de los proyectos.

A continuación, se describen las entidades del modelo de datos y sus relaciones:

1. Ámbito geográfico de influencia

Es la entidad geográfica que delimita el área sobre la que un grupo de interés tiene influencia o sobre el que presenta algún tipo de preocupación, necesidad o restricción.

Cada área de influencia puede estar relacionada con ' $n$ ' grupos de interés, es decir, varios grupos de interés comparten un mismo ámbito geográfico de influencia. Consta además de un código y un nombre que lo identifican.

2. Grupo de interés

Entidad alfanumérica que lo describe. Un mismo grupo puede tener interés en más de un ámbito geográfico y puede tener relacionadas ' $\mathrm{n}$ ' acciones. Además, un mismo grupo puede influenciar en más de una fase de cada proyecto y, también, en más de un proyecto.

3. Proyecto

Entidad que relaciona el grupo de interés y el proyecto sobre el que puede influir. 
4. Fase de proyecto

Entidad que relaciona la fase del proyecto con los grupos de interés asociados a este.

5. Acción

Entidad que describe la actuación necesaria con cada grupo de interés en concreto. Se podrán relacionar tantas acciones a un mismo grupo como sea necesario.

6. Observación

Entidad no obligatoria que matiza o añade información a cada una de las acciones registradas. Podrá haber 'n' observaciones para cada Acción.

4.3.6.2 Identificación, registro y categorización de los grupos de interés

La identificación de los grupos en cada fase en cada proyecto se realiza de dos formas diferentes:

a. De forma automática, a través de la coincidencia espacial entre el ámbito geográfico de influencia, utilizado en otro proyecto u otra fase, y la información geográfica que define el proyecto en cada fase.

b. Manualmente por los técnicos territoriales que, tras analizar la información geográfica que define el proyecto en cada fase, advierten la existencia de grupos no registrados.

Para registrar un grupo en la base de datos, tras ser identificado, lo primero es definir el ámbito geográfico de influencia y relacionarlo con los ' $\mathrm{n}$ ' posibles grupos de interés diferentes. Con tal fin se ha desarrollado una herramienta que gestiona este modelo de datos. Esta se compone de un visor geográfico con diferentes utilidades que facilitan la interacción con la información de los grupos de interés y de los proyectos. La arquitectura de la herramienta diseñada es la que se muestra en la Figura 4-85.
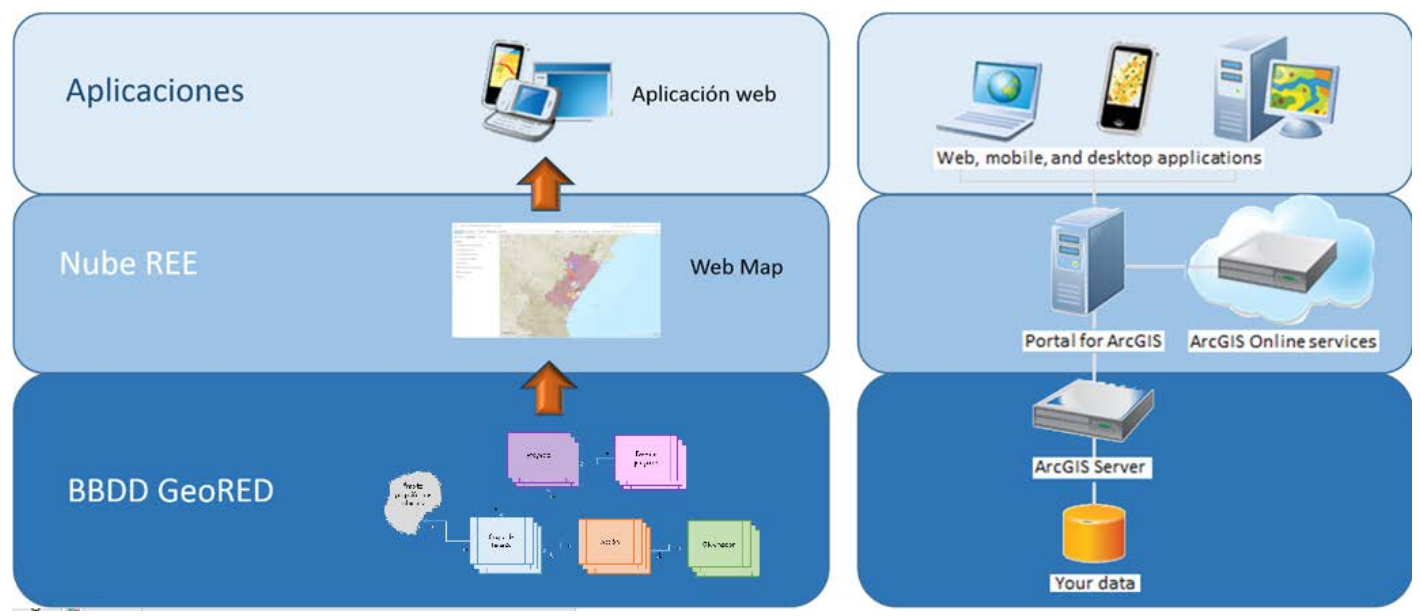

Figura 4-85. Arquitectura de herramienta geográfica

En la Figura 4-86 se muestra la interfaz gráfica de la herramienta con distintos niveles de granularidad, siendo (a) una vista general de los ámbitos geográficos de influencia registrados para un proyecto concreto; (b) una vista autonómica; (c) una vista provincial y municipal y (d) la información geográfica del proyecto. 
(a)

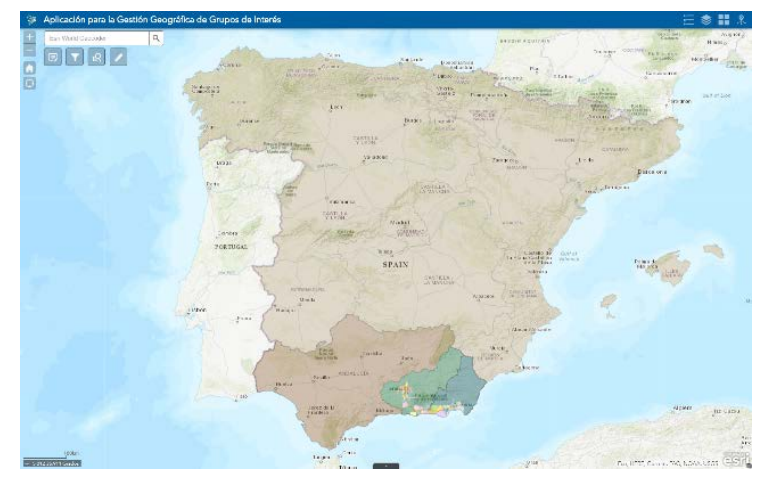

(c)

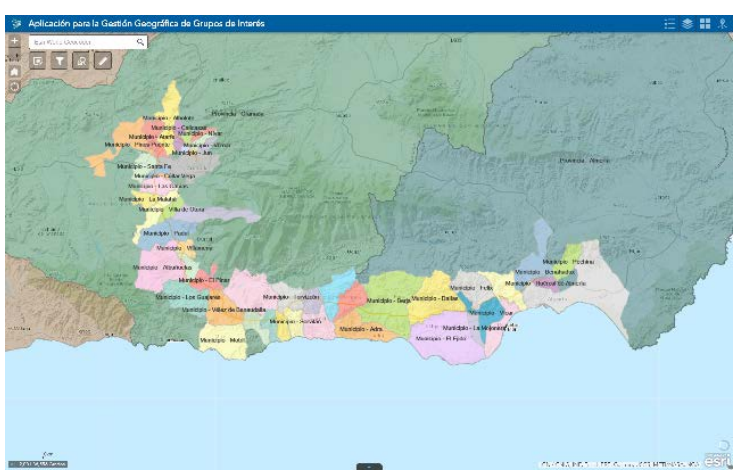

(b)

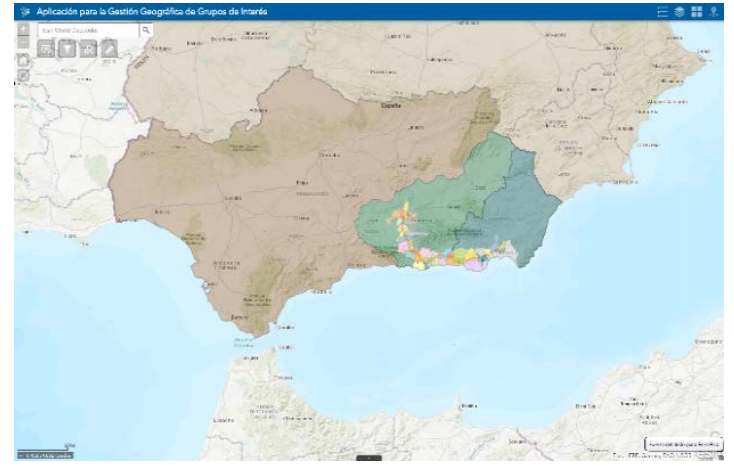

(d)

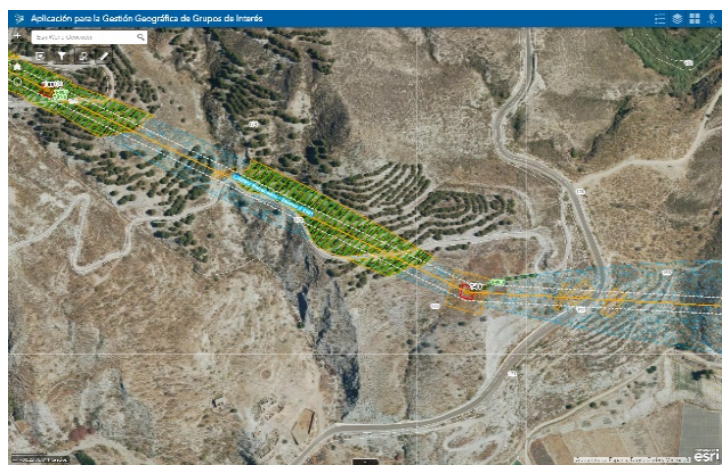

Figura 4-86. Interfaz gráfica de la herramienta

También el modelo de datos define una jerarquía o dependencia entre entidades que establece el comportamiento de la herramienta:

- Los ámbitos geográficos de influencia de cada grupo de interés pueden ser creados a criterio del usuario.

- Para registrar un nuevo grupo de interés, previamente tiene que existir su ámbito geográfico.

- Para asociar una acción, antes tiene que existir el grupo de interés al que asociar la acción.

- Las observaciones se asocian a acciones ya asociadas a grupos de interés, por tanto, debe existir esta asociación antes de crear una observación.

El orden de las tareas a realizar es: registrar un grupo de interés asociándolo a un ámbito, incluir las acciones a realizar sobre el grupo y añadir las observaciones pertinentes sobre las acciones. El registro de los grupos de interés consta de los campos mostrados en la Figura 4-87. 


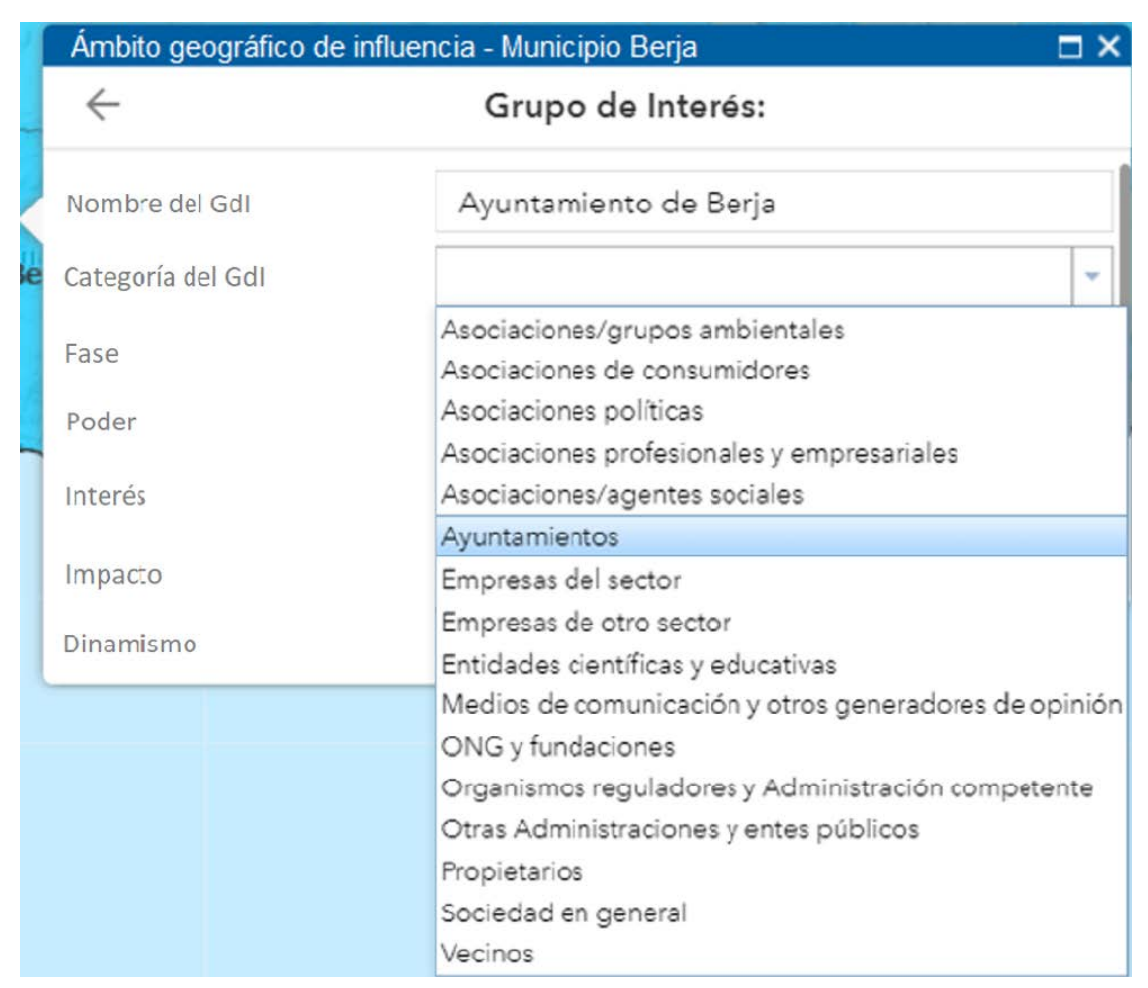

Figura 4-87. Información para el registro de grupo de interés

La descripción de estos campos que, excepto en nombre, están limitados a un dominio de valores ya gestionado por la herramienta, es la siguiente:

- Nombre del grupo de interés es el nombre con el que se conocerá al grupo de interés

- Categoría de grupo de interés se refiere al segmento en el que se engloba el grupo de interés identificado, de acuerdo con sus características comunes y razón de la relación con Red Eléctrica, y acorde a la catalogación del sistema de gestión de grupos de interés corporativo

- El proyecto indica el proyecto en el que ha sido identificado y sobre el que puede tener influencia

- Los valores poder, interés e impacto permite situarlo en la matriz poder-interés y ayudará a establecer el tipo de estrategia a usar con cada grupo.

4.3.6.3 Asociación de acciones a los grupos de interés

Mediante la misma herramienta, se han de asociar las acciones a cada grupo de interés existente y consta de los siguientes atributos, ver Figura 4-88. 
Acción:
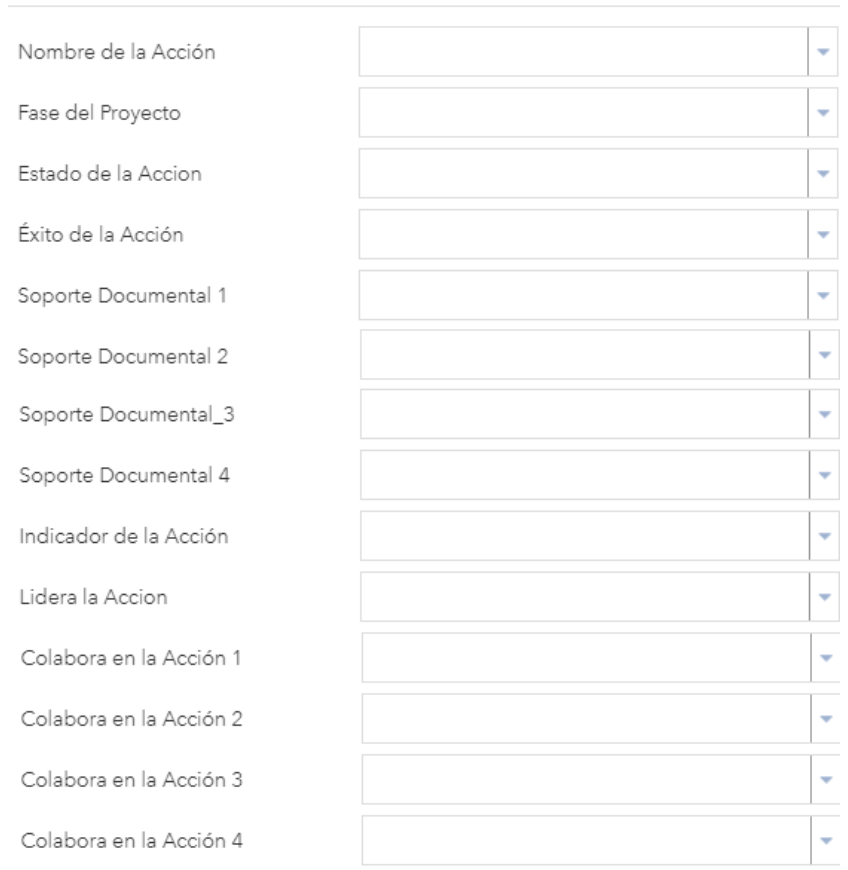

Figura 4-88. Atributos para asociar una acción a un grupo de interés

Los campos disponibles para registrar los atributos de las acciones están limitados a dominios de valores predefinidos.

- Nombre de la acción está condicionado a un dominio de valores cuyo origen es la lista de actividades referentes a cualquier servicio, solicitud, atención o vínculo entre el grupo y la compañía.

- La Fase del proyecto define el momento en el que se ejecutará la acción.

- El Estado de la acción define si la acción ha comenzado y se está desarrollando, ha sido finalizada o se encuentra en fase de lanzamiento.

- El éxito de la acción evidencia el cumplimiento de la acción descrita.

- Los campos de soporte documental informan de la documentación necesaria para llevarla a cabo.

- El indicador de la acción informa del tipo de documentación que sirva como evidencia de haber finalizado la misma.

- Lidera la acción indica la unidad organizativa responsable de llevar a cabo la acción descrita.

- Los campos de colaboradores informan de las unidades organizativas que darán soporte a la unidad que lidera la acción.

Sin embargo, la observación es un campo de texto libre para recoger cualquier tipo de comentario.

4.3.6.4 Alertas automáticas al gestor corporativo de grupos de interés

Al igual que los técnicos pueden estar suscritos a las alertas automáticas tras la ejecución de cualquier modelo del marco de trabajo para IEAT, el gestor corporativo debe estarlo a los resultados de la ejecución de los modelos que tengan relación con los grupos de interés gracias a 
la integración en el SIG del marco de trabajo basado en geodiseño propuesto y la gestión de los grupos de interés.

A fecha de redacción de este documento la gestión de grupos de interés se encuentra en fase de implementación.

\subsection{Resultados}

En la disciplina de los SIG la estructuración y la catalogación, o la creación de metadatos, de la información (Manso-Callejo, 2009) son garantía de éxito. La metodología propuesta y su implementación realizan este tipo de tareas de forma automática. Por un lado, la información cargada y generada por el propio marco de trabajo responde a una estructura definida y, por otro lado, los metadatos relativos al proyecto se asignan de forma transparente al usuario.

La implementación de la metodología propuesta en el capítulo 3 muestra tres grandes bloques. El primero de ellos es el SIG corporativo GeoRED. El segundo es el marco de trabajo basado en geodiseño, que aprovecha todas capacidades de GeoRED en cuanto a herramientas de visualización, análisis espacial, gestión de contenidos y usuarios, y su capacidad de generar entornos de colaboración. El tercero la gestión geográfica de los grupos de interés aprovechando las capacidades de los dos primeros.

En su implementación se ha seguido el mismo orden por necesitar los dos últimos su soporte. Por tanto, se puede afirmar que GeoRED es un producto por sí mismo, que el marco de trabajo basado en geodiseño necesita el soporte y las herramientas de un SIG, así como que la gestión geográfica de grupos de interés necesita los resultados que se generan en cada fase que avanza el proyecto. Desde este punto de vista, aunque se presenta de forma conjunta, el segundo y tercer bloque pueden implementarse de forma independiente, es decir, el marco de trabajo necesita un SIG que dé soporte a sus necesidades y podría ser diferente a GeoRED, y la gestión geográfica de grupos de interés también necesita un SIG como soporte tecnológico y un gestor de proyectos que le nutra de información para establecer la colaboración de los grupos de interés. Esta información también podría obtenerse de un modo diferente al marco de trabajo basado en geodiseño implementado. Aunque podrían ser independientes en esta tesis se han diseñado e implementado de forma progresiva por lo que se puede afirmar que se trata de una solución que escala.

\subsubsection{GeoRED}

En una compañía cuya razón de ser está enfocada al sector eléctrico, la implementación del SIG corporativo GeoRED ha facilitado el cambio en la forma de gestionar los activos. Este cambio en la gestión viene marcado por la "también" gestión geográfica de activos.

Sus principales ventajas son las siguientes:

- Reduce los tiempos y costes de las comunicaciones.

- Registra las comunicaciones y conocimiento valioso para la organización.

- Permite a sus usuarios crear espacios de trabajo en grupo, dentro y fuera de la organización.

- Maximiza la captura y reutilización del conocimiento. 
- Fomenta la comunicación y optimiza las relaciones.

- Mejora la productividad con clientes, empleados, proveedores y asociados.

\subsubsection{Marco de trabajo basado en geodiseño}

El marco de trabajo basado en geodiseño nace con la vocación de organizar y sistematizar la información geográfica de los proyectos de instalaciones eléctricas de alta tensión, y de alinear los criterios de la gestión de esta con las directrices corporativas.

Las dimensiones de este tipo de infraestructuras, que pueden ser de cientos de kilómetros, exigen la captura, la explotación y la generación de grandes volúmenes de información geográfica cuya gestión, por un numeroso colectivo multidisciplinar y sin conocimientos técnicos avanzados en topografía, cartografía o SIG, puede provocar discrepancias entre las diferentes fases del proyecto que desemboquen en retrabajos, ampliación de plazos y el peligro del no cumplimiento con las necesidades del sector eléctrico.

La red de transporte española de electricidad está en continua expansión y es dinámica. Esta expansión se lleva a cabo a través de proyectos de ingeniería que requieren planificación y toma de decisiones e involucran a muchos agentes e intereses diferentes.

Sin embargo, ni las administraciones ni las agencias responsables de la ejecución (de la planificación de las infraestructuras de las líneas eléctricas) tienen herramientas adecuadas para hacer frente a las necesidades, restricciones, limitaciones y deseos de cada una de las partes interesadas.

Los técnicos de REE son un grupo de interés fundamental en todas las fases de estos proyectos. Tradicionalmente, estos proyectos se han diseñado internamente en REE (por su encomienda para mantener, desarrollar y expandir la infraestructura nacional). Además, la comunicación o divulgación de los proyectos nunca se ha llevado a cabo conjuntamente por todos los interesados. En consecuencia, el diálogo llevaba a menudo mucho tiempo, y no era posible acceder a los planes y la documentación del proyecto por medios electrónicos.

La información geográfica desempeña un papel fundamental en el desarrollo de estos proyectos, pero debe usarse de acuerdo con una metodología consolidada: cada capa de información temática debe tener un peso adecuado y tenerse en cuenta de manera coherente, siempre aplicándola de la misma manera y siguiendo los mismos criterios. La creación del marco de trabajo basado en geodiseño para este tipo de proyectos ha permitido estandarizar los criterios para analizar datos que apoyen la toma de decisiones, lo que limita la influencia de los criterios personales de los técnicos encargados y aumenta la aplicación de los criterios homogéneos establecidos para cada escenario. Esta homogeneización es posible mediante la creación de procedimientos y relaciones entre ellos, proporcionando así una metodología de sostenibilidad sólida para el desarrollo de este tipo de proyectos.

Al utilizar el marco de trabajo basado en geodiseño de REE, el ciclo de vida de la información geográfica de un proyecto está sujeto a criterios corporativos. Por lo tanto, se requieren datos específicos para los modelos de cada fase. Estos datos siempre deben tener la misma estructura (en cuanto al formato, precisión, atributos descriptivos, etc.) y los modelos siempre deben realizar 
los mismos procedimientos establecidos. Esto garantiza que siempre sea posible acceder a los datos cuando sea necesario durante el proceso, según lo estipulado corporativamente. Esto confirmará la calidad de los resultados, ya que el flujo de trabajo de la información geográfica se gestiona a través de procedimientos con criterios estandarizados.

Basado en principios de geodiseño, el marco de trabajo para los proyectos de REE proporciona, por un lado, procedimientos de homogeneización de criterios técnicos en todas las fases de los proyectos y, por otro lado, una herramienta de colaboración capaz de recopilar, en el mismo entorno, todos los condicionantes, necesidades, preocupaciones, restricciones del proyecto, toma de decisiones y la historia del diseño; por lo tanto, constituye un entorno que permite la terna "retroalimentación - iteración - consenso" necesaria en cualquier proyecto de geodiseño.

Este nuevo marco de trabajo de geodiseño propuesto representa un cambio de paradigma para este tipo de proyectos. Se está terminando de implementar en el sistema de información geográfica corporativo (GeoRED) lo que le permite representar, establecer escenarios de colaboración y aplicar modelos de geoprocesamiento.

Existe un interés creciente por la geolocalización en diferentes disciplinas. Cada una de estas disciplinas está asociada a sus tecnologías, y todas ellas comparten la componente espacial. La forma en que GeoRED gestiona los contenidos (información geográfica) está relacionada con la gestión de usuarios. El fundamento de esta relación es la distribución de la responsabilidad de la información geográfica a los respectivos responsables, para integrarla en un mismo sistema. De esta forma, la asociación de perfiles de usuarios a los contenidos hace que se generen espacios virtuales de trabajo para cada temática o proyecto en los que un grupo reducido de personas trabaja de forma colaborativa para alcanzar soluciones de consenso. Estas personas pueden no pertenecer a la misma organización; es decir, GeoRED permite colaborar con usuarios ajenos a la organización. Esta colaboración se lleva a cabo por los equipos multidisciplinares de REE, distribuidos sobre el territorio estando en contacto con las partes interesadas: administración central, administración local que representa las preocupaciones de la población local, asociaciones ambientales y animalistas, o cualquier institución que represente sus intereses.

GeoRED permite que los diferentes servicios de mapas utilizados por varios grupos de interés coexistan simultáneamente, y esto prepara el escenario para la colaboración, la discusión, la negociación y, en última instancia, el consenso. Siendo estos los escenarios en los que el geodiseño se hace patente.

Además del objetivo de gestionar todos los servicios de mapas necesarios para un proyecto en un solo entorno, GeoRED tiene un objetivo más específico en relación con su funcionalidad como un SIG corporativo. Este objetivo es definir y gestionar procedimientos geográficos corporativos. De esta manera se pretende garantizar que todos los proyectos se desarrollen utilizando los mismos criterios. Estos criterios deben decidirse a nivel corporativo para minimizar la influencia de los criterios personales de los técnicos encargados, en favor de los criterios corporativos, haciendo que los resultados de los proyectos globalmente sean más homogéneos y sostenibles. El marco de trabajo basado en geodiseño se inició como una propuesta teórica que requería una plataforma SIG para convertirse en realidad. GeoRED, por su capacidad de representación, de establecer 
escenarios de colaboración, de aplicar modelos de geoprocesamiento y de gestionar la trazabilidad de la información geográfica de cada proyecto, ha sido idóneo para su implementación.

Como ejemplo de resultado, se muestra en la Figura 4-89 la consola, en fase de análisis ambiental de alternativas, con todos los controles disponibles de los cuadros de mando. La Figura 4-89 (a) muestra la consola antes de comenzar y la Figura 4-89 (b) muestra la consola con todos los procesos ejecutados, para proyectos de línea y proyectos de subestación, donde ya se aprecian todos los controles disponibles en los cuadros de mando.

(a)

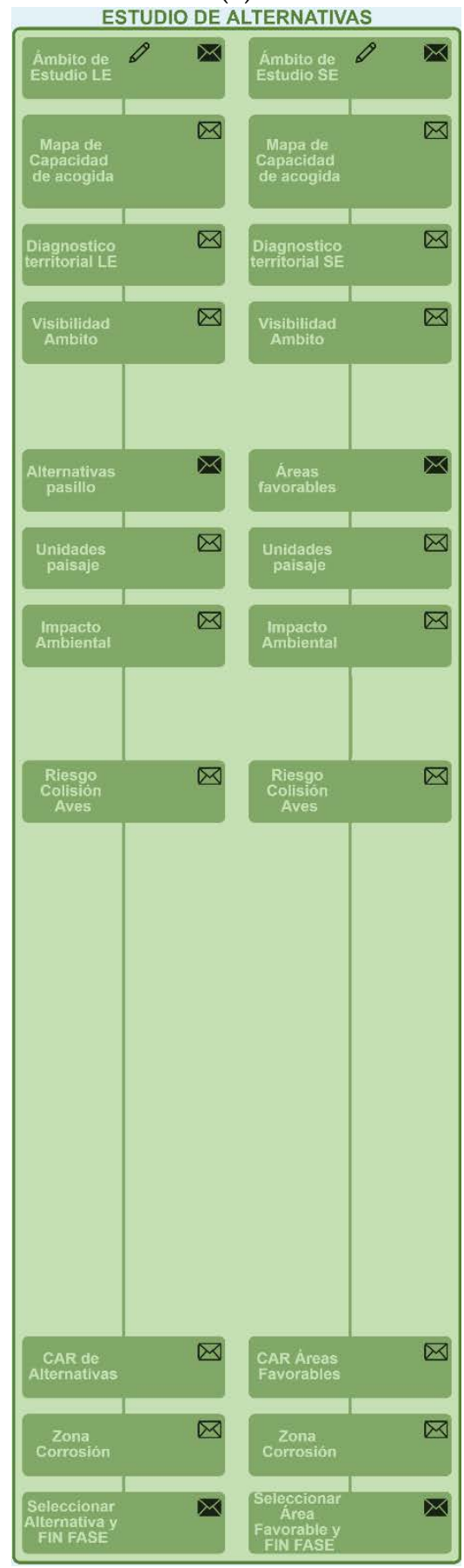

(b)

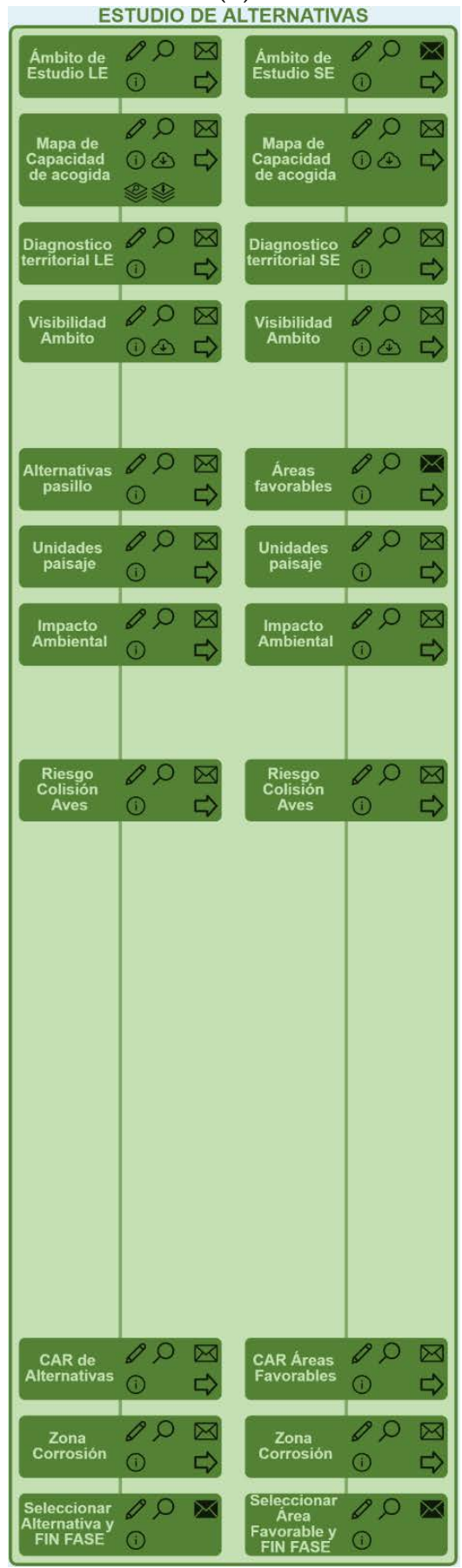

Figura 4-89. Apariencia de la consola antes y después de la ejecución de procesos de fase ambiental 
A continuación, se muestra la Tabla 4-21 que sintetiza el número de geoprocesos implementados en cada fase, de diferentes tipos y dificultad.

\begin{tabular}{|l|c|c|c|c|c|c|}
\hline Tipo & Planificación & $\begin{array}{c}\text { Análisis ambiental } \\
\text { de alternativas }\end{array}$ & Ingeniería & $\begin{array}{c}\text { Obtención de } \\
\text { permisos }\end{array}$ & Construcción & Trazabilidad \\
\hline Generación & 2 & 22 & 25 & 4 & 2 & \\
\hline Consulta & 2 & 22 & 27 & 8 & 8 & 5 \\
\hline Descarga & & 4 & 6 & 4 & & \\
\hline TOTAL & 4 & 48 & 58 & 16 & 10 & 5 \\
\hline
\end{tabular}

Tabla 4-21. Número y tipo de geoprocesos generados

La metodología se ha ido validando a través de la implementación del flujo que ordena la ejecución de los geoprocesos y sus interdependencias. La implementación se ha ajustado con los proyectos en curso de la planificación eléctrica 2015-2020, quedando la herramienta preparada para la planificación 2021-2026 ya presentada y a la espera de la inminente aprobación por el Consejo de Ministros. Fruto de los ajustes con proyectos reales se ha detectado alguna necesidad que ya se ha diseñado y se encuentra en fase de implementación.

Se ha verificado la sincronización entre el marco de trabajo implementado y los servicios de mapa con los que interactúa cada geoproceso. También se ha validado con los equipos técnicos los puntos de colaboración con los equipos de otras fases.

\subsubsection{Gestión de grupos de interés}

Los modelos y el marco de trabajo basado en el geodiseño garantizan que los proyectos se desarrollen utilizando los mismos criterios corporativos, minimizando el uso de criterios personales de los técnicos en cada fase y obteniendo resultados más homogéneos y sostenibles. Es una realidad en el SIG corporativo (GeoRED), que permite representar y establecer escenarios de colaboración y aplicar modelos de geoprocesamiento de forma iterativa. Estos modelos responden a procesos que, desde un punto de vista técnico, dan como resultado la ejecución de geoprocesos cuyos resultados describen la instalación futura desde diferentes puntos de vista.

La gestión geográfica de los grupos de interés permite tratar la información geoespacial que los representa como otra de las variables a tener en cuenta en el desarrollo de los proyectos de la red de transporte. Permite la integración de los grupos de interés con factores estratégicos, técnicos, económicos, sociales y ambientales en la gestión, buscando el desarrollo sostenible. De este modo se puede controlar el riesgo y la reputación de la compañía ya que se difunde la actividad y el valor aportado al mejorar la información y favorecer su acceso para los grupos de interés, se favorece la identificación de los interlocutores, percepciones y actitudes de los grupos de interés ante un nuevo proyecto de desarrollo de la red de transporte de electricidad.

La incorporación de su gestión en paralelo con la ejecución de los geoprocesos permite que la información generada por los grupos se comparta con las diferentes partes interesadas en el momento en que se genera. De esta manera, la gestión de los interesados también se sistematiza y homogeneiza. Se identificarán, clasificarán y asociarán con un plan de acción, y se considerarán 
una parte integral de los procesos iterativos, buscando el consenso de acuerdo con los criterios corporativos.

El segundo objetivo de investigación ha sido definir un marco conceptual para la gestión de los grupos de interés asociada al desarrollo de proyectos y un catálogo de acciones suficiente. Se ha desarrollado la propuesta metodológica para la integración de la gestión de los grupos de interés con el marco de trabajo basado en el geodiseño para proyectos de la red de transporte de electricidad.

Además de integrar su gestión en GeoRED, este favorece la colaboración de los usuarios externos a la organización con los técnicos responsables de los proyectos a través de sus gestores corporativos. La incorporación de la gestión de los grupos de interés en el flujo de trabajo basado en el diseño geográfico de los proyectos permite a los interlocutores de los grupos de interés encontrar su propio espacio de trabajo en el que, paralelamente a la ejecución de los geoprocesos, pueden expresar sus opiniones sobre cada uno de los resultados, formando parte del proceso iterativo en que todas las partes interesadas colaborarán para facilitar el consenso.

Gracias a este ejercicio de transparencia y colaboración, la empresa aplica un plan de acción diseñado y supervisado por el gestor corporativo para cada uno de los grupos de interés identificados y clasificados al comienzo de cada fase del proyecto. Este plan se ejecuta en forma de acciones que son inducidas en base a su posición en la matriz de poder-interés, el impacto que puede tener en el proyecto y la estabilidad de su posición. Esto requiere monitoreo, más o menos intenso, para asegurar que el tipo de acciones asignadas sean las más apropiadas.

La figura del gestor corporativo de grupos de interés se destaca como un facilitador relevante en el marco de trabajo basado en el geodiseño para proyectos, ya que materializa y centraliza el diálogo que acompaña internamente el desarrollo técnico de los proyectos y transmite externamente las sensaciones de los grupos de interés a medida que avanza su desarrollo.

Todo ello garantiza que la gestión del proyecto sea única tanto para la parte técnica como para los grupos de interés, ya que la ejecución de los modelos alimenta tanto a los procesos técnicos como a los argumentos que ayudan a explicar el proyecto al mundo exterior.

Como prueba de concepto del marco de gestión de grupos de interés se presentan algunos resultados de aplicar esta propuesta en un grupo representativo de proyectos desarrollados dentro de la empresa. Se ha demostrado cómo se ha llevado a cabo la integración de su gestión basada en GeoRED y algunas herramientas auxiliares que facilitan la exploración y visualización de las dimensiones de las matrices de decisión y la simbología propuesta y adoptada, a nivel corporativo.

La metodología se ha aplicado a 13 proyectos distribuidos en 223 ámbitos geográficos de influencia en todo el país y de diferentes tipos: aéreos, subterráneos, submarinos y mixtos. La prueba con estos proyectos ha permitido mejorar la metodología y validarla, iniciando el cambio hacia una forma más sostenible de emprender los proyectos de desarrollo de la red de transporte de energía eléctrica. Todo esto muestra un fuerte compromiso institucional con la sostenibilidad 
(social, técnico-económica y ambiental), dirigido a apoyar el desarrollo de la sociedad y la conservación de su capital natural.

Los 13 proyectos seleccionados son representativos tanto de la diversidad de instalaciones como de relaciones con el territorio. La Figura 4-90 muestra los ámbitos geográficos de influencia de los 13 proyectos.

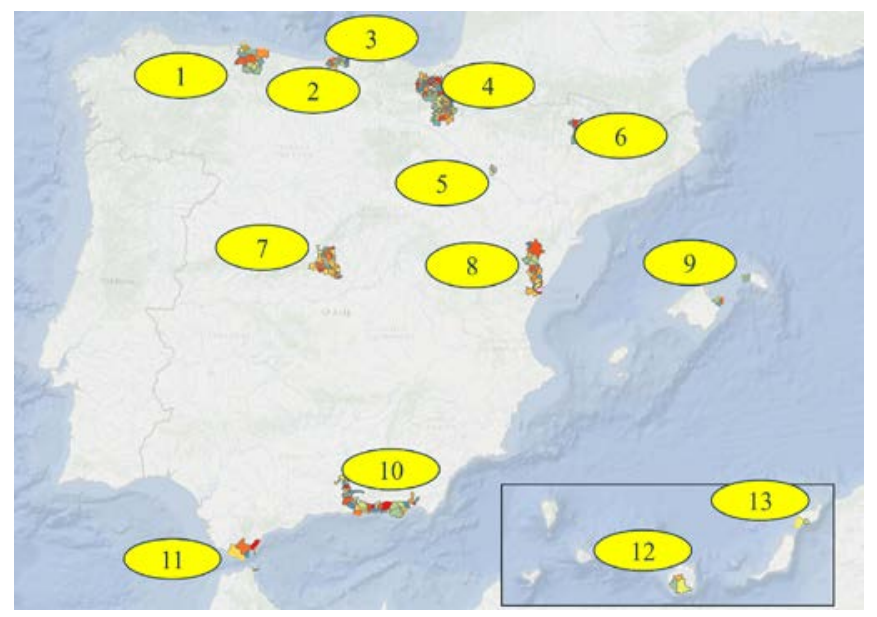

Figura 4-90. Misma figura que 3-16 (a). Ámbitos geográficos de influencia de los 13 proyectos

En la Tabla 4-22 se presenta un resumen de su gestión con la nueva metodología.

La leyenda para la fase del proyecto es $\mathrm{MA}=$ Análisis ambiental de alternativas; $\mathrm{CO}=$ Construcción. La leyenda para el tipo de proyecto es LA = Línea aérea; LST = línea subterránea; $\mathrm{SE}=$ Subestación; CSM = línea submarina. La última fila expresa la suma de los temas escritos en el encabezado, excepto la columna de \# de diferentes Categorías que expresa el número de diferentes categorías registradas en los 13 proyectos.

\begin{tabular}{|c|c|c|c|c|c|c|c|c|c|c|c|}
\hline 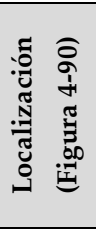 & $\begin{array}{l}\sum_{0}^{5} \\
\frac{0}{\pi} \\
\frac{0}{0} \\
0\end{array}$ & 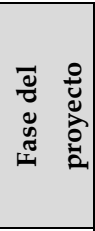 & 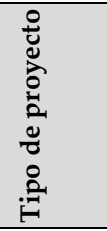 & 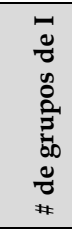 & 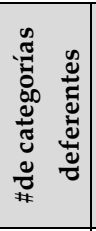 & 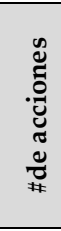 & 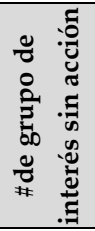 & 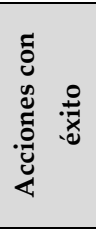 & 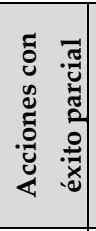 & 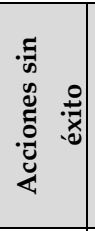 & 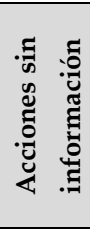 \\
\hline 1 & 220 & MA & LA & 39 & 11 & 39 & & 29 & 2 & 4 & 4 \\
\hline 2 & 220 & $\mathrm{CO}$ & LA & 67 & 13 & 11 & 56 & 9 & & & 2 \\
\hline 3 & 220 & $\mathrm{CO}$ & LA & 72 & 13 & 6 & 66 & 4 & & 1 & 1 \\
\hline 4 & 400 & MA & LA & 432 & 11 & 407 & 25 & 296 & 75 & 16 & 20 \\
\hline 5 & 220 & MA & LST & 36 & 13 & 36 & & 22 & 4 & 4 & 6 \\
\hline 6 & $220-400$ & MA & SE & 39 & 8 & 39 & & 26 & 5 & 2 & 6 \\
\hline 7 & 400 & MA & LA & 34 & 10 & 6 & 28 & 3 & 1 & & 2 \\
\hline 8 & 400 & SA & LA & 58 & 9 & 25 & 33 & 17 & 3 & 2 & 3 \\
\hline 9 & 132 & $\mathrm{CO}$ & $\mathrm{CSM}$ & 94 & 9 & 85 & 9 & 55 & 13 & 7 & 10 \\
\hline 10 & 220 & MA & LA & 21 & 8 & 21 & & 16 & 2 & 1 & 2 \\
\hline 11 & 132 & MA & LST & 55 & 9 & 55 & & 29 & 21 & 3 & 2 \\
\hline 12 & 220 & MA & $\mathrm{SE}+\mathrm{LA}$ & 60 & 10 & 46 & 14 & 31 & 1 & 5 & 9 \\
\hline \multirow[t]{2}{*}{13} & 220 & SA & CSM & 34 & 9 & 19 & 15 & & & & 19 \\
\hline & & & Sum & 1041 & 15 & 795 & 246 & 537 & 127 & 45 & 86 \\
\hline
\end{tabular}


Los proyectos no han sido analizados en todas las fases. La muestra utilizada para la validación lo ha sido en la fase de estudio medioambiental de alternativas y en la de construcción. Esto ha dependido de la fase en la que se encontraba el proyecto en el momento del análisis. En los proyectos cuyo estado es construcción, se incorporan los grupos de interés de las fases anteriores que tienen relevancia para esa fase. En la tabla se cuantifica el número de grupos de interés identificados, registrados y catalogados en sus correspondientes categorías. También el número de acciones realizadas y su valoración de éxito.

En algunos proyectos no se dispone de las acciones asignadas a los grupos de interés debido a su estado de avance. Los responsables de liderar las acciones a realizar con los grupos de interés son quienes realizan las valoraciones del éxito. Éstos son los responsables de las unidades organizativas de la compañía que están totalmente coordinados con el gestor corporativo de grupos de interés. De forma agregada estos 13 proyectos arrojan una tasa de éxito del 68\%, un $16 \%$ de éxito parcial (bien porque el resultado no ha sido totalmente satisfactorio, o porque la acción no ha finalizado y continúa abierta), un 5,7\% de acciones no exitosas y $11 \%$ de acciones sin valorar.

La distribución de los 1041 grupos de interés identificados y registrados, en la matriz que muestra las variables poder, interés, impacto, se muestra en la Figura 4-91.

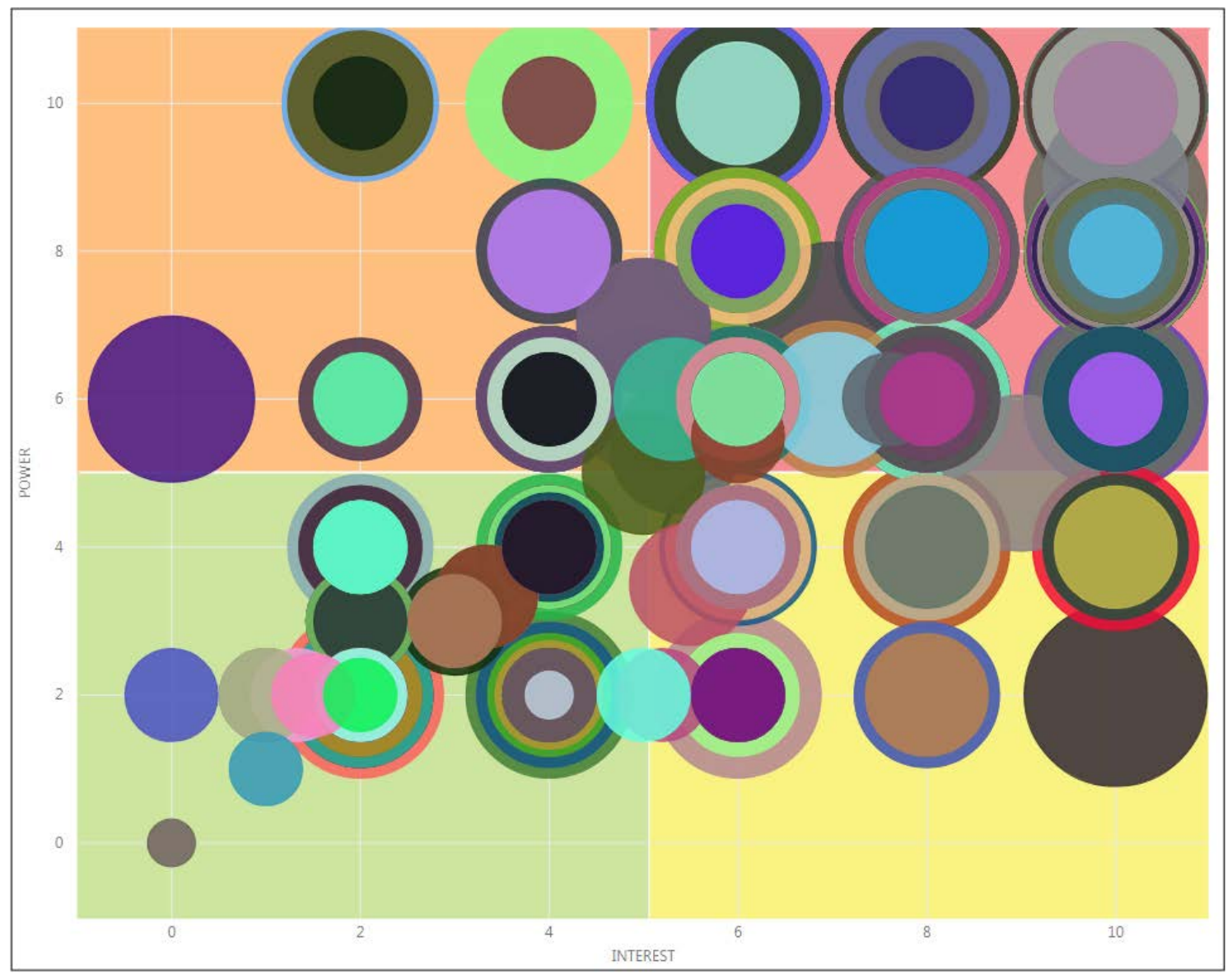

Figura 4-91. Representación de la matriz poder-interés-impacto del conjunto de grupos de interés analizados en los 13 proyectos

En ella no se muestra la variable estabilidad de la postura o dinamismo por la alta aglomeración de grupos de interés que dificultaría su interpretación, por lo que se muestra cada uno de ellos 
en un color diferente. Se observa que existe una mayor aglomeración en el cuadrante superior derecho, donde los impactos además también son grandes.

Si analizamos solo un proyecto, el número 8 (ver Tabla 4-21 y Figura 4-90, para consultar sus características y ubicación respectivamente), se observa en la Figura 4-92 (a) una distribución similar de los grupos de interés en la matriz poder-interés a la del conjunto de proyectos. En ella también se concentran los grupos de interés de impactos grandes en el cuadrante superior derecho.

En cuanto a las categorías de estos grupos de interés, los de mayor impacto están ubicados en los cuadrantes derechos de la matriz preocupando especialmente las asociaciones políticas, los ayuntamientos y los medios de comunicación como grandes generadores de opinión que pueden influir en los grupos de interés de su propia categoría y de otras categorías. La Figura 4-92 (a) muestra la representación de la posición de la matriz de poder de interés, y el impacto y la estabilidad de los interesados. El nombre de los interesados no es relevante para mostrar su distribución en la matriz. La Figura 4-92 (b) muestra el valor promedio de las variables de poder e interés. La variable de impacto se muestra utilizando el tamaño de las categorías de partes interesadas del proyecto; La leyenda de las categorías es la siguiente: $\square$ Ayuntamientos;

Propietarios de tierras, propietarios de bosques y agricultores; Conservacionistas de la naturaleza; Creadores de opinión; $\square$ Autoridades de planificación, permisos e implementación;

Asociaciones políticas; $\square$ Asociaciones profesionales y empresariales; $\square$ Entidades científicas y educativas; $\square$ Agentes sociales

(a)

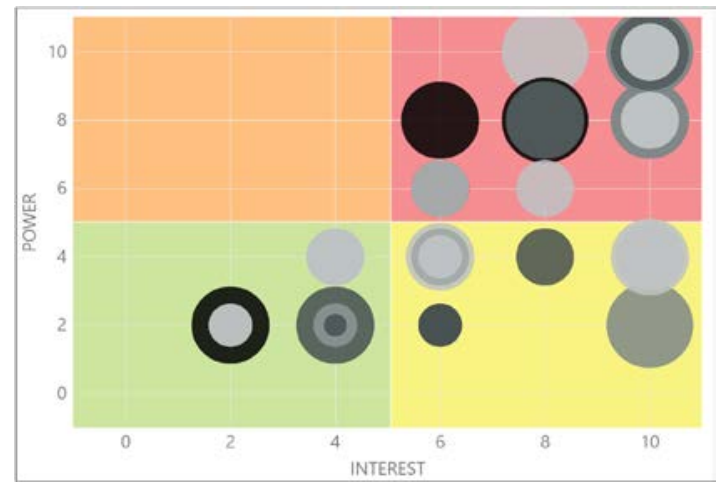

(b)

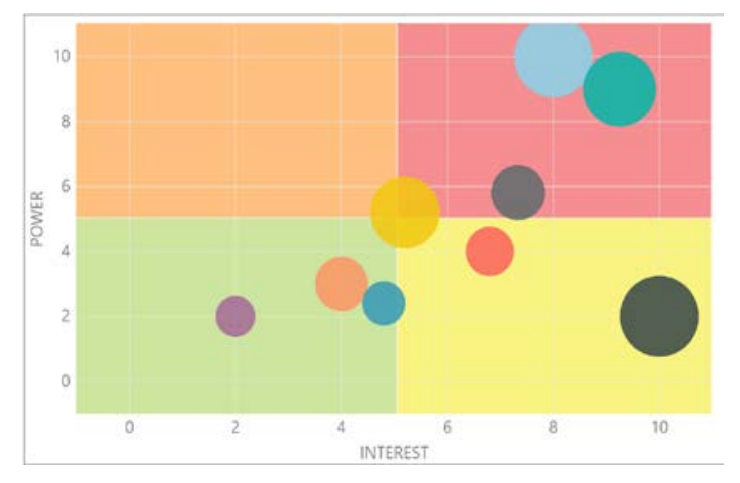

Figura 4-92. Representación de matrices del proyecto nํㅛ 8

Analizando las acciones realizadas, se observa que tiene un comportamiento alineado con la media de los 13 proyectos, teniendo un 68\% de éxito, un 12\% de éxito parcial (bien porque el resultado no ha sido totalmente satisfactorio, o porque la acción no ha finalizado y continúa abierta), un $8 \%$ de acciones no exitosas y $12 \%$ de acciones aún sin valorar.

Analizando los grupos de interés con los que la acción realizada no ha tenido éxito, o ha sido parcial, se observa que en ambos casos han sido del tipo Ayuntamiento y las Autoridades de planificación, permisos e implementación. 
Una de las acciones realizada con el grupo de interés "Ayuntamiento" del municipio con código 2037 (ver Figura 4-93), que ha sido una "Reunión informativa y/o para recoger aportaciones al proyecto" (ver Tabla 3-5) sorprende por su valoración negativa ya que el impacto territorial es pequeño, al pasar la futura línea eléctrica próxima al límite municipal. Este grupo de interés solicita que, considerando que futura subestación (fin de la línea eléctrica) estará en el municipio contiguo (ver Figura 4-93, código 2068), el trazado sea desplazado a este último territorio.

No ocurre lo mismo con el grupo de interés que representa al municipio que limita al sur (Figura 4-93, código 2030) que ha entendido que la orografía e impacto ambiental son más complicados en Morella y acepta el trazado propuesto.

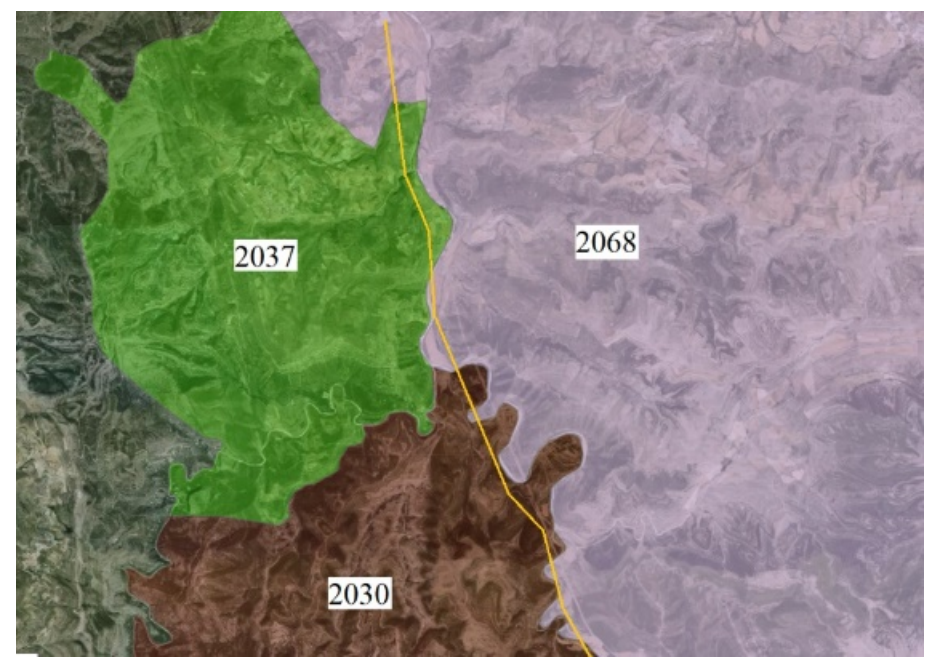

Figura 4-93. Trazado propuesto del proyecto nำ a su paso por el municipio 2037 


\section{CONCLUSIONES}

En este último capítulo de la tesis se exponen las contribuciones científicas aportadas. A continuación, se revisan las cuestiones de investigación, que se plantearon en el primer capítulo, y se muestra cómo se ha dado respuesta a las mismas. El capítulo se cierra planteando nuevas cuestiones que quedan pendientes como futuros trabajos de investigación.

Las contribuciones científicas que aporta esta tesis doctoral son las siguientes:

- El diseño de un nuevo marco de trabajo basado en geodiseño para proyectos de instalaciones eléctricas de alta tensión: Se ha diseñado un nuevo marco de trabajo basado en geodiseño, para gestionar la información geográfica de los proyectos de instalaciones eléctricas de alta tensión, que establece criterios homogéneos y corporativos en todas sus fases mediante la implementación de modelos de geo-procesamiento, fomentando la colaboración de los equipos multidisciplinares y registrando la trazabilidad de la información geográfica en su avance.

- El diseño de una nueva metodología para sistematizar la gestión de grupos de interés en proyectos de instalaciones eléctricas de alta tensión: Se ha diseñado una nueva metodología para sistematizar la gestión de grupos de interés en el desarrollo de proyectos de instalaciones eléctricas de alta tensión, fusionando esta con el marco de trabajo de la contribución anterior, utilizando como elemento de vínculo la componente geográfica del ámbito de influencia.

- El diseño de una nueva metodología para analizar la visibilidad de las instalaciones eléctricas de alta tensión: Se ha diseñado una nueva metodología para analizar la visibilidad de este tipo de instalaciones añadiendo, edificaciones y vegetación como elementos de apantallamiento visual, y analizando lo crítico que puede ser la visibilidad en cada punto de estudio en función del número de instalaciones que se ven, qué parte de ellas y a qué distancia cada una de ellas. Siendo uno de los resultados un entorno 3D que ayuda a proyectar virtualmente el entorno con la instalación construida.

- El diseño de una nueva metodología para la generación automática de las relaciones de bienes y derechos afectados por una instalación: Se ha diseñado una nueva metodología que automatiza la interrelación entre los distintos aspectos que componen una relación de bienes y derechos afectados. Comparado con la anterior metodología, se ha conseguido aumentar el número de afectaciones a considerar, su fiabilidad y reducir drásticamente los plazos para su creación.

- El diseño de una nueva metodología para la revisión digitalizada de las relaciones de bienes y derechos afectados por una instalación: Se ha diseñado una nueva metodología para digitalizar la revisión de las relaciones de bienes y derechos al implementar validaciones automáticas y sincronizar la vista alfanumérica con la geográfica. Se ha integrado, en el mismo entorno digital, toda la información necesaria para esta tarea eliminando el uso de papel y las prácticas no digitales. 


\subsection{Revisión de las cuestiones de investigación}

Con el objetivo de facilitar la revisión de las cuestiones de investigación planteadas en el primer capítulo, se presentan nuevamente para, a continuación, responderlas en el mismo orden.

1. ¿Es posible armonizar el tratamiento de la información geográfica de los proyectos de líneas eléctricas de alta tensión e integrar su ciclo de vida en el flujo de trabajo basado en geodiseño?

2. ¿Es posible implementar una metodología como flujo de trabajo basada en geodiseño para proyectos de líneas eléctricas de alta tensión e integrarla en GeoRED (SIG corporativo de REE) como una herramienta de sistema de soporte a la planificación?

3. ¿El uso del flujo de trabajo basado en el geodiseño para el desarrollo de proyectos de líneas eléctricas de alta tensión, como el implementado por REE, ayudará a administrar de forma geográfica y conjuntamente, tanto los activos proyectados como los que ya se encuentren en servicio, junto con los grupos de interés identificados en cada caso?

\subsubsection{Armonización del tratamiento de la IG de proyectos de líneas eléctricas de alta tensión}

La cuestión de investigación planteada en primer lugar es la siguiente: ¿Es posible armonizar el tratamiento de la información geográfica de los proyectos de líneas eléctricas de alta tensión e integrar su ciclo de vida en el flujo de trabajo basado en geodiseño?

Los equipos técnicos encargados del desarrollo de proyectos de líneas eléctricas de alta tensión son heterogéneos en cada una de las fases de los proyectos. La heterogeneidad viene marcada por el rango de edad o brecha generacional, que supone distinta formación y experiencia, que implica la aplicación de técnicas diferentes, de las más analógicas a las digitales actuales, lo que afloraba una acusada diferencia en la forma de enfocar y desarrollar cada fase de los proyectos.

Esta pregunta puede responderse afirmativamente gracias al establecimiento de modelos de geoprocesamiento que aseguran el uso de criterios corporativos y a su implementación en una metodología de trabajo que establece un flujo común para todos los proyectos. De este modo se consigue armonizar la gestión de su información geográfica en lo relativo a un almacenamiento centralizado, su modelo de datos, los sistemas de coordenadas, los formatos, la resolución o precisión para cada proceso. También en lo relativo a los análisis e informes derivados, limitando el uso de los criterios personales a lo imprescindible.

Con la automatización de los modelos de geoprocesamiento se nivela la capacidad de todos los usuarios para realizar los análisis que cada fase del proyecto requiere contribuyendo a minimizar los aspectos de heterogeneidad derivada de los equipos de trabajo, para convertirla en una fortaleza. 


\subsubsection{Integración del marco de trabajo basado en geodiseño en el SIG corporativo - GeoRED}

La segunda cuestión de investigación es: ¿Es posible implementar una metodología como flujo de trabajo basada en geodiseño para proyectos de líneas eléctricas de alta tensión e integrarla en GeoRED (SIG corporativo de REE) como una herramienta de sistema de soporte a la planificación?

En el capítulo de metodología se ha descrito cómo se ha diseñado un marco de trabajo basado en geodiseño para los proyectos de instalaciones de alta tensión. Esta metodología inspirada en los modelos de la metodología de Steinitz (Steinitz, 2012) de geodiseño ha sido estudiada, adaptada y mejorada para responder a todas las fases de los proyectos de este tipo de infraestructuras: líneas y subestaciones. Esta metodología incorpora también los flujos de trabajo y las iteraciones de la información entre las distintas fases de los proyectos y los distintos actores involucrados, definiendo la secuencia de ejecución de los geoprocesos que lo componen. Este marco de trabajo además ha permitido eliminar la heterogeneidad de los procesos, fuentes de datos y tomas de decisiones existentes entre los actores que intervenían en los proyectos. Por tanto, la primera parte de la cuestión se responde afirmativamente. En cuanto a la segunda parte, el marco de trabajo basado en geodiseño propuesto, precisa de un Sistema de Información capaz de reproducir sus directrices, además este sistema de información debe gestionar toda la información geográfica. El SIG corporativo de la compañía, GeoRED, ha dado soporte a su implementación e integración, añadiendo las funcionalidades que posibilitan la necesaria colaboración para recibir retroalimentación, poder iterar y finalmente llegar al consenso. GeoRED, diseñado e implementado para permitir esta colaboración, representa el motor geográfico capaz de ejecutar los modelos de geoprocesamiento que el marco de trabajo actual establece o los que se establezcan en el futuro para cada hito de avance de las secuenciales fases de los proyectos.

Por tanto, la respuesta a esta cuestión de investigación es afirmativa y no únicamente como sistemas de soporte a la planificación, sino también como sistema de soporte para la toma de decisiones que permitirá tomar decisiones informadas y motivadas en base a la realidad del territorio, contribuyendo a que los nuevos proyectos serán más sólidos, organizados, trazables, eficientes y presumiblemente se desarrollarán más ágilmente.

A fecha de redacción de este documento está pendiente de aprobación, por parte del Consejo de Ministros, la planificación eléctrica para el horizonte 2021-2026 que incluye una apuesta muy ambiciosa para la integración de fuentes de generación renovable. La implementación realizada ha sido clave para los estudios de viabilidad y dar significado geográfico a dicha planificación. En cuanto al resto de fases, los proyectos ya en curso y cada uno en su fase de desarrollo, han servido para ajustar los parámetros de los modelos de geoprocesamiento, los momentos críticos de colaboración y las interdependencias entre modelos. La herramienta, en su conjunto, está preparada para el nuevo horizonte 2021-2026 de la nueva planificación eléctrica. 


\subsubsection{Gestión conjunta de condicionantes técnicos y de los grupos de interés de un}

proyecto en el marco de trabajo basado en geodiseño

La tercera y última cuestión de investigación dice "¿El uso del flujo de trabajo basado en el geodiseño para el desarrollo de proyectos de líneas eléctricas de alta tensión, como el implementado por REE, ayudará a administrar de forma geográfica y conjuntamente, tanto los activos proyectados como los en servicio, con los grupos de interés identificados en cada caso?"

Los proyectos de instalaciones eléctricas de alta tensión tienen un marcado carácter territorial ya que se trata de instalaciones que modifican los entornos en los que se construyen. Estos entornos son sensibles al paisaje, su patrimonio histórico, la actividad económica y el ritmo social, su política y su riqueza natural. Esta sensibilidad está representada por los diferentes grupos de interés, es decir, representan la sensibilidad del entorno en el que se construyen las instalaciones eléctricas.

Tanto en la fase metodológica como en la de implementación se ha definido un marco de trabajo para la gestión de los grupos, basada en el ámbito geográfico de influencia. Se ha caracterizado y analizado su capacidad para influir y se ha propuesto un rol importante a nivel corporativo como es el gestor de grupos de interés. En la implementación, se ha integrado su gestión, la planificación de las acciones y la trazabilidad de la información en el SIG corporativo. Todo ello con el último fin de incorporar su gestión en el flujo de trabajo de los proyectos basado en geodiseño, buscando los escenarios de colaboración e integrándoles en el diseño de los proyectos. Por tanto, también se puede responder afirmativamente a esta cuestión de investigación. Se han analizado y usado para validar esta propuesta metodológica los resultados de la experiencia piloto en 13 proyectos en los que se ha gestionado un total de 223 ámbitos geográficos de influencia, 1041 grupos de interés de 15 categorías diferentes y 795 acciones llevadas a cabo con ellos. Experiencia que ha permitido testar y ajustar la metodología.

A fecha de redacción de este documento se encuentra en fase de implementación.

\subsection{Confirmación de las hipótesis planteadas con anterioridad a la investigación}

Las cuestiones de investigación son consecuencia de las hipótesis establecidas con anterioridad al desarrollo de la investigación. A modo de recordatorio se presentan nuevamente y se relata cómo la respuesta a las cuestiones de investigación las confirma:

- H1: Los condicionantes y restricciones de los diferentes grupos de interés involucrados en los proyectos de nuevas instalaciones eléctricas de alta tensión pueden representarse, por medio de su abstracción con un modelo de datos geoespacial, en un Sistema de Información Geográfica.

- H2: Es posible gestionar, mediante una metodología de trabajo basada en geodiseño, la información geoespacial asociada al ciclo de vida de los proyectos de instalaciones eléctricas de alta tensión, homogeneizando los procedimientos corporativos para todas las fases de los proyectos. La hipótesis que se plantea es que la representación y gestión, en el mismo entorno, de los diferentes requerimientos de los actores involucrados, crea 
espontáneamente un marco colaborativo que facilitará el consenso en la toma de las decisiones.

- H3: Las interacciones entre condicionantes, restricciones y preferencias (técnicas, socioeconómicas, medioambientales o políticas) de los grupos de interés involucrados, en los proyectos de instalaciones eléctricas de alta tensión, pueden ser gestionadas por un Sistema de Información Geográfica colaborativo, basado en geodiseño, como herramienta de ayuda a la toma de decisiones consensuadas.

En el trabajo desarrollado y sintetizado en las respuestas a las cuestiones de investigación, se hace un recorrido por diferentes aspectos que, de forma conjunta, confirman las tres hipótesis planteadas.

Se describe un sistema de información capaz de crear escenarios de colaboración, representar los diferentes puntos de vista de los actores involucrados en cada proyecto e integrar en él un marco de trabajo compuesto por geoprocesos que establecen criterios corporativos y ordenados en un flujo que les da secuencia y establece interdependencias.

El marco de trabajo basado en geodiseño para proyectos de instalaciones eléctricas de alta tensión, es el elemento de unión de un sistema de información geográfica y los condicionantes de los grupos de interés de estos proyectos. Extiende la funcionalidad del SIG corporativo y establece las bases de colaboración necesaria para gestionar los distintos puntos de vista del proyecto, confirmando la segunda hipótesis.

Se confirma también la idoneidad de gestionar geográficamente el ámbito de influencia de cada grupo de interés. Este ámbito, independientemente de si representa las zonas de preocupaciones o de necesidades, que se traducen en condicionantes y/o restricciones para el diseño del proyecto, permiten crear un escenario de colaboración en el mismo entorno con el que se gestiona la información técnica del proyecto. GeoRED permite la colaboración de distintos servicios de mapa, cada uno con su propio modelo de datos, y la interacción entre sus entidades, confirmando así las hipótesis uno y tres.

\subsection{Futuras líneas de investigación}

Los resultados de la investigación suponen un concepto revolucionario en la gestión de la información geográfica de proyectos de instalaciones eléctricas de alta tensión en España y buena parte de los países europeos. Esto se ha constatado en el marco del proyecto INSPIRE GRID (INSPIRE-GRID-Project, 2013). Durante el desarrollo de la tesis surgen otras cuestiones que salen del contexto de este tipo de proyectos. Alguna de estas cuestiones son las siguientes:

- ¿las metodologías aquí diseñadas son aplicables a infraestructuras distintas a las eléctricas de alta tensión? Podemos encontrar ejemplos de infraestructuras que también tienen un alto componente territorial como los proyectos de carreteras, ferrocarril, gasoductos, oleoductos o infraestructuras eléctricas de menor tensión.

Desde el punto de vista de alteración del territorio y su ocupación, así como el posible impacto ambiental de la infraestructura, por un lado, y la aparición de grupos de interés, 
la problemática de las compañías que construyen o gestionan infraestructuras lineales de grandes dimensiones son muy parecidas, por lo que abordar su desarrollo con el mismo enfoque de un marco de trabajo basado en geodiseño supondría beneficios similares a los destacados en esta tesis.

- Se ha abordado el desarrollo de nuevos proyectos desde la planificación hasta la construcción, pero en la actualidad, con un marco retributivo cada vez menos favorable, es necesario buscar eficiencias para rentabilizar la actividad de la gestión de la red de transporte de electricidad. Asociada a este reto surge la siguiente pregunta de investigación: ¿Sería igual de útil el diseño de otro flujo de trabajo basado en geodiseño para la gestión del mantenimiento de instalaciones eléctricas de alta tensión? Su diseño, implementación e integración con el propuesto en esta tesis representaría un gran desafío para REE, ya que implica la integración de dos mundos que actualmente están aislados: proyecto y explotación de infraestructuras.

- El diseño metodológico se ha complementado con la implementación y uso de la metodología presentada en proyectos reales, habiendo obtenido ventajas en cuanto a eficiencias, transformación digital, transmisión de conocimiento e imagen corporativa que son deseables para cualquier compañía, así, alineado con la cuestión anterior, ¿sería rentable la inversión necesaria de recursos para generar un producto vertical para infraestructuras de grandes dimensiones como iniciativa de diversificación del negocio de REE? 


\section{CONTRIBUCIONES}

Ha habido diferentes líneas de trabajo que han llevado a la automatización de procesos, armonización en la gestión de la información geográfica, ordenado y establecido flujos de trabajo con criterios corporativos, y la fusión de la gestión de la información geográfica del proyecto con la gestión de los grupos de interés del mismo.

Para llegar al nivel de automatización explicado el proceso ha ido mejorando progresivamente, al igual que la gestión integrada de todas las fases de un proyecto en un único marco de trabajo basado en geodiseño, siendo las siguientes contribuciones, presentadas en diferentes conferencias, congresos o publicaciones, los trabajos previos que han permitido la evolución al estado actual:

- 2010: Implementación de estándares OGC en el flujo de trabajo para la implantación de nuevas instalaciones eléctricas. (Moreno-Marimbaldo, et al., 2010)

- 2011: GeoServicios-Web en la comunicación de afectaciones por obras lineales: Líneas eléctricas de alta tensión. (Moreno-Marimbaldo, et al., 2011)

- 2012: E-Report generator supporting communications and fieldwork: a practical case of electrical network expansion projects. (Castaneda-Sanabria, et al., 2012)

- 2012: Integrated Geoprocessing for Generation of Affected Assets and Rights Reports for High Voltage Electrical Infrastructures. (Gutierrez-Corea, et al., 2012)

- 2012: Geoprocesamiento como Herramienta de Cálculo y Comunicación de Afectaciones por Obras Lineales: Líneas Eléctricas de Alta Tensión. (Moreno-Marimbaldo, et al., 2012)

- 2012: Using 3D GeoDesign for Planning of New Electricity Networks in Spain. (MorenoMarimbaldo, et al., 2012)

- 2014: Using GeoDesign to Plan New Electricity Circuits in Spain. (Moreno-Marimbaldo \& Manso-Callejo, 2014)

- 2016: 3D multi-viewpoints environment to analyze the visual impact of overhead lines (Moreno-Marimbaldo, 2016)

- 2017: GeoRED. Un entorno geográfico colaborativo basado en GeoDiseño (MorenoMarimbaldo, 2017)

- 2018: A Methodological Approach to Using Geodesign in Transmission Line Projects (Moreno-Marimbaldo, et al., 2018)

- 2019: Lifecycle of Geospatial Data in a High-Voltage Electrical Infrastructure Project: Geodesign Framework in the Electrical Network of Spain (REE) (Moreno-Marimbaldo, et al., 2019)

Como trabajo previo realizado en la temática de gestión de grupos de interés se añade la siguiente publicación:

- 2020: Methodological Approach to Incorporate the Involve of Stakeholders in the Geodesign Workflow of Transmission Line Projects (Moreno-Marimbaldo \& MansoCallejo, 2020). 


\section{REFERENCIAS BIBLIOGRÁFICAS}

50Hertz, 2019. Documento Web. Visitado el 1 junio 2020 enlace: www.50hertz.com

Abukhater, A. \& Walker, D., 2010. Making Smart Growth Smarter with GeoDesign. Dir. Mag..

Acuña, A. P., 2012. La gestión de los stakeholders: análisis de los diferentes modelos. Trelew, Universidad Nacional del Sur.

Aditya, T., 2010. Usability Issues in Applying Participatory Mapping for Neighborhood Infrastructure Planning. Transactions in GIS, Volumen 14, p. 119-147.

Andrienko, G. y otros, 2007. Geovisual analytics for spatial decision support: Setting research agenda. International Journal of Geographical Information Science, 17 July, 21(8), p. 839-857.

Artz, M., 2010. GeoDesign: New Concept or New Name. En: G. J. S. E. Stan, ed. Planning Support Systems: An Inventory of Current Practice, Computers, Environment and Urban Systems. Hyderabad, India: Gateway Media Private Limited, pp. 291-310.

Asimov, M., 1962. Introduction to Design. Englewood Cliffs(NJ): Prentice Hall.

Ball, M., 2010. Is GeoDesign an activity, a practice or a software-enabled modeling approach?. Spatial Sustain Blog, March 12 (2010)

BESTGRID-Project, 2015. BESTGRID. Documento Web. Visitado el 1 junio 2020 enlace: http://www.bestgrid.eu/

BOE, 2008. Reglamento de líneas eléctricas. Documento Web. Visitado el 1 junio 2020.

BOE, 2013. Ley 21/2013, de 9 de diciembre, de evaluación ambiental. Documento Web. Visitado el 1 junio 2020 enlace.

Bohr, N., 1928. The quantum postulate and the recent development of atomic theory. Nature, 121(3050), p. 580-590.

Brail, R.-K. \& Batty, M., 2008. Planning Support Systems for Cities and Regions. Cambridge, MA, USA: Lincoln Institute of Land Policy.

Brown, T., 2009. Change by Design: How Design Thinking Transforms Organizations and Inspires Innovation. New York(NY): Harper Collins.

Cáceres, D., Quintero, N. \&. C. \& Andrés, C., 2015. Stakeholders: A Corporate Sustainability Framework. Daena: International Journal of Good Conscience, August, 10(2), pp. 94-108. 
Campagna, M., Ivanov, K. \& Massa, P., 2014. Orchestrating the spatial planning process: From Business Process Management to 2nd generation Planning Support Systems. In Proceedings of the 17th AGILE Conference on Geographic Information Science, 3-6 June.

Campagna, M. y otros, 2016. Collaboration in planning: The Geodesign approach. En: Rozwój Regionalny i Polityka Regionalna. s.1.ss.n., p. 27-43.

Castaneda-Sanabria, E., Manso-Callejo, M.-Á., Moreno-Marimbaldo, F.-J. \& Gutierrez-Corea, F.V., 2012. E-Report generator supporting communications and fieldwork: a practical case of electrical network expansion projects.

Cocco, C., Fonseca, B. M. \& Campagna, M., 2015. Applying GeoDesign in urban planning: Case study of Pampulha, Belo Horizonte, Brazil. 27th International Cartographic Conference and Brazilian Journal of Cartography, Volumen 67.

Cooper, S. C. L. ed., 2014. Wiley Encyclopedia of Management. s.1.:John Wiley \& Sons, Ltd.

Craglia, M. y otros, 2012. Digital Earth 2020: Towards the vision for the next decade. International Journal of Digital Earth, Volumen 5, pp. 4-21.

Dalcher, D., 2016. Further Advances in Project Management: Guided Exploration in Unfamiliar Landscapes. s.1.:Routledge.

Dangermond, J., 2009. GIS: Designing Our Future. ArcNews.

Dangermond, J., 2012. Creating Our Future. In Proceedings of the Third GeoDesign Summit Conference, Redlands.

Delgado, S., 2019. Paisaje y líneas eléctricas: Sí, pero aquí no. Agenda publica. EL País. Documento Web. Visitado el 1 junio 2020 enlace: http://agendapublica.elpais.com/paisaje-y-lineas-electricassi-pero-no-aqui/

Eikelboom, T. \& Janssen, R., 2015. 31 January.

Eirgrid-Group, 2019. Documento Web. Visitado el 1 junio 2020 enlace: www.eirgridgroup.com

ELIA, 2019. Documento Web. Visitado el 1 junio 2020 enlace: www.elia.be

Energinet.dk, 2019. energinet.dk. Documento Web. Visitado el 1 junio 2020 enlace: https://en.energinet.dk/Electricity.

Ervin, S.-M., 27 May 2011. A System for GeoDesign. Dessau. 
ESRI, 2020. Thiessen Polygons. Documento Web. Visitado el 1 junio 2020 enlace: https://desktop.arcgis.com/es/arcmap/10.7/tools/business-analyst-toolbox/thiessen-

polygons.htm

Flacke, J. \& Boer, C. d., 2017. An Interactive Planning Support Tool for Addressing Social Acceptance of Renewable Energy Projects in The Netherlands. International Journal of GeoInformation, 6 (313).

Flaxman, M., 2009. GeoDesign: Fundamental Principles and Routes Forward.

Fogler, H. \& LeBlanc, S., 1995. Strategies for Creative Problem Solving. Upper Saddle River(NJ): PTR Prentice Hall.

Foster, K., 2016. Geodesign parsed: Placing it within the rubric of recognized design theories. Landscape and Urban Planning, December, Volumen 156, pp. 92-100.

Freeman, R. E., 1994. The Politics of Stakeholder Theory: Some Future Directions. Business Ethics Quarterly, 4(4), pp. 409-421.

Freeman, R. E., 2012. Stakeholder Management and Reputation. En: Values and Ethics for the 21st Century. s.1.:TF Editores, p. 389.

Freeman, R.-E. \& Mcvea, J.-F., 2001. Strategic Management: A Stakeholder Approach. SSRN Electronic Journal, Enero.

Gardner, J., Rachlin, R. \& Sweeny, 1986. Handbook of Strategic Planning. New York: H.W.A. (eds).

Geertman, S. \& Stillwell, J., 2003. Planning Support Systems in Practice. Springer Science \& Business Media.

Giuffrida, N., Pira, M. L., Inturri, G. \& Ignaccolo, M., 2019. Mapping with Stakeholders: An Overview of Public Participatory GIS and VGI in Transport Decision-Making. International Journal of Geo-Information, 24 April.8(198).

Globalreporting, 2019. www.globalreporting.org. Documento Web. Visitado el 1 junio 2020 enlace: www.globalreporting.org

Goodchild, M., 2010. Twenty years of progress: GIScience in 2010. Journal of Spatial Information Science, 27 July, Volumen 1, pp. 3-20. 
Gutierrez-Corea, F.-V., Manso-Callejo, M.-Á., Moreno-Marimbaldo, F.-J. \& Castaneda-Sanabria, E., 2012. Integrated Geoprocessing for Generation of Affected Assets and Rights Reports for High Voltage Electrical Infrastructures.

Hanzl, M., 2007. Information technology as a tool for public participation in urban planning: A review of experiments and potentials. Design Studies, May, 28(3), p. 289-307.

Harris, B., 1989. Beyond geospatial information-systems-computers and the planning professional. J. Am. Plan. Assoc., 31 3, Volumen 55, p. 85-90.

Hester, P. T., Bradley, J. M. \& Adams, K. M., 2012. Stakeholders in systems problems. Int. J. System of Systems Engineering, 3(3/4), p. 225-232.

IDE, 2020. Infraestructuras de Datos Espaciales. Documento Web. Visitado el 1 junio 2020 enlace: https://www.ign.es/web/resources/docs/IGNCnig/IDE-Teoria.pdf

IFC, I.-F.-C., 2019. Stakeholder Engagement.

IGN, 2020. Instituto Geográfico Nacional. Documento Web. Visitado el 1 junio 2020 enlace: www.ign.es

INSPIRE-GRID-Project, 2013. INSPIRE GRID Project. Documento Web. Visitado el 1 junio 2020 enlace: http://www.inspire-grid.eu/

Kubicek, H., 2010. The potential of E-Participation in Urban Planning: A European Perspective. En: C. E. Silva, ed. In Handbook of Research on E-Planning: ICTs for Urban Development and Monitoring. New York(NY): IGI Global, p. 168-194.

Kumar, A., Bhatnagar, S. \& Saxena, P., 2002. Integrated multimedia based intelligent group decision support system for electrical power network. 9(2).

Kumar, V., 2012. 101 Design Methods: A Structured Approach for Driving Innovation in Your Organization. Hoboken(NJ): JohnWiley \& Sons.

Kuzmin, O. \& Khilukha, O., 2016. Regulation of stakeholders' interests in corporate governance through negotiations. 161(9-10), pp. 56-60.

Lee, D., Dias, E. \& Scholten, H., 2014. Geodesign by Integrating Design and Geospatial Sciences. En: Heidelberg: Springer, p. 14.

López, E., 2014. tPropongo: web map application that proposes alternative locations for power transmission corridors and substations sites, Madrid. 
Manso-Callejo, M.-A., 2009. El uso de los metadatos para el desarrollo de un modelo de interoperabilidad para las Infraestructuras de Datos Espaciales. Tesis doctoral.

McHarg, I. L., 1961. Design with Nature. Manhattan, New York(NY): Wiley Series in Sustainable Design.

Mendelow, A. L., 1981. Environmental Scanning--The Impact of the Stakeholder Concept. s.l., Association for Information Systems. AIS Electronic Library (AISeL).

Miller, E. \& William, R., 2012. Introducing Geo-Design: The Concept.

Mitchell, R., Agle, B. \& Wood, D., 1997. Toward a Theory of Stakeholder Identification and Salience: Defining the Principle of Who and What Really Counts. The Academy of Management Review, 22(4), pp. 853-886.

Moreno, F., Gutierrez, F. \& Manso-Callejo, M., 2012. Using 3D GeoDesign for Planning of new Electricity Networks in Spain, Salvador de Bahía.

Moreno, F. \& Manso-Callejo, M., 2014. Planning New Power Lines in Spain with GeoDesign.. París (París).

Moreno-Marimbaldo, F.-J., 2017. ERIAC. 3D multi-viewpoints environment to analyze the visual impact of overhead lines. Ciudad del Este, Paraguay.

Moreno-Marimbaldo, F.-J., 2017. ERIAC. GeoRED. Un entorno geográfico colaborativo basado en GeoDiseño. Ciudad del Este, Paraguay.

Moreno-Marimbaldo, F.-J., Gutierrez-Corea, F.-V. \& Bernabé-Poveda, M.-A., 2010. Implementación de estándares OGC en el flujo de trabajo para la implantación de nuevas instalaciones eléctricas.

Moreno-Marimbaldo, F.-J., Gutierrez-Corea, F.-V. \& Manso-Callejo, M.-Á., 2012. Geoprocesamiento como Herramienta de Cálculo y Comunicación de Afecciones por Obras Lineales: Líneas Eléctricas de Alta Tensión.

Moreno-Marimbaldo, F.-J., Gutierrez-Corea, F.-V. \& Manso-Callejo, M.-Á., 2012. Using 3D GeoDesign for Planning of New Electricity Networks in Spain.

Moreno-Marimbaldo, F.-J., Gutierrez-Corea, F.-V., Manso-Callejo, M.-A. \& Castaneda-Sanabria, E., 2011. GeoServicios-Web en la comunicación de afecciones por obras lineales: Líneas eléctricas de alta tensión. 
Moreno-Marimbaldo, F.-J. \& Manso-Callejo, M.-Á., 2014. Using GeoDesign to Plan New Electricity Circuits in Spain. París.

Moreno-Marimbaldo, F.-J. \& Manso-Callejo, M.-Á., 2020. Methodological Approach to Incorporate the Involve of Stakeholders in the Geodesign Workflow of Transmission Line Projects. ISPRS - International Journal of Geo-Information, 9(3).

Moreno-Marimbaldo, F.-J., Manso-Callejo, M.-Á. \& Alcarria-Garrido, R., 2018. A Methodological Approach to Using Geodesign in Transmission Line Projects. Sustainability - Open Access Journal from MDPI, v. 10(n. 8), pp. pp. 1-30.

Moreno-Marimbaldo, F.-J., Manso-Callejo, M.-Á. \& Alcarria, R., 2019. Lifecycle of Geospatial Data in a High-Voltage Electrical Infrastructure Project: Geodesign Framework in the Electrical Network of Spain (REE).

National-Grid, T., 2019. www.nationalgrid.com. Documento Web. Visitado el 1 junio 2020 enlace: www.nationalgrid.com

Nyerges, T. y otros, 2016. Geodesign dynamics for sustainable urban watershed development. Sustainable Cities and Society, August, Volumen 25, pp. 13-24.

OGC, 2020. Open Geospatial Consortium (OGC). Documento Web. Visitado el 1 junio 2020 enlace: https://www.ogc.org/

Olander, S. \& Landin, A., 2005. Evaluation of stakeholder influence in the implementation of construction projects. International Journal of Project Management, 321-328 Mayo.23(4 ).

ONU, O. d. 1. N. U., 2020. Marco de indicadores mundiales para los Objetivos de Desarrollo Sostenible y metas de la Agenda 2030 para el Desarrollo Sostenible. Objetivos y metas (de la Agenda 2030 para el Desarrollo Sostenible).

Pickles, J., 1995. Ground Truth: The Social Implications of Geographical Information Systems. London, UK: Guilford Press.

Planificación, R., 2020. Planificación elécrica - REE. Documento Web. Visitado el 1 junio 2020 enlace: https://www.ree.es/es/actividades/planificacion-electrica

PLS-CADD $^{\mathrm{TM}}$, s.f. Definition of prohibited and special zones (section 6.10 .3 of the user manual) and Automatic distribution of pylons (section 14.2 of the user manual). En: PLS-CADD ${ }^{\mathrm{TM}}$ (Power Line Systems-Computer Aided Design and Drafting). V 14.2.

PMBOK®, P., s.f. Project Management Institute. PMBOK® Guide. 6 ed. 
Ramachandra, T., George, V., Vamsee, K. \& Purnima, G., 2006. Decision support system for regional electricity planning. s.l.:Energy Education Science and Technology.

RGI, 2019. Renewables Grid Initiative. Documento Web. Visitado el 1 junio 2020 enlace: https://renewables-grid.eu/about.html

Rivas-Martínez, S., 2017. Biogeografía y suelos. Documento Web. Visitado el 1 junio 2020 enlace: https://www.ign.es/web/resources/docs/IGNCnig/ANE/Capitulos/05_Biogeografiaysuelos.pdf

Rivero, R., Smith, A., Ballal, H. \& Steinitz, C., 2015. Promoting Collaborative Geodesign in a Multidisciplinary and Multiscale Environment: Coastal Georgia 2050, USA. In Proceedings of the Digital Landscape Architecture, 3-7 June.

RTE, 2019. Documento Web. Visitado el 1 junio 2020 enlace: www.rte-france.com

Santini, L. \& Pecori, S., 2014. Sensitivity assessment. Localization of road transport infrastructures in the Province of Lucca. TeMA - Journal of Land Use, Mobility and Environment. Input 2014, May.

Savage, G. T., Nix, T. W., Whitehead, C. J. \& Blair, J. D., 1991. Strategies for Assessing and Managing Organizational Stakeholders. Academy of Management Perspectives, Mayo, 5(2), pp. 61-75.

SEC, 2020. Sede Electrónica del Catastro. Documento Web. Visitado el 1 junio 2020 enlace: http://www.sedecatastro.gob.es

Shamo, H. et al., 2019. Changing attitudes and conflicting arguments: Reviewing stakeholder communication on electricity technologies in Germany. Energy Research \& Social Science, September, Volume 55, pp. 106-121.

Simon, H., 1977. Administrative Behavior. New York(NY): Free Press.

Simon, H., 1977. The New Science of Management Decision. Englewood Cliffs,(NJ): Prentice Hall.

Sostenibilidad-GRE, 2020. Sostenibilidad GRE. Documento Web. Visitado el 1 junio 2020 enlace: https://www.ree.es/es/sostenibilidad/compromiso-con-la-sostenibilidad/grupos-de-interes

Statnett, 2019. Documento Web. Visitado el 1 junio 2020 enlace: www.statnett.no

Steinitz, C., 1990. A Framework for Theory Applicable to the Education of Landscape Architects (and Other Environmental Design Professionals). Landscape Journal, 21 September, Volumen 9, p. 136-143. 
Steinitz, C., 1990. Toward a Sustainable Landscape with High Visual Preference and High Ecological Integrity: The Loop Road in Acadia National Park, USA.. Landsc. Urban Plan, Volumen 19, p. 213-250.

Steinitz, C., 2012. A Framework for Geodesign: Changing Geography by Design.. Redlands, CA, USA. ESRI Press

Steinitz, C. y otros, 2003. Alternative Futures for Changing Landscapes: The Upper San Pedro River Basin In Arizona And Sonora. Washington, DC, USA: Island Press.

Steinitz, C. \& Rogers, P., 1969. A Systems Analysis Model or Urbanization and Change: An Experiment in Interdisciplinary Education. MIT Press.

Tennet, 2019. Documento Web. Visitado el 1 junio 2020 enlace: www.tennet.eu

Usmani, F., 2019. Stakeholder Classification and Management Strategy. Documento Web. Visitado el 1 junio 2020 enlace: https://pmstudycircle.com/2012/06/stakeholder-analysisstakeholder-management-strategy/

Vlek, C. \& Keren, G., 1992. Behavioral decision theory and environmental risk management: Assessment and resolution of four 'survival' dilemmas. Elsevier Science Publishers B.V., Agosto.

Vonk, G., Geertman, S. \& Schot, P., 2005. Bottlenecks Blocking Widespread Usage of Planning Support Systems. Environment and Planning A: Economy and Space, 1 May, Volumen 37(5), p. 909-924.

Zipf, M. y otros, 2019. Multi-Criteria High Voltage Power Line Routing-An Open Source GISBased Approach. International Journal of Geo-Information, 24 July.8(316). 